\title{
Composition and compositional zoning of olivine as a tracer for pre-eruptive magmatic processes: Application to Piton de la Fournaise, Laacher See, and Shiveluch volcano
}

\author{
Dissertation \\ zur Erlangung des mathematisch-naturwissenschaftlichen Doktorgrades \\ „Doctor rerum naturalium“ \\ der Georg-August Universität Göttingen \\ im Promotionsprogramm Geowissenschaften / Geographie \\ der Georg-August University School of Science (GAUSS)
}

vorgelegt von

Caren Sundermeyer

aus Ankum, Deutschland

Göttingen, 2020 
Betreuungsausschuss:

Prof. Dr. Gerhard Wörner

Abteilung Geochemie, GZG,

Georg-August Universität Göttingen

Prof. Dr. Andreas Pack

Abteilung Isotopengeologie, GZG,

Georg-August Universität Göttingen

Dr. Andreas Kronz

Abteilung Geochemie, GZG,

Georg-August Universität Göttingen

\section{Mitglieder der Prüfungskommission}

$\underline{\text { Referent: }}$

Prof. Dr. Gerhard Wörner

Abteilung Geochemie, GZG,

Georg-August Universität Göttingen

Korreferent:

Prof. Dr. Andrea Di Muro

Observatoire volcanologique du Piton de la Fournaise,

Institut de Physique du Globe de Paris, La Réunion

\section{Weitere Mitglieder der Prüfungskommission:}

Prof. Dr. Stefan Weyer

Prof. Dr. Andreas Pack

Dr. Andreas Kronz

Dr. Burkhard Schmidt
Abteilung Geochemie, Institut für Mineralogie,

Leibniz Universität Hannover

Abteilung Isotopengeologie, GZG,

Georg-August Universität Göttingen

Abteilung Geochemie, GZG,

Georg-August Universität Göttingen

Abteilung für Experimentelle und Angewandte Mineralogie, GZG,

Georg-August Universität Göttingen

Tag der mündlichen Prüfung: 03.06.2020 




\section{Abstract}

This dissertation deals with the reconstruction of pre-eruptive magmatic processes with respect to their timescales. Deep recharges of mafic magma into shallower reservoirs and subsequent magma mixing are assumed to play a key role in triggering eruptions. The timespan between mixing and eruption is therefore a crucial factor to answer the question how fast magmatic systems can reactivate and erupt. Timing of magmatic processes and chemical composition of interacting magmas are archived in the zoning of crystals. This study uses zoned olivine crystals as a tool to track pre-eruptive recharge and mixing events of magmas and characterize the interacting magmas with respect to their composition for three different volcanic settings: (1) the subduction-related basaltic volcanism at Shiveluch, Kamchatka, (2) the basaltic hot-spot volcano Piton de la Fournaise on La Réunion, and (3) the alkaline intraplate volcanic field of the Eifel in western Germany with basanitic to phonolitic magma compositions.

Olivine crystals in clasts from a maar deposit of Shiveluch volcano, Kamchatka, were analyzed with line profiles at the electron microprobe to track crystal histories. High-Fo olivine cores (Fo86${ }_{91}$ ) show complex zoning with a normal zoned core, a dissolution boundary, and a rim overgrowth $\left(\mathrm{Fo}_{90}\right)$. The normal zoned cores are interpreted as result from magma mixing, subsequent dissolution, and partial re-equilibration, whereas the overgrowths represent crystallization subsequent to magma mixing and during ascent. Diffusion modeling of $\mathrm{Mg}-\mathrm{Fe}$ and $\mathrm{Ni}$ reveal times of 100-2000 days for the partial equilibration of olivine cores, but only 1-10 days since the rim overgrowth formed indicating that the ascent of mafic arc magmas can occur quite fast.

At Piton de la Fournaise, La Réunion, olivine crystals were analyzed in basaltic samples from three small and one large eruption occurring during the eruptive cycle 2014-2015 after nearly four years of inactivity. Magmas erupted during the small eruptions in June 2014, February, May, and July 2015 were evolved basalts and became increasingly more mafic during the large August-November 2015 eruptions. Olivine cores show variable compositions $\left(\mathrm{Fo}_{73.2-85.1}\right)$, whereas the rims have similar compositions in every sample, which are in equilibrium with the host melt in which the crystals were erupted. Olivine crystals from small eruptions in June 2014 and May 2015 have only short diffusion times of days to few months. Combined with the more evolved magma compositions and associated shallow seismicity, this indicates that the small eruptions were fed from more shallow magma batches after recharge. In contrast, olivine crystals in lavas from the large August- 
November 2015 eruption started re-equilibration during three distinct episodes days up to seven months prior to the eruptions in June 2014, February 2015, and in the time between the eruptions in July and August-November. The correlation to deep seismic signals and the eruption of increasingly more mafic magmas during the large August-November eruption indicate that mafic magmas intruded periodically into the central reservoir of Piton de la Fournaise since the beginning of 2014. These deep recharges and the associated mixing and diffusion are simultaneous to the smaller eruptions of more evolved magmas from shallow levels. However, these deeper stored, more mafic magmas themselves were not erupted until during the large August-November eruption.

The Eifel Volcanic Fields in the western part of Germany formed by Quaternary, alkaline intraplate volcanism, with the most voluminous eruption taking place at $12.900 \mathrm{yrs}$ BP at Laacher See. We analyzed olivine crystals in nine samples from the mafic phonolite of the Upper Laacher See tephra. The mafic phonolite is deemed to be a hybrid resulting from magma mixing and mingling between the more evolved phonolite of the Laacher See magma chamber and an intruding basanite. Diffusion profiles of $\mathrm{Mg}-\mathrm{Fe}, \mathrm{Mn}, \mathrm{Ca}$, and $\mathrm{Ni}$ were modeled in olivine from Laacher See and two basanite samples from Rothenberg and Eppelsberg. Furthermore, olivine crystals in basanite and nephelinite samples from the East and West Eifel were analyzed with point measurements to determine chemical similarities to the basanite, which acted as Mg-rich mixing endmember during the magma mixing at Laacher See volcano. Olivine from hybrid clasts of the Upper Laacher See tephra show reverse zoning with variable core compositions $\left(\mathrm{Fo}_{83-89}\right)$ overgrown by uniform and more forsteritic (Fo87.5-89) rims. The olivine crystals from the East Eifel basanite samples have a similar zoning pattern and core compositions (Fo80-88) but less forsteritic rims (Fo83-88). This indicates that the basanite intruding into the Laacher See magma chamber was Mg-richer than any other basanite that were erupted from basanitic scoria cones in the East Eifel. In contrast, olivine crystals in the nephelinite samples from the West-Eifel are normal zoned, have Fo-richer cores (Fo86-92) and similar rim compositions as olivine from Laacher See hybrid clasts (Fo87.5-91.5).

Diffusion times for olivine from the Laacher See samples are less than 50 days to max. 410 days for the time between basanite-phonolite hybridization and eruption. Our approach to diffusion modeling is a maximum estimate. This implies that a long-lived, highly differentiated magmatic system such as Laacher See magma reservoir can be reactivated and erupt within months. In contrast, diffusion times of olivine from the basanitic samples are remarkably longer with up to 490 days. 


\section{Zusammenfassung}

Diese Dissertation behandelt die Rekonstruktion magmatischer Prozesse vor einer Eruption im Hinblick auf ihre zeitlichen Abläufe. Der Aufstieg von tief gespeicherten Magmen in flachere Reservoire und damit verbundene Magmenmischungen spielen wahrscheinlich eine Schlüsselrolle bei der Auslösung von Eruptionen. Die Zeit zwischen Magmenmischung und Eruption ist daher ein wichtiger Faktor bei der Beantwortung der Frage, wie schnell sich magmatische Systeme reaktivieren und eruptieren können. Die Zeitspannen magmatischer Prozesse und die chemischen Zusammensetzungen der beteiligten Magmen sind in zonierten Kristallen erhalten. Wir nutzen zonierte Olivinkristalle, um Nachschübe und Mischungen von Magmen nachzuweisen und die beteiligten Magmen hinsichtlich ihrer Zusammensetzung zu charakterisieren. Diese Technik wird auf drei verschiedene vulkanische Settings angewandt. (1) den durch Subduktion hervorgerufenen, basaltischen Vulkanismus am Shiveluch, Kamchatka, (2) den basaltischen Hot-Spot-Vulkan Piton de la Fournaise auf La Réunion und (3) das alkaline Intraplatten-Vulkanfeld der Eifel im westlichen Deutschland mit basanitischen bis phonolitischen Magmenzusammensetzungen.

Olivine in Klasten aus einer Maar-Ablagerung am Shiveluch, Kamchatka, wurden mithilfe von Linienprofilen an der Elektronenmikrosonde untersucht, um ihre Geschichte zu rekonstruieren. Forsterit-reiche Olivinkerne (Fo86-91) zeigen komplexe Zonierungen mit einem normal zonierten

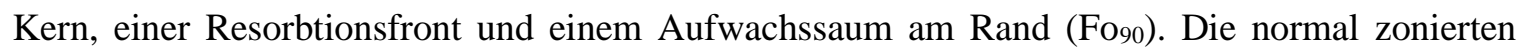
Kerne werden als Folge einer Magmenmischung und darauffolgender Auflösung sowie teilweiser Reequilibrierung interpretiert, wohingegen die Aufwachssäume den Aufstieg des Magmas repräsentieren. Diffusionsmodellierungen von Mg-Fe und Ni ergeben Zeitspannen von 100-2000 Tagen für die Equilibrierung der Olivinkerne, jedoch nur 1-10 Tage für den Aufwachssaum am Rand, was darauf hindeutet, dass der Magmenaufstieg sehr schnell ablaufen kann.

Am Piton de la Fournaise, La Réunion, wurden Olivine aus basaltischen Proben von drei kleinen und einer großen Eruption analysiert, die sich während des Eruptionszyklus 2014-2015 nach einer beinahe vierjährigen inaktiven Phase ereignet haben. Bei den Magmen, die während der kleinen Eruptionen gefördert wurden, handelte es sich um höher differenzierte Basalte, deren Zusammensetzung während der großen August-November 2015 Eruption zunehmend mafischer wurde. Die Olivinkerne zeigen variable Zusammensetzungen (Fo73.2-85.1), wohingegen die Ränder in jeder Probe eine ähnliche Zusammensetzung haben, die mit der eruptierten Schmelze im 
Gleichgewicht steht. Olivine, die während der kleinen Eruptionen im Juni 2014 und Mai 2015 eruptiert wurden, haben nur kurze Diffusionszeiten von Tagen bis wenigen Monaten. Zusammen mit den höher differenzierten Magmenzusammensetzungen und der verbundenen, flachen Seismizität deutet dies darauf hin, dass die kleinen Eruptionen wahrscheinlich aus weniger tief gelegenen Magmentaschen gespeist wurden. Im Gegensatz dazu begannen die Olivine in der Lava der August-November Eruption ihre Reequilibrierung während drei unterschiedlicher Episoden wenige Tage bis sieben Monate vor den Eruptionen im Juni 2014, Februar 2015 sowie der Zeit zwischen den Eruptionen im Juli und August-November. Die Korrelation zu tiefen seismischen Signalen sowie die Eruption zunehmend mafischerer Magmen während der großen AugustNovember Eruption lassen darauf schließen, dass es bereits Anfang 2014 periodisch magmatische Intrusionen in das zentrale Reservoir des Piton de la Fournaise gab. Diese tiefen Intrusionen und die damit verbundene Magmenmischung und Diffusion sind zeitlich verbunden mit den simultan ablaufenden, kleinen Eruptionen höher differenzierter Magmen aus flacheren Leveln. Diese tiefer gespeicherten, mafischeren Magmen wurden selbst jedoch erst während der großen AugustNovember Eruption eruptiert.

Die Eifel im westlichen Deutschland ist geprägt durch quartären, alkalinen Intraplattenvulkanismus, dessen prominenteste Eruption sich vor 12.900 Jahren am Laacher See ereignet hat. Neun Proben des mafischen Phonoliths aus dem Oberen Laacher See Tephra wurden untersucht. Der mafische Phonolith gilt als Hybrid einer Magmenmischung zwischen höher differenziertem Phonolith in der Magmenkammer des Laacher Sees und einem eindringenden Basanit. Diffusionsprofile von $\mathrm{Mg}-\mathrm{Fe}, \mathrm{Mn}, \mathrm{Ca}$ und $\mathrm{Ni}$ wurden in Olivinen vom Laacher See sowie zwei Basanit-Proben vom Rothenberg und Eppelsberg modelliert. Desweiteren wurden Olivine aus Basanit- und Nephelinit-Proben der Ost- und Westeifel mit Punktmessungen analysiert, um chemische Ähnlichkeiten zu dem Basanit festzustellen, der als Mg-reiches Mischungsendglied während der Magmenmischung am Laacher See Vulkan fungiert hat. Die Olivine in Klasten aus dem Oberen Laacher See Tephra zeigen reverse Zonierungen mit variablen Kernzusammensetzungen $\left(\mathrm{Fo}_{83-89}\right)$ überwachsen von einheitlichen und forsterit-reichen Rändern (Fo87.5-89). Die Olivine aus den Basanit-Proben der Osteifel haben ähnliche Zonierungen und Kernzusammensetzungen ( $\mathrm{Fo}_{83-88}$ ), aber weniger forsterit-reiche Ränder ( $\mathrm{Fo}_{80-88}$ ). Das deutet darauf hin, dass der Basanit, der in die Magmenkammer des Laacher Sees intrudiert ist, Mg-reicher war als die, die von den basanitischen Aschekegeln in der Osteifel eruptiert wurden. Im Gegensatz dazu sind die Olivine aus den Nephelinit-Proben der Westeifel normal zoniert, forsterit-reicher im Kern (Fo86-92) und ähneln in ihrer Randzusammensetzung den Olivinen aus den Hybrid-Klasten des Laacher Sees (Fo87.5-91.5).

Die Diffusionszeiten von Olivinen aus den Proben vom Laacher See ergeben weniger als 50 Tage bis maximal 410 Tage zwischen Basanit-Phonolith-Hybridisierung und Eruption. Unser Modell zur 
Diffusionsmodellierung ergibt maximale Zeiten. Dies zeigt, dass sich ein langlebiges, hochdifferenziertes, magmatisches System wie das des Laacher Sees innerhalb von Monaten reaktivieren und eruptieren kann. Dagegen sind die Diffusionszeiten von Olivinen aus den basanitischen Proben mit bis zu 490 Tagen deutlich länger. 



\section{Statement of originalty}

I hereby confirm that to my best of knowledge this dissertation is my own work. It contains no content written by other persons or previously published, unless it is clearly acknowledged and cited.

Göttingen, 31.03.2020

Caren Sundermeyer 



\section{Acknowledgements}

First, I would like to thank my supervisor Gerhard Wörner, who supports me since my Bachelor thesis and gave me the chance to continue my research on volcanoes as part of this dissertation. This work and my abilities benefited greatly from his experience, knowledge and passion for volcanoes.

I am very thankful to Andrea Di Muro for guiding me during my stay on La Réunion and sharing his great knowledge about Piton de la Fournaise. At the same time, I wish to express my thanks to the whole team of the OVPF for their support and for providing the samples from Piton de la Fournaise.

I am deeply thankful to the Institut de Physique du Globe de Paris (IPGP) and the GeoGender Chancenfonds of the Georg-August University Göttingen for financial support that enabled me to spend nearly three months on La Réunion.

Many thanks to all my colleagues for the support and fruitful discussions.

I would especially like to thank Andreas Kronz for the great support at the electron microprobe and for the help regarding any analytical questions.

I am very grateful to Boris Gordeychik. My understanding of diffusion and diffusion models profited mainly from his mathematical knowledge.

Many thanks to Kirsten Techmer for the support at the scanning electron microscope.

I would like to thank Smruti Sourav Rout for the helpful comments on my work and for always having a sympathetic ear for my questions. I also appreciate the work of Lena Weimann and Jochen Gätjen, who supported the research on Eifel volcanism as part of their "Geochemistry Project".

This dissertation would not have been possible without the support of many other people. I am grateful to have many friends and fellow students. Thank you, Tamara, Tina, Anne, Steffi, and Olli for sharing many years of studying with me. Thank you, Frauke and Christin, for always listening to me in my numerous crises. Thanks, Joana and Carina, for all the fruitful discussions and afternoons over coffee and cake. Most notably: Thank you, Marlene, for encouraging me and taking care of my pets and plants during my field trips. 
Last but not least, many thanks to my family, who has encouraged me since my childhood to never give up my dream to work on volcanoes. 


\section{Content}

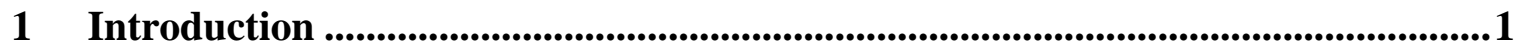

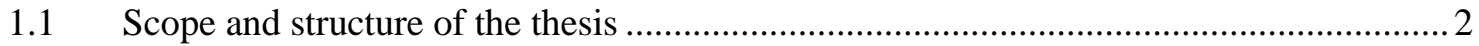

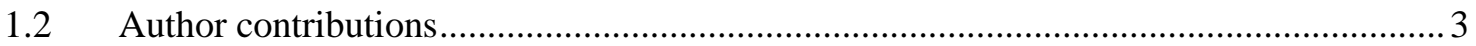

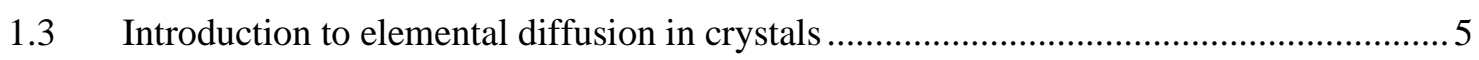

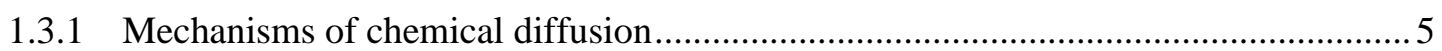

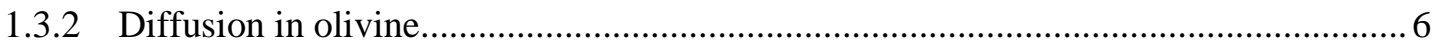

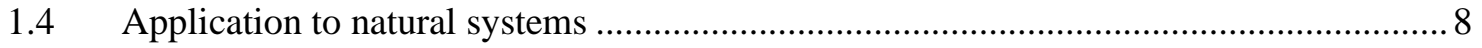

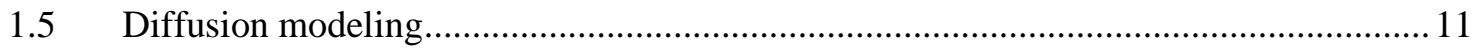

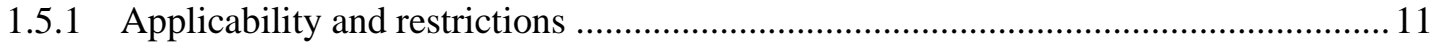

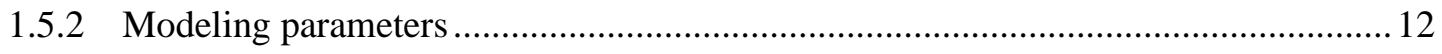

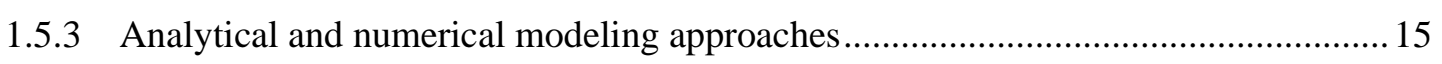

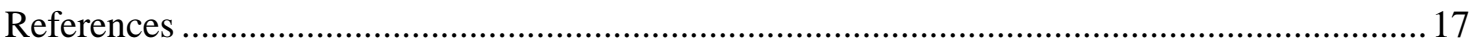

\section{Growth of, and diffusion in, olivine in ultra-fast ascending basalt magmas from}

Shiveluch volcano .....................................................................................................................29

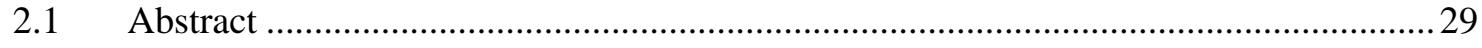

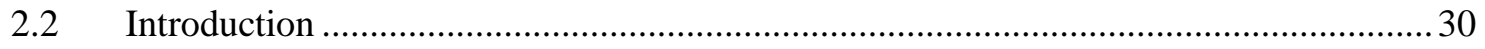

2.3 Shiveluch volcano, Kamchatka: geology and sampling .............................................. 31

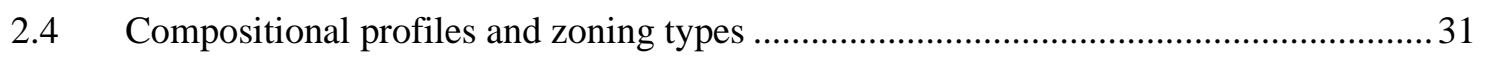

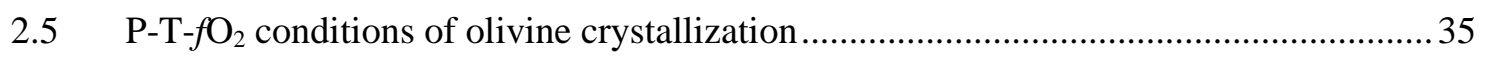

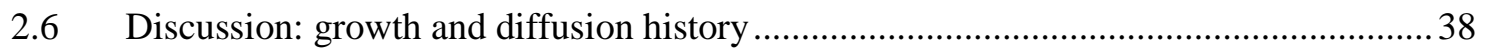

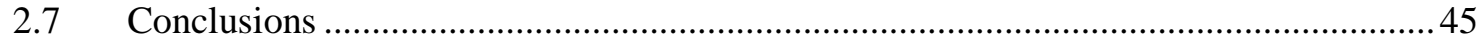

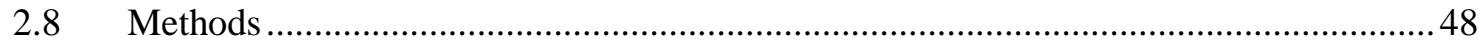

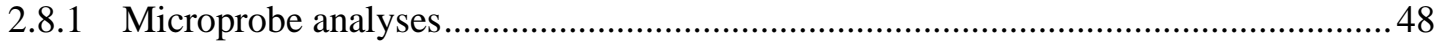

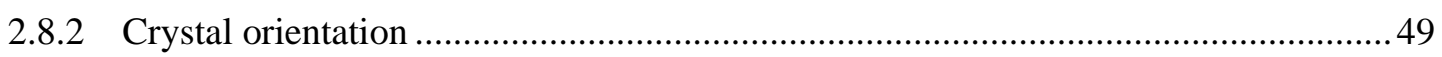

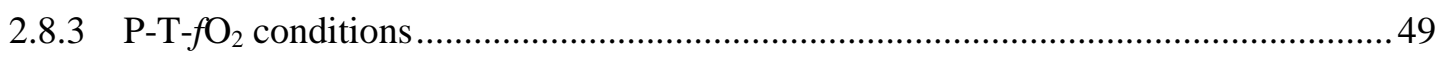

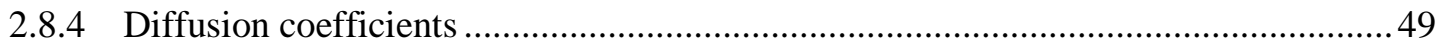

2.8.5 Analytical approximations of diffusion profiles..................................................... 49

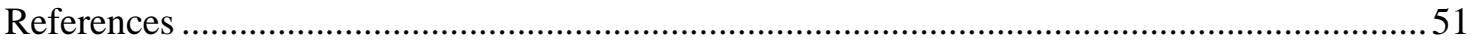

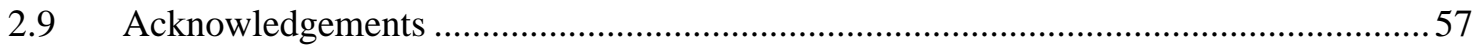

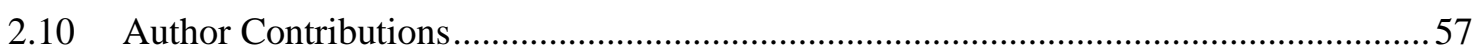


3 Timescales of magmatic processes during the eruptive cycle 2014-2015 at Piton de la Fournaise, La Réunion, obtained from Mg-Fe diffusion modelling in olivine..59

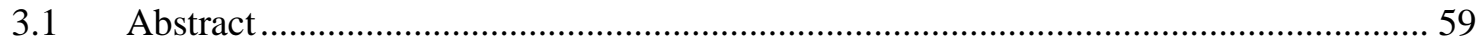

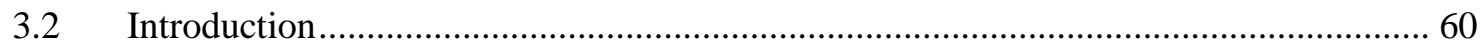

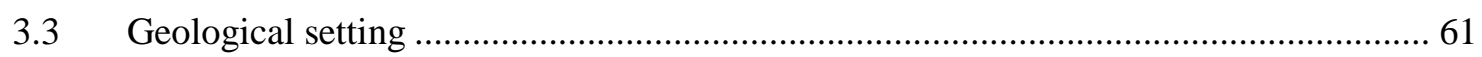

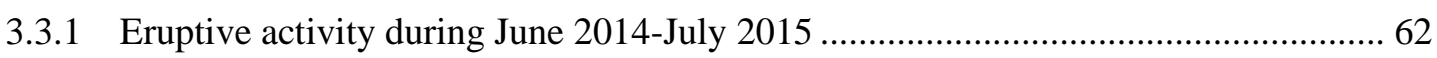

3.3.2 August-November 2015: Phase I (August 24 - September 11) ................................. 63

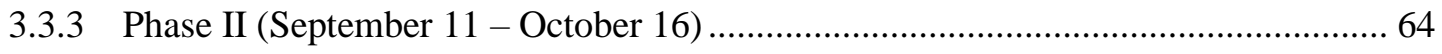

3.3.4 Phase III (October 16 - November 02) ………....................................................... 64

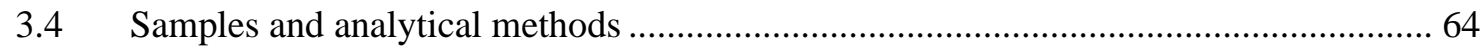

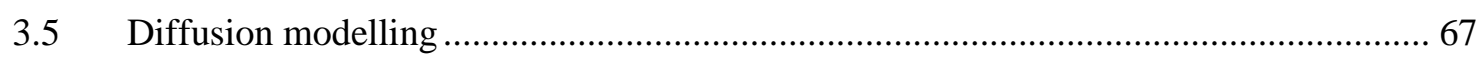

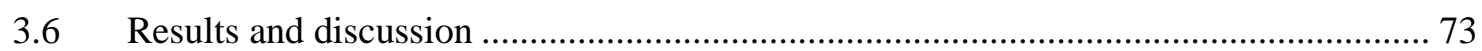

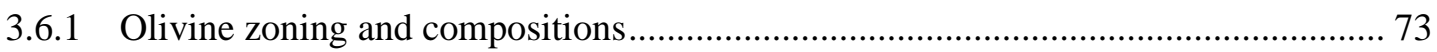

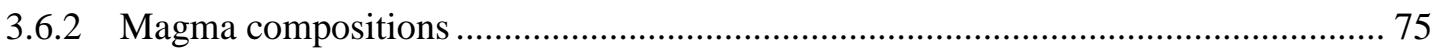

3.6.3 Diffusion times and olivine reactivation episodes ................................................ 76

3.6.4 Process and timing of renewed activity during the 2014/2015 eruptive cycle........... 79

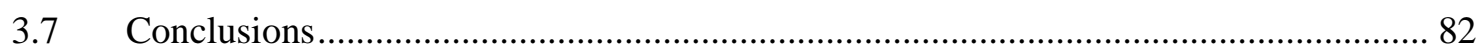

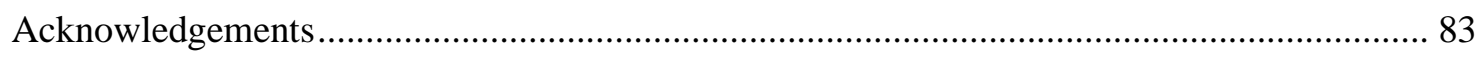

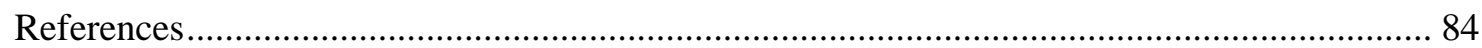

4 Timescales from magma mixing to eruption in alkaline volcanism in the Eifel volcanic fields, western Germany ...........................................................................................91

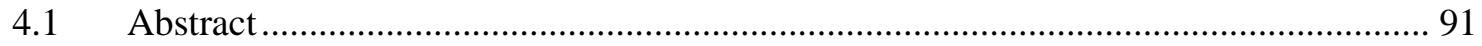

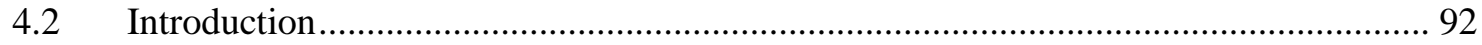

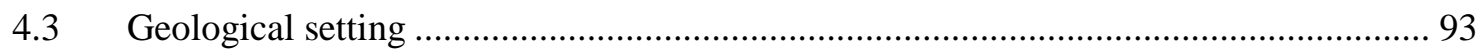

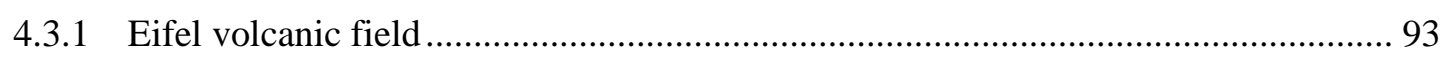

4.3.2 Laacher See volcano - chemical evolution and eruption .......................................... 94

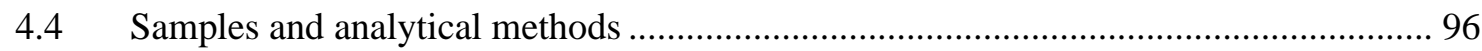

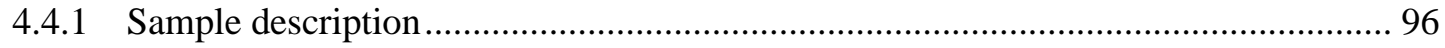

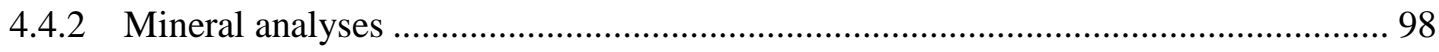

4.4.3 Constraints on temperature, pressure, and crystal orientation ................................. 99

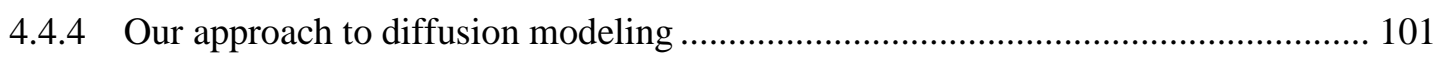

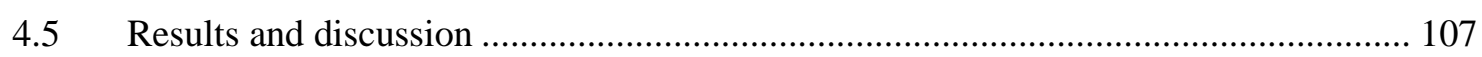

4.5.1 Chemical composition of olivine crystals from Laacher See hybrids ...................... 107

4.5.2 Chemical composition of olivine phenocrysts in East Eifel basanites ..................... 110

4.5.3 Chemical composition of olivine crystals from West Eifel nephelinites ................. 112 
4.5.4 Ol-rich xenoliths

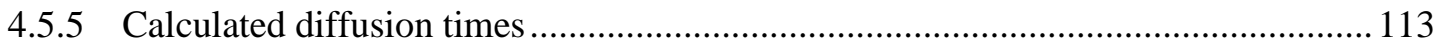

4.6 Implications for magmatic evolution and eruption..................................................... 116

4.6.1 History and composition of the Laacher See recharge magma ................................ 117

4.6.2 Origin and mixing history of basanite magmas in the East Eifel ............................. 118

4.6.3 What happened prior to the eruption of the Laacher See volcano? .......................... 119

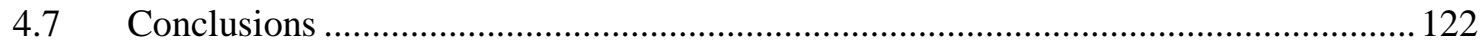

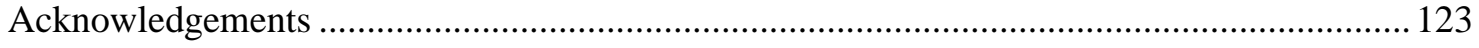

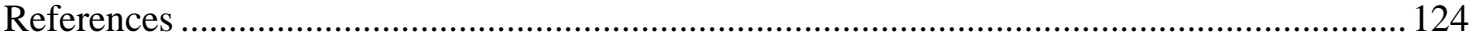

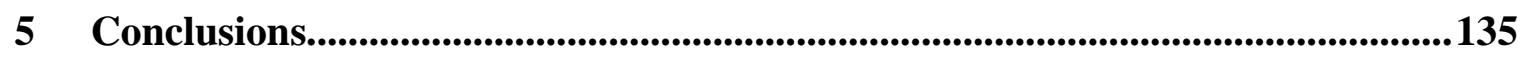

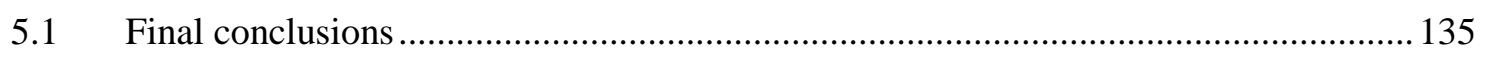

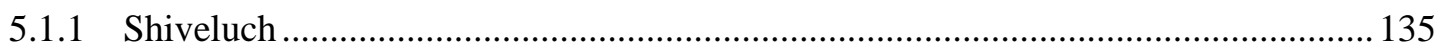

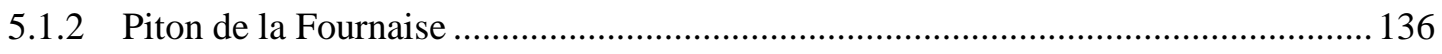

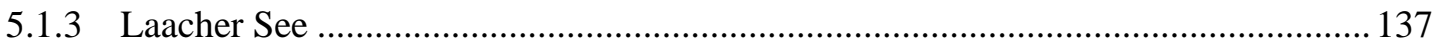

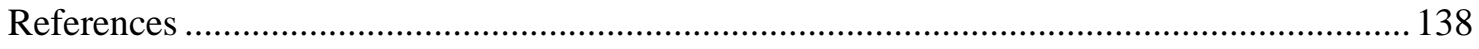

Appendix I - Curriculum vitae....................................................................................139

Appendix II - Publication bibliography .......................................................................... 141

Appendix III - Index of Electronic Supplementary Material ......................................143 



\section{List of abbreviations}

asl - above sealevel

BSE - backscattered electron

bsl - below sealevel

$\mathrm{C}$ - chemical concentration

cpx - clinopyroxene

$\mathrm{D}$ - diffusion coefficient

DIPRA - diffusion process analysis

E - activation energy

EBSD - electron backscatter diffraction

EEVF - East Eifel volcanic field

EMP - electron microprobe

Fo - forsterite

$f \mathrm{O}_{2}$ - oxygen fugacity

LS - Laacher See

LLST - Lower Laacher See Tephra

LST - Laacher See Tephra

MLST - Middle Laacher See Tephra

NNO - nickel-nickeloxide

$\mathrm{Ol}$ - olivine

opx - orthopyroxene

$\mathrm{P}$ - pressure

PED - pure extrinsic diffusion

PdF - Piton de la Fournaise

$\mathrm{pl} /$ plag - plagioclase

$\mathrm{R}$ - ideal gas constant

SEM - scanning electron microscope

sp - spinel

$\mathrm{t}$ - time

$\mathrm{T}$ - temperature

TaMED - transition metal extrinsic domain

ULST - Upper Laacher See Tephra 
WEVF - West Eifel volcanic field 


\section{Introduction}

Volcanoes have always been part of human life as a source for risk and fascination. Since early times, humans chose volcanic areas for their settlements due to the fertile soils, either underestimating or unknowing the risks of dormant but still active volcanoes. The dense population of many volcanic areas (e.g. the Gulf of Naples or the Eifel, western Germany) necessitate a better forecasting for explosive silicic eruptions. Their eruptions occur relatively rare in the time perception of humans, but are potentially disastrous to human life, infrastructure, and economy. The eruption of Laacher See in western Germany at $12.9 \mathrm{kyr}$ BP, which is part of this dissertation, produced $6.3 \mathrm{~km}^{3}$ of tephra (DRE; van den Bogaard and Schmincke 1985) that can still be found in northern Italy and southern Sweden (van den Bogaard and Schmincke 1985; van den Bogaard 1995). The eruption affected a recently densely populated area including cities as Coblenz, Cologne, Bonn, and Frankfurt (Leder et al. 2017; Park and Schmincke 2020).

However, the threat of basaltic volcanoes (e.g. Kilauea on Hawaii or Piton de la Fournaise on La Réunion) is often underestimated due to their less violent, mostly effusive eruptions, but they remain nevertheless unpredictable and dangerous for inhabitants and tourists. Such are the 1783 eruption of Laki, Iceland, whose immediate and long-term consequences caused the death of more than 10.000 people (Thordarson and Self 1993), or more recently the large eruptions of Piton de la Fournaise in 2007 (e.g. Staudacher et al. 2009; Di Muro et al. 2014) and Kilauea in 2018 (Patrick et al. 2018; Neal et al. 2019).

Due to their potential to threaten human life, volcanoes are focus of extensive research with respect to their geological history, plumbing systems, structures, eruptions, and magmatic compositions (e.g. Blundy and Cashman 2008; Cashman and Giordano 2014; Magee et al. 2018). However, many processes within magmatic plumbing systems, especially those that potentially trigger eruptions (e.g. magma mixing; Sparks et al. 1977; Murphy et al. 2000; Rae et al. 2016; Viccaro et al. 2016; Oeser et al. 2018), are still not completely understood. In the last 20 years, the timing of magmatic processes with respect to the duration between their occurrence and eruption became a focus of interest (e.g. Costa and Chakraborty 2004; Costa and Dungan 2005; Kahl et al. 2011, 2013; Chamberlain et al. 2014; Albert et al. 2015, 2016, 2019; Ferguson et al. 2016; Hartley et al. 2016 Iovine et al. 2017). How long do magmas need to ascent from mantle to surface? How fast can magmatic systems reactivate from dormancy and erupt? 
The tools that have been established to constrain times and ages are radiometric dating and diffusion modelling (Turner and Costa 2007; Cooper and Kent 2014; Dohmen et al. 2017). Although both methods allow the determination of times, they differ in the type of provided information. Radiometric dating, giving the absolute ages of crystals, does not reveal information about processes into which crystals might have been involved during their history (Turner and Costa 2007). Absolute ages do not reflect the duration of magmatic processes and the dated crystals may be much older than the processes immediately related to an eruption (Turner and Costa 2007). However, zoned crystals act as an archive preserving information about (1) magmatic composition and (2) the timescales of the crystal-melt contact like fingerprints in their zoning pattern (e.g. Kahl et al. 2011, 2013; Druitt et al. 2012; Bradshaw et al. 2018; Gordeychik et al. 2018). The zoning pattern can be used to model the duration of magmatic processes, which is related to the diffusive equilibration of zoned crystals (Chakraborty 2008; Dohmen et al. 2017).

Diffusion of elements in zoned crystals has been widely used in the last two decades to constrain timescales of processes in various magmatic settings as basaltic (e.g. Costa et al. 2010; Hartley et al. 2016; Gordeychik et al. 2018; Brenna et al. 2018; Lynn et al. 2018; Oeser et al. 2018; Albert et al. 2019) and silicic systems (e.g. Druitt et al. 2012; Matthews et al. 2012; Iovine et al. 2017; Rout and Wörner 2018). Given an excellent monitoring record, timescales can be additionally related to seismic events, variations in gas emissions, or ground deformation prior to the eruption of a volcano to eventually link the timing of magmatic processes to depth information (e.g. Saunders et al. 2012; Kahl et al. 2011, 2013; Kilgour et al. 2014; Albert et al. 2019).

\subsection{Scope and structure of the thesis}

The research of this thesis aims at the reconstruction of pre-eruptive magmatic processes, whose timing and compositional information are preserved in zoned crystals. Olivine crystals were chosen due to their abundance in many volcanic systems and their ability to preserve short-time processes via fast $\mathrm{Mg}$-Fe diffusion. This dissertation consists of two published and one submitted manuscript, which are presented as separate chapters. They comprise three distinct volcanic settings, which include intraplate and arc volcanism. Piton de la Fournaise, La Réunion, and Shiveluch, Kamchatka, are frequently active basaltic volcanoes, whereas the phonolitic Laacher See volcano belongs to a suite of alkalic volcanic centers in the Eifel volcanic field, Germany.

The first chapter introduces to the mechanisms of diffusion and the available modeling techniques, which can be used to calculate timescales from zoned crystals. It also outlines the applicability and limits of diffusion modeling and their use in geosciences. A detailed description of analytical methods, measurement conditions, and modeling parameters used in the distinct studies is included in the following chapters. 
The second chapter addresses the basaltic Shiveluch volcano, which is part of the Kamchatka magmatic arc. The study attempts to reconstruct deep storage times and ascent rates of magmas from combined $\mathrm{Mg}-\mathrm{Fe}$ and $\mathrm{Ni}$ diffusion modeling in olivine crystals from a maar deposit. Olivine crystals were analyzed with electron microprobe using a highly sensitive trace element program to track major $(\mathrm{Si}, \mathrm{Mg}, \mathrm{Fe})$, minor $(\mathrm{Ca}, \mathrm{Mn}, \mathrm{Ni})$, and trace elements ( $\mathrm{P}, \mathrm{Al}, \mathrm{Cr}, \mathrm{Co}, \mathrm{Zn})$ precisely. Diffusion profiles of four populations of complex zoned olivine crystals were modeled in different steps using analytical approaches.

The third chapter covers the 2014-2014 eruptive cycle at the basaltic, hot-spot triggered Piton de la Fournaise volcano on La Réunion, Indian Ocean. Due to the excellent monitoring record, this study focuses on the link of calculated timescales from $\mathrm{Mg}$-Fe diffusion in olivine crystals to geophysical monitoring data during the entire eruptive period and geochemical data on erupted lava compositions. We reconstructed magmatic activity in a transcrustal magmatic system during an eruptive cycle, that started after 41 months of quiescence and culminated after $1.5 \mathrm{yrs}$ in one of the largest eruptions observed at Piton de la Fournaise (Sundermeyer et al. 2020). Line profiles in olivine crystals from the four small eruptions in June 2014, February, May, and July 2015 and the large August-November eruption were analyzed to constrain diffusion timescales using a numerical model. Given the end of diffusion with the cooling after the eruption, these timescales were used to calculate the dates, when the olivine crystals were reactivated by ascending mafic magmas. Compared to the monitoring record of seismicity at different depths, $\mathrm{CO}_{2}$ degassing, and ground deformation during 2014-2015, these episodes of olivine reactivation could be used to track the activity of magmas at different depths of the volcanic plumbing system with time.

The fourth chapter adresses the phonolitic Laacher See volcano in the East Eifel volcanic field, western Germany. Using the analytical methods of Gordeychik et al. (2018), line profiles in olivine were measured focusing on minor and trace elements. Diffusion times of $\mathrm{Mg}-\mathrm{Fe}, \mathrm{Mn}, \mathrm{Ca}$, and $\mathrm{Ni}$ in olivine were calculated for samples from Laacher See hybrid rocks and two basanites from Rothenberg and Eppelsberg to track pre-eruptive basanitic recharges and discuss the role of recharge and mixing as potential eruption trigger at Laacher See volcano. Further point analyses were carried out on olivine from basanitic and nephelinitic maar deposits and scoria cones in the East and West Eifel volcanic field in order to characterize potential basanitic mixing endmembers. The last chapter summarizes the results of this dissertation.

\subsection{Author contributions}

Since this dissertation consists of three manuscripts, the contributions of the authors are listed in this chapter. 
The paper "Growth of, and diffusion in, olivine in ultra-fast ascending basalt magmas from Shiveluch volcano" was published on August 062018 in Scientific Reports. The version given in this dissertation is identical to the published version. Author contributions were taken from Gordeychik et al. (2018): B.G. and T.C. performed the fieldwork and sampling. T.C. and G.W. performed the petrographic description. B.G., T.C. and A.K. performed measurements on the electron microprobe. T.C. and C.S. performed the orientation analyses. T.C. estimated the P-T-fO2 conditions. B.G., T.C. and A.S. performed the mathematical modelling and computations. B.G., T.C., A.S., and G.W. discussed the interpretation to guide the modeling approach. B.G., T.C. and G.W. prepared the manuscript with all components of text and figures. All authors prepared the Supplementary Materials and participated in discussions related to topics of this manuscript.

The paper "Timescales of magmatic processes during the eruptive cycle 2014-2015 at Piton de la Fournaise, La Réunion, obtained from Mg-Fe diffusion modelling in olivine" was published online on November 162019 in Contributions to Mineralogy and Petrology. The version given in this dissertation is identical to the published version. Samples were collected by Andrea Di Muro and the team of the OVPF during the eruptions in 2014 and 2015. The initial version of the manuscript was written by me. I performed the petrographic analyses, chemical analyses at the electron microprobe, and crystal orientation measurements at the scanning electron microscope. Andrea Di Muro's knowledge on the structure of Piton de la Fournaise helped to improve especially the chapter Geological setting and all aspects regarding the monitoring data and magma movement in the transcrustal plumbing system. Boris Gordeychik developed the analytical diffusion model that was used in the early phase of the study. He also gave strong support to mathematical questions and the theoretical background of diffusion modeling. Gerhard Wörner contributed mainly to the interpretation of the data, structure of the manuscript, figure-layout, and writing of the final version of the manuscript text. All other co-authors also commented and improved the manuscript.

The manuscript "Timescales from magma mixing to eruption in alkaline volcanism in the Eifel volcanic fields, western Germany" was submitted to Contributions to Mineralogy and Petrology on March 13 2020. The version given in this dissertation is identical to the submitted version except of the correction of a few typing errors. EBSD measurements and electron microprobe analyses of all samples except of the line profiles, thermometry, and element distribution maps of the EPB19 samples were done by me. Line profiles, spinel and olivine analyses for the thermometry, and the element distribution maps of the EPB19 samples were measured by Lena Weimann and Jochen Gätjen as part of a "Geochemistry Project" guided by me and Gerhard Wörner. The raw first version of the manuscript was written by me. Gerhard Wörner greatly contributed to the interpretation of the data as well as the structure and writing of the manuscript. All other authors also commented and improved the manuscript. 


\subsection{Introduction to elemental diffusion in crystals}

The analytical methods and diffusion models used in the distinct studies are described in detail in chapters 2.8, 3.4, and 4.4. This chapter will outline the general mechanisms of diffusion in crystals, available models, and the application of diffusion modeling to natural systems.

\subsubsection{Mechanisms of chemical diffusion}

The term "chemicial diffusion" describes the random movement of atoms (Crank 1975) along gradients of chemical potential. In a crystal lattice, ions are able under certain conditions to move to near vacant positions due to point defects in the crystal lattice, either created by ions occupying interstitial spaces (Frenkel defect) or by unoccupied places in the crystal lattice (Schottky defect; Balluffi et al. 2005; Zhang 2010). How fast and many ions are able to move by diffusion depends in general on temperature and the number of vacancies that are available for the ions to move to (Zhang 2010; Costa and Morgan 2011; Kohn and Penniston-Dorland 2017).

The diffusive flux $\mathbf{J}$ depends on diffusivity $\mathrm{D}$ (diffusion coefficient) of an element and a concentration gradient according to Fick's first law (e.g. Crank 1975, Eq. 1.1; Balluffi et al. 2005; Eq. 3.1; Costa et al. 2008, Eq. 2; Zhang 2010, Eq. 1; Costa and Morgan 2011):

$J=-D \frac{\partial C}{\partial x}$

where $\mathrm{D}$ is the diffusion coefficient, $\frac{\partial \mathrm{C}}{\partial \mathrm{x}}$ is the gradient of either an element concentration $\mathrm{C}$ or a chemical potential for a distance $\mathrm{x}$ (Costa et al. 2008).

The rate of diffusion is positively correlated to temperature, because a defined amount of energy (the activation energy) is required to induce the diffusion process (Chakraborty 2008). The temperature-dependent diffusion coefficient is described by the equation (Costa and Morgan 2011):

$\mathrm{D}=\mathrm{D}_{0} \exp \left(\frac{-\mathrm{E}-\Delta \mathrm{V}\left(\mathrm{P}-10^{5}\right)}{\mathrm{RT}}\right)$

with $\mathrm{D}_{0}$ as diffusion coefficient at infinite temperature, $\mathrm{E}$ as activation energy, $\Delta V$ as activation volume, $\mathrm{P}$ as pressure, $\mathrm{R}$ as the ideal gas constant, and $\mathrm{T}$ as temperature. The activation energy $\mathrm{E}$ is the energy allowing an ion to move from one position to the next and the activation volume $\Delta V$ corresponds to the crystal volume change during the movement (Ganguly 2002).

The diffusion process can be subdivided into several types based on (1) the diffusing particle and (2) the surrounding medium (Zhang 2010). Diffusion along chemical gradients is used for timescale-modeling due to the measurable chemical differences and is termed as interdiffusion (Balluffi et al. 2005; Chakraborty 2010; Zhang 2010). Diffusion can occur in binary systems (known as binary diffusion), where two elements A and B diffuse along a chemical gradient 
between a zone with a high concentration of $\mathrm{A}$ and a zone with high concentration of $\mathrm{B}$, e.g. MgFe (forsterite / fayalite content, respectively) in olivine (Costa et al. 2008; Chakraborty 2010; Zhang 2010). Diffusion over a chemical gradient is induced by different chemical potentials between both components, e.g. two endmember mineral compositions (Costa and Morgan 2011). In order to minimize the free energy, both components start to mix until the reach an equilibrium (the lowermost free energy possible for the whole system with both components; Costa and Morgan 2011). Interdiffusion must be distinguished from diffusion of e.g. isotopes that occurs without any chemical concentration gradients (self-diffusion, tracer diffusion; Balluffi et al. 2005; Chakraborty 2010; Zhang 2010).

The simplest form of diffusion is one-dimensional diffusion, which can be expressed by Fick's second law (e.g. Crank 1975, Eq. 7; Chakraborty 2008; Costa et al. 2008, Eq. 11a; Zhang 2010, Eq. 5; Costa and Morgan 2011):

$\frac{\partial \mathrm{C}}{\partial \mathrm{t}}=\frac{\partial}{\partial \mathrm{x}}\left(\mathrm{D} \frac{\partial \mathrm{C}}{\partial \mathrm{x}}\right)$

Eq. 3 considers a dependency of $\mathrm{D}$ on chemical composition, which is the case for elemental diffusion in many crystals, e.g. Mg-Fe, Mn, and $\mathrm{Ni}$ in olivine depend on the Fo-content (see Eq. 5, 6). If diffusion is independent on composition, the Eq. 3 can be converted to a simpler form (Crank 1975, Eq. 1.4; Zhang 2010, Eq. 2):

$\frac{\partial \mathrm{C}}{\partial \mathrm{t}}=\mathrm{D} \frac{\partial^{2} \mathrm{C}}{\partial \mathrm{x}^{2}}$

Depending on the temperature, the diffusion process can be subdivided into several types, which distinguish by their dependency on $\mathrm{P}, \mathrm{T}, f \mathrm{O}_{2}$, and chemical composition: intrinsic, transition metal extrinsic domain (TaMED), and purely extrinsic (PED; Chakraborty 2008, 2010). At high temperatures, vacancies in the crystal lattice are dominantly intrinsic and diffusion depends merely on P and T (Ganguly 2002; Chakraborty 2010). At intermediate temperatures, diffusion is influenced additionally by oxygen fugacity (TaMED), and at low temperatures, diffusion becomes independent of oxygen fugacity, but is influenced by trace element contents (Chakraborty 2010). Within the temperature range, where diffusion in olivine is modeled, diffusion occurs mostly within the transition metal extrinsic domain (Chakraborty 2010).

\subsubsection{Diffusion in olivine}

Olivine is one of Earth's most abundant minerals, it forms a prominent component in the upper mantle and is common in primitive, mantle-derived magmas. Olivine is a nesosilicate crystallizing in the orthorhombic system with the general formula $\mathrm{X}_{2} \mathrm{SiO}_{4}$ that has a solid solution series between the Fe-endmember fayalite $\left(\mathrm{Fe}_{2} \mathrm{SiO}_{4}\right)$ and the $\mathrm{Mg}$-endmember forsterite $\left(\mathrm{Mg}_{2} \mathrm{SiO}_{4}\right.$; Brown 1982). 
The octahedral position $\mathrm{X}$ in the crystal structure of common $\mathrm{Mg}$-Fe-olivine can also be occupied by low amounts of $\mathrm{Ca}, \mathrm{Mn}$, and $\mathrm{Ni}$ (Brown 1982). Olivine usually also contains traces of $\mathrm{Co}, \mathrm{Cr}$, as well as P (up to 0.4 wt. \%, Milman-Barris et al. 2008; mostly <0.1 wt \%, Jankovics et al. 2019; $<0.09$ wt. \%, this study) and $\mathrm{Al}$ (Milman-Barris et al. 2008). Other chemical endmembers occur only rarely (Mn-, Ca-Fe-, Ca-Mg-endmembers; Brown 1982).

The diffusive exchange of Mg-Fe in olivine studied here belongs to the binary interdiffusion (Costa et al. 2008). In the olivine crystal structure, $\mathrm{Mg}^{2+}$ and $\mathrm{Fe}^{2+}$ are placed on the $\mathrm{M} 1$ and $\mathrm{M} 2$ positions within the octahedra (Brown 1982). The M1 octahedra have a chain-like order along the c-axis, which allows diffusing cations to move faster in c-direction and therefore creates a strong anisotropic effect of diffusion that must be considered for diffusion modeling (Chakraborty 2010). The difference in diffusion coefficients of $\mathrm{Mg}-\mathrm{Fe}$ is given as $6^{*} \mathrm{D}_{\mathrm{a}}=6^{*} \mathrm{D}_{\mathrm{b}}=\mathrm{D}_{\mathrm{c}}($ Costa and Chakraborty 2004) with $\mathrm{D}_{\mathrm{a}, \mathrm{b}, \mathrm{c}}$ as diffusion coefficients along the crystallographic axes.

Olivine belongs, together with feldspars and pyroxenes, to the most studied silicate minerals with respect to the diffusion coefficients of their elements (Brady and Cherniak 2010). Diffusivities of the divalent cations in olivine have been experimentally dertermined (e.g. Morioka 1981; Nakamura and Schmalzried 1984; Jurewicz and Watson 1988b; Petry et al. 2004; Coogan et al. 2005a; Dohmen et al. 2007; Dohmen and Chakraborty 2007, Holzapfel et al. 2007). Several studies investigated diffusivities of $\mathrm{Cr}$ (Ito and Ganguly 2006; Spandler and O’Neill 2010; Jollands et al. 2018; Oeser et al. 2018), Ti (Spandler and O’Neill 2010; Jollands et al. 2016a), Al (Jurewicz and Watson 1988b; Zhukova et al. 2017; Oeser et al. 2018), Si (Houlier et al. 1990; Dohmen et al. 2002), and H (Houlier et al. 1988; Mackwell and Kohlstedt 1990; Dohmen et al. 2002; Demouchy et al. 2006; Demouchy and Mackwell 2006). Diffusivities of $P$ have been determined by Watson et al. (2015). Spandler and O'Neill (2010) performed additional experiments on diffusion coefficients of several other elements (Na, Sc, V, Co, Zn, Y, Zr, Eu, Gd, Lu, and Hf) in San Carlos olivine. However, it must be noticed that the diffusivities for trace elements that are given by distinct authors can differ by orders of magnitude (Spandler and O’Neill 2010; Cherniak and Liang 2014; Tollan et al. 2015).

Similar to $\mathrm{Mg}$ and $\mathrm{Fe}$, other divalent cations within the olivine crystal structure are suitable for diffusion modeling, e.g. Ni (Nakamura 1995; Lynn et al. 2017; Gordeychik et al. 2018), Ca, and Mn (Costa and Dungan 2005). However, $\mathrm{Ca}$ and Mn are mostly combined with Mg-Fe diffusion modeling (e.g. Costa and Dungan 2005). Other studies have shown that timescales can be obtained from diffusion of H (Demouchy et al. 2006), Li (Dohmen et al. 2010; Lynn et al. 2018), Be (Jollands et al. 2016b), Cr (Oeser et al. 2018), and P (Albert et al. 2019).

Diffusion modeling in olivine crystals allows covering a broad range of timescales depending on the storage conditions of the crystals (temperature) and the elements that are chosen for modeling. 
The most common are the divalent cations ( $\mathrm{Mg}-\mathrm{Fe}, \mathrm{Mn}, \mathrm{Ca}, \mathrm{Ni}$ ), that allow to track processes in the range of days / weeks and months up to (tens of) years (e.g. Costa and Dungan 2005). Modeling Li diffusion allows to constrain even shorter timescales in the range of hours to tens of minutes (Lynn et al. 2018).

This dissertation focuses on major and minor elements ( $\mathrm{Mg}-\mathrm{Fe}, \mathrm{Mn}, \mathrm{Ca}$, and $\mathrm{Ni}$ ) whose diffusivities are described below. The diffusion coefficients of $\mathrm{Mn}$ and $\mathrm{Ni}$ depend not only on $\mathrm{T}, \mathrm{P}, \mathrm{fO}_{2}$, and crystal orientation but also on the Fo content (Girona and Costa 2013). The equations for the composition-dependent diffusion coefficients $\left(\mathrm{m}^{2} \mathrm{~s}^{-1}\right)$ of $\mathrm{Mg}-\mathrm{Fe}, \mathrm{Mn}$, and $\mathrm{Ni}$ are summarized by Chakraborty (2010):

$\mathrm{D}_{\mathrm{Mg}-\mathrm{Fe}, \mathrm{Mn}}=10^{-9.21}\left(\frac{f \mathrm{O}_{2}}{10^{-7}}\right)^{\frac{1}{6}} 10^{3\left(\mathrm{X}_{\mathrm{Fe}}-0.1\right)} \exp \left(-\frac{201000+\left(\mathrm{P}-10^{5}\right)\left(7 * 10^{-6}\right)}{\mathrm{RT}}\right)$

$\mathrm{D}_{\mathrm{Ni}}=3.84 * 10^{-9}\left(\frac{f \mathrm{O}_{2}}{10^{-6}}\right)^{\frac{1}{4.25}} 10^{1.5}\left(\mathrm{X}_{\mathrm{Fe}}-0.1\right) \exp \left(-\frac{220000+\left(\mathrm{P}-10^{5}\right)\left(7 * 10^{-6}\right)}{\mathrm{RT}}\right)$

with $f \mathrm{O}_{2}$ as oxygen fugacity $(\mathrm{Pa}), \mathrm{X}_{\mathrm{Fe}}$ as fayalite content (mol), and $\mathrm{P}$ as pressure (Pa). Eq. 5 and 6 describe diffusion coefficients for $\mathrm{Mg}-\mathrm{Fe}$ and $\mathrm{Ni}$ along c-axis. Diffusivity of $\mathrm{Ca}$ is independent of Fo-content and has a distinct anisotropic behavior as Mg-Fe, Mn, and Ni (Coogan et al. 2005a; Chakraborty 2010):

$$
\begin{aligned}
& \mathrm{D}_{\mathrm{Ca}(100)}=16.59 * 10^{-12}\left(\frac{f \mathrm{O}_{2}}{10^{-7}}\right)^{\frac{1}{3.2}} \exp \left(-\frac{19300}{\mathrm{RT}}\right) \\
& \mathrm{D}_{\mathrm{Ca}(010)}=34.67 * 10^{-12}\left(\frac{f \mathrm{O}_{2}}{10^{-7}}\right)^{\frac{1}{3.2}} \exp \left(-\frac{201000}{\mathrm{RT}}\right) \\
& \mathrm{D}_{\mathrm{Ca}(001)}=95.49 * 10^{-12}\left(\frac{f \mathrm{O}_{2}}{10^{-7}}\right)^{\frac{1}{3.2}} \exp \left(-\frac{207000}{\mathrm{RT}}\right)
\end{aligned}
$$

\subsection{Application to natural systems}

Diffusion modeling is used in geosciences to calculate timescales from chemically zoned crystals. In the following, explanations focus on diffusion modeling in crystals from volcanic settings, although this technique is not restricted to magmatic systems. However, magmatic and metamorphic systems are predestinated for diffusion modeling in crystals due to the high temperatures required for measurable diffusion.

Crystal zoning is created when a crystal enters a new environment, in which its composition is no longer in equilibrium with the host medium. The equilibrium between a mineral and its environment (i.e. the melt) is defined by the partition coefficient $K_{d}=\frac{C_{c r y s t a l}^{i}}{C_{\text {melt }}^{i}}$, where $C^{i}$ terms the concentration of an element $\mathrm{i}$ in the crystal and the melt, respectively (e.g. Roeder and Emslie 1970; Toplis 2005; 
Matzen et al. 2011). Any changes of the melt composition, T, $\mathrm{P}$, or $f \mathrm{O}_{2}$ due to e.g. ascent, magma mixing, or cooling create a new crystal equilibrium composition (Toplis 2005). If a crystal of a distinct composition is transferred into a new environment, it will start to change its composition by diffusion until it reaches a new equilibrium. The crystal may dissolve, may continue to crystallize or may resume crystallization after dissolution. If it does crystallize, it forms an overgrowth that is compositionally in equilibrium with the new melt (Oeser et al. 2015). The crystal core and rim are then separated by an initially step-like gradient, that smoothes with time due to diffusive equilibration between the "old" crystal core and the new overgrowth (Sundermeyer et al. 2020). Alternatively, the crystal may start to homogenize directly with the melt (Oeser et al. 2015; Fig. 1).

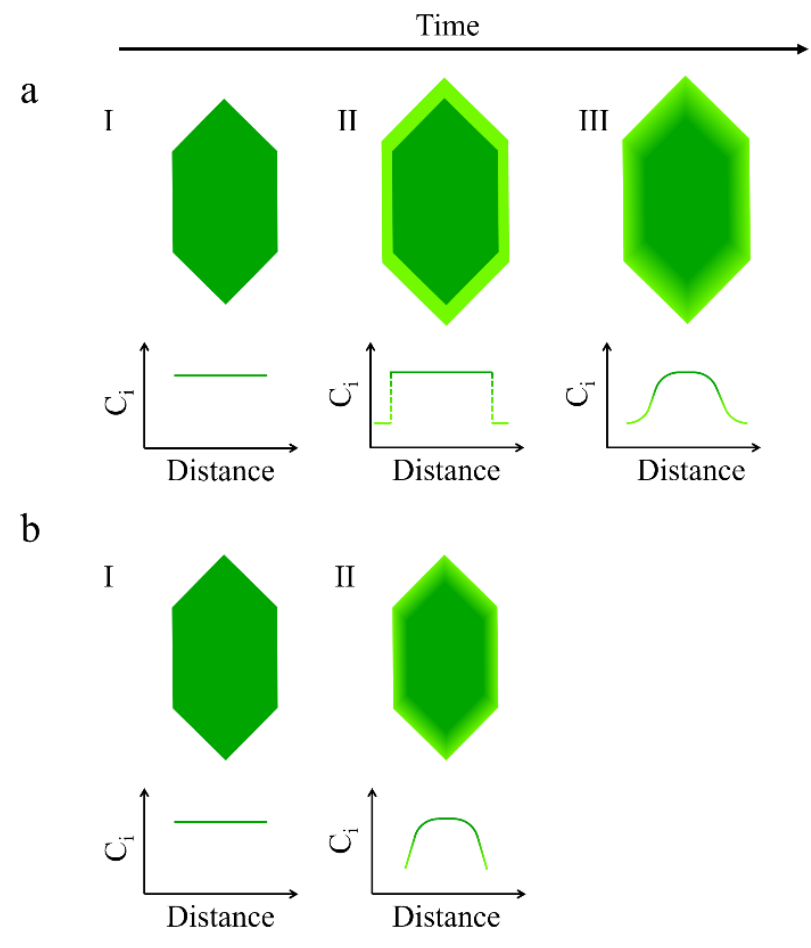

Fig. 1 Schematic drawing of possible crystal evolution with time (modified after Kahl et al. 2011 and Dohmen et al. 2017). (a) Formation of an overgrowth (II) on an initially unzoned crystal core (I) and diffusion between both zones (III). With time, the step-like gradient smoothes until the crystal is completely homogenized or diffusion is interrupted (Gordeychik et al. 2018; chapter 2.4; chapter 4.4.4). (b) Example of an initially unzoned crystal equilibrating in direct contact with the melt without an overgrowth. The characteristic sshape of the gradient as formed in (a) is absent (Gordeychik et al. 2018; Fig. 6; Sundermeyer et al. 2020; Fig. $3)$.

Elemental diffusion in crystals covers a broad range of timescales depending on the mineral and the chosen elements. Li and $\mathrm{H}$ diffusion in olivine occur within minutes to hours (Demouchy et al. 2006; Dohmen et al. 2010; Lynn et al. 2018), whereas the coupled NaSi - CaAl diffusion in 
plagioclase takes place in the range of millions of years (Turner and Costa 2007; Chakraborty 2008). The diversity of suitable minerals and elements, which can be analyzed with common techniques at sufficient precision and spatial resolution (e.g. electron microprobe), enables to track the rates of magma ascent (e.g. Demouchy et al. 2006; Ferguson et al. 2016), timing of recharge and mixing (e.g. Kahl et al. 2011, 2013; Matthews et al. 2012; Chamberlain et al. 2014; Rae et al. 2016; Sundermeyer et al. 2020) and melt-mush interaction (e.g. Costa et al. 2010) in different volcanic systems.

Common pairs of major / trace elements in abundant minerals have been established for diffusion modeling in volcanic systems: Mg-Fe in olivine (Costa and Chakraborty 2004; Costa and Dungan 2005; Albert et al. 2015, 2019; Hartley et al. 2016; Viccaro et al. 2016; Bradshaw et al. 2018; Brenna et al. 2018; Gordeychik et al. 2018; Mutch et al. 2019; Sundermeyer et al. 2020), Mg-Fe in pyroxene (Morgan et al. 2004; Chamberlain et al. 2014; Krimer and Costa 2017), Sr-Ba in plagioclase (Zellmer et al. 1999, 2003b; Costa et al. 2003, 2010; Druitt et al. 2012), K-Na and SrBa in sanidine (Morgan and Blake 2006; Chamberlain et al. 2014; Iovine et al. 2017; Rout and Wörner 2019), and Ti in quartz (Matthews et al. 2012; Chamberlain et al. 2014; Seitz et al. 2018). In the last ten years, several studies investigated the link of diffusion modeling, chemical analysis, and geophysical and geochemical monitoring (e.g. Saunders et al. 2012; Kahl et al. 2011, 2013; Kilgour et al. 2014; Rae et al. 2016; Rasmussen et al. 2018; Ubide and Kamber 2018; Albert et al. 2019). Frequently active volcanoes are well monitored regarding e.g. seismicity, gas emission, and ground deformation. It is, however, difficult to explicitly relate processes that occurred in erupted magmas to geophysical evidence of prior magmatic activity at depth, because monitored signals may be also induced by unerupted magmas or may simply be volcano-tectonic. For example, ascending and underplating triggered shallow magma batches to erupt during the May 2015 eruption at Piton de la Fournaise, La Réunion, without significant mixing (Sundermeyer et al. 2020). This gap can be closed when using the full temporal and compositional information from zoned crystals from many eruption cycles for reconstructing pre-eruptive processes during periods of unrest. The link of monitored data to compositional and temporal information improves the understanding of crustal magmatic activity, but is suitable only for eruptions for which a monitoring record exists, which restricts its applicability to frequently active basaltic to andesitic volcanoes (e.g. Mt. Etna, Sicily, Kahl et al. 2011, 2013; Ubide and Kamber 2018; Kilauea, Hawaii, Rae et al. 2016; Piton de la Fournaise; La Réunion, Albert et al. 2019; Sundermeyer et al. 2020; Mt. Ruapehu, New Zealand, Kilgour et al. 2014). 


\subsection{Diffusion modeling}

\subsubsection{Applicability and restrictions}

Diffusion modeling is an appropriate tool to constrain timescales in natural systems. However, one must be aware of the applicability and the limitations of this technique. First, diffusion modeling provides crystal residence times that can be significantly different from direct radiometric dating (e.g. U-Th-disequilibria, Ar-Ar-dating; Turner and Costa 2007; Cooper and Kent 2014). This implies that the type of timescales obtained from both techniques, i.e. what was actually dated, can be quite different. Radiometric dating detects the absolute total ages of the analyzed crystals from their crystallization to the present day (Cooper and Kent 2014). In contrast, diffusion times reports only on relative periods of time that the crystal spend in disequilibrium with the surrounding melt at temperatures high enough to allow re-equilibration (e.g. after entrainment by a new magma from a crystal mush or mixing of two magmas; Chakraborty 2008; Kahl et al. 2011, 2013). Any periods of "cold storage" are not recorded in estimated diffusion times (Cooper and Kent 2014). Timescales of diffusion are preserved in the crystal zoning after cooling regardless of the sample age (Chakraborty 2008). Since crystal zoning marks only distinct events, the times obtained from diffusion modeling do not provide any absolute information on crystal age. Direct dating, e.g. by U-Th isotope measurements, only records the time of crystallization, not necessarily the age or residence time of magma.

Further, diffusion timescales can be only retrieved from crystals, whose re-equilibration remained incomplete due to cooling e.g. during the eruption. It must be considered that the crystal history is often longer and more complex than can be extracted from the zoning of major elements (e.g. Bouvet de Maissoneuve et al. 2016). Chemical zoning in crystals is sensitive to heating / reequilibration and any information is lost when the crystal completely re-equilibrates during a later heating event. However, the growth history of crystals can be partially reconstructed by analyzing slow- or non-diffusing trace elements as e.g. P and Al in olivine (Milman-Barris et al. 2008; Bouvet de Maissoneuve et al. 2016; Manzini et al. 2017).

The commonly used major element diffusion modeling (e.g. Mg-Fe in olivine) is applicable only for certain time spans of days to years / decades (Costa and Dungan 2005) depending on temperature at which diffusion occured. It is restricted at low temperatures and short timescales (< days) due to narrow diffusion profiles and analytical limitations (Bradshaw and Kent 2017) and at long timescales and high temperatures due to complete re-equilibration of the crystal. This requires either the usage of faster ( $\mathrm{Li}, \mathrm{H}$ in olivine; Demouchy et al. 2006; Lynn et al. 2018) or slower diffusing elements (e.g. Cr in olivine; Ito and Ganguly 2006; Oeser et al. 2018) but this requires the availability of more sensitive analytics with higher spatial resolution (e.g. Nano SIMS for short 
diffusion profiles or LA-ICPMS / SIMS for trace elements, if a lower spatial resolution is acceptable; Bradshaw and Kent 2017).

A major disadvantage of diffusion time estimates is their large relative error. Apart from analytical uncertainty, the influence of many parameters such as $\mathrm{T}, \mathrm{P}, \mathrm{fO}_{2}$, chemical composition, crystal orientation, and uncertainties of the model itself (goodness of fit; Girona and Costa 2013) results in uncertainties that can easily reach 50 to $>100 \%$ of the calculated time scale values (chapter 4.5.5). Temperature uncertainties have the largest impact due to the exponential dependency of $\mathrm{D}$ on $\mathrm{T}$, even if the calculated temperatures are in a narrow range and only the statistical uncertainty of the thermometers is considered (e.g. $\pm 10{ }^{\circ} \mathrm{C}, \mathrm{Mg}$ in glass thermometer from Helz and Thornber 1987; chapter 3.5).

\subsubsection{Modeling parameters}

This chapter briefly outlines the basics of diffusion modeling with respect to the required parameters and the different modeling approaches. Detailed descriptions of the used models and conditions in the distinct studies are given in the chapters 2.8, 3.5, and 4.4.4.

Several parameters must be constrained to calculate diffusion times:

1. chemical composition of the crystal

2. crystal orientation

3. storage conditions $\left(\mathrm{P}, \mathrm{T}, \mathrm{fO}_{2}\right)$

4. initial conditions at $\mathrm{t}_{0}$ (core and rim composition)

5. changing conditions with time (moving boundaries, temperature and pressure changes).

(1) Compositional profiles of zoned crystals can be obtained from measuring line profiles at e.g. electron microprobe, which has a variable spatial resolution of few microns depending on measurement conditions, the element analyzed, and the mineral studied. If the crystal zoning is only created by a diffusing element pair, such as $\mathrm{Mg}-\mathrm{Fe}$, accumulated backscattered electron images are also suitable to determine the composition, because the electron backscatter intensity (i.e. greyvalue in BSE images) is directly and only correlated to the compositional zoning (i.e. the mass contrasts). In this case, the BSE grey value can be calibrated for composition (e.g. Ginibre et al. 2002; Chamberlain et al. 2014; Hartley et al. 2016; Iovine et al. 2017; Bradshaw et al. 2018; Rout and Wörner 2018). Based on BSE grey values, the spatial resolution is much higher compared to quantitative measurements with lower spatial resolution, whose modeling will result in overestimated timescales (Costa and Morgan 2011). An identical effect can arise from oblique crystal cuts, which may broaden one site of the zoning pattern (Costa and Morgan 2011; Shea et al. 2015a). The analyzed crystals should be selected carefully to avoid oblique cuts. They are indicated 
e.g. by asymmetrical zonation with respect to the crystal shape (Costa and Morgan 2011; Shea et al. 2015a). Selecting only crystals with symmetrical zoning patterns and cuts along the crystallographic axes as it can be estimated from the crystal shape help to reduce the risk of significant influence of diffusion in more than one direction (Costa and Dungan 2005; Shea et al. 2015a). We additionally searched for grain boundaries perpendicular to the sample surface to ensure that the line profiles are mostly perpendicular to the zoning.

(2) Since crystals in thin sections are mostly randomly cut, the determination of crystal orientation (i.e. the angle between the measured line profile and the crystallographic axes) is required, when diffusive behaviour in the measured crystal is anisotropic. Due to the anisotropy of diffusion in olivine along the c-axis, the angle between profile and a- / b-axis is less important. Crystal orientation can be roughly estimated from the crystal shape, but it must be considered that a tilt of the crystal (i.e. the c-axis) into or out of the sample, respectively, cannot be easily detected and may be significant $\left(>10^{\circ}\right)$ even if the crystal is apparently cut parallel to c-axis (Fig. 2).

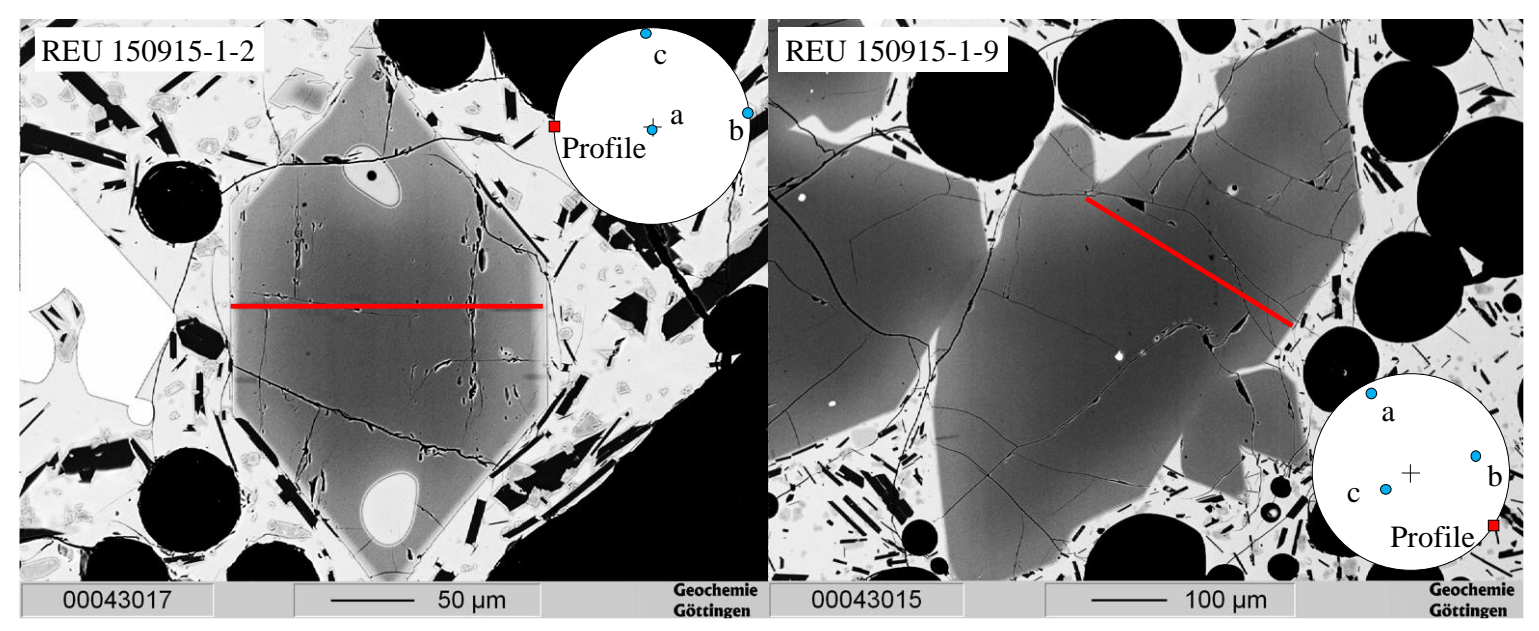

Fig. 2 BSE images of two olivine crystals from the August-November eruption at Piton de la Fournaise (Sundermeyer et al. 2020), which are apparently cut parallel to the c-axis. Whereas the angle between the measured profile (red line) and c-axis in the left crystal is indeed $89^{\circ}$, the angle is only $79^{\circ}$ degrees for the right crystal that is cut nearly perpendicular to c-axis as determined by EBSD measurements.

A common tool to determine crystal orientation is EBSD (electron backscatter diffraction; Prior et al. 1999), which can be done at a scanning electron microscope. Less precise alternatives to determining crystal orientation via EBSD is to either estimate the orientation from the crystal shape as described above or calculate maximum and minimum diffusion times for diffusion along c- and a- / b-axis. This, however, results in large, possibly inadequate uncertainties. For short timescales and already large errors due to e.g. temperature uncertainties, it may be advised to aim at maximum 
timescales. This was applied to olivine crystals from Laacher See (Chapter 4.5.5) with maximum times of 50 days and up to $100 \%$ uncertainty.

(3) The storage conditions of the magma at which the crystal re-equilibrated must be determined due to the dependence of diffusivity dominantly on temperature, but also on pressure, $f \mathrm{O}_{2}$, and possibly $\mathrm{H}_{2} \mathrm{O}$-content (Chakraborty 2010; Dohmen et al. 2017).

(4) Before the measured profile can be modeled, the initial conditions at the compositional interface prior to onset of diffusion must be constrained (Dohmen et al. 2017). This includes the shape of the initial profile, the composition of the crystal core and the rim at the beginning of diffusion (see Fig. $3 a$ in chapter 3.5). Such information can be derived from the shape of the diffusion profile, where e.g. a s-shaped profile indicates an initial step-like zoning between two growth zones, whereas a simple gradient may originate from an unzoned crystal that equilibrated in direct contact with the melt (Costa et al. 2008; Dohmen et al. 2017; Sundermeyer et al. 2020; see Fig. 1 in chapter 1.4).

The profiles of other elements (e.g. minor elements as $\mathrm{Mn}, \mathrm{Ca}$, and $\mathrm{Ni}$ in olivine) of different diffusivities should be checked to distinguish diffusion and growth. Profiles formed by diffusion will show narrower / steeper gradients for more slowly diffusing elements (chapter 3.5, Fig. 3b-e). It is also useful for minerals with anisotropic diffusion to analyze line profiles in different crystallographic directions, which should give similar timescales (e.g. along a- and c-axis in olivine; e.g. Costa and Chakraborty 2004; Costa and Dungan 2005; Costa et al. 2008; Shea et al. 2015b). It must be further considered that diffusion is a 3D-process, which causes the simple 1D-models to potentially overestimate timescales (Costa and Chakraborty 2004; Costa and Dungan 2005; Chakraborty 2008; Shea et al. 2015a). However, the effect of diffusion in different dimensions is difficult to estimate, because most samples are thin sections, where the crystals are randomly cut (Shea et al. 2015a).

(5) It must be examined, if the diffusion profiles where influenced by non-diffusion processes such as growth or dissolution. Neglecting these possibilities may lead to timescales to be significantly in error, because they shorten or lengthen the profile during diffusion (moving boundaries; Costa et al. 2008). If the rate and the amount of growth / dissolution are known, which is particularly difficult to determine, their influence can be expressed by a modification of Eq. 1 (Costa et al. 2008):

$\mathrm{J}=-\mathrm{D} \frac{\partial \mathrm{C}}{\partial \mathrm{x}}+v C$

with $v$ as rate of growth or dissolution.

It must be also defined if the boundary compositions changed with time or remained fixed (closed or open system; Chakraborty and Ganguly 1991; Dohmen et al. 2017). The latter can be assumed if diffusion took place at the direct contact of crystal and melt. For such diffusion between crystal and melt, it is often simplified assumed that the melt behaves - ideally - as infinite reservoir, whose 
composition does not change at the melt-crystal interface during the diffusion process (Spandler and O'Neill 2010; Kahl et al. 2011; Oeser et al. 2015; chapter 3.5). This assumption necessitates in theory that the elements leaving the crystal immediately diffuse away from the crystal surface and that, on the other hand, elements entering the crystal are not depleted in the surrounding melt. Since diffusion should always be much faster in melts compared to solids (e.g. in basaltic melt compared to olivine; Spandler and O’Neill 2010), this is a valid assumption.

Changing storage conditions that are related to temperature changes (e.g. cooling) should be considered. They can be either incorporated in an appropriate numerical model (see chapter 1.5.3) or estimated by using an average, or maximum / minimum values, respectively. However, it must be taken into account that the relationship between $\mathrm{D}$ and $\mathrm{T}$ is non-linear. Most of diffusion will occur at temperatures close to the peak temperature, and an effective temperature for the diffusion modeling may be expressed by $\mathrm{T}_{\text {effective }}=0.95^{*} \mathrm{~T}_{\text {peak }}$ for elements with an activation energy $\sim 200$ $\mathrm{kJ} \mathrm{mol}^{-1}$ (Chakraborty and Ganguly 1991; Costa et al. 2008; chapter 4.4.3).

\subsubsection{Analytical and numerical modeling approaches}

Since the diffusion process depends on time and measurable parameters, the time of diffusion can be calculated using distinct models (Costa et al. 2008). Two main modeling approaches can be applied to diffusion profiles using an analytical or a numerical solution. The solutions are presented below for Mg-Fe diffusion in olivine. A semi-infinite and an infinite analytical approach are detailed described in Gordeychik et al. (2018; chapter 2.6). Detailed descriptions of a finite numerical solution are given in Sundermeyer et al. (2020; chapter 3.5), chapter 4.4.4 and Girona and Costa (2013).

Analytical approaches can be used when the diffusivity remains constant with time (i.e. the diffusion coefficient is independent of chemical composition). The diffusion profile can then be fitted using an error function (modified from Chakraborty 2008, Fig. 3a):

$C_{F o}=m * \operatorname{erf}\left(\frac{x}{2 \sqrt{D_{M g-F e} t}}\right)+b$

where $\mathrm{C}_{\mathrm{Fo}}$ is the forsterite content $(\mathrm{Fo}(\mathrm{mol} \%)=\mathrm{MgO} /(\mathrm{MgO}+\mathrm{FeO}) * 100)$, $\mathrm{x}$ is the distance, and $\mathrm{m}$ and $b$ are the slope and intersection with the y-axis, respectively.

Since in olivine, the diffusion coefficients for major and minor elements depend on Fo content of the olivine (Chakraborty 2010), the analytical solution gives different timescales compared to the numerical solution which can be large. An analytical approach is valuable for high-Fo olivine due to the decreasing dependency of D on composition with increasing Fo-content $($ Eq. 5,6$)$ or when 
the compositional difference between core and rim is small. D can then be calculated based on the average Fo composition of core and rim (Oeser et al. 2015).

Utilizing a more complex numerical model allows to consider the composition dependency of D (Girona and Costa 2013). Numerical models use series of space- and time-steps to find the best-fit for the measured profiles (Girona and Costa 2013). They also allow to simulate changing magmatic conditions with time by implementing e.g. cooling rates or pressure changes. The numerical model calculates D for every spatial step and recalculates D for every time-step considering the changing composition with time (Girona and Costa 2013). This makes the numerical model more precise for especially longer timescales and large compositional differences between core and rim (i.e. larger variations in D). If the modeled profiles are high in Fo (>90 mol\%; Gordeychik et al. 2018) and have low compositional differences between core and rim (Oeser et al. 2015), an analytical solution is also applicable, because the uncertainties arising from the model are small compared to those due to temperature uncertainty (Gordeychik et al. 2018). 


\section{References}

Albert H, Costa F, Martí J (2015) Timing of magmatic processes and unrest associated with mafic historical monogenetic eruptions in Tenerife Island: J Petrol 56(10):1945-1966. https://doi.org/10.1093/petrology/egv058

Albert H, Costa F, Martí J (2016) Years to weeks of seismic unrest and magmatic intrusions precede monogenetic eruptions. Geology 44(3):211-214. https://doi.org/10.1130/G37239.1

Albert H, Costa F, Di Muro A, Herrin J, Métrich N, Deloule E (2019) Magma interactions, crystal mush formation, timescales, and unrest during caldera collapse and lateral eruption at ocean island basaltic volcanoes (Piton de la Fournaise, La Réunion). Earth Planet Sci Lett 515: 187-199. https://doi.org/10.1016/j.eps1.2019.02.035

Baales M, Jöris O, Street M, Bittmann F (2002) Impact of the late glacial eruption of Laacher See volcano, Central Rhineland, Germany. Quat Res 58(3):272-288. https://doi.org/10.1006/qres.2002.2379

Balluffi RW, Allen SM, Carter WC (2005) Kinetics of materials. John Wiley \& Sons, Inc., Hoboken, New Jersey.

Blundy J, Cashman K (2008) Petrologic reconstruction of magmatic system variables and processes. Rev Mineral Geochem 69(1):179-239. https://doi.org/10.2138/rmg.2008.69.6

Bouvet de Maissonneuve C, Costa F, Huber C, Vonlanthen P, Bachmann O, Dungan MA (2016) How do olivines record magmatic events? Insights from major and trace element zoning. Contrib Mineral Petrol 171(56). https://doi.org/10.1007/s00410-016-1264-6

Bradshaw RW, Kent AJR, Tepley III FJ (2018) Chemical fingerprints and residence times of olivine in the 1959 Kilauea Iki eruption, Hawaii: Insights into picrite formation. Am Mineral 103(11):1812-1826. https://doi.org/10.2138/am-2018-6331

Bradshaw RW, Kent AJR (2017) The analytical limits of modeling short diffusion timescales. Chem Geol 406: 667-677. https://doi.org/10.1016/j.chemgeo.2017.07.018

Brady JB, Cherniak DJ (2010) Diffusion in minerals: An overview of published experimental $\begin{array}{llll}\text { diffusion } & \text { data. Rev }\end{array}$ https://doi.org/10.2138/rmg.2010.72.20 
Brenna M, Cronin SJ, Smith IEM, Tollan PME, Scott LM, Prior DJ, Baambery K, Ukstins IA (2018) Olivine xenocryst diffusion reveals rapid monogenetic basaltic magma ascent following complex storage at Pupuke Maar, Auckland Volcanic Field, New Zealand. Earth Planet Sci Lett 499:13-22. https://doi.org/10.1016/j.epsl.2018.07.015

Brown GE Jr (1982) Olivines and silicate spinels. Rev Mineral Geotherm 5:275-381.

Cashman KV, Giordano G (2014) Calderas and magma reservoirs. J Volcanol Geotherm Res 288:28-45. https://doi.org/10.1016/j.jvolgeores.2014.09.007

Chakraborty S (2008) Diffusion in solid silicates: A tool to track timescales of processes comes of age. Annu Rev Earth Planet Sci 36:153-190.

Chakraborty S (2010) Diffusion coefficients in olivine, wadsleyite and ringwoodite. Rev Mineral Geochem 72(1):603-639. https://doi.org/10.2138/rmg.2010.72.13

Chakraborty, S, Ganguly J (1991) Compositional zoning and cation diffusion in garnets. In: Ganguly J (ed) Diffusion, atomic ordering and mass transport. Advances in Physical Geochemistry, Vol. 8. Springer-Verlag, New York, p 120-175. https://doi.org/10.1007/978-1-4613-9019-0_4

Chamberlain KJ, Morgan DJ, Wilson CJN (2014) Timescales of mixing and mobilisation in the Bishop Tuff magma body: perspectives from diffusion chronometry. Contrib Mineral Petrol 168:1034. https://doi.org/10.1007/s00410-014-1034-2

Cherniak DJ, Liang Y (2014) Titanium diffusion in olivine. Geochim Cosmochim Acta 147:43-57. http://dx.doi.org/10.1016/j.gca.2014.10.016

Coogan LA, Hain A, Stahl S, Chakraborty S (2005a). Experimental determination of the diffusion coefficient for calcium in olivine between $900^{\circ} \mathrm{C}$ and $1500^{\circ} \mathrm{C}$. Geochim Cosmochim Acta 69(14):3683-3694. https://doi.org/10.1016/j.gca.2005.03.002

Cooper KM, Kent AJR (2014) Rapid remobilization of magmatic crystals kept in cold storage. Nature 506:480-483. https://doi.org/10.1038/nature12991

Costa F, Chakraborty S, Dohmen R (2003) Diffusion coupling between trace and major elements and a model for calculation of magma residence times using plagioclase. Geochim Cosmochim Acta 67(12):2189-2200. https://doi.org/10.1016/S0016-7037(02)01345-5 
Costa F, Dohmen R, Chakraborty S (2008) Time scales of magmatic processes from modeling the zoning patterns of crystals. Rev Mineral Geochem 69(1):545-594. https://doi.org/10.2138/rmg.2008.69.14

Costa F, Coogan LA, Chakraborty S (2010) The time scales of magma mixing and mingling involving primitive melts and melt-mush interaction at mid-ocean ridges. Contrib Mineral Petrol 159:371-387. https://doi.org/10.1007/s00410-009-0432-3

Costa F, Chakraborty S (2004) Decadal time gaps between mafic intrusion and silicic eruption obtained from chemical zoning patterns in olivine. Earth Planet Sci Lett 227(3-4):517-530. https://doi.org/10.1016/j.epsl.2004.08.011

Costa F, Dungan M (2005) Short time scales of magmatic assimilation from diffusion modeling of multiple elements in olivine. Geology 33(10):837-840. https://doi.org/10.1130/g21675.1

Costa F, Morgan D (2011) Time constraints from chemical equilibration in magmatic crystals. In: Dosseto A, Turner SP, Van Orman JA (eds) Timescales of magmatic processes: from core to atmosphere. John Wiley \& Sons, Ltd. Chichester, UK, pp. 125-159. https://doi.org/10.1002/9781444328509.ch7

Crank J (1975) The mathematics of diffusion. Clarendon Press, Oxford.

Demouchy S, Jacobson SD, Gaillard F, Stern CR (2006) Rapid magma ascent recorded by water diffusion profiles in mantle olivine. Geology 34(6):429-432. https://doi.org/10.1130/G22386.1

Demouchy S, Mackwell S (2006) Mechanisms of hydrogen incorporation and diffusion in ironbearing olivine. Phys Chem Minerals 33:347-355. https://doi.org/10.1007/s00269-006$\underline{0081-2}$

Di Muro A, Métrich N, Vergani D, Rosi M, Armienti P, Fougeroux T, Deloule E, Arienzo I, Civetta L (2014) The shallow plumbing system of Piton de la Fournaise volcano (La Réunion island, Indian ocean) revealed by the major 2007 caldera-forming eruption. J Petrol 55(7):1287-1315. https://doi.org/10.1093/petrology/egu025

Dohmen R, Chakraborty C, Becker HW (2002) Si and O diffusion in olivine and implications for characterizing plastic flow in the mantle. Geophys Res Lett 29(21):2030. https://doi.org/10.1029/2002GL015480 
Dohmen R, Becker HW, Chakraborty S (2007) Fe-Mg diffusion in olivine I: experimental determination between 700 and $1,200^{\circ} \mathrm{C}$ as a function of composition, crystal orientation and oxygen fugacity. Phys Chem Minerals 34:389-407. https://doi.org/10.1007/s00269$\underline{007-0157-7}$

Dohmen R, Kasemann SA, Coogan L, Chakraborty S (2010) Diffusion of Li in olivine. Part I: Experimental observations and a multi species diffusion model. Geochim Cosmochim Acta 74(1):274-292. https://doi.org/10.1016/j.gca.2009.10.016

Dohmen R, Faak K, Blundy JD (2017) Chronometry and speedometry of magmatic processes using chemical diffusion in olivine, plagioclase and pyroxenes. Rev Mineral Geochem 83:535575. https://doi.org/10.2138/rmg.2017.83.16

Dohmen R, Chakraborty S (2007) Fe-Mg diffusion in olivine II: point defect chemistry, change of diffusion mechanisms and a model for calculation of diffusion coefficients in natural olivine. Phys Chem Minerals 34:409-430. https://doi.org/10.1007/s00269-007-0158-6

Druitt TH, Costa F, Deloule E, Dungan M, Scaillet B (2012) Decadal to monthly timescales of magma transfer and reservoir growth at a caldera volcano. Nature 482, 77-80.

Ferguson DJ, Gonnermann HM, Ruprecht P, Plank T, Hauri EH, Houghton BF, Swanson DA (2016) Magma decompression rates during explosive eruptions of Kîlauea volcano, Hawaii, recorded by melt embayments. Bull Volcanol 78(71). https://doi.org/10.1007/s00445-016-1064-X

Ganguly J (2002) Diffusion kinetics in minerals: principles and applications to tectonometamorphic processes. In: Gramacciolli CM (ed) EMU Notes in Mineralogy, Energy Modelling in Minerals 4, pp. 271-309. https://doi.org/10.1180/EMU-notes.4.9

Ginibre C, Kronz A, Wörner G (2002) High-resolution quantitative imaging of plagioclase composition using accumulated backscattered electron images: new constraints on oscillatory zoning. Contrib Mineral Petrol 142:436-448.

Girona T, Costa F (2013) DIPRA: A user-friendly program to model multi-element diffusion in olivine with applications to timescales of magmatic processes. Geochem Geophys Geosyst 14(2):422-431. https://doi.org/10.1029/2012GC004427 
Gordeychik B, Churikova T, Kronz A, Sundermeyer C, Simakin A, Wörner G (2018) Growth of, and diffusion in, olivine in ultra-fast ascending basalt magmas from Shiveluch volcano. Sci Rep 8(11775):1-15. https://doi.org/10.1038/s41598-018-30133-1

Hartley ME, Morgan DJ, Maclennan J, Edmonds M, Thordarson T (2016) Tracking timescales of short-term precursors to large basaltic fissure eruptions through $\mathrm{Mg}$-Fe diffusion in olivine. Earth Planet Sci Lett 439:58-70. http://dx.doi.org/10.1016/j.eps1.2016.01.018

Helz RT, Thornber CR (1987) Geothermometry of Kilauea Iki lava lake, Hawaii. Bull Volcanol 49(5):651-668. https://doi.org/10.1007/bf01080357

Holzapfel C, Chakraborty S, Rubie DC, Frost DJ (2007) Effect of pressure on Fe-Mg, Ni and Mn diffusion in $\left(\mathrm{Fe}_{\mathrm{x}} \mathrm{Mg}_{1-\mathrm{x}}\right)_{2} \mathrm{SiO}_{4}$ olivine. Phys Earth Planet Inter 162(3-4):186-198. https://doi.org/10.1016/j.pepi.2007.04.009

Houlier B, Cheraghmakani M, Jaoul O (1990) Silicon diffusion in San Carlos olivine. Phys Earth Planet Inter 62:329-340.

Iovine RS, Fedele L, Mazzeo FC, Arienzo I, Cavallo A, Wörner G, Orsi G, Civietta L, D’Antonio M (2017) Timescales of magmatic processes prior to the $4.7 \mathrm{ka}$ Agnano-Monte Spina eruption (Campe Flegrei caldera, Southern Italy) based on diffusion chronometry from sanidine phenocrysts. Bull Volcanol 79:18. https://doi.org/10.1007/s00445-017-1101-4

Ito M, Ganguly J (2006) Diffusion kinetics of $\mathrm{Cr}$ in olivine and ${ }^{53} \mathrm{Mn}-{ }^{53} \mathrm{Cr}$ thermochronology of early solar system objects. Geochim Cosmochim Acta 70(3):799-809. https://doi.org/10.1016/j.gca.2005.09.020

Jankovics MÉ, Sági T, Astbury RL, Petrelli M, Kiss B, Ubide T, Németh K, Ntaflos T, Harangi S (2019) Olivine major and trace element compositions coupled with spinel chemistry to unravel the magmatic systems feeding monogenetic basaltic volcanoes. J Volcanol Geotherm Res 369:203-223. https://doi.org/10.1016/j.jvolgeores.2018.11.027

Jollands MC, Padrón-Navarta JA, Hermann J, O’Neill HStC (2016a) Hydrogen diffusion in Tidoped forsterite and the preservation of metastable point defects. Am Mineral 101(7):15711583. https://doi.org/10.2138/am-2016-55681571

Jollands MC, Burnham AD, O’Neill HStC, Hermann J, Qian Q (2016b) Beryllium diffusion in olivine: A new tool to investigate timescales of magmatic processes. Earth Planet Sci Lett 450:71-82. http://dx.doi.org/10.1016/j.eps1.2016.06.028 
Jollands MC, O’Neill HStC, Van Orman J, Berry AJ, Hermann J, Newville M, Lanzirotti A (2018) Substitution and diffusion of $\mathrm{Cr}^{2+}$ and $\mathrm{Cr}^{3+}$ in synthetic forsterite and natural olivine at 1200-1500 ${ }^{\circ} \mathrm{C}$ and 1 bar. Geochim Cosmochim Acta 220:407-428. https://doi.org/10.1016/j.gca.2017.09.030

Jurewicz AJG, Watson EB (1988b) Cations in olivine, Part 2: Diffusion in olivine xenocrysts, with applications to petrology and mineral physics. Contrib Mineral Petrol 99:189-201.

Kahl M, Chakraborty S, Costa F, Pompilio M (2011) Dynamic plumbing system beneath volcanoes revealed by kinetic modeling, and the connection to monitoring data: An example from Mt. Etna. Earth Planet Sci Lett 308(1-2):11-22. https://doi.org/10.1016/j.eps1.2011.05.008

Kahl M, Chakraborty S, Costa F, Pompilio M, Liuzzo M, Viccaro M (2013) Compositionally zoned crystals and real-time degassing data reveal changes in magma transfer dynamics during the 2006 summit eruptive episodes of Mt. Etna. Bull Volcanol 75(2):692. https://doi.org/10.1007/s00445-013-0692-7

Kilgour GN, Saunders KE, Blundy JD, Cashman KV, Scott BJ, Miller CA (2014) Timescales of magmatic processes at Ruapehu volcano from diffusion chronometry and their comparison to monitoring data. J Volcanol Geotherm Res 288:62-75. http://dx.doi.org/10.1016/j.jvolgeores.2014.09.010

Kohn MJ, Penniston-Dorland SC (2017) Diffusion: Obstacles and opportunities in petrochronology. Rev Mineral Geochem 83(1):103-152. https://doi.org/10.2138/rmg.2017.83.4

Krimer D, Costa F (2017) Evaluation of the effects of 3D diffusion, crystal geometry, and initial conditions on retrieved time-scales from Fe-Mg zoning in natural oriented orthopyroxene $\begin{array}{llll}\text { crystals. Geochim } & \text { Cosmochim }\end{array}$ http://dx.doi.org/10.1016/j.gca.2016.09.037

Leder J, Wenzel F, Daniell JE, Gottschämmer E (2017) Loss of residential buildings in the event of a re-awakening of the Laacher See Volcano (Germany). J Volcanol Geotherm Res 337:111-123. https://doi.org/10.1016/j.jvolgeores.2017.02.019

Lynn KJ, Shea T, Garcia MO (2017) Nickel variability in Hawaiian olivine: Evaluating the relative contributions from mantle and crustal processes. Am Mineral 102:507-518. http://dx.doi.org/10.2138/am-2017-5763 
Lynn KJ, Shea T, Garcia MO, Costa F, Norman MC (2018) Li diffusion in olivine records magmatic priming of explosive basaltic eruptions. Earth Planet Sci Lett 500:127-135. https://doi.org/10.1016/j.eps1.2018.08.002

Mackwell S J, Kohlstedt DL (1990) Diffusion of hydrogen in olivine: Implications for water in the mantle. J Geophys Res 95(B4):5079-5088. https://doi.org/10.1029/JB095iB04p05079

Magee C, Stevenson CTE, Ebmeier SK, Keir D, Hammond JOS, Gottsmann JH, Whaler KA, Schofield N, Jackson CAL, Petronis MS, O’Driscoll B, Morgan J, Cruden A, Vollgger SA, Dering G, Micklethwaite S, Jackson MD (2018) Magma plumbing systems: A geophysical perspective. J Petrol 59(6):1217-1251. https://doi.org/10.1093/petrology/egy064

Manzini M, Bouvier AS, Baumgartner LP, Müntener O, Rose-Koga EF, Schiano P, Escrig S, Meibom A, Shimizu N (2017) Weekly to monthly time scale of melt inclusion entrapment prior to eruption recorded by phosphorous distribution in olivine from mid-ocean ridges. Geology 45(12):1059-1062. https://doi.org/10.1130/G39463.1

Matthews NE, Huber C, Pyle DM, Smith VC (2012) Timescales of magma recharge and reactivation of large silicic systems from Ti diffusion in quartz. J Petrol 53(7):1385-1416. https://doi.org/10.1093/petrology/egs020

Matzen AK, Baker MB, Beckett JR, Stolper EM (2011) Fe-Mg partitioning between olivine and high-magnesian melts and the nature of hawaiian parental liquids. J Petrol 52(7-8):12431263. https://doi.org/10.1093/petrology/egq089

Milman-Barris MS, Beckett JR, Baker MB, Hofmann AE, Morgan Z, Crowley MR, Vielzeuf D, Stolper E (2008) Zoning of phosphorous in igneous olivine. Contrib Mineral Petrol 155(6):739-765. https://doi.org/10.1007/s00410-007-0268-7

Morgan DJ, Blake S (2006) Magmatic residence times of zoned phenocrysts: introduction and application of the binary element diffusion modelling (BEDM) technique. Contrib Mineral Petrol 151:58-70. https://doi.org/10.1007/s00410-005-0045-4

Morgan DJ, Blake S, Rogers NW, DeVivo B, Rolandi G, Macdonald R, Hawkesworth CJ (2004) Time scales of crystal residence and magma chamber volume from modelling of diffusion profiles in phenocrysts: Vesuvius 1944. Earth Planet Sci Lett 222(3-4):933-946. https://doi.org/10.1016/j.eps1.2004.03.030 
Morioka M (1981) Cation diffusion in olivine - II. Ni-Mg, Mn-Mg, Mg and Ca. Geochim Cosmochim Acta 45:1573-1580.

Murphy MD, Sparks RSJ, Barclay J, Carroll MR, Brewer TS (2000) Remobilization of andesite magma by intrusion of mafic magma at the Soufriere Hills Volcano, Montserrat, West Indies. J Petrol 41(1):21-42.

Mutch EJF, Maclennan J, Shorttle O, Edmonds M, Rudge JF (2019) Rapid transcrustal magma movement under Iceland. Nat Geosci 12:569-574. https://doi.org/10.1038/s41561-019$\underline{0376-9}$

Nakamura M (1995) Residence times and crystallization history of nickeliferous olivine phenocrysts from the northern Yatsugatake volcanoes, Central Japan: Application of a growth and diffusion model in the system Mg-Fe-Ni. J Volcanol Geotherm Res 66(1-4):81100.

Nakamura A, Schmalzried H (1984) On the $\mathrm{Fe}^{2+}-\mathrm{Mg}^{2+}$-interdiffusion in olivine (II). Berichte der Bunsengesellschaft für physikalische Chemie 88(2):140-145. https://doi.org/10.1002/bbpc.19840880212

Neal A, Brantley SR, Antolik L et al. (2019) The 2018 rift eruption and summit collapse of Kīlauea Volcano. Science 363(6425):367-374. https://doi.org/10.1126/science.aav7046

Oeser M, Dohmen R, Horn I, Schuth S, Weyer S (2015) Processes and time scales of magmatic evolution as revealed by $\mathrm{Fe}-\mathrm{Mg}$ chemical and isotopic zoning in natural olivines. Geochim Cosmochim Acta 154:130-150. https://doi.org/10.1016/j.gca.2015.01.025

Oeser M, Ruprecht P, Weyer S (2018) Combined Fe-Mg chemical and isotopic zoning in olivine constraining magma mixing-to-eruption timescales for the continental arc volcano Irazú (Costa Rica) and $\mathrm{Cr}$ diffusion in olivine. Am Mineral 103(4):582-599. https://doi.org/10.2138/am-2018-6258

Park C, Schmincke H-U (2020) Multistage damming of the Rhine River by tephra fallout during the 12,900 BP Plinian Laacher See Eruption (Germany). Syn-eruptive Rhine damming I. J Volcanol Petrol 389:106688. https://doi.org/10.1016/j.jvolgeores.2019.106688

Patrick MR, Dietterich HR, Lyons JJ, Diefenbach AK, Parcheta C, Anderson KR, Namiki A, Sumita I, Shiro B, Kauahikaua JP (2018) Cyclic lava effusion during the 2018 eruption of Kīlauea Volcano. Science 366(6470). https://doi.org/10.1126/science.aay9070 
Petry C, Chakraborty S, Palme H (2004) Experimental determination of Ni diffusion coefficients in olivine and their dependence on temperature, composition, oxygen fugacity, and crystallographic orientation. Geochim Cosmochim Acta 68(20):4179-4188. https://doi.org/10.1016/j.gca.2004.02.024

Prior DJ, Boyle AP, Brenker F, Cheadle MC, Day A, Lopez G, Peruzzi L, Potts G, Reddy S, Spiess R, Timms NE, Trimby P, Wheeler J, Zetterstrom L (1999) The application of electron backscatter diffraction and orientation contrast imaging in the SEM to textural problems in rocks. Am Mineral 84(11-12):1741-1759. https://doi.org/10.2138/am-1999-11-1204

Rae ASP, Edmonds M, Maclennan J, Morgan D, Houghton B, Hartley ME, Sides I (2016) Time scales of magma transport and mixing at Kîlauea Volcano, Hawai'i. Geology 44(6):463466. https://doi.org/10.1130/G37800.1

Rasmussen DJ, Plank TA, Roman DC, Power JA, Bodnar RJ, Hauri EH (2018) When does the eruption run-up begin? Multidisciplinary insight from the 1999 eruption at Shishaldin volcano. Earth Planet Sci Lett 486:1-14. https://doi.org/10.1016/j.eps1.2018.01.001

Roeder PL, Emslie RF (1970) Olivine-liquid equilibrium. Contrib Mineral Petrol 29:275-289.

Rout SR, Wörner G (2018) Zoning and exsolution in alkali feldspars from Laacher See volcano (Western Germany): constraints on temperature history prior to eruption. Contrib Mineral Petrol 173(95). https://doi.org/10.1007/s00410-018-1522-x

Saunders K, Blundy J, Dohmen R, Cashman K (2012) Linking petrology and seismology at an active volcano. Science 336(6084):1023-1027. https://doi.org/10.1126/science.1220066

Seitz S, Pulitz B, Baumgartner L, Meibom A, Escrig S, Bouvier AS (2018) A NanoSIMS investigation on timescales recorded in volcanic quartz from the silicic Chon Aike Province (Patagonia). Front Earth Sci 6:95. https://doi.org/10.3389/feart.2018.00095

Shea T, Costa F, Krimer D, Hammer JE (2015a) Accuracy of timescales retrieved from diffusion modeling in olivine: A 3D perspective. Am Mineral 100(10):2026-2042. https://doi.org/10.2138/am-2015-5163

Shea T, Lynn KJ, Garcia MO (2015b) Cracking the olivine zoning code: Distinguishing between crystal growth and diffusion. Geology 43(10):935-938. https://doi.org/10.1130/G37082.1 
Spandler C, O’Neill HStC (2010) Diffusion and partition coefficients of minor and trace elements in San Carlos olivine at $1,300^{\circ} \mathrm{C}$ with some geochemical implications. Contrib Mineral Petrol 159:791-818. https://doi.org/10.1007/s00410-009-0456-8

Sparks SRJ, Sigurdsson H, Wilson L (1977) Magma mixing: a mechanism for triggering acid explosive eruptions. Nature 267:315-318.

Sundermeyer C, Di Muro A, Gordeychik B, Wörner G (2020) Timescales of magmatic processes during the eruptive cycle 2014-2015 at Pion de la Fournaise, La Réunion, obtained from $\mathrm{Mg}-\mathrm{Fe}$ diffusion modelling in olivine. Contrib Mineral Petrol 175(1). https://doi.org/10.1007/s00410-019-1642-y

Staudacher T, Ferrazzini V, Peltier A, Kowalski P, Boissier P, Catherine P, Lauret F, Massin F (2009) The April 2007 eruption and the Dolomieu crater collapse, two major events at Piton de la Fournaise (La Réunion Island, Indian Ocean). J Volcanol Geotherm Res 184(12):126-137. https://doi.org/10.1016/j.jvolgeores.2008.11.005

Thordarson T, Self S (1993) The Laki (Skaftár Fires) and Grímsvötn eruptions in 1783-1785. Bull Volcanol 55:233-263.

Tollan PME, O’Neill HStC, Hermann J, Benedictus A, Arculus RJ (2015) Frozen melt-rock reaction in a peridotite xenolith from sub-arc mantle recorded by diffusion of trace elements and water in olivine. Earth Planet Sci Lett 422:169-181. http://dx.doi.org/10.1016/j.eps1.2015.03.055

Toplis MJ (2005) The thermodynamics of iron and magnesium partitioning between olivine and liquid: criteria for assessing and predicting equilibrium in natural and experimental systems. Contrib Mineral Petrol 149:22-39. https://doi.org/10.1007/s00410-004-0629-4

Turner S, Costa C (2007) Measuring timescales of magmatic evolution. Elements 3:267-272.

Ubide T, Kamber BS (2018) Volcanic crystals as time capsules of eruption history. Nat Commun 9(326):1-12. https://doi.org/10.1038/s41467-017-02274-w

Viccaro M, Giuffrida M, Nicotra E, Cristofolini R (2016) Timescales of magma storage and migration recorded by olivine crystals in basalts of the March-April 2010 eruption at Eyjafjallajökull volcano, Iceland. Am Mineral 101(1):222-230. https://doi.org/10.2138/am-2016-5365 
van den Bogaard P, Schmincke H-U (1985) Laacher See Tephra: A widespread isochronous late Quaternary tephra layer in central and northern Europe. GSA Bulletin 96(12):1554-1571. https://doi.org/10.1130/0016-7606(1985)96<1554:LSTAWI>2.0.CO;2

van den Bogaard $\mathrm{P}(1995){ }^{40} \mathrm{Ar} /{ }^{39} \mathrm{Ar}$ ages of sanidine phenocrysts from Laacher See Tephra $(12,900$ yr BP): Chronostratigraphic and petrological significance. Earth Planet Sci Lett 133:163174.

Watson EB, Cherniak DJ, Holycross ME (2015) Diffusion of phosphorous in olivine and molten basalt. Am Mineral 100(10):2053-2065. http://dx.doi.org/10.2138/am-2015-5416

Zellmer GF, Blake S, Vance D, Hawkesworth C, Turner S (1999) Plagioclase residence times at two island arc volcanoes (Kameni Islands, Santorini, and Soufriere, St. Vincent) determined by $\mathrm{Sr}$ diffusion systematics. Contrib Mineral Petrol 136(4):345-357. https://doi.org/10.1007/s004100050543

Zellmer GF, Sparks RSJ, Hawkesworth CJ, Wiedenbeck M (2003b) Magma emplacement and remobilization timescales beneath Montserrat: Insights from $\mathrm{Sr}$ and $\mathrm{Ba}$ zonation in $\begin{array}{lllll}\text { plagioclase } & \text { phenocrysts. } & \text { J }\end{array}$ https://doi.org/10.1093/petrology/44.8.1413

Zhukova I, O’Neill H, Campbell IH (2017) A subsidiary fast-diffusing substitution mechanism of $\mathrm{Al}$ in forsterite investigated using diffusion experiments under controlled thermodynamic conditions. Contrib Mineral Petrol 172:53. https://doi.org/10.1007/s00410-017-1365-X

Zhang Y (2010) Diffusion in minerals and melts: Theoretical background. Rev Mineral Geochem 72(1):5-59. https://doi.org/10.2138/rmg.2010.72.2 


\title{
2 Growth of, and diffusion in, olivine in ultra-fast ascending basalt magmas from Shiveluch volcano
}

\author{
Boris Gordeychik ${ }^{1,2, *}$, Tatiana Churikova ${ }^{2,3}$, Andreas Kronz², \\ Caren Sundermeyer ${ }^{2}$, Alexander Simakin ${ }^{1}$, and Gerhard Wörner ${ }^{2}$ \\ ${ }^{1}$ Institute of Experimental Mineralogy, Russian Academy of Sciences, Chernogolovka, 142432, Russia \\ ${ }^{2}$ Geowissenschaftliches Zentrum Göttingen, Abteilung Geochemie, Universität Göttingen, Göttingen, 37077, \\ Germany \\ ${ }^{3}$ Institute of Volcanology and Seismology, Far East Branch, Russian Academy of Sciences, Petropavlovsk- \\ Kamchatsky, 683006, Russia \\ * Correspondence and requests for materials should be addressed to B.G. (email: gordei@mail.ru)
}

\subsection{Abstract}

Complex core-rim zoning of Mg-Fe-Ni-Ca-Cr-Al-P in high-Mg olivine crystals from a tuff ring of Shiveluch volcano, Kamchatka, enables reconstruction of the entire olivine crystallization history from mantle conditions to eruption. Bell-shaped $\mathrm{FO}_{86-92}$ and Ni profiles in crystal cores were formed by diffusion after mixing with evolved magma. Diffusion proceeded to the centres of crystals and completely equilibrated Fo and Ni in some crystals. Diffusion times extracted from Fo and Ni core profiles range from 100 to 2000 days. During subsequent mixing with mafic mantle-equilibrated melt, the cores were partially dissolved and overgrown by Fo90 olivine. Times extracted from Fo and $\mathrm{Ni}$ diffusion profiles across the resorption interface between the core and its overgrowth range within 1-10 days, which corresponds to the time of magma ascent to the surface. The overgrowth shows identical smooth Fo-Ni decreasing zoning patterns for all crystals towards the margin, indicating that all crystals shared the same growth history after last mixing event prior to eruption. At the same time, $\mathrm{Ca}$, and to an even greater extent $\mathrm{Cr}, \mathrm{Al}$, and $\mathrm{P}$ have oscillatory growth patterns in the crystals overgrowth. Our data show that magma ascent can be extremely short during maar/tuff ring eruption. 


\subsection{Introduction}

We have a good understanding of the principal processes of compositional differentiation and mixing of magmas prior to their eruption. However, the duration of these magmatic processes preceding eruption, i.e. differentiation, storage, mixing, and rejuvenation of melts from crystal mush, as well as amalgamation of distinct magma batches, are yet to be understood ${ }^{1-7}$. Also, our understanding of how fast mantle-derived magmas transit through the crust to surface is limited. Diffusion speedometry is one method to extract residence times of zoned crystals at given P-T- $f \mathrm{O}_{2}$ conditions, i.e. following recharge and mixing processes. Zoning in olivine has the potential to directly link recharge by new input of mafic melts into resident magmas, which is an eruption trigger, and ascent times from deep magma sources ${ }^{1,5,8}$. Many studies of zoned minerals focus on olivine and the shallow parts of magma systems in an attempt to find a link with such processes as degassing and seismic events before the eruption ${ }^{9-11}$. Olivine hosts a range of elements, such as Li, $\mathrm{Al}, \mathrm{Ca}, \mathrm{Cr}, \mathrm{Mn}, \mathrm{Co}, \mathrm{Ni}$, which have different diffusion coefficients. Information about zoning of multiple elements in one crystal offers the possibility of simultaneous modelling of diffusion ${ }^{1,8,12-}$ 16. Diffusion of $\mathrm{Mg}-\mathrm{Fe}$ and $\mathrm{Ni}$ in olivine is relatively fast and therefore different stages of ascent, crystallization and mixing of mantle-derived magmas are generally obliterated during the extended history of olivine crystals. Based on Ni diffusion modeling of olivine crystals from Irazú volcano, Costa Rica, it was suggested that magmas can rise from mantle depth during a period ranging from a hundred days to a few years prior to eruption ${ }^{5}$. Even such short periods were sufficiently long to erase any Fo zoning in olivine. Thus, the earlier record of the deeper history of olivine crystals is difficult to constrain.

We document olivine crystals from a basaltic maar deposit at Shiveluch volcano (Kamchatka) that preserve rich records of the full history of growth and diffusion from the deep mantle source of the magmas to the Earth's surface. Fo92 cores were formed from primary magmas and suffered from diffusional exchange to various extents in evolving host magmas. Recharge caused partial dissolution and renewed growth of $\mathrm{Fo}_{90}$ olivine and resulted in the formation of identical overgrowths on a variety of olivine cores. Subsequently, a next stage of diffusion smoothed out the compositional interface between cores and overgrowth. The overgrowths have distinct growth bands for slow diffusing $\mathrm{Cr}$, Al, P, despite smooth Fo-Ni zoning. Based on Fo and Ni diffusion, we demonstrate that these olivine crystals had been growing at mantle depths for about 100 to 2000 days before their final ascent to the surface in only 1-10 days. 


\subsection{Shiveluch volcano, Kamchatka: geology and sampling}

Kamchatka is one of the most active magmatic arcs in the world with abundant mafic lavas that contain high-Mg olivine phenocrysts. We studied here high-Mg middle- $\mathrm{K}$ basalts from a phreatomagmatic maar deposit in order to constrain the residence and ascent times for basalts feeding one of the most active volcanoes in Kamchatka - Shiveluch ${ }^{17}$, located near the northern edge of the subducting Pacific Plate ${ }^{18}$. The volcano is located about $90 \mathrm{~km}$ above the slab that descends at an angle of $35^{\circ}$ (e.g. ${ }^{19,20}$ ). Petrological and geophysical studies suggest that a slab window beneath Shiveluch was formed by a transform fault between the Pacific and Bering Plates ${ }^{21-}$

${ }^{23}$ and the slab edge became heated and partially melts to import a slab-melt signature to resultant magmatism ${ }^{18}$. The abundance of peridotite xenoliths ${ }^{24}$ indicates that the magma system is fed by fast-ascending mantle-derived magmas. Shiveluch volcano erupted mainly high-Mg andesites ${ }^{18,25,26}$ during Holocene times, however, previous tephrochronological studies ${ }^{25,27}$ described two high-Mg tephra layers dated at $3600 \mathrm{yr} \mathrm{BP}$ and $7600 \mathrm{yr} \mathrm{BP}$, respectively $\left({ }^{14} \mathrm{C}\right.$ dating). Our samples were derived from deposits of a phreatomagmatic maar that was recently discovered at the SW end of the Baidarny ridge ${ }^{28}$ and is likely the source of the $7600 \mathrm{yr}$ BP tephra layer ${ }^{29}$. Sample SHIV-08-05 is a weakly-vesiculated ol-cpx-pl basaltic andesite bomb and sample SHIV-08-07 was collected from fine-grained scoria of the phreatomagmatic tephra deposit. Euhedral olivine grains can reach up to $8 \mathrm{~mm}$ in size with inclusions of chromium spinel up to $0.05 \mathrm{~mm}$. These basaltic andesites have $\mathrm{SiO}_{2}=52-54$ wt. $\%, \mathrm{MgO}=8-8.5$ wt. $\%$, and $\mathrm{K}_{2} \mathrm{O}=0.85-0.95$ wt. $\%{ }^{28}$. The composition of different mineral phases (olivine, spinel, clinopyroxene, plagioclase) in our samples can be found in Supplementary Materials (SM) Tables SM2-A, SM3-A, and SM3-B.

\subsection{Compositional profiles and zoning types}

Compositional zoning in high-Mg olivine is documented by 27 profiles across 19 grains for elements with different diffusivities ( $\mathrm{Mg}, \mathrm{Fe}, \mathrm{Ni}, \mathrm{Ca}, \mathrm{Cr}$, Al, P; Fig. 1-3, supplement SM2, and Tables SM2-A, SM2-C). Olivine crystals show distinctly different Mg-Fe distributions: normal zoning (Fig. 1b), complex reverse zoning (Fig. 1d), and complex repetitive zoning (Fig. 1c), indicating different growth-diffusion histories. An example of an unusual Fo-Ni zoning in SHIV08-05 17 Ol-8-2 profile is analysed in detail in supplement SM2.1.

We define different zones (Fig. 1a) to aid the data presentation and discussion. The core includes the area from the centre of a crystal to a prominent resorption surface. This smoothly curved interface with abundant melt/fluid inclusions occur in all crystals (Fig. 1) and all element maps, indicative of partial dissolution prior to further growth. The analysis shows that the resorption interface is also represented in the profiles as a point of $\mathrm{NiO}$ inflection, referred to as the Ni-kink 
here. Cores of olivine grains have bell-shaped (Fig. 1b, c) to flat (Fig. 1d) forsterite and nickel distributions. Fo varies from 92 to $86 \mathrm{~mol}$ \% in the core and we distinguish between the inner core with minor Fo-Ni variations and the outer core with steeper compositional gradients. An overgrowth is formed on the cores after the resorption event and extends from the Ni-kink to the crystal margin. We term the area between core and overgrowth, i.e. around of Ni-kink, the transition zone. Points of inflection at the dissolution interface also occur in the Fo-profiles, but are not as clearly expressed as for $\mathrm{NiO}$. The transition zones are variable in width in different grains but do not exceed $0.02 \mathrm{~mm}$ for $\mathrm{NiO}$ and $0.04 \mathrm{~mm}$ for Fo. The rim is defined as an outer part of the overgrowth which is characterized by a sharp drop in Ni and Fo close to the margin of the crystal (Fig. 1).

The Fo-Ni diagram (Fig. 2a) shows individual Fo-Ni profiles and their schematic representation (Fig. 2b). To understand the continuous evolution of olivine compositions, dissolution, growth and subsequent diffusion, we distinguish four groups, from a high-Mg-high-Ni group 1 to the low-Mglow-Ni group 4 (Fig. 2b). Centres of cores (red points in Fig. 2) and their corresponding groups (grey circles in Fig. 2b) form a gentle concave downwards trend in the Fo-Ni diagram. The parts of profiles from the centre across the cores and transition zones are represented by green lines in Fig. 2a and show irregular tangled trajectories, depicted schematically in Fig. 2b. These compositional trajectories originate at distinct core compositions but all meet at a common composition of about $\mathrm{Fo}_{89}$ and $\mathrm{NiO} 0.4$ wt. \%. From this point, the compositions in the overgrowths and rims (blue lines in Fig. 2a) unite and all follow identical paths of smoothly decreasing Fo and $\mathrm{NiO}$ (represented by a single blue line in in Fig. 2b). This means that the last stage of evolution in terms of Fo and $\mathrm{Ni}$ was similar for all crystals.

To better compare profiles for many olivine crystals of different sizes, we used dimensionless spatial coordinates in Fig. 3a. The margin, the Ni-kink, and centre of each crystal are allocated coordinates of $-1,0$, and 1 , respectively. The transformations are linear in both intervals inside and outside of the Ni-kink. Such normalized profiles of Fo and $\mathrm{NiO}$ (Fig. 3a) for every group of olivine allow us to more clearly define distinct cores and transition zones, as well as common overgrowths and their rims. The shapes of the core Fo and Ni profiles vary continuously from bell-shaped to flat from group 1 to 4; Fo and Ni level differences increases in the transition zone from group 1 to 4 , while zoning of the Fo and $\mathrm{Ni}$ in the overgrowth beyond the transition zone is similar in all groups. Group 1 cores have well-defined bell-shaped distributions for forsterite and nickel (Fig. 3). These zoning patterns are reminiscent of diffusion profiles. All inner cores have identical high Fo91.6-92.2 and $\mathrm{NiO}=0.45-0.5 \mathrm{wt} \%$. Their rims indicate equilibrium with less mafic and lower-Ni melt. These cores with bell-shaped Fo and Ni distributions contrast strongly with group 4 cores, which have low and flat $\mathrm{Fo}$ and $\mathrm{NiO}$ distributions inside the core $\left(\mathrm{Fo}_{86.5-87.8}, \mathrm{NiO}=0.22-0.31\right.$ wt. \%). Groups 2 and 3 are intermediate and their cores are successively lower in Fo and $\mathrm{NiO}$ (group 2: Fo89.9-90.8, 
$\mathrm{NiO}=0.39-0.45$ wt. \%; group 3: Fo $87.7-89.2, \mathrm{NiO}=0.34-0.39$ wt. \%) and their zoning patterns become flat. Even though the Fo contents and zoning patterns of these various cores $(1-4)$ are different, the trace element concentrations of slowly-diffusing elements $(\mathrm{Ca}, \mathrm{Al}, \mathrm{P})$ are similar, indicating a common origin.

The Fo-Ni composition of different inner cores in Fig. 2 shows a distinctly concave trend that is not consistent with fractional crystallization. By contrast, the overgrowth shows convex downwards Fo-Ni trends, which is consistent with fractional crystallization ${ }^{5,30-33}$. These observations indicate that (1) the cores had a similar origin but different history that has affected the Fe-Mg distribution, (2) the cores and their overgrowths were formed by distinct processes from different magmas and (3) after dissolution of the cores the crystals continued to grow from increasingly differentiated magma. While Fo and Ni smoothly decrease in the overgrowth, all slow diffusing elements (Ca, $\mathrm{Cr}, \mathrm{Al}, \mathrm{P}$ ) show sharp oscillatory growth patterns (Fig. 3b, 4).
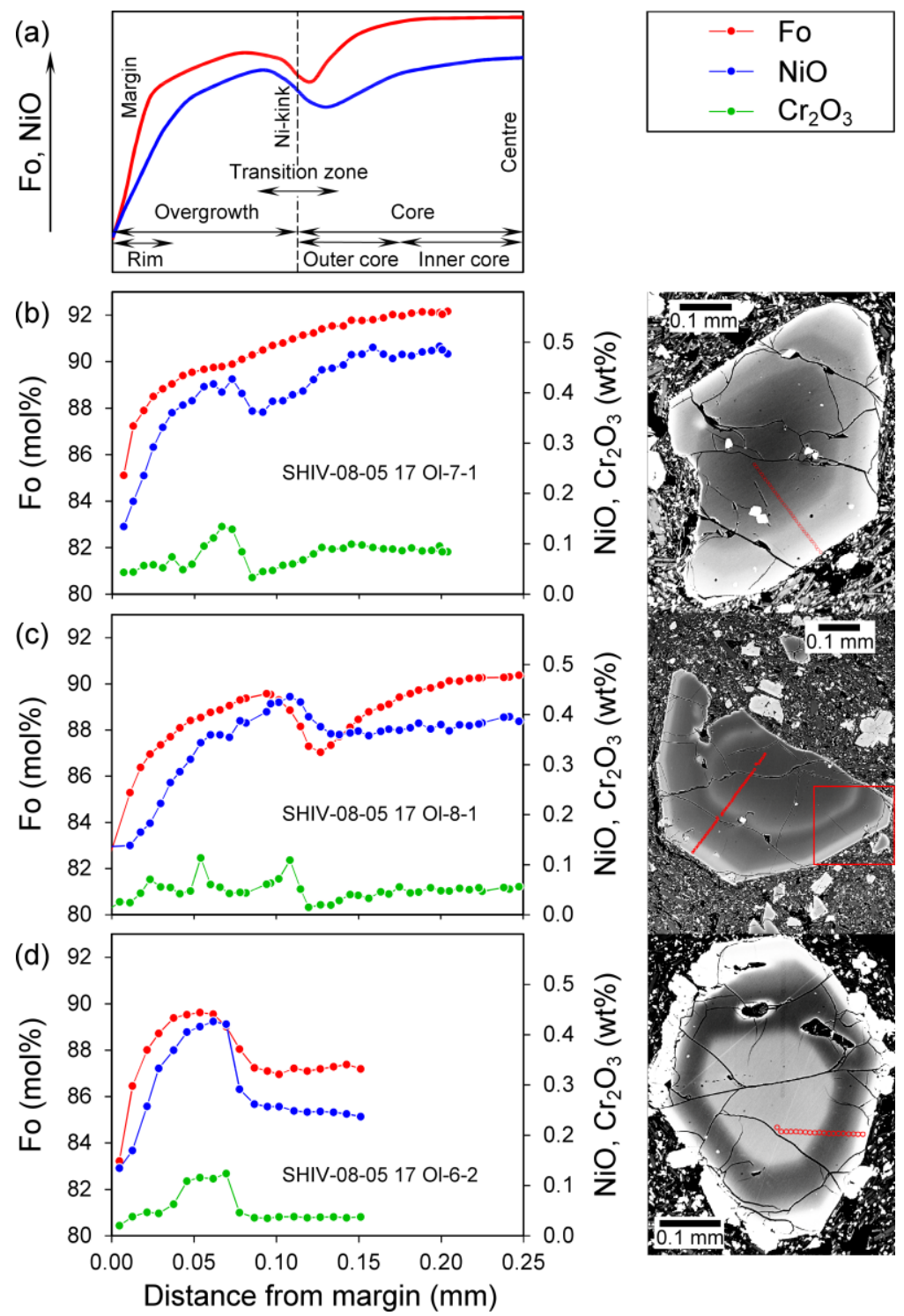
Fig. 1. (a) Schematic representation of core-rim zoning defining the descriptive terms used here. (b-d) Fo, $\mathrm{NiO}$ and $\mathrm{Cr}_{2} \mathrm{O}_{3}$ distributions in representative olivine crystals and their BSE images from high-Mg middle-K Shiveluch basalt. Olivine crystals show variable zoning patterns: (b) - normal, (d) - complex reverse, and (c) - complex repetitive. The profiles are marked by red dots on the BSE-images. All profiles were measured from the margin of the crystal to the most central part. Forsterite values (red) are shown on the left axis, NiO (blue) and $\mathrm{Cr}_{2} \mathrm{O}_{3}$ (green) values are shown on the right axis. Red square in Fig. 1c denotes detail shown in Fig. 4.
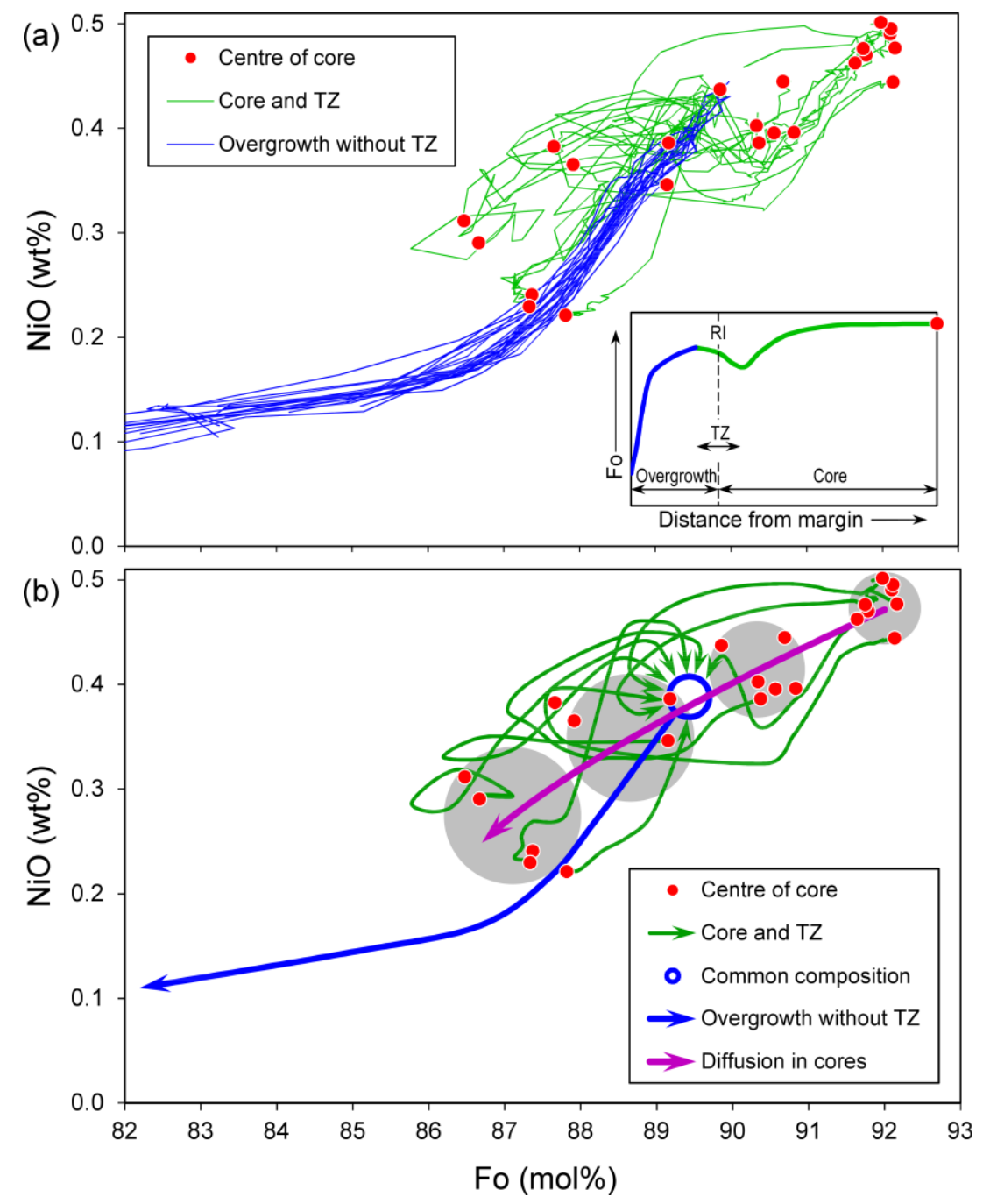

Fig. 2. Fo-Ni variations along compositional profiles: (a) - measured olivine crystals and (b) - schematic representation emphasizing growth and diffusion histories. Measurements show distinct core compositions (red dots) and complex and irregular trajectories from the centres to transition zones (green lines) all coming to a common composition (blue circle). Fo-Ni depletion trend starts from this common composition and compositional zoning towards the crystal margins is similar for all crystals (blue lines). RI - resorption interface, $\mathrm{TZ}$ - transition zone. 


\section{$2.5 \mathrm{P}-\mathrm{T}-f \mathrm{O}_{2}$ conditions of olivine crystallization}

Pressures determined from cpx-melt equilibria range from 6 to $10 \mathrm{kbar}(18-30 \mathrm{~km})$ consistent with the results of cpx-only barometry $(6 \mathrm{kbar})^{34}$. These are in good agreement with previous estimates ${ }^{35}$ (7-9 kbar). Olivines with Fo86-92 were formed at similar or even greater depths. The rationale for this is: (1) pyroxene crystals were formed after olivine and are invariably smaller grading into cpx of the fine-grained matrix, (2) pyroxene Mg\# varies from 87 to 68 (Table SM3-B) indicating crystallization from more evolved melt than that of the olivines, and (3) pyroxene lacks overgrowths on resorbed cores unlike the more complex zoning observed in the olivine crystals.

Temperature estimates are based on Al-in-olivine thermometry ${ }^{36}$, which utilizes the Al-Cr distribution between olivine and spinel. We used the composition of the local spinel inclusion adjacent to the host olivine for every zone (Fig. 1a). Temperatures for the inner cores of olivines range from 1230 to $1260{ }^{\circ} \mathrm{C}$ and are lower in outer cores (1170-1190 ${ }^{\circ} \mathrm{C}$; Table SM3-C). Temperatures vary from $1150-1220{ }^{\circ} \mathrm{C}$ in the transition zone to $1160-1200{ }^{\circ} \mathrm{C}$ and $1130-1155{ }^{\circ} \mathrm{C}$ in the overgrowth towards the rim, respectively. Pre-eruption temperatures of around $1100{ }^{\circ} \mathrm{C}$ in Shiveluch lavas ${ }^{35}$ are similar to the temperatures estimated from the rim of our olivine crystals. The relatively high pressures and temperatures suggest that the cores and overgrowth of the olivine crystals were formed under mantle conditions. 

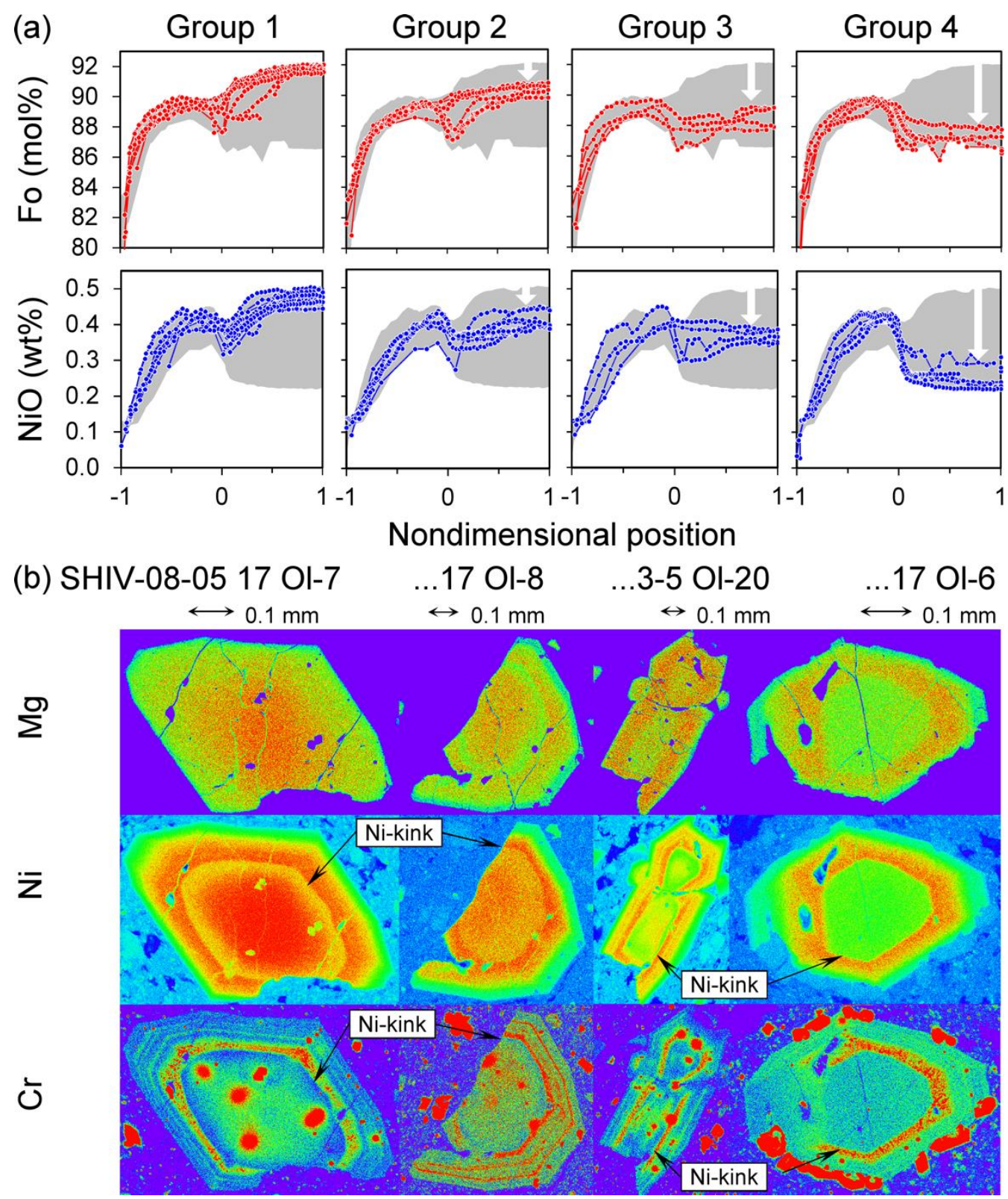

Fig. 3. (a) Olivine crystals with Fo and Ni zoning are divided into four groups. Spatial axes along the profiles are in dimensionless coordinates: the margin, the Ni-kink, and centre of each crystal are allocated coordinates of $-1,0$, and 1 , respectively. Grey fields show all data for reference. The shapes of gradients in the cores change from bell-shaped to flat from group 1 to 4 . Forsterite and nickel contents in the centre of the cores decrease with increasing diffusive equilibration to a more evolved melt ("advanced core diffusion", white arrows) (b) Representative compositional maps of crystals for four different groups of cores for elements of different diffusivities. The spectrum colors from red to violet correspond to element concentration from maximum to minimum. Note the smooth compositional variations for Fe-Mg distributions. Ni shows more structure and clearly defines the dissolution interface (Ni-kink) between outer core and subsequent overgrowth. $\mathrm{Cr}$ is an element with slow diffusivity and defines the dissolution boundary between the core and the overgrowth more clearly than $\mathrm{Fe}, \mathrm{Mg}$, and $\mathrm{Ni}$. $\mathrm{Cr}$ also has retained delicate oscillatory growth zoning in the overgrowth on the cores. The high-chromium inclusions in olivine are chromite. 
Numerical simulation of the temperature distribution in the mantle wedge under Shiveluch ${ }^{37}$ provide indirect evidence of the maximum depth of origin for the olivine cores. Temperatures that we estimated for olivine core crystallization are $1130-1260{ }^{\circ} \mathrm{C}$ and such temperatures are predicted at a depth of $55-80 \mathrm{~km}$.

Oxygen fugacity is $\triangle \mathrm{QFM}=+1.04 \pm 0.26$ at a pressure of $6 \mathrm{kbar}$ and $\Delta \mathrm{QFM}=+0.90 \pm 0.26$ at $10 \mathrm{kbar}$ (Table SM3-A), both being somewhat lower than previously estimated ${ }^{35}$ for similar lavas $\Delta \mathrm{QFM}=+1.8 \pm 0.15$.
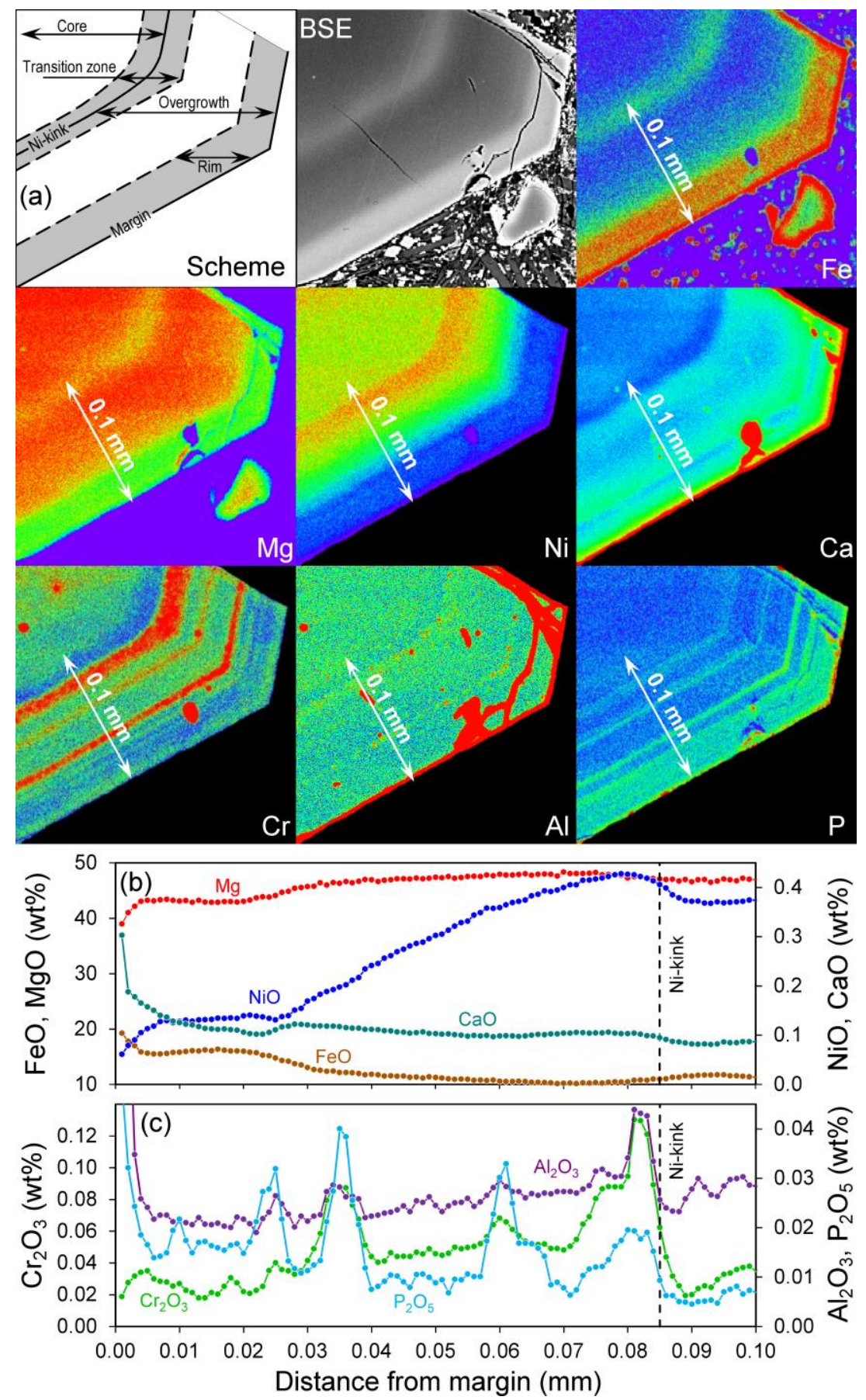
Fig. 4. (a) Fe-, Mg-, Ni-, Ca-, Cr-, Al-, and P-distribution maps in the olivine crystal showing distinct growth zones. Here we show only a small part of crystal SHIV-08-05 17 Ol-8 that is marked by a red frame in Fig. 1c. The spectrum of colors from red to violet corresponds to element concentration from maximum to minimum. Many other crystals that we analyzed have similar zoning patterns. (b, c) - detailed profile with steps of $0.001 \mathrm{~mm}$, marked by white arrows on Fig. $4 \mathrm{a}$, shows variable widths of the high-concentration zones, which depend on their relative diffusivities $(\mathrm{P}<\mathrm{Al}<\mathrm{Cr}<\mathrm{Ca}<\mathrm{Fe}-\mathrm{Mg}$ ). For example, the half-widths of $\mathrm{Al}$ peaks are only 2-3 microns. $\mathrm{Ca}$ and $\mathrm{Ni}$ profiles are increasingly smoother and $\mathrm{Fe}-\mathrm{Mg}$ profiles show almost equilibrated profiles across peaks for $\mathrm{P}, \mathrm{Al}, \mathrm{Cr}$. This clearly indicates that the overgrowths of the olivine crystals were initially zoned in all these elements during crystallization but subsequent diffusion has partially erased $\mathrm{Mg} / \mathrm{Fe}$ and, less so, $\mathrm{Ni}$ zoning patterns.

\subsection{Discussion: growth and diffusion history}

The olivine crystals record two distinct stages of crystallization for core and overgrowth, which are separated by a dissolution interface. With respect to diffusion in the core, we distinguish two stages (Fig. 3a): (1) outer core diffusion that does not reach the centres of the crystals, preserving initial Fo and Ni values in their inner cores (group 1); (2) advanced core diffusion smoothed out the gradients and also decreased the Fo and $\mathrm{Ni}$ in the centres of the cores forming olivine groups 2-3 with partial and olivine group 4 with complete equilibrium with a more evolved melt. A third stage of diffusion (3) occurs across the dissolution interface between core and its overgrowth that formed after recharge by a more mafic magma. A last diffusion stage (4) affected the overgrowth towards the crystal margin. We will now discuss these four diffusion stages and try to assess time scales by modeling their gradients.

Outer core diffusion has not affected the maximum values of $\mathrm{Fo}$ and $\mathrm{NiO}$ in the inner core. Initial compositions of the flat core ${ }^{38-40} \mathrm{Fo}_{\text {core }}=92 \mathrm{~mol} . \%$ and $\mathrm{NiO}_{\text {core }}=0.5$ wt. $\%$ indicate that these crystals were formed in a mantle-derived magma ${ }^{41}$. Subsequently, due to mixing with more evolved melt, the composition of the outer cores equilibrated with a new melt to values of $\mathrm{Fo}_{\mathrm{dm}}$ and $\mathrm{NiO}_{\mathrm{dm}}$. Here "dm" refers to the original (now dissolved) margin of the crystals (now cores) that have been modified by dissolution and overgrowth. The analytical solutions for one-dimensional diffusion can be formulated for both, Fo and $\mathrm{Ni}$ and describe the profiles from the margin with coordinate $\mathrm{x}_{\mathrm{dm}}$ into the core:

$$
\begin{aligned}
& F O=F o_{d m}+\left(F O_{c o r e}-F o_{d m}\right) \operatorname{Erf}\left(\frac{1}{2 \sqrt{D_{F o}}} \cdot \frac{\left(x-x_{d m}\right)}{\sqrt{t}}\right) \\
& N i O=N i O_{d m}+\left(N i O_{\text {core }}-N i O_{d m}\right) \operatorname{Erf}\left(\frac{1}{2 \sqrt{D_{N i}}} \cdot \frac{\left(x-x_{d m}\right)}{\sqrt{t}}\right) .
\end{aligned}
$$


Where: Erf - error function, $t$ - time, $x$ - spatial along the diffusion profile, $\mathrm{D}_{\mathrm{Fo}}$ and $\mathrm{D}_{\mathrm{Ni}}$ - the diffusion coefficients for Fo and Ni, respectively. The values with the index "core" refer to the centre of a crystal.

Elimination of $\left(\mathrm{x}-\mathrm{x}_{\mathrm{dm}}\right) / \mathrm{t}^{1 / 2}$ from the analytical solutions gives equation 3 linking Fo and Ni variations through the inverse error function $\mathrm{Erf}^{-1}$ along the diffusive profiles independent of diffusion time and $\mathrm{x}_{\mathrm{dm}}$ position:

$\operatorname{Erf}^{-1}\left(\frac{N i O-N i O_{d m}}{N i O_{\text {core }}-N i O_{d m}}\right)=\sqrt{\frac{D_{F o}}{D_{N i}}} \operatorname{Erf}^{-1}\left(\frac{F o-F o_{d m}}{F o_{c o r e}-F o_{d m}}\right)$

This simple formula represents diffusive $\mathrm{Ni}$ and Fo co-variations by a linear relation where the slope only depends on the relative values of the diffusion coefficients. Fig. 5 shows three examples from outer core diffusion profiles. Fig. $5 \mathrm{c}$ with $\mathrm{FO}_{\mathrm{dm}}=88.7$ and $\mathrm{NiO}_{\mathrm{dm}}=0.23$ wt. \% documents a linear correlation between left and right sides of eq. 3 for three crystals which directly confirms the diffusive nature of the compositional gradients. From the slope of the regression line, the relative diffusions coefficients are determined to be $\mathrm{D}_{\mathrm{Ni}} / \mathrm{D}_{\mathrm{Fo}}=0.86$.

We modeled diffusion times as explained in Methods section and supplement SM4. Table SM4-A contains the results for 5 profiles on 3 grains from group 1 olivine cores, an example of our modeling can be found in Fig. 6a. The diffusion time estimated for outer core diffusion ranges from 400 to 1800 days (Fig. 7, blue line).

Advanced core diffusion was the next stage of outer core diffusion. Advanced core diffusion not only smoothed the gradients, but also decreased the Fo and Ni in the inner cores. This suggests diffusive equilibration of olivine cores with a more evolved melt that was incomplete in groups 2 and 3 but complete in group 4 (Fig. 3).

The centres of the four groups of olivine cores (red dots in Fig. 2) exhibit a low-sloping, scattered Fo-Ni trend with a concave downwards shape that contrasts with typical convex fractionation crystallization trends. Such a concave trend has not been previously described for olivines from arc rocks. To interpret this finding we consider the problem of Fo and Ni decrease by diffusion with respect to different diffusion coefficients for $\mathrm{D}_{\mathrm{Fo}}$ and $\mathrm{D}_{\mathrm{Ni}}$. $\mathrm{Fo}_{\text {core }}$ and $\mathrm{Ni}_{\text {core }}$ are the initial values in the crystal at time $0, \mathrm{Fo}_{\mathrm{dm}}$ and $\mathrm{Ni}_{\mathrm{dm}}$ are compositions for olivine in equilibrium with more evolved surrounding melt on the dissolved margin of the crystal. By analogy with heat conduction, it is possible (e.g. ${ }^{42}$ ) to describe chemical diffusion and the change of $\mathrm{Fo}$ and $\mathrm{NiO}$ in the crystals as a function of time using Newton's cooling law ${ }^{43}$ :

$$
\begin{aligned}
& F o=F o_{d m}+\left(F o_{c o r e}-F o_{d m}\right) \cdot \exp \left(-t / \tau_{F o}\right), \\
& N i O=N i O_{d m}+\left(N i O_{c o r e}-N i O_{d m}\right) \cdot \exp \left(-t / \tau_{N i}\right) .
\end{aligned}
$$


Here $\tau$ is relaxation time, which depends on the size and form of the crystals and is inversely proportional to the diffusion coefficient. By cancelling out time and using the relation between relaxation times and diffusion coefficients, the dependency of Fo and $\mathrm{NiO}$ on time (Eq. 4-5) can be reduced to a function that describes the dependence of $\mathrm{NiO}$ from Fo as expressed in Eq. 6. This equation gives the dependence of $\mathrm{Ni}$ from Fo for a high-Mg and high-Ni crystal that was exposed to a low-Mg and low-Ni melt:

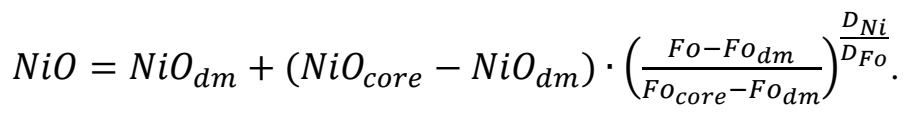
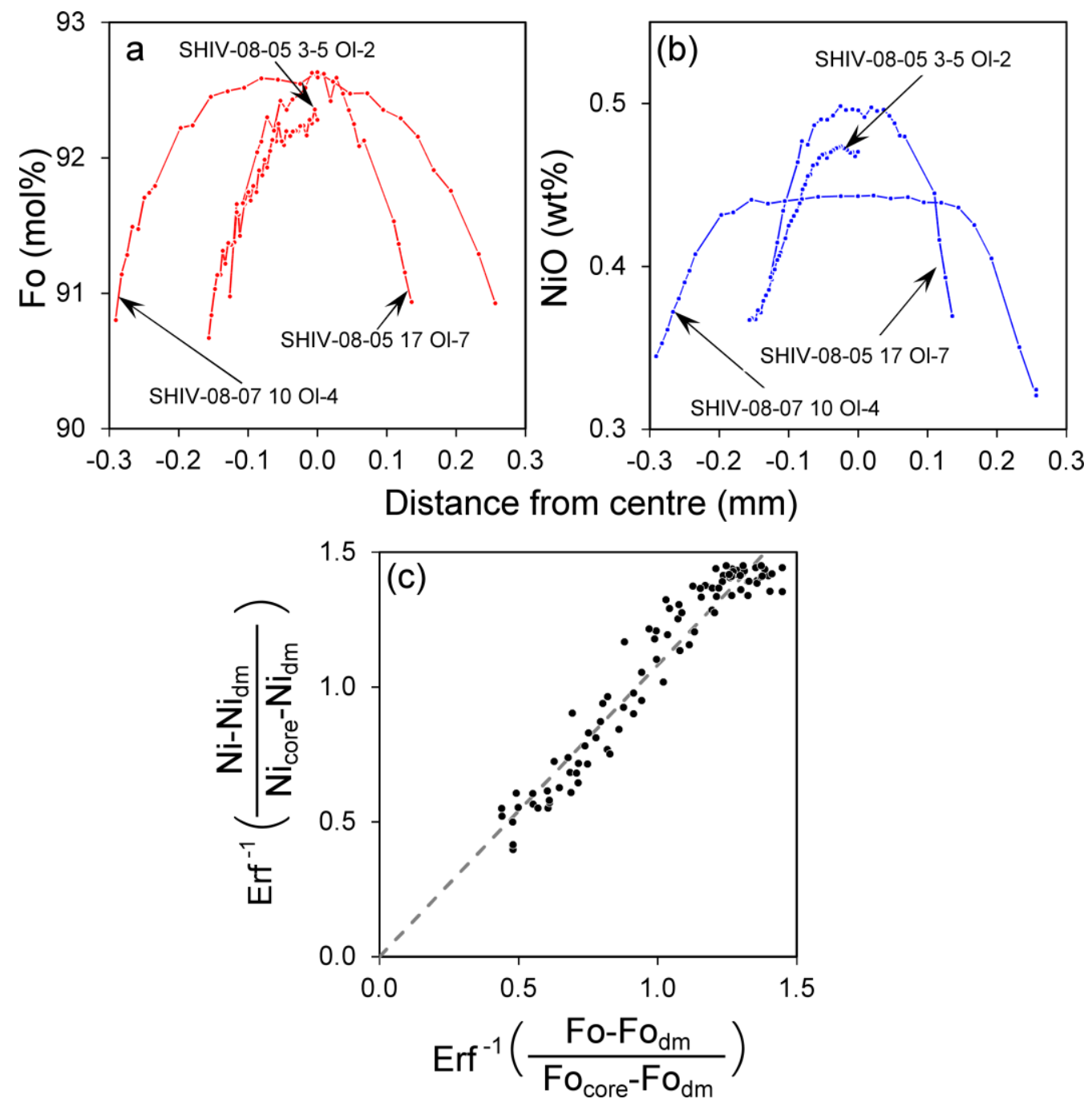

Fig. 5. Fo (a) and $\mathrm{NiO}$ (b) profiles across Mg-rich olivine cores from group 1 show diffusion after the mixing event with a more evolved melt (which is in equilibrium with $\mathrm{Fo}_{\operatorname{margin}}=88.7$ mol. $\%$ and $\mathrm{NiO}_{\text {margin }}=0.23$ wt. $\%)$. Diffusion only affected the outer cores, the inner cores remained at maximum values of about Fo92. (c) The plot shows the correlation between inverse error function for Fo-values and inverse error function for Ni-values. The slope of the dashed line shows the $\mathrm{D}_{\mathrm{Ni}} / \mathrm{D}_{\mathrm{Fo}}$ ratio of 0.86 for the outer core diffusion. 
Using the values $\mathrm{Fo}_{\mathrm{dm}}=86.4$ mol. $\%$ and $\mathrm{NiO}_{\mathrm{dm}}=0.22$ wt. $\%$ from group 4 olivine, the $\mathrm{D}_{\mathrm{Ni}} / \mathrm{D}_{\mathrm{Fo}}$ relation was determined to be 0.74 by least squares fitting of the observed core compositions, which are represented by red points in Fig. 2b. The dependence of Fo is quantitatively represented in Fig. $2 b$ by the violet line. In our case $\mathrm{D}_{\mathrm{N}} / \mathrm{D}_{\mathrm{Fo}}<1$ therefore the violet line has a concave curvature, which is distinctly opposite to the convex trend for fractional crystallization represented by the blue line in Fig. 2b.

However, Newton's cooling law and its diffusion analogy have a number of limitations: (1) the crystal is treated as a point object, (2) the law is not applicable to partial diffusion that does not reach the centre of the core and so does not describe the complete process from its starting point in time, and, finally (3) anisotropic properties of the crystal are not considered.

On the other hand, these limitations do not affect the curvature of the modeled diffusion trend. The problem regarding component concentration in a diffusion sphere with a finite radius at any time is accurately solved by equation 6.18 from ref. ${ }^{44}$. Calculations using this complex formula with an exponential series instead of Newton's cooling law (Eq. 4-5) and the detailed numerical simulation of anisotropic diffusion in crystals of various shapes and size also all yield a concave shape for the Ni-Fo relation at $\mathrm{D}_{\mathrm{Ni}}<\mathrm{D}_{\mathrm{Fo}}$. The details of these analyses, however, are beyond the scope of this paper.

The use of Newton's cooling law as an analogue for diffusion provides a simple analytical explanation for the concave trend for high-Mg high-Ni olivines undergoing diffusion and reequilibration after being exposed to a low-Mg, low-Ni melt at $\mathrm{D}_{\mathrm{Ni}}<\mathrm{D}_{\mathrm{Fo}}$ (violet line, Fig. $2 \mathrm{~b}$ ). In other words, the concave trend shows that the crystal exchanges Fo faster than Ni with the new melt as long as $\mathrm{D}_{\mathrm{Ni}}<\mathrm{D}_{\mathrm{Fo}}$. Thus, concave trends in Ni-Fo space in olivine that run contrary to typical trends during fractional crystallization can be taken as solid evidence for diffusion. 


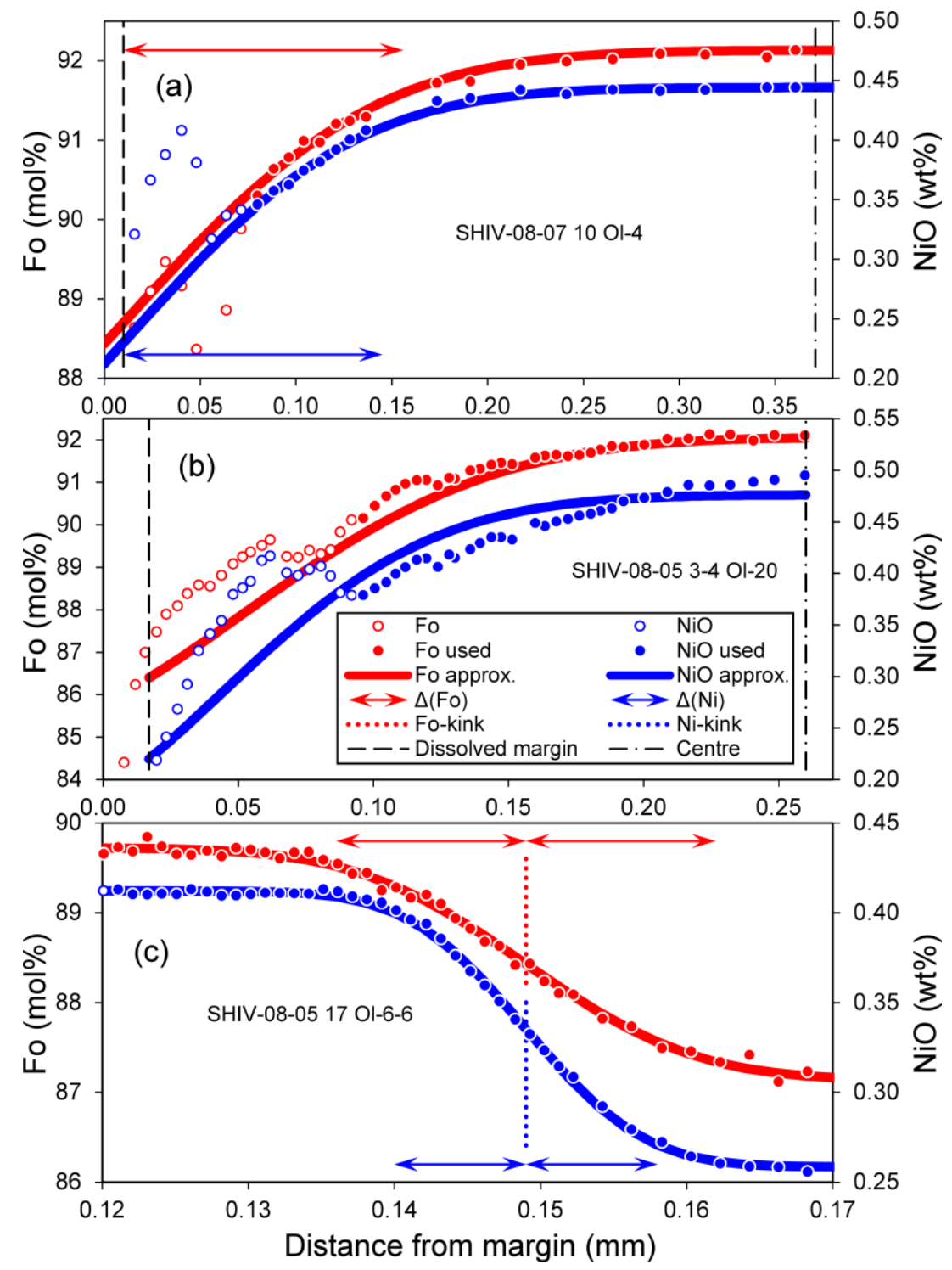

Fig. 6. Three representative profiles with model approximations of the observed data used for the diffusion time estimates: (a) - outer core diffusion, (b) - advanced core diffusion, and (c) - diffusion between core and overgrowth. Fo profiles are shown in red (left axis), and $\mathrm{NiO}$ profiles shown in blue refer to the axis on the right. Only data points with filled circles were considered in the modeling. The solid lines show the calculated model result based on an analytical approximation (described in Methods section and supplements SM4SM6). Red and blue arrows are the widths of diffusion zones $\Delta_{\mathrm{Fo}}$ and $\Delta_{\mathrm{Ni}}$, respectively. Dashed lines are the calculated positions of the dissolved margin of the cores before their resorption. Dash-dotted lines are the positions of crystal's centre. Red and blue dotted lines are the positions of the resorption interface across which diffusion occurs between core and overgrowth for $\mathrm{Fo}$ and $\mathrm{Ni}$, respectively. 


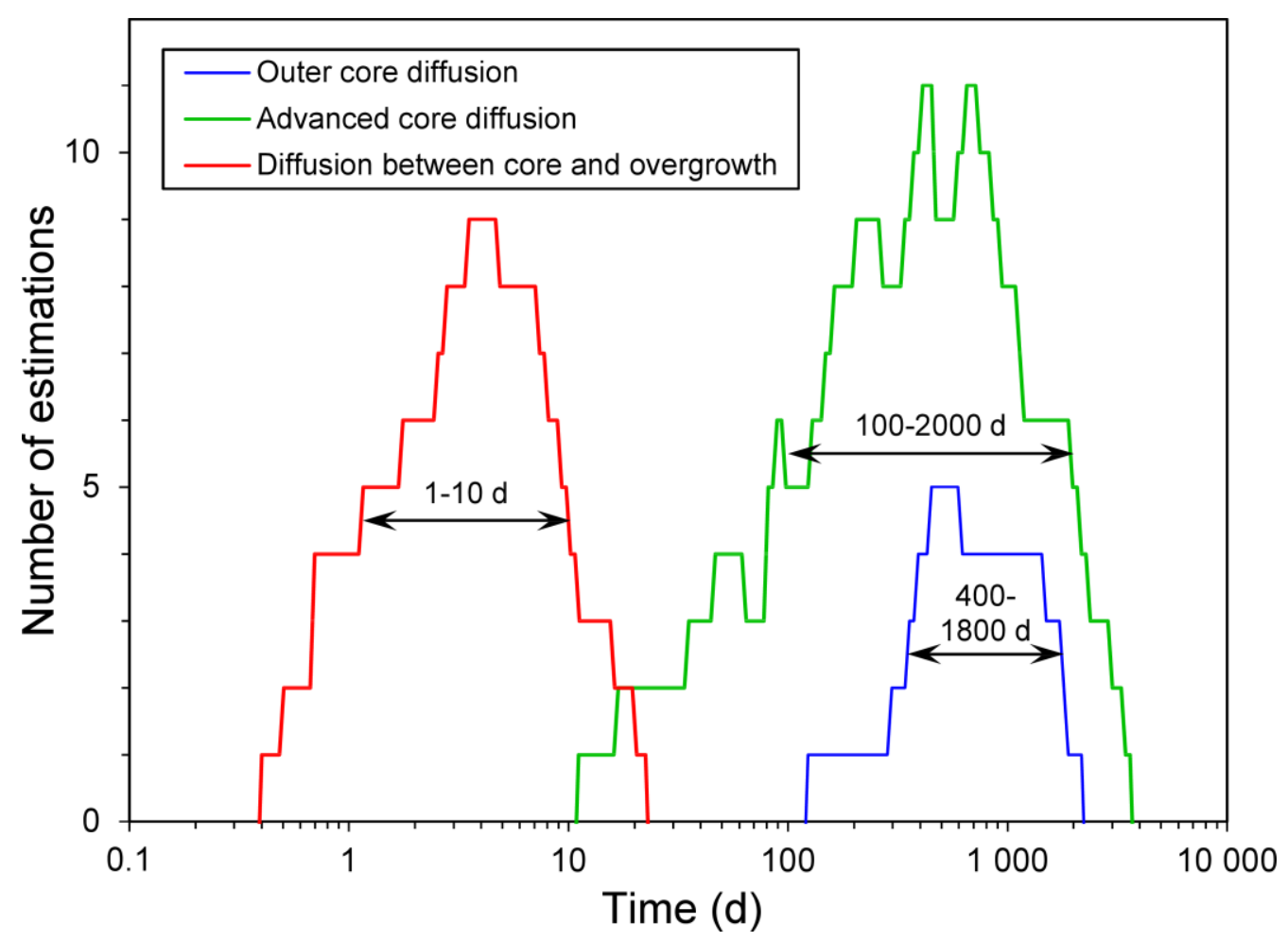

Fig. 7. Results of individual diffusion time calculations for many measured gradients of the different diffusion stages in the form of a frequency diagram: for outer core diffusion (blue line), advanced core diffusion (green line) and diffusion across the resorption boundary (red line). Ranges for diffusion time values are defined by the half-width of the distributions.

The Methods section and supplement SM5 document the model fits by equation 6.18 from ref. ${ }^{44}$ for 18 profiles on 15 grains from which diffusion times were extracted, except for the fully equilibrated cores of group 4. Examples of such model fits can be found in Fig. 6b. Based on the entire data set, we conclude that the time scale of diffusion that modified the outer cores of the crystals range from 100 to 2000 days (Fig. 7, green line). Since outer core diffusion is only a particular case of advanced core diffusion for the largest grains, both diffusion time estimates should be similar, which is indeed the case (400 to 1800 days for outer core diffusion vs. 100 to 2000 days for advanced core diffusion).

Such complexly Fo- and Ni-zoned cores of olivine crystals have not been documented before and is most likely due to fast Fo-Ni diffusivity and magmatic residence times at high temperatures during and/or after ascent are typically much longer. This observation and our modeling then implies that most mafic magmas have transfer times from source to surface that would normally be >2000 days or longer. Instead, our olivine crystals from Shiveluch must have had unusually fast ascent times, as discussed in more detail below. Another conclusion we made is that concave FoNi trends reflect a diffusion process with $\mathrm{D}_{\mathrm{Ni}}<\mathrm{D}_{\mathrm{Fo}}$ (Fig. $2 \mathrm{~b}$ ). Such concave compositional trends 
have previously been documented in olivine crystals from komatiites and kimberlites ${ }^{45-51}$ and probably indicate similar diffusion process.

Diffusion between crystal core and overgrowth followed after mixing with, and growth from, a more mafic higher-temperature recharge magma into the reservoir where the olivine crystals resided in a more evolved melt. The diffusion interface is clearly marked by the sharp breaks in concentrations of slowly diffusing elements ( $\mathrm{Cr}, \mathrm{Al}$ and/or P, Fig. 1, 3, 4, Tables SM2-A, SM2-C), as well as by Ni-kink between outer cores and overgrowth (Fig. 1, 3, 4, Tables SM2, SM2-C). The Fo and $\mathrm{NiO}$ profiles from group 4 olivines (Fig. 3a) are the best for diffusion modeling as the initial/boundary conditions allow the application of the analytical solutions.

As an alternative interpretation to the origin of the four groups of olivine cores, low-Mg olivine could also form after fractional crystallization in a more evolved melt, rather than exchange by diffusion with an evolved melt after magma mixing. Irrespective of the origin of group 4 olivine cores, a magma mixing event is clearly indicated by the resorption interface and so we can use the width of the transition zone to determine the time elapsed since the mixing event. As emphasized above, there are continuous transitions from core group 1 to group 4 , which would not be expected if there had been two distinct processes and two distinct magmas that formed these cores. Therefore, we prefer the interpretation of diffusive exchange to explain the different core types.

We measured and modeled diffusion of both $\mathrm{Fo}$ and $\mathrm{NiO}$ across the resorption interface (the analytical solutions of the diffusion equations and comparison with observed gradients are described in Methods section and supplement SM6). The width of the diffusion zones for Ni are consistently narrower than that for Fo, suggesting $\mathrm{D}_{\mathrm{Ni}}<\mathrm{D}_{\mathrm{Fo}}$. In previous studies, such diffusion modeling was performed separately either for forsterite ${ }^{38}$ or for nickel ${ }^{5}$ and modeling of olivine profiles with simultaneous exchange Fo and $\mathrm{NiO}$ has only been described previously for the rims of crystals ${ }^{1,52}$. However, as we show in this study, such rims may be affected by both diffusion and crystal growth and comparing results for $\mathrm{Ni}$ and Fo may not be reasonable in this case. However, the measured data and our modeling across the resorption interface allows us, for the first time, to directly assess the contribution of each diffusion component.

The modeling of diffusion time is documented for 8 profiles on 3 grains across the transition zone for group 4 cores in Table SM6-A. An example of a model fit to the data can be found in Fig. 6c. The diffusion times range from 1 to 10 days (Fig. 7, red line). Thus, the time of diffusion between core and overgrowth is orders of magnitude shorter than the time of diffusion that had affected the cores prior to their resorption.

Zoning and diffusion in the overgrowth must have postdated the resorption event and at least partly the subsequent overgrowth. All profiles outside the transition zone towards the margin show the same compositional Fo-Ni trends (blue lines in Fig. 2). This and oscillatory growth bands in $\mathrm{Cr}$, Al, 
and P (Fig. 3, 4) clearly demonstrates that (1) all crystals had a common history after the mixing event and (2) this history was dominated by crystallization from the current host melt. The widths of the Fo and Ni gradients in this growth zone are significantly wider than widths across the resorption interface. This indicates that smoother gradients within the overgrowth cannot result from diffusion, because the time of diffusion within cannot be longer than for diffusion further inside the crystal. Thus, the formation of the overgrowth reflects olivine growth in a progressively evolving melt. Repeated excursions to more mafic compositions (high $\mathrm{Cr}$ ) are inferred to reflect minor recharge events during the fractional crystallization process. However, these high Cr growth zones are also enriched in $\mathrm{Ca}, \mathrm{Al}$, and $\mathrm{P}$. Slow-diffusing $\mathrm{P}$ can be strongly affected by slow kinetics during fast crystal growth ${ }^{13,53-55}$. Therefore we ascribe the narrow oscillatory growth bands to kinetic effects rather than growth from changing melt compositions. In any case, diffusion after growth has partially smoothed out variations in $\mathrm{Mg}, \mathrm{Fe}, \mathrm{Ni}$ and - less so - $\mathrm{Ca}$, but not for $\mathrm{Cr}, \mathrm{Al}$ and $\mathrm{P}$.

\subsection{Conclusions}

Successive stages of olivine growth and diffusion history are schematically shown in Fig. 8 and described below:

1. Olivine cores were formed from a high-Mg and high-Ni melt and initially had a uniform Fo and Ni composition (Fo92 and NiO 0.5 wt. \%; Fig. 8a).

2. These olivine crystals encountered a more evolved melt in which they diffused to different extents towards an equilibrium composition of Fo86,4 and $\mathrm{NiO} 0.22$ wt. \% at their rims (Fig. 8b). When the diffusion process did not reach the inner cores (group 1) this indicates times scales ranging from 400 to 1800 days (Fig. 7, blue line). The inner cores of olivine of groups 2 and 3 were affected by diffusion to variable degrees with diffusion times ranging from 100 to 2000 days (Fig. 7, green line). Some olivine crystals completely equilibrated with this evolved melt (group 4).

3. The next event in the history of these olivine crystals was magma mixing with a new high-Mg and high-Ni melt. Due to the high temperature of this melt, the rims of olivine cores were partly dissolved creating a prominent resorption interface between cores and their overgrowths (Fig. 8c).

4. Subsequent cooling resulted in new high-Fo and high-Ni olivine growths over the resorption interface that formed the overgrowth of the crystals (Fig. 8d). Newly grown olivine in this zone is enriched in $\mathrm{Cr}_{2} \mathrm{O}_{3}$ up to 0.3-0.4 wt. \%. Further crystallization produced olivine down to Fo 80 towards the rims of crystals and concentric, oscillatory and correlated growth bands of slow-diffusing elements (Cr, Al, P; Fig. 4) that most likely formed by kinetic effects during fast crystal growth. 
5. While $\mathrm{Cr}, \mathrm{Al}$, and $\mathrm{P}$ show sharp growth bands in the overgrowth, $\mathrm{Fo}$ and $\mathrm{NiO}$ variations were partly smoothed out by diffusion at the same time during which diffusion modified the resorption interface (Fig. 8e). The duration of this last growth and diffusion stage is only 1-10 days (Fig. 7, red line). This suggests a very short time between the last recharge event (core resorption) and surface eruption.

Thus, high-Mg high-Ni overgrowths on the cores were formed only a few days after the last mixing event and this mixing event likely triggered the eruption. The composition of recharging melt at the resorption interface has $\mathrm{Mg \#}=64-65^{28}$, i.e. it is close to a mantle-derived melt and from this we conclude that mixing took place close to mantle levels which is in accord with the P-T- $\mathrm{fO}_{2}$ conditions of olivine crystallization $(18-30 \mathrm{~km})$. Therefore, ascent from such depths should have taken place within 1 to 10 days, implying ascent rates of 80 to $1200 \mathrm{~m} / \mathrm{h}$. By contrast, the formation of the cores, their storage and magma mixing and diffusion must have all occurred at mantle levels around 100 to 2000 days before eruption. 
(a)

High-Mg olivine is in equilibrium with melt $\mathrm{Fo}_{92}, \mathrm{NiO}=0.5$ wt.\%

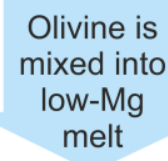

(b)

\section{Olivine with different extents of outer and advanced core diffusion \\ Olivine is mixed into hot high-Mg melt}

(c)

Olivine with partially dissolved margin

Temperature falls and overgrowth crystallizes

(d)

Overgrowths recording oscillatory $\mathrm{Cr}, \mathrm{P}$, and $\mathrm{Al}$ concentrations

$$
\begin{aligned}
& \text { Diffusion } \\
& \text { smoothes } \\
& \text { out the } \\
& \text { gradients }
\end{aligned}
$$

(e)

Observed olivine zoning: normal, repetitive and reverse

\section{Group 1 Group 2 Group 3 Group 4}

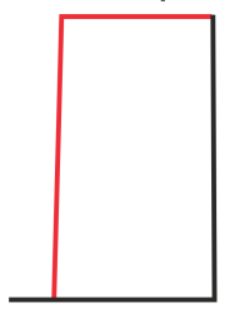

400-1800 days
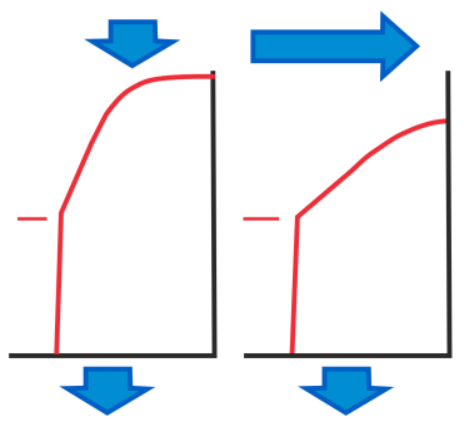

100-2000 days
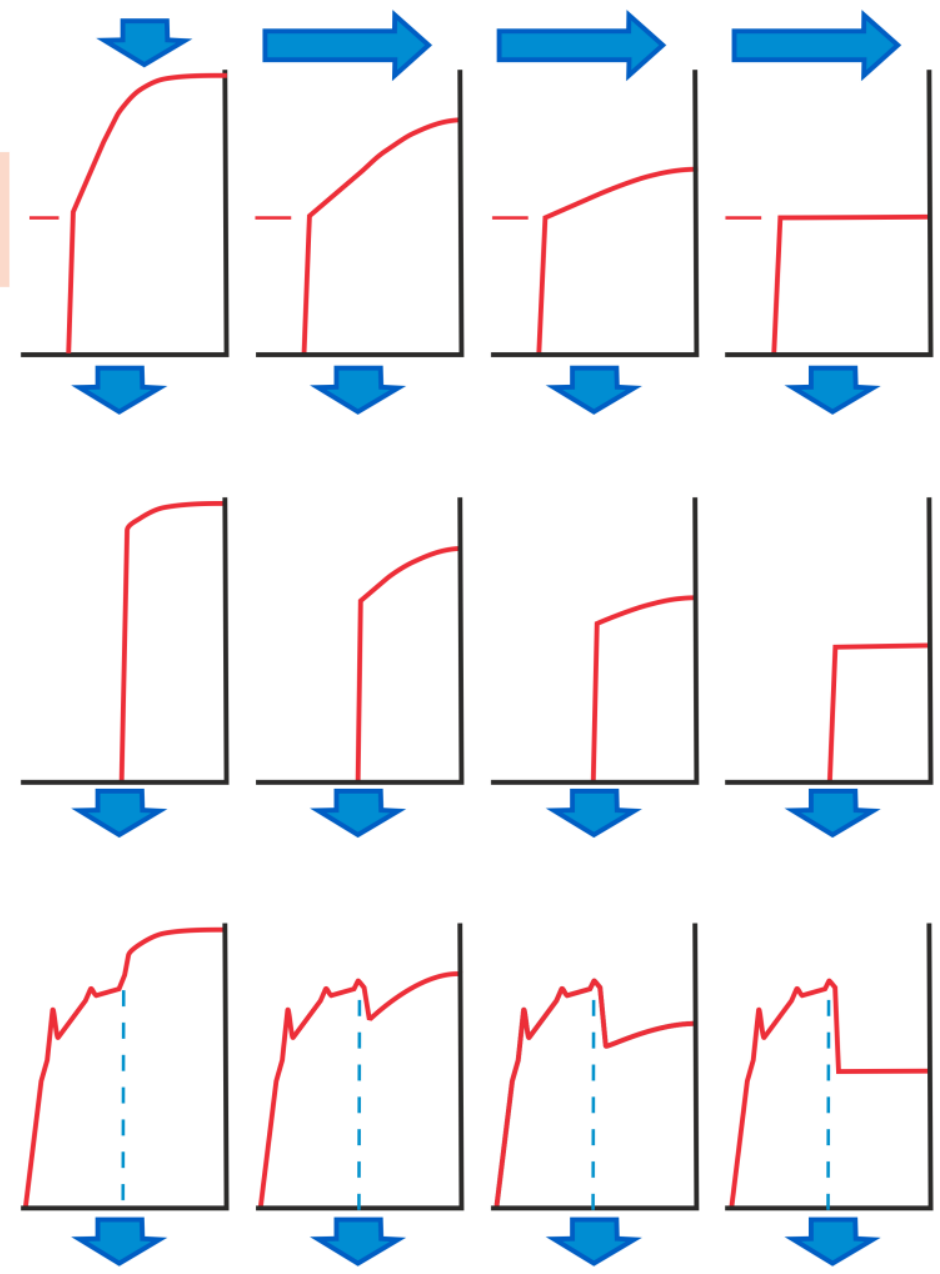

1-10 days
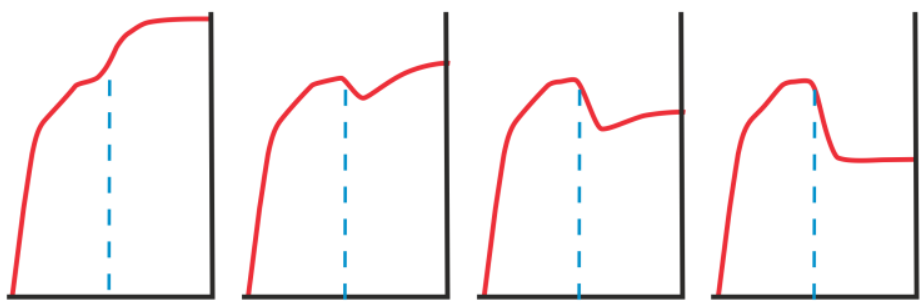

Fig. 8. The schematic evolution of the complex growth, dissolution and diffusion history of olivine crystals from high-Mg middle-K Shiveluch basalt is depicted in simplified centre-to-margin Fo-profiles. (a) The high$\mathrm{Mg}$ olivine with a flat Fo-distribution were formed first. (b) High-Mg cores were exposed to a low-Mg melt after magma mixing. As a result, olivine crystals were affected by diffusion to differing extents and decreasing Fo is observed. (c) Recharge with a hot high-Mg melt dissolved outer parts of the zoned olivine 
crystals, and (d) high-Mg overgrowths were formed over the different types of resorbed cores. (e) Finally, diffusion across the resorption interface and across the overgrowth started. Compare these final Fo-profiles to the measured profiles in Fig. 1 and Fig. 3. Blue dotted line indicates the position of the resorption interface.

Fast ascent may be more frequent than previously thought because slow cooling during the late stages of ascent and cooling in lava flows or recharge into larger shallow magma reservoirs within volcanic edifices, generally erases zoning records like those described here. One possibility for preserving records of fast ascent of mafic magmas from great depth is the nature of the maar eruption which has formed the 7600 BP Shiveluch tephra deposit. Such phreatomagmatic eruptions in general tend to (1) be derived from basalts that ascend relatively fast, possibly driven by deep $\mathrm{CO}_{2}$-degassing and (2) therefore often carry abundant xenoliths

Relatively short timescales of hundred days to a few years were documented for ascent of mafic magmas from mantle depths ${ }^{5}$. However, in these olivine crystals Fo-zoning had already been erased by diffusion processes and the width of the Ni-diffusion zone was about $100 \mu \mathrm{m}$, i.e. much wider than the width of the Ni-diffusion zone of 3-13 $\mu$ m that we observe here (Table SM6-A). The time scales for ascent of magmas and olivine crystals in lavas of the Shiveluch 7600 BP eruption apparently rose to the surface by orders of magnitude faster.

Our research shows that crystal growth, mixing and diffusion processes on the way from mantle source to surface may be quite complex and the time of ascent can be fast - just a few days before the eruption.

\subsection{Methods}

\subsubsection{Microprobe analyses}

All measurements were conducted with a JEOL JXA 8900RL electron microprobe at the GZG (Geowissenschaftliches Zentrum Göttingen), Göttingen University. We used specifically designed high-precision methods based on increased current and increased voltage ${ }^{56}$. The electron microprobe was configured at accelerating voltage of $20 \mathrm{kV}$, beam current of $300 \mathrm{nA}$, and focused beam of $0-5 \mu \mathrm{m}$ in diameter. The methods allowed us to analyse olivine profiles for major and trace elements, to conduct precision microelement measuring for thermobarometry, and to build elemental maps. All methods including standards and references are described in the supplements SM1.1-SM1.2. 


\subsubsection{Crystal orientation}

The crystal orientation was determined via electron backscatter diffraction ${ }^{57}$ (EBSD) on a Quanta 200 F instrument at the Crystallography Department at the GZG, Göttingen University. For EBSD analysis, the thin sections were polished in addition to the normal procedure for EMS to a final polishing fineness of $0.05 \mu \mathrm{m} \mathrm{Al}_{2} \mathrm{O}_{3}$. Every sample was covered with a very thin carbon layer to minimize electrostatic charge due to the high vesicularity of the samples. Several points were measured along the compositional profile of every grain to ensure that crystal orientation does not change within the crystal due to cracks or deformation. All details are included in supplement SM1.3, the results of measurements are shown in Tables SM2-B and SM2-C.

\subsubsection{P-T- $-\mathrm{fO}_{2}$ conditions}

Temperature estimates for olivine crystallization are based on Al-in-olivine thermometry ${ }^{36}$, which utilizes the Al-Cr distribution between olivine and spinel (Table SM3-A). Oxygen fugacity was estimated by using the improved Ballhaus-Berry-Green ol-opx-sp oxybarometer ${ }^{58}$. To calculate the pressure, we use $\mathrm{H}_{2} \mathrm{O}$ estimates in the melt as $4 \%^{59}$. Pressure was determined from cpx-melt compositions and cpx-only barometry ${ }^{34}$. The details of the $\mathrm{P}-\mathrm{T}-\mathrm{fO}_{2}$ estimates are included in supplement SM3, mineral microprobe analyses used for P-T- $f \mathrm{O}_{2}$ estimates and individual values are shown in Tables SM3-A, SM3-B, SM3-C.

\subsubsection{Diffusion coefficients}

Diffusion coefficients were calculated using estimated P-T- $f \mathrm{O}_{2}$ conditions with correction for crystal orientation (Table SM2-B), as described in supplement SM3. Table SM3-C contains diffusion coefficients for all zones of the crystals, calculated ${ }^{4}$ with P-T- $f \mathrm{O}_{2}$ conditions and Fo content in these zones. In our calculations for every profile we selected the values of the slowest and fastest diffusion coefficients. For modelling of diffusion inside the cores we used external P$\mathrm{T}-f \mathrm{O}_{2}$ conditions determined for the transition zones. For modeling of diffusion in the transition zone we used $\mathrm{P}-\mathrm{T}-\mathrm{fO}_{2}$ conditions determined for the overgrowth.

\subsubsection{Analytical approximations of diffusion profiles}

For the approximation of the measured profiles by the least square method in the case of outer core diffusion we used the analytical solution of the one-dimensional problem for diffusion in a semiinfinite medium (Eq. 3.13 in ref. $^{44}$ ). For the initial conditions and the boundary condition at infinity we used the values of Fo and $\mathrm{Ni}$ in the centres of a olivine cores. For the boundary conditions of 
the dissolved margin of the cores we used the estimate (Fig. 5 c) values $\mathrm{Fo}_{\mathrm{dm}}=88.7$ and $\mathrm{NiO}_{\mathrm{dm}}=0.23$ wt. \%. Simultaneous adjustment for Fo and Ni solutions allowed to find the diffusion times and the position of the dissolved margin for every profile. All details are included in supplement SM4 and Table SM4-A. An example of the approximation between data and the model is given in Fig. 6a.

For the approximation of the measured profiles by the least squares method in the case of advanced core diffusion we used the analytical solution of the spherically symmetric problem for diffusion in a sphere (Eq. 6.18 in ref. $^{44}$ ). For the initial conditions we used the composition of the most magnesian core SHIV-08-05 17 Ol-7 from group $1, \mathrm{Fo}_{\text {core }}=92.16$ and $\mathrm{NiO}_{\text {core }}=0.48$ wt. \%. For the boundary condition on the margin of the sphere we used the average composition of the olivine from group 4, $\mathrm{FO}_{\mathrm{dm}}=86.4$ and $\mathrm{NiO}_{\mathrm{dm}}=0.22$ wt. \%. Simultaneous adjustment for Fo and Ni solutions allowed us to find the diffusion time and the position of the dissolved margin for every profile. All details are included in supplement SM5 and Table SM5-A, an example for the model fits can be found in Fig. 6 b.

For the approximation of the measured profiles by the least squares method in the case of transition zones we used the analytical solution of the one-dimensional problem for diffusion in an infinite medium (Eq. 3.13 in ref. ${ }^{44}$ ). The initial and boundary conditions on both sides of the diffusion zones were automatically determined by parameter fitting of the analytical solution. The solutions for Fo and $\mathrm{Ni}$ were approximated independently. All details are included in supplement SM6 and Table SM6-A, an example for the model approximation can be found in Fig. 6c. 


\section{References}

1. Costa, F. \& Dungan, M. Short time scales of magmatic assimilation from diffusion modeling of multiple elements in olivine. Geology 33, 837-840, doi:http://doi.org/10.1130/g21675.1 (2005).

2. Costa, F. \& Chakraborty, S. The effect of water on Si and O diffusion rates in olivine and implications for transport properties and processes in the upper mantle. Phys. Earth Planet. Inter. 166, 11-29, doi:http://doi.org/10.1016/j.pepi.2007.10.006 (2008).

3. Chakraborty, S. Diffusion in solid silicates: A tool to track timescales of processes comes of age. Annu. Rev. Earth Planet. Sci. 36, 153-190, doi:http://doi.org/10.1146/annurev.earth.36.031207.124125 (2008).

4. Chakraborty, S. Diffusion coefficients in olivine, wadsleyite and ringwoodite. Rev. Mineral. Geochem. 72, 603-639, doi:http://doi.org/10.2138/rmg.2010.72.13 (2010).

5. Ruprecht, P. \& Plank, T. Feeding andesitic eruptions with a high-speed connection from the mantle. Nature 500, 68-72, doi:http://doi.org/10.1038/nature12342 (2013).

6. Cooper, K. M. \& Kent, A. J. R. Rapid remobilization of magmatic crystals kept in cold storage. Nature 506, 480-483, doi:http://doi.org/10.1038/nature12991 (2014).

7. Dohmen, R., Faak, K. \& Blundy, J. D. Chronometry and speedometry of magmatic processes using chemical diffusion in olivine, plagioclase and pyroxenes. Rev. Mineral. Geochem. 83, 535575, doi:http://doi.org/10.2138/rmg.2017.83.16 (2017).

8. Costa, F., Dohmen, R. \& Chakraborty, S. Time scales of magmatic processes from modeling the zoning patterns of crystals. Rev. Mineral. Geochem. 69, 545-594, doi:http://doi.org/10.2138/rmg.2008.69.14 (2008).

9. Saunders, K., Blundy, J., Dohmen, R. \& Cashman, K. Linking petrology and seismology at an active volcano. Science 336, 1023-1027, doi:http://doi.org/10.1126/science.1220066 (2012).

10. Kahl, M., Chakraborty, S., Costa, F. \& Pompilio, M. Dynamic plumbing system beneath volcanoes revealed by kinetic modeling, and the connection to monitoring data: An example from Mt. Etna. Earth Planet. Sci. Lett. 308, 11-22, doi:http://doi.org/10.1016/j.epsl.2011.05.008 (2011). 
11. Kahl, M., Chakraborty, S., Costa, F., Pompilio, M., Liuzzo, M. \& Viccaro, M. Compositionally zoned crystals and real-time degassing data reveal changes in magma transfer dynamics during the 2006 summit eruptive episodes of Mt. Etna. Bull. Volcanol. 75, 692, doi:http://doi.org/10.1007/s00445-013-0692-7 (2013).

12. Dohmen, R., Kasemann, S. A., Coogan, L. \& Chakraborty, S. Diffusion of Li in olivine. Part I: Experimental observations and a multi species diffusion model. Geochim. Cosmochim. Acta 74, 274-292, doi:http://doi.org/10.1016/j.gca.2009.10.016 (2010).

13. Milman-Barris, M. S. Beckett, J. R., Baker, M. B., Hofmann, A. E., Morgan, Z., Crowley, M. R., Vielzeuf, D. \& Stolper, E. Zoning of phosphorus in igneous olivine. Contributions Mineral. Petrol. 155, 739-765, doi:http://doi.org/10.1007/s00410-007-0268-7 (2008).

14. Spandler, C. \& O'Neill, H. S. C. Diffusion and partition coefficients of minor and trace elements in San Carlos olivine at $1,300^{\circ} \mathrm{C}$ with some geochemical implications. Contributions Mineral. Petrol. 159, 791-818, doi:http://doi.org/10.1007/s00410-009-0456-8 (2010).

15. Watson, E. B., Cherniak, D. J. \& Holycross, M. E. Diffusion of phosphorus in olivine and molten basalt. Am. Mineral. 100, 2053-2065, doi:http://doi.org/10.2138/am-2015-5416 (2015).

16. Peslier, A. H., Bizimis, M. \& Matney, M. Water disequilibrium in olivines from Hawaiian peridotites: Recent metasomatism, $\mathrm{H}$ diffusion and magma ascent rates. Geochim. Cosmochim. Acta 154, 98-117, doi:http://doi.org/10.1016/j.gca.2015.01.030 (2015).

17. Melekestsev, I. V., Volynets, O. N., Ermakov, V. A., Kirsanova, T. P. \& Masurenkov, Y. P. Sheveluch Volcano in Active Volcanoes of Kamchatka Vol. 1 (eds Fedotov, S. A. \& Masurenkov, Yu. P.) 84-103 (Nauka, 1991).

18. Yogodzinski, G. M., Lees, J. M., Churikova, T. G., Dorendorf, F., Wörner, G. \& Volynets, O. N. Geochemical evidence for the melting of subducting oceanic lithosphere at plate edges. Nature 409, 500-504, doi:http://doi.org/10.1038/35054039 (2001).

19. Gorbatov, A., Kostoglodov, V., Suárez, G. \& Gordeev, E. Seismicity and structure of the Kamchatka subduction zone. J. Geophys. Res.: Solid Earth 102, 17883-17898, doi:http://doi.org/10.1029/96JB03491 (1997).

20. Park, J., Levin, V., Brandon, M., Lees, J., Peyton, V., Gordeev, E. \& Ozerov, A. A dangling slab, amplified arc volcanism, mantle flow and seismic anisotropy in the Kamchatka plate corner in Plate Boundary Zones (eds Stein, S. \& Freymueller, J. T.) 295-324 (AGU, 2002). 
21. Davaille, A. \& Lees, J. M. Thermal modeling of subducted plates: tear and hotspot at the Kamchatka corner. Earth Planet. Sci. Lett. 226, 293-304, doi:http://doi.org/10.1016/j.epsl.2004.07.024 (2004).

22. Portnyagin, M., Hoernle, K., Avdeiko, G., Hauff, F., Werner, R., Bindeman, I., Uspensky, V. \& Garbe-Schönberg, D. Transition from arc to oceanic magmatism at the Kamchatka-Aleutian junction. Geology 33, 25-28, doi:http://doi.org/10.1130/g20853.1 (2005).

23. Levin, V., Shapiro, N. M., Park, J. \& Ritzwoller, M. H. Slab portal beneath the western Aleutians. Geology 33, 253-256, doi:http://doi.org/10.1130/g20863.1 (2005).

24. Bryant, J. A., Yogodzinski, G. M. \& Churikova, T. G. Melt-mantle interactions beneath the Kamchatka arc: Evidence from ultramafic xenoliths from Shiveluch volcano. Geochem. Geophys. Geosys. 8, 1-24, doi:http://doi.org/10.1029/2006GC001443 (2007).

25. Ponomareva, V., Kyle, P., Pevzner, M., Sulerzhitsky, L. \& Hartman, M. Holocene eruptive history of Shiveluch volcano, Kamchatka peninsula, Russia in Volcanism and Subduction: The Kamchatka Region Vol. 172 Geophysical Monograph Series (eds Eichelberger, J. et al.) 263-282 (AGU, 2007).

26. Auer, S., Bindeman, I., Wallace, P., Ponomareva, V. \& Portnyagin, M. The origin of hydrous, high- $\delta 180$ voluminous volcanism: diverse oxygen isotope values and high magmatic water contents within the volcanic record of Klyuchevskoy volcano, Kamchatka, Russia. Contributions Mineral. Petrol. 157, 209-230, doi:http://doi.org/10.1007/s00410-008-0330-0 (2009).

27. Volynets, O. N., Ponomareva, V. V. \& Babansky, A. D. Magnesian basalts of Shiveluch andesite volcano, Kamchatka. Petrology 5, 183-196 (1997).

28. Churikova, T. G., Gordeychik, B. N., Belousov, A. B. \& Babansky, A. D. Find the centre of the eruption of basalts on the volcano Shiveluch in Materials of All-Russian Conference Dedicated to the 75th Anniversary of the Kamchatka Volcanological Station: Petropavlovsk-Kamchatsky, September 9-15, 2010 (ed Gordeev, E. I.) (IViS FEB RAS, 2010). (In Russian). URL: http://www.kscnet.ru/ivs/slsecret/75-KVS/Material conferenc/art25.pdf.

29. Tolstykh, M. L., Pevzner, M. M., Naumov, V. B., Babanskii, A. D. \& Kononkova, N. N. Types of parental melts of pyroclastic rocks of various structural-age complexes of the Shiveluch volcanic massif, Kamchatka: Evidence from inclusions in minerals. Petrology 23, 480-517, doi:http://doi.org/10.1134/S0869591115040050 (2015). 
30. Straub, S. M., LaGatta, A. B., Pozzo, A. L. M. D. \& Langmuir, C. H. Evidence from high-Ni olivines for a hybridized peridotite/pyroxenite source for orogenic andesites from the central Mexican Volcanic Belt. Geochem. Geophys. Geosys. 9, doi:http://doi.org/10.1029/2007GC001583 (2008).

31. Wang, Z. \& Gaetani, G. A. Partitioning of Ni between olivine and siliceous eclogite partial melt: experimental constraints on the mantle source of Hawaiian basalts. Contributions Mineral. Petrol. 156, 661-678, doi:http://doi.org/10.1007/s00410-008-0308-y (2008).

32. Straub, S. M., Gomez-Tuena, A., Stuart, F. M., Zellmer, G. F., Espinasa-Perena, R., Cai, Y. \& Iizuka, Y. Formation of hybrid arc andesites beneath thick continental crust. Earth Planet. Sci. Lett. 303, 337-347, doi:http://doi.org/10.1016/j.eps1.2011.01.013 (2011).

33. Nishizawa, T. Nakamura, H., Churikova, T., Gordeychik, B., Ishizuka, O., Haraguchi, S., Miyazaki, T., Vaglarov, B. S., Chang, Q., Hamada, M., Kimura, J.-I., Ueki, K., Toyama, C., Nakao, A. \& Iwamori, H. Genesis of ultra-high-Ni olivine in high-Mg andesite lava triggered by seamount subduction. Sci. Rep. 7, 11515, doi:http://doi.org/10.1038/s41598-017-10276-3 (2017).

34. Putirka, K. D. Thermometers and barometers for volcanic systems. Rev. Mineral. Geochem. 69, 61-120, doi:http://doi.org/10.2138/rmg.2008.69.3 (2008).

35. Gorbach, N. V. \& Portnyagin, M. V. Geology and petrology of the lava complex of Young $\begin{array}{lllll}\text { Shiveluch } \quad \text { Volcano, } & \text { Kamchatka. } & \text { Petrology } & \text { 134-166, }\end{array}$ doi:http://doi.org/10.1134/s0869591111020068 (2011).

36. Coogan, L. A., Saunders, A. D. \& Wilson, R. N. Aluminum-in-olivine thermometry of primitive basalts: Evidence of an anomalously hot mantle source for large igneous provinces. Chem. Geol. 368, 1-10, doi:http://doi.org/10.1016/j.chemgeo.2014.01.004 (2014).

37. Portnyagin, M. \& Manea, V. C. Mantle temperature control on composition of arc magmas along the Central Kamchatka Depression. Geology 36, 519-522, doi:http://doi.org/10.1130/G24636A.1 (2008).

38. Kahl, M., Chakraborty, S., Pompilio, M. \& Costa, F. Constraints on the nature and evolution of the magma plumbing system of Mt. Etna volcano (1991-2008) from a combined thermodynamic and kinetic modelling of the compositional record of minerals. J. Petrol. 56, 2025-2068, doi:http://doi.org/10.1093/petrology/egv063 (2015). 
39. Viccaro, M., Giuffrida, M., Nicotra, E. \& Cristofolini, R. Timescales of magma storage and migration recorded by olivine crystals in basalts of the March-April 2010 eruption at Eyjafjallajökull volcano, Iceland. Am. Mineral. 101, 222-230, doi:http://doi.org/10.2138/am-2016$\underline{5365}$ (2016).

40. Giuffrida, M. \& Viccaro, M. Three years (2011-2013) of eruptive activity at Mt. Etna: Working modes and timescales of the modern volcano plumbing system from micro-analytical studies of crystals. Earth-Sci. Rev. 171, 289-322, doi:http://doi.org/10.1016/j.earscirev.2017.06.003 (2017).

41. Arai, S. Characterization of spinel peridotites by olivine-spinel compositional relationships: Review and interpretation. Chem. Geol. 113, 191-204, doi:http://doi.org/10.1016/00092541(94)90066-3 (1994).

42. Bird, R. B., Stewart, W. E. \& Lightfoot, E. N. Transport Phenomena (John Wiley \& Sons, Inc., 2002).

43. Besson, U. The history of the cooling law: when the search for simplicity can be an obstacle. Science \& Education 21, 1085-1110, doi:http://doi.org/10.1007/s11191-010-9324-1 (2012).

44. Crank, J. The Mathematics of Diffusion (Oxford University Press, 1975).

45. Sobolev, A. V., Hofmann, A. W., Kuzmin, D. V., Yaxley, G. M., Arndt, N. T., Chung, S.-L., Danyushevsky, L. V., Elliott, T., Frey, F. A., Garcia, M. O., Gurenko, A. A., Kamenetsky, V. S., Kerr, A. C., Krivolutskaya, N. A., Matvienkov, V. V., Nikogosian, I. K., Rocholl, A., Sigurdsson, I. A., Sushchevskaya, N. M. \& Teklay, M. The amount of recycled crust in sources of mantlederived melts. Science 316, 412-417, doi:http://doi.org/10.1126/science.\%201138113 (2007).

46. Kamenetsky, V. S., Kamenetsky, M. B., Sobolev, A. V., Golovin, A. V., Demouchy, S., Faure, K., Sharygin, V. V. \& Kuzmin, D. V. Olivine in the Udachnaya-East kimberlite (Yakutia, Russia): types, compositions and origins. J. Petrol. 49, 823-839, doi:http://doi.org/10.1093/petrology/egm033 (2008).

47. Arndt, N. T., Guitreau, M., Boullier, A. M., Le Roex, A., Tommasi, A., Cordier, P. \& Sobolev, A. Olivine, and the origin of kimberlite. J. Petrol. 51, 573-602, doi:http://doi.org/10.1093/petrology/egp080 (2010). 
48. Sazonova, L. V., Nosova, A. A., Kargin, A. V., Borisovskiy, S. E., Tretyachenko, V. V., Abazova, Z. M. \& Griban', Y. G. Olivine from the Pionerskaya and V. Grib kimberlite pipes, Arkhangelsk diamond province, Russia: Types, composition, and origin. Petrology 23, 227-258, doi:http://doi.org/10.1134/S0869591115030054 (2015).

49. Cordier, C., Sauzeat, L., Arndt, N. T., Boullier, A.-M., Batanova, V. \& Barou, F. Metasomatism of the lithospheric mantle immediately precedes kimberlite eruption: new evidence from olivine

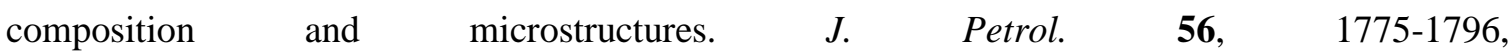
doi:http://doi.org/10.1093/petrology/egv054 (2015).

50. Cordier, C., Sauzeat, L., Arndt, N. T., Boullier, A.-M., Batanova, V. \& Barou, F. The geochemical complexity of kimberlite rocks and their olivine populations: a Reply to the comment on Cordier et al. (2015) by Andrea Giuliani \& Stephen F. Foley. J. Petrol. 57, 927-932, doi:http://doi.org/10.1093/petrology/egw027 (2016).

51. Cordier, C., Sauzeat, L., Arndt, N. T., Boullier, A.-M., Batanova, V. \& Barou, F. Quantitative modelling of the apparent decoupling of $\mathrm{Mg \#}$ and $\mathrm{Ni}$ in kimberlitic olivine margins: a Reply to the comment on Cordier et al. (2015) by A. Moore. J. Petrol. 58, 391-393, doi:http://doi.org/10.1093/petrology/egx013 (2017).

52. Qian, Q., O'Neill, H. S. C. \& Hermann, J. Comparative diffusion coefficients of major and trace elements in olivine at $\sim 950^{\circ} \mathrm{C}$ from a xenocryst included in dioritic magma. Geology 38, 331-334, doi:http://doi.org/10.1130/G30788.1 (2010).

53. Shea, T., Lynn, K. J. \& Garcia, M. O. Cracking the olivine zoning code: Distinguishing between crystal growth and diffusion. Geology 43, 935-938, doi:http://doi.org/10.1130/G37082.1 (2015).

54. Bouvet de Maisonneuve, C., Costa, F., Huber, C., Vonlanthen, P., Bachmann, O. \& Dungan, M. A. How do olivines record magmatic events? Insights from major and trace element zoning. Contributions Mineral. Petrol. 171, 56, doi:http://doi.org/10.1007/s00410-016-1264-6 (2016).

55. Manzini, M., Bouvier, A.-S., Baumgartner, L. P., Müntener, O., Rose-Koga, E. F., Schiano, P., Stéphane E., Anders M. \& Shimizu, N. Weekly to monthly time scale of melt inclusion entrapment prior to eruption recorded by phosphorus distribution in olivine from mid-ocean ridges. Geology 45, 1059-1062, doi:10.1130/G39463.1 (2017). URL: https://pubs.geoscienceworld.org/gsa/geology/article/45/12/1059/516689/weekly-to-monthlytime-scale-of-melt-inclusion. 
56. Batanova, V. G., Sobolev, A. V. \& Kuzmin, D. V. Trace element analysis of olivine: High precision analytical method for JEOL JXA-8230 electron probe microanalyser. Chemical Geology 419, 149-157, doi:http://doi.org/10.1016/j.chemgeo.2015.10.042 (2015).

57. Coogan, L. A., Hain, A., Stahl, S. \& Chakraborty, S. Experimental determination of the diffusion coefficient for calcium in olivine between $900^{\circ} \mathrm{C}$ and $1500^{\circ} \mathrm{C}$. Geochim. Cosmochim. Acta 69, 3683-3694, doi:http://doi.org/10.1016/j.gca.2005.03.002 (2005).

58. Nikolaev, G. S., Ariskin, A. A., Barmina, G. S., Nazarov, M. A. \& Almeev, R. R. Test of the Ballhaus-Berry-Green Ol-Opx-Sp oxybarometer and calibration of a new equation for estimating the redox state of melts saturated with olivine and spinel. Geochem. Int. 54, 301-320, doi:http://doi.org/10.1134/s0016702916040078 (2016).

59. Portnyagin, M., Bindeman, I., Hoernle, K. \& Hauff, F. Geochemistry of primitive lavas of the Central Kamchatka Depression: magma generation at the edge of the Pacific plate in Volcanism and Subduction: The Kamchatka Region Vol. 172 Geophysical Monograph Series (eds Eichelberger, J. et al.) 199-239 (AGU, 2007).

\subsection{Acknowledgements}

This research was supported by DFG grant No Wo 362/51-1, RFBR-DFG grant \# 16-55-12040, and RFBR grant \# 17-55-50005. We thank Simon Turner, Alexander Iveson, and Ekaterina Rossovskaya for careful proof reading and language editing and two reviewers and editor for their constructive comments.

\subsection{Author Contributions}

B.G. and T.C. performed the fieldwork and sampling. T.C. and G.W. performed the petrographic description. B.G., T.C. and A.K. performed measurements on the electron microprobe. T.C. and C.S. performed the orientation analyses. T.C. estimated the P-T-fO2 conditions. B.G., T.C. and A.S. performed the mathematical modelling and computations. B.G., T.C., A.S., and G.W. discussed the interpretation to guide the modeling approach. B.G., T.C. and G.W. prepared the manuscript with all components of text and figures. All authors prepared the Supplementary Materials and participated in discussions related to topics of this manuscript. 


\subsection{Additional Information}

Supplementary information includes files with Supplementary Materials and electronic tables.

Competing Interests: The authors declare that they have no competing interests. 


\title{
3 Timescales of magmatic processes during the eruptive cycle 2014-2015 at Piton de la Fournaise, La Réunion, obtained from Mg-Fe diffusion modelling in olivine
}

\author{
Caren Sundermeyer $^{1 *}$, Andrea Di Muro ${ }^{2,4}$, Boris Gordeychik ${ }^{1,3}$, and Gerhard Wörner ${ }^{1}$ (2020) \\ ${ }^{1}$ Geowissenschaftliches Zentrum, Georg-August Universität, Göttingen, Germany \\ ${ }^{2}$ Université de Paris, Institut de Physique du Globe de Paris, CNRS, F-75005 Paris, France \\ ${ }^{3}$ Institute of Experimental Mineralogy RAS, Chernogolovka, Russia \\ ${ }^{4}$ Observatoire Volcanologique du Piton de la Fournaise, Institute de Physique du Globe de Paris, Bourg \\ Murat, F-97518 La Plaine des Cafres, France \\ * Correspondence and requests for materials should be addressed to C.S. (email: csunder@gwdg.de)
}

\subsection{Abstract}

Piton de la Fournaise started a new eruptive cycle in June 2014 after 41 months of quiescence. The small eruptions in June, February 2015, May, and July produced evolved basalts, whereas magmas of the large August-November eruption became increasingly mafic. Compositional zoning of olivine crystals was analysed to model diffusion times representing residence times between magma mixing and eruption. These correlate to the geophysical and geochemical records. Olivine crystals of various core compositions $\left(\mathrm{Fo}_{73.2-85.1}\right)$ were periodically reactivated days to seven months prior to June 2014 and February 2015 eruptions and during July and August-November by different magmas (in equilibrium with Fo $77.7-84.5$ ). June 2014, February, and May eruptions were fed from the top of the reservoir as shown by the eruption of evolved magmas and olivine crystals with short diffusion times. At the same time, olivine crystals were reactivated probably from mush by recharging basalt during the formation of hybrid magmas (in equilibrium with Fo80.1-84.5) in the central reservoir. These hybrids remained unerupted (> 235 days) until October 2015. However, products of July 2015 eruption bear already olivine crystals with long diffusion times, which is a strong similarity to those of the August-November eruption 2015. This eruption marks the transition between earlier small eruptions fed from shallow levels to those fed from the central reservoir. 
Timescales of magmatic processes during the eruptive cycle 2014-2015 at Piton de la Fournaise, La Réunion, obtained from $\mathrm{Mg}-\mathrm{Fe}$ diffusion modelling in olivine

Such linking of magma mixing and activation processes and geophysical signals helps for a better understanding of the process and timescale of eruption at Piton de la Fournaise and basaltic hotspotrelated magma systems in general.

\subsection{Introduction}

Modelling of elemental diffusion profiles in zoned crystals from basaltic lavas is an important technique to constrain chemical compositions of crystals and their relative timescales of residence. These can be linked to magmatic processes such as ascent, recharge and mixing of magmas that govern a sequence of eruptions at active basaltic volcanoes (Zellmer et al. 1999, 2003; Costa et al. 2003, 2010; Costa and Chakraborty 2004; Morgan et al. 2004; Costa and Dungan 2005; Oeser et al. 2015, 2018; Cooper et al. 2016; Viccaro et al. 2016; Albert et al. 2019). Distinct populations of olivine compositions allow the identification of variable magma batches, whereas diffusion times after reservoir recharge and magma mixing can constrain times of magma residence and "reactivation" of older crystals. Such reactivation occurs when olivine crystals that were previously stored in crystal mush are entrained by new magma or are displaced into a hybrid magma after mixing. This reactivation initiates diffusive equilibration of the crystals with the new host magma. For well-documented eruptions, the timing of these processes and eventual eruption of their magmatic products can be related to monitoring data (seismicity, ground deformation and gas composition and fluxes) recorded over similar timescales (e.g. Kahl et al. 2011, 2013, 2015; Saunders et al. 2012; Rae et al. 2016; Ruth et al. 2018; Albert et al. 2019).

Diffusion of $\mathrm{Mg}$ and $\mathrm{Fe}$ in olivine crystals allows to extract timescales of days to a few years which has been shown to be applicable to magmatic processes that govern active basaltic magma plumbing systems (e.g. Costa and Chakraborty 2004; Costa and Dungan 2005; Kahl et al. 2015; Hartley et al. 2016; Rae et al. 2016; Viccaro et al. 2016; Gordeychik et al. 2018). Our understanding of active basaltic magma plumbing systems changed in recent decades from that of a single (often spherical) magma chamber filled with melt to the concept of a network of sills and dykes, partly filled with older magma batches and their heterogeneous crystal mushes in a transcrustal magma system (Marsh 2006; Kahl et al. 2011; Cooper and Kent 2014, Cooper et al. 2016; Gordeychik et al. 2018) that is fed by deep magmatic recharges from the mantle. This model is derived from the observation of frequent and complex interactions between melts and crystals of different compositions and ages in shallow systems, the disaggregation of crystal cumulates, and incorporation of older antecrysts into new recharging magmas (Costa et al. 2010; Salaün et al. 2010; Cashman and Giordano 2014; Cooper et al. 2016).

The interaction of different magma batches and the recharge of shallow stored reservoirs with mafic magma can occur months to only days prior to eruptions in basaltic systems, as shown by previous 
Timescales of magmatic processes during the eruptive cycle 2014-2015 at Piton de la Fournaise, La Réunion, obtained from $\mathrm{Mg}$-Fe diffusion modelling in olivine

studies on e.g. Tatara San Pedro, Chile (Costa and Dungan 2005), Llaima, Chile (Ruth et al. 2018), Kilauea, Hawai'i (Rae et al. 2016), Laki, Iceland (Hartley et al. 2016), and Mt. Etna, Sicily (Kahl et al. 2011, 2013, 2015; Ubide and Kamber 2018). In contrast, longer timescales and multi-step mixing are documented for several arc volcanoes, which can range from months and few years (e.g. Irazú, Costa Rica; Oeser et al. 2018; Shiveluch, Kamchatka; Gordeychik et al. 2018) to decades (Volcán San Pedro, Chile; Costa and Chakraborty 2004). Although many basaltic volcanoes such as Piton de la Fournaise, La Réunion (Fig. 1), are well monitored and studied due to their frequent activity, many details of processes within the plumbing system and their link to ground-based geophysical and geochemical monitoring data remain poorly constrained.

In this study, the elemental diffusion in olivine crystals from June 2014, May, July, and AugustNovember 2015 eruptions at Piton de la Fournaise was modelled in order to identify magmatic recharge and mixing after an unusually long phase of volcano quiescence in 2010-2014. We choose $\mathrm{Mg}-\mathrm{Fe}$ to track magmatic processes at timescales of weeks to months before and during the eruptions. The olivine crystals studied here originate from both, crystal mushes stored in the shallow system and entrainment by new and more mafic olivine-bearing basaltic magmas rising from deeper levels. We relate the composition of olivine crystals and their diffusion times after reactivation to the well-documented timing of individual eruption episodes and to the monitoring signals of unrest that were recorded during and prior to each eruptive event between June 2014 (i.e. six months before the eruption) and the final climactic activity of Piton de la Fournaise between August and November 2015.

\subsection{Geological setting}

Piton de la Fournaise (PdF) in the south-eastern part of La Réunion Island, Indian Ocean, is one of the most active volcanoes in the world. The plumbing system of PdF consists of a shallow reservoir at +0.5 to $-1.5 \mathrm{~km}$ below sea level (Nercessian et al. 1996; Peltier et al. 2009, 2016; Prôno et al. 2009) and a network of sills and dikes above sea level extending beneath the Enclos Fouqué caldera (Di Muro et al. 2014, 2015) and a set of rift zones. A prominent rift zone extends to the NW towards the older Piton de Neiges edifice and represents pathways for the deep magmas feeding the central magma conduits and the shallow system that is periodically refilled by magmas from deeper levels (Lénat and Bachèlery 1990; Bureau et al. 1999; Di Muro et al. 2015; Boudoire et al. 2017, 2019). Decade long cycles have been recently identified by Vlastélic et al. (2018) in the composition of PdF lavas. New magma inputs can bear olivine crystals from deeper reservoirs (e.g. from the central reservoir in the oceanic crust or from below the crust-mantle boundary, Bureau et al. 1999) or may be disaggregated from cumulative olivine-rich crustal bodies the magmas pass during ascent (Albarède et al. 1997; Salaün et al. 2010; Di Muro et al. 2014). These earlier studies of olivine 
Timescales of magmatic processes during the eruptive cycle 2014-2015 at Piton de la Fournaise, La Réunion, obtained from $\mathrm{Mg}-\mathrm{Fe}$ diffusion modelling in olivine

crystals at PdF suggest that many generations of magmas left a crystal mush in the plumbing system which hosts olivine crystals of various ages and histories (Albarède et al. 1997; Bureau et al. 1999; Boivin et al. 2009; Di Muro et al. 2014). Olivine crystals can be entrained and erupted during subsequent volcanic activity to represent a cognate crystal cargo (antecrysts) in olivine-rich ("oceanitic") lava flows with up to $60 \%$ accumulated olivine crystals (Albarède et al. 1997; Bureau et al. 1998a, 1999; Di Muro et al. 2014).

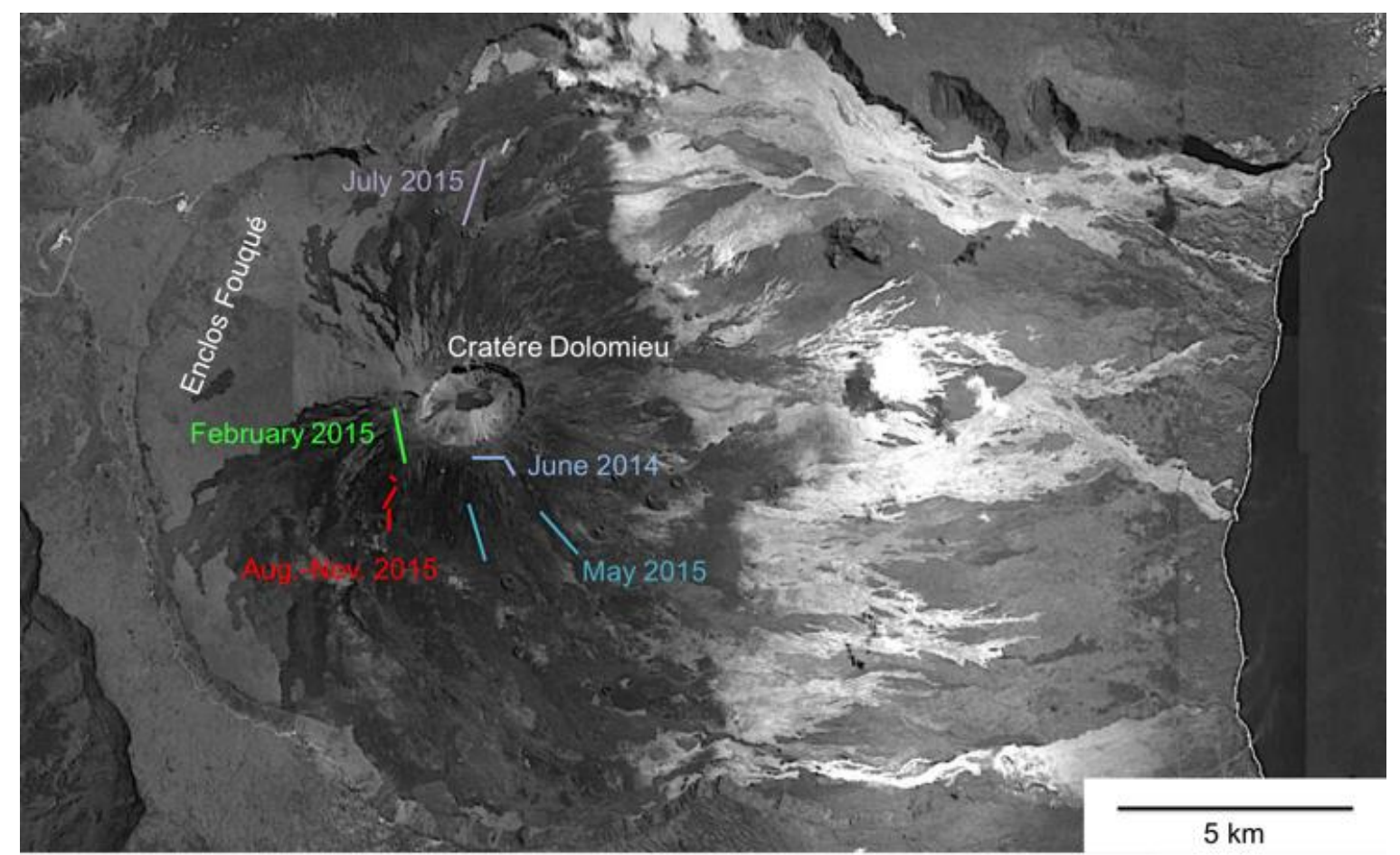

Fig. 1 Satellite image of Piton de la Fournaise and the Enclos Fouqué caldera (image source: Google Earth Pro). Coloured lines mark the eruption fissures in 2014-2015 (Coppola et al. 2017). Except for July 2015, the activity during the eruptive cycle 2014-2015 concentrated close to the summit and on the southern flanks

\subsubsection{Eruptive activity during June 2014-July 2015}

Despite its frequent eruptive activity since 1998 (Peltier et al. 2009; Roult et al. 2012), PdF fell into a phase of quiescence for 41 months after December 2010 that was characterized by a continuous deflation of the volcano's surface, low-level of shallow volcano-tectonic seismicity, and watervapour dominated low-temperature gas emissions by the summit intracaldera fumaroles (Staudacher and Peltier 2015; Peltier et al. 2016; Coppola et al. 2017; Gurioli et al. 2018). An increase in soil $\mathrm{CO}_{2}$ emission on the distal western flank of the PdF edifice together with eccentric deep (mantle level) seismicity from March to April 2014 indicated the eventual rise of new deep magma and heralded a new eruptive cycle (Liuzzo et al. 2015; Boudoire et al. 2017). This deep 
Timescales of magmatic processes during the eruptive cycle 2014-2015 at Piton de la Fournaise, La Réunion, obtained from $\mathrm{Mg}-\mathrm{Fe}$ diffusion modelling in olivine

reactivation was then followed by a short and weak phase of inflation of the summit cone starting on June 9 only 11 days before the first small June 2014 eruption $\left(0.4 * 10^{6} \mathrm{~m}^{3}\right.$, Peltier et al. 2016; Gurioli et al. 2018). The June 20-21 eruption was the start of a new and still ongoing eruptive cycle and was followed by three short eruptions in February, May, and July 2015 (0.82, 6.54 and 1.63 * $10^{6} \mathrm{~m}^{3}$; Coppola et al. 2017). These eruptions are characterized by an exponential decrease of the initially strong output rate, which indicates a fast reduction of the source overpressure (Coppola et al. 2017). Erupted lavas are olivine-poor cotectic $(\mathrm{cpx}+$ plag $+/$ - ol) basalts that were slightly more evolved than the typical products erupted at PdF, the so-called "steady state" basalts (SSB; Albarède et al. 1997).

The four small eruptions were preceded by shallow seismicity interpreted to be due to the reopening of magmatic pathways (Peltier et al. 2016). Low rate of inflation preceded the eruptions of June 2014 and February 2015. Lavas erupted from June 2014 to May 2015 became increasingly more evolved, which indicates a differentiation process in the shallow system (Coppola et al. 2017). In April 2015, strong seismic unrest was monitored at PdF (Peltier et al. 2016; Coppola et al. 2017) and an unusually deep earthquake swarm was recorded in mid-April rising from $7.5 \mathrm{~km}$ below sea level (bsl) to $\sim 2.5 \mathrm{~km}$ bsl towards the end of April (Lengliné et al. 2016; Peltier et al. 2016). Simultaneously, the onset of shallow seismicity at sea level (asl) depth was observed. Deep seismicity and an increase in distal soil $\mathrm{CO}_{2}$ flux are related to magma rising from depth, causing shallow seismicity and continuous inflation of the volcano's surface, whose acceleration started during mid-April (Peltier et al. 2016). The acceleration of surface inflation that accompanied this elevated $\mathrm{CO}_{2}$-discharge just before May 2015 eruption was interpreted to be caused by the intrusion of new, deeply derived, mafic magmas into the shallow crustal plumbing system below the central vent area of PdF (Peltier et al. 2016).

\subsubsection{August-November 2015: Phase I (August 24 - September 11)}

The final and main eruption lasted 65 days from August to November 2015 and is divided into three phases based on eruptive volume, ground deformation and seismicity. It produced $45 * 10^{6} \mathrm{~m}^{3}$ of basaltic lava and was one of the largest observed at PdF (Coppola et al. 2017). Activity started on August 24 at the south-western flank of PdF with high lava output rates $\left(60 \mathrm{~m}^{3} / \mathrm{s}\right.$; Fig. 2; Coppola et al. 2017) and the eruption of clinopyroxene- and plagioclase-bearing evolved basalts. After strong precursory seismic activity recorded at shallow (asl) and intermediate levels $(\sim 1.5 \mathrm{~km} \mathrm{bsl}$, Lengliné et al. 2016) in mid-August, the number of seismic signals decreased significantly in Phase I. Output rates and surface deformation also decreased towards September 11. 


\subsubsection{Phase II (September 11 - October 16)}

A slight increase in lava flux, deflation of the volcano's surface, and an increasing olivine content of erupted products introduced Phase II that culminated in a strong pulse of lava output on October $16\left(22 \mathrm{~m}^{3} / \mathrm{s}\right.$, Fig. 2). Phase II is characterized by low seismicity until October 16, when deep and shallow seismic signals were again recorded as precursors to Phase III. The renewal of deep seismicity and the change in lava composition were associated with enrichment in $\mathrm{CO}_{2}$ of the summit fumarole emissions (Coppola et al. 2017).

\subsubsection{Phase III (October 16 - November 02)}

Two new eruptive pulses of Phase III followed on October $24\left(32 \mathrm{~m}^{3} / \mathrm{s}\right)$ and October $31\left(20 \mathrm{~m}^{3} / \mathrm{s}\right)$ with an intervening week of inactivity (Fig. 2). Each pulse was accompanied by rapid inflation prior to, and deflation during each pulse. Deep and shallow seismic signals together with enrichment in $\mathrm{CO}_{2}$ of the summit fumaroles were recorded during the pulses of strong eruptive activity (Coppola et al. 2017). This final phase emitted the lavas with the highest olivine content since the beginning of the new eruptive cycle.

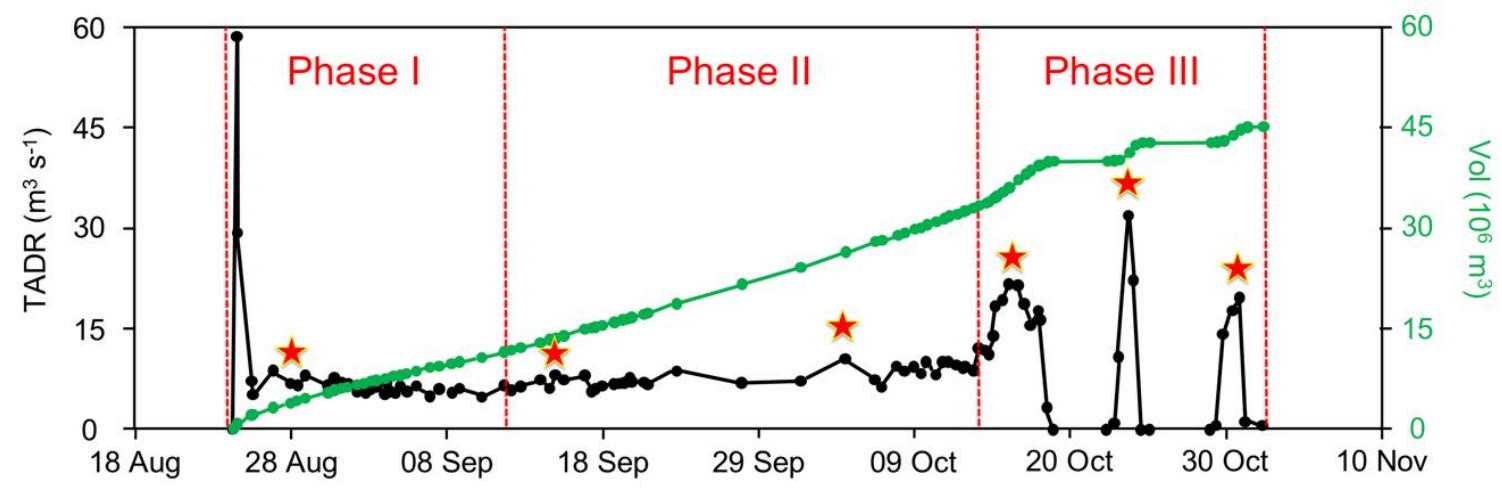

Fig. 2 Lava output rate (TADR - Time Averaged Lava Discharge Rate) and total erupted volumes during the August-November 2015 eruption (drawn after Coppola et al. 2017). Dashed red lines mark the three phases of the eruption. Stars represent the samples from August-November eruption analysed in this study. After strong lava output at the beginning of Phase I, the erupted rates remained nearly constant during Phase II until October 16, when Phase III was introduced by the first of three final lava pulses that occurred at the same crater and were interrupted by days of inactivity

\subsection{Samples and analytical methods}

Nine quenched lava and tephra samples were analysed here. Three samples cover the small eruptions on June 21, 2014 (REU 140624-12), May 18 (REU 150518-1), and July 312015 (REU 
Timescales of magmatic processes during the eruptive cycle 2014-2015 at Piton de la Fournaise, La Réunion, obtained from $\mathrm{Mg}$-Fe diffusion modelling in olivine

150731-7b). No olivine crystals suitable for analysis were found in the mostly aphyric February 2015 sample (REU 150204-2). Representative samples of the August-November eruption cover the early Phase I (August 28, REU 150828-6), Phase II (September 15 and October 07, REU 1509151, REU 151007-3), and the three strong lava pulses of Phase III (October 16, 24, and 31, REU 151016-1, REU 151026-1a, REU 151031-1). All samples were collected at eruption temperature and immediately quenched in water except sample REU 151026-1a, which are quickly cooled partly glassy lapilli sampled two days after eruption. Lavas erupted during 2014-2015 sequence are all olivine-poor, slightly evolved SSB within $\mathrm{MgO}=6.1-6.6$ wt.\% for June 2014 to May 2015 and 6.611.0 wt. \% for the large August to November eruption (Coppola et al. 2017) that characterise typical and most common eruptive products from the central vent area of PdF. 103 olivine crystals from these samples were analysed by electron microprobe. Analysed crystals are euhedral to subhedral and show no resorption except of slightly rounded olivine crystals embedded in July 2015 lava and one strongly resorbed crystal that was erupted on October 31 (REU 151031-1-1).

Chemical compositions were analysed with the JEOL JXA 8900 electron microprobe at the Department of Geochemistry at the Geoscience Center (GZG), Georg-August-University Göttingen. Line profiles were measured from rim to core, using step sizes from 5-10 $\mu \mathrm{m}$ in the core down to $2 \mu \mathrm{m}$ at the narrow outermost rims and a focused beam (diameter $\sim 2 \mu \mathrm{m}$ ) to optimize the spatial resolution for narrow diffusion gradients (Bradshaw and Kent 2017). Major ( $\mathrm{Si}, \mathrm{Fe}, \mathrm{Mg}$, $\mathrm{Mn})$ and trace elements ( $\mathrm{Al}, \mathrm{Ca}, \mathrm{Ni}$ ) were analysed with $15 \mathrm{keV}$ and $20 \mathrm{nA}$. Counting times were 15/5 s for peak / background of Si, $\mathrm{Al}, \mathrm{Fe}$, and $\mathrm{Mg}, 40 / 20 \mathrm{~s}$ for $\mathrm{Ni}$, and 60/30 s for $\mathrm{Ca}$ and $\mathrm{Mn}$. All analyses of olivine line profiles are listed in Online Resource 1.

Melt inclusions (MI) in olivine crystals and glassy groundmass (GM) were analysed for $\mathrm{Mg}$ thermometry using $15 \mathrm{keV}, 15 \mathrm{nA}$, and a spot size of $20 \mu \mathrm{m}$. Counting times were $15 / 5 \mathrm{~s}$ for Si, Al, $\mathrm{Ca}, \mathrm{Mg}, \mathrm{Mn}, \mathrm{Ni}, \mathrm{K}$, and $\mathrm{Na}$, whereas $\mathrm{Ti}, \mathrm{Cr}, \mathrm{Co}$, and Fe were measured for 30/15 s.

The Mg-in-glass thermometer from Helz and Thornber (1987), modified by Putirka (2008, Eq. 13) was used to obtain temperatures from glassy groundmass and melt inclusions in olivine. The chemical data and calculated temperatures can be found in Online Resource 2. The calculated temperature range for magmas from August-November 2015 eruption is $1125-1161 \pm 10^{\circ} \mathrm{C}$ from GM and 1112-1173 $\pm 10{ }^{\circ} \mathrm{C}$ from MI in olivine. These temperatures correlate to those calculated for the June 2014 products $\left(1115-1148{ }^{\circ} \mathrm{C}\right.$; Gurioli et al. 2018). As the MI compositions were not recalculated for post-entrapment crystallization, the temperatures are similar to those calculated from the groundmass $\left(<10^{\circ} \mathrm{C}\right.$ difference) except for the samples REU 151007-3 and REU 1510161 (16-20 ${ }^{\circ} \mathrm{C}$ difference). We used temperatures obtained from MIs for diffusion modelling to avoid a potential underestimation of real equilibration temperatures due to magma cooling and degassing. 
Timescales of magmatic processes during the eruptive cycle 2014-2015 at Piton de la Fournaise, La Réunion, obtained from $\mathrm{Mg}-\mathrm{Fe}$ diffusion modelling in olivine

Pressures of crystallization are likely to be low $(<1 \mathrm{kbar})$ for magmas residing in the shallow plumbing system as indicated by fluid inclusion and glass inclusion analyses by Di Muro et al. $(2014,2016)$. A range of oxygen fugacities was calculated for PDF lavas in several studies, ranging from NNO + 0.7 to NNO - 1.8 (Bureau et al. 1998b; Boivin and Bachèlery 2009; Pichavant et al. 2016). To evaluate the effect of variable oxygen fugacities, we used the published average of NNO -0.5 (Pichavant et al. 2016) for diffusion modelling, but tested also for NNO + 0, resulting in $~ 15$ $\%$ variation of calculated diffusion times. This effect is small compared to the effect of temperature uncertainty, as discussed below.

The $\mathrm{Fe}^{3+} / \mathrm{Fe}_{\text {total }}$ of the magmas from PdF is given as $\sim 0.11$ (Bureau et al. 1998b; Di Muro et al. 2016; Gurioli et al. 2018). For the samples from Phase III of August-November eruption, this value results in a good fit of calculated olivine equilibrium composition and measured composition at olivine diffusion margins. However, the samples from the earlier eruptions fit better assuming a slightly higher $\mathrm{Fe}^{3+} / \mathrm{Fe}_{\text {total }}$ of 0.18 for June 2014 to Phase I and 0.14 for Phase II.

Crystal orientation is crucial for diffusion modelling due to strongly anisotropic $\mathrm{Mg}$-Fe diffusion in olivine, which can be described as $6 D_{a}=6 D_{b}=D_{c}$, with $D_{a}, D_{b}, D_{c}$ as Fo diffusion coefficients along the a-, b-, and c-axis (Costa and Chakraborty 2004). Crystal orientation was determined via electron backscatter diffraction (EBSD, Prior et al. 1999) using the FEI Quanta 200 F scanning electron microscope at the Department of Crystallography at the Geoscience Center and a FEI Nova NanoSEM 650 (only sample REU 140624-12) at the Institute of Material Physics (IMP), GeorgAugust-University Göttingen. The EBSD measurements have been carried out using a DigiView V camera of EDAX-Ametek and the data collection software TSL OIM. The measurement conditions were $15-20 \mathrm{keV}, 150 \mu \mathrm{A}$, and a spot size of 4-5 $\mu \mathrm{m}$. Sample surfaces were polished with $0.05 \mu \mathrm{m}$ $\mathrm{Al}_{2} \mathrm{O}_{3}$ corundum powder for $90 \mathrm{~s}$. Every thin section was covered with a thin carbon coating $(6 \mathrm{~s}$ coating time at $4.6 \mathrm{~V}$ ) and connected with conductive silver to the holder to avoid electrostatic charge of highly porous tephra samples. The carbon layer must be as thin as possible being a compromise to avoid electrostatic charge without weakening the signal during measurements. Glassy samples with low porosity (REU 151007-3) were therefore analysed without coating.

We used Kernel density estimations (KDE) to visualize the crystal size distribution of olivine crystals with respect to their zoning type and diffusion time. The advantages of KDE's compared to common histograms are the continuity of the function, resulting in a smoothed curve, and a less strong dependency on parameters, that must be defined for histograms, as bin-width and the position of the bins, which can change a histogram significantly (Wand and Jones 1995). 


\subsection{Diffusion modelling}

Residence times were obtained from modelling diffusion profiles from core to the diffusive margin (Fig. 3 a) in olivine crystals from each of the individual eruptions during the June 2014 to November 2015 activity. In this study we use the term margin for the outer composition, which represents the equilibrium with the host melt, in which the olivine crystals started to homogenize after reactivation (Fig. 3 a). Diffusive equilibration resulted in a compositional gradient between core and this margin that was modelled to constrain the residence times of olivine cores under changing magmatic conditions. The comparison of Fo-content and trace elements such as $\mathrm{Ca}$ and $\mathrm{Ni}$ allows distinguishing growth and diffusive zoning. Due to their slower diffusion, $\mathrm{Ca}$ and $\mathrm{Ni}$ show a steeper gradient and shorter profile than Fo (Fig. 3 b, c). Other crystals are almost unzoned for these elements except at the outermost narrow rim (Fig. $3 \mathrm{~d}$, e). Therefore, compositional zoning of the olivine crystals is caused by diffusion rather than crystal growth.

Diffusion follows after the reactivation of olivine crystals (either phenocrysts from resident magma batches or older cumulates) due to ascent and mixing with new, more mafic magma. This process causes re-equilibration of the "old" olivine cores with the new hybrid melt. Normal zoning of Forich cores and low-Fo rims (Fig. 4 a, c-i; 5 a) and reverse zoning with low-Fo cores and Fo-richer rims (Fig. 4 b, c, e, i; 5 b) originate typically from "simple" mixings of two compositional distinct magmas, which is a common process in shallow and frequently refilled reservoirs of many basaltic systems (e.g. Hawaii, Rae et al. 2016). Complex zoned crystals constrain a multi-step history that may include several mixing events during ascent (Gordeychik et al. 2018). Only one crystal with a weak wavy change in Fo-content from core to rim (normal-reverse-normal) was found in the present study (REU 151026-1a).

During magma mixing, the "old" reactivated olivine cores start to homogenize to the new magmatic composition. This results in a smoothing of compositional gradient between core and diffusive margin with diffusion rates depending on storage conditions such as temperature, oxygen fugacity, and pressure. Given the rapid quenching during eruption, which interrupts the diffusion process, the compositional gradient can be used to model the duration of diffusion and partial reequilibration in the new magma (Fig. 5). Since the eruption date is known for each sample, this relative time information can be cast into the date of reactivation. This date can be compared to geophysical and geochemical monitoring datasets. 
Timescales of magmatic processes during the eruptive cycle 2014-2015 at Piton de la Fournaise, La Réunion, obtained from $\mathrm{Mg}$-Fe diffusion modelling in olivine
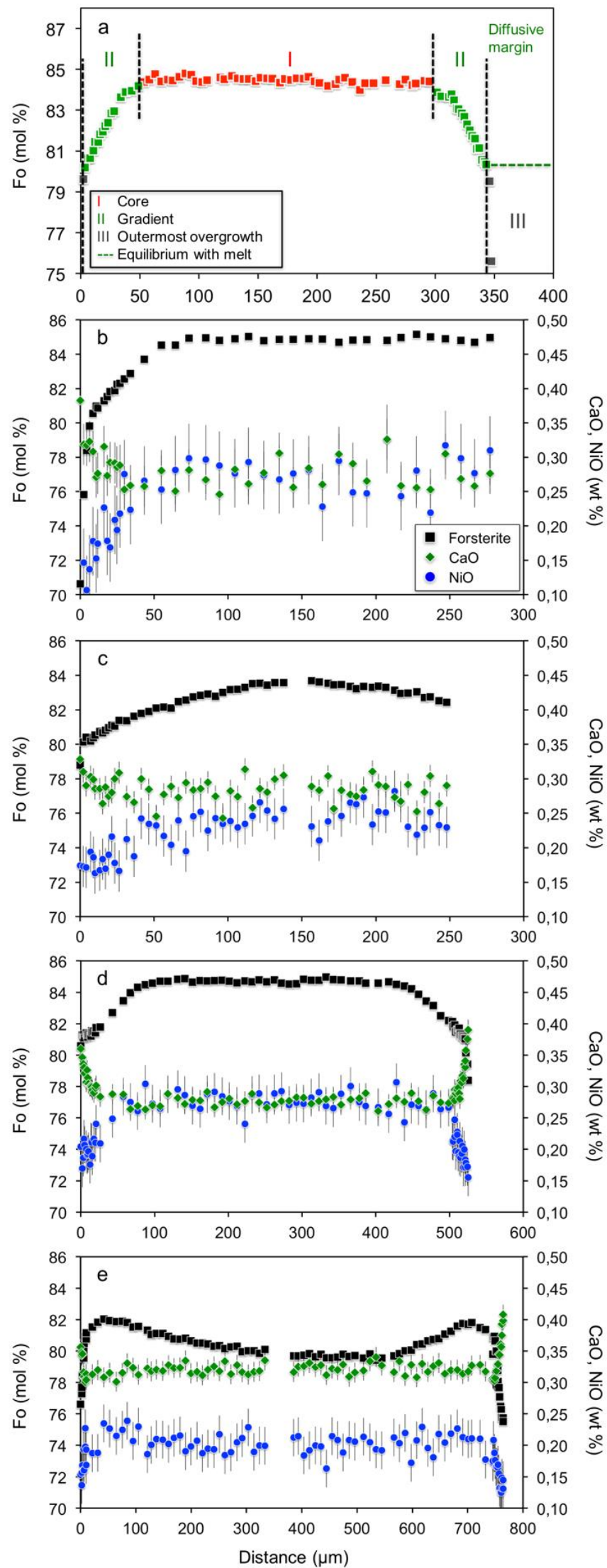

Fig. 3 (a) Representative compositional olivine profile to show the different crystal sections we modelled in this study. (I) is the unzoned crystal core. (II) represents the compositional gradient between core and the 
Timescales of magmatic processes during the eruptive cycle 2014-2015 at Piton de la Fournaise, La Réunion, obtained from $\mathrm{Mg}$-Fe diffusion modelling in olivine

diffusive margin (= equilibrium composition within the melt the olivine was entrained to after mixing; green dashed line). The transition of (I) and (II) was defined as the first data point that differed $>0.2 \mathrm{~mol} . \%$ ( $2 \sigma$ error of forsterite) from the average core composition. We modelled diffusion time using the gradient (II) to obtain the residence time in the hybrid melt after mixing. (III) is considered to be a late overgrowth which was caused by cooling during or after the eruption. (b-e) Profiles of Fo-content compared to $\mathrm{CaO}$ and $\mathrm{NiO}$ to distinguish growth and diffusion zoning. The slower diffusion of $\mathrm{CaO}$ and $\mathrm{NiO}$ results in steeper gradients $(b, c)$ or the lack of any zoning (d, e). Uncertainties of Fo are within the symbols

We selected olivine crystals, where both core and margin compositions and the gradient between them were clearly constrained by measurements to ensure correct initial/boundary conditions for modelling. A fixed boundary concentration was used assuming that the olivine rims remained in contact with the new melt during the diffusion process. The compositional profiles give further evidence of the lack of an overgrowth due to the absence of a compositional plateau at the outer cores (Fig. 3, 4, 5) except of two crystals (150915-1-2 and 150915-1-3). The profiles were modelled based on the assumption of an initially unzoned crystal as indicated by the unzoned trace elements as $\mathrm{Ca}$ and $\mathrm{Ni}$ (Fig. $3 \mathrm{~d}$, e) at the time $\mathrm{t}_{0}$, when the olivine was entrained into a new magma. The crystal started to equilibrate a timespan $\Delta t$ until the time $t_{1}$, when the diffusion process ended due to cooling of the melt at eruption (Fig. 5). The narrow outermost rim $(<3 \mu \mathrm{m})$, which can be seen in most profiles, is interpreted as result of late cooling and depressurization during ascent and eruption and subsequent cooling of the lava at the surface. The linear correlation of Fo and $\mathrm{NiO}$ contents of the outermost rims. Also, outermost rims are generally in equilibrium with the matrix glass (Fig. 4). Both observations indicate that these rims indeed represent a late crystallization process related to eruption. 
Timescales of magmatic processes during the eruptive cycle 2014-2015 at Piton de la Fournaise, La Réunion, obtained from $\mathrm{Mg}$-Fe diffusion modelling in olivine
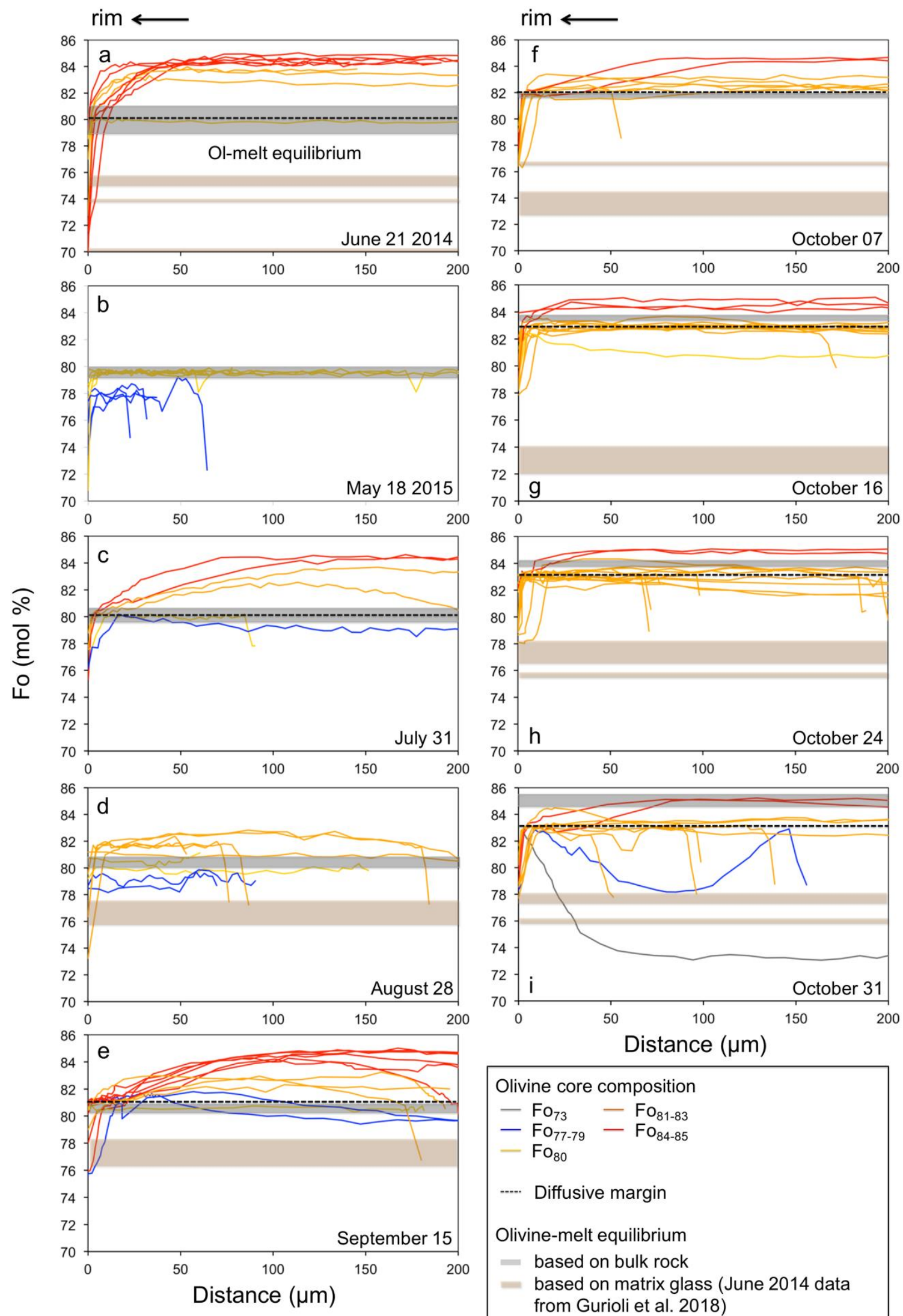

Distance $(\mu \mathrm{m})$

Olivine core composition

$$
\begin{aligned}
& -\mathrm{Fo}_{73}-\mathrm{Fo}_{81-83} \\
& -\mathrm{Fo}_{77-79}-\mathrm{Fo}_{84-85} \\
& -\mathrm{Fo}_{80} \\
& \text {--.- Diffusive margin } \\
& \text { Olivine-melt equilibrium } \\
& \text { - based on bulk rock } \\
& \text { - based on matrix glass (June } 2014 \text { data } \\
& \text { from Gurioli et al. 2018) }
\end{aligned}
$$

Fig. 4 Line profiles of all olivine crystals analysed in this study. Normal, reverse, complex and non-zoned olivine grains were found. Three groups of olivine cores can be generally distinguished by their composition: Fo-rich $\left(\mathrm{Fo}_{84}\right)$, intermediate $\left(\mathrm{Fo}_{80-83}\right)$, and Fo-poor $\left(\mathrm{Fo}_{<80}\right)$. (i) Strongly resorbed olivine cores that were 
Timescales of magmatic processes during the eruptive cycle 2014-2015 at Piton de la Fournaise, La Réunion, obtained from $\mathrm{Mg}$-Fe diffusion modelling in olivine

erupted on October 31 can be very Fo-poor $\left(\mathrm{F}_{73}\right)$. Grey bars mark the olivine equilibrium composition based on the calculation with whole rock composition assuming a Fe ${ }^{3+} / \mathrm{Fe}_{\text {total }}$ of 0.18 for June 2014 to Phase I, 0.14 for Phase II, and 0.11 for Phase III. We suggest that outermost narrow rims formed by crystallization during late ascent and eruption due to the equilibrium with matrix glass (brown bars). The black dashed line marks prominent diffusion margins. All olivine cores equilibrated to (or were already in equilibrium with) intermediate compositions that were lowest during (a) June (Fo80.8-82.2) and (c) July (Fo80.1-80.8). Olivine crystals from (b) May and (d) August samples show no clear equilibrium composition due to the occurrence of two nearly unzoned olivine groups (May) and a large compositional scattering of unzoned olivine (August). (e-i) During Phases II and III of the large August-November eruption, the compositions at diffusion margins of analysed olivine grains increased systematically from Fo ${ }_{80.5-83.4}$ (Phase II) to Fo ${ }_{82.1-84.5}$ (Phase III)

Diffusion times can be calculated via modelling of $\mathrm{Mg}$-Fe exchange along the measured compositional gradients in Fo-content in zoned olivine crystals. All input parameters used for modelling are given in Online Resource 3. We used the software DIPRA (Diffusion Process Analysis) by Girona and Costa (2013) for diffusion modelling. The software provides a onedimensional, numerical approach, that allows to model the diffusion profiles as a series of spatial and time-steps and take into account the compositional dependency of the diffusion coefficient (Girona and Costa 2013):

$\frac{\partial C_{i}}{\partial \mathrm{t}}=\frac{\partial}{\partial \mathrm{x}}\left(\mathrm{D}_{\mathrm{i}} \frac{\partial C_{i}}{\partial \mathrm{x}}\right)$

with $\mathrm{C}_{\mathrm{i}}$ as concentration $\mathrm{C}$ of the diffusing element $\mathrm{i}$ (here: $\mathrm{Mg}-\mathrm{Fe}$ ), $\mathrm{x}$ as distance, $\mathrm{D}_{\mathrm{i}}$ as diffusion coefficient $\mathrm{D}$ of the element $\mathrm{i}$, and $\mathrm{t}$ as time. The software calculates diffusion times by searching the best fit of the measured data with all modelled curves within a time range defined by the user with using the root mean square method (Girona and Costa 2013):

$\mathrm{rms}=\sqrt{\frac{1}{\mathrm{~N}} \sum \mathrm{N}\left(\mathrm{C}_{\mathrm{i}}^{\mathrm{xn}}-\mathrm{C}_{\mathrm{i}}^{\mathrm{x}}\right)^{2}}$

with $\mathrm{N}$ as the number of data, $C_{i}^{x n}$ as modelled concentration $\mathrm{C}$ of the element $\mathrm{i}$ at a distance $\mathrm{x}$ after $\mathrm{n}$ time steps and $C_{i}^{x}$ as measured concentration of the element $\mathrm{i}$ at distance $\mathrm{x}$.

The basic diffusion coefficient $\mathrm{D}_{\mathrm{c}}$ for diffusivity of $\mathrm{Mg}$-Fe along the c-axis is calculated based on the equation of Chakraborty (2010) and specified as a $D_{\text {profile }}$ due to the strong anisotropic diffusion in olivine (Carslaw and Jaeger 1959): 
$D_{\text {profile }}=D_{a}(\cos \alpha)^{2}+D_{b}(\cos \beta)^{2}+D_{c}(\cos \gamma)^{2}$

with $\alpha, \beta$, and $\gamma$ as angles between measured profile and a-, b-, and c-axis, and $6 \mathrm{D}_{\mathrm{a}}=6 \mathrm{D}_{\mathrm{b}}=\mathrm{D}_{\mathrm{c}}$ (Costa and Chakraborty 2004).
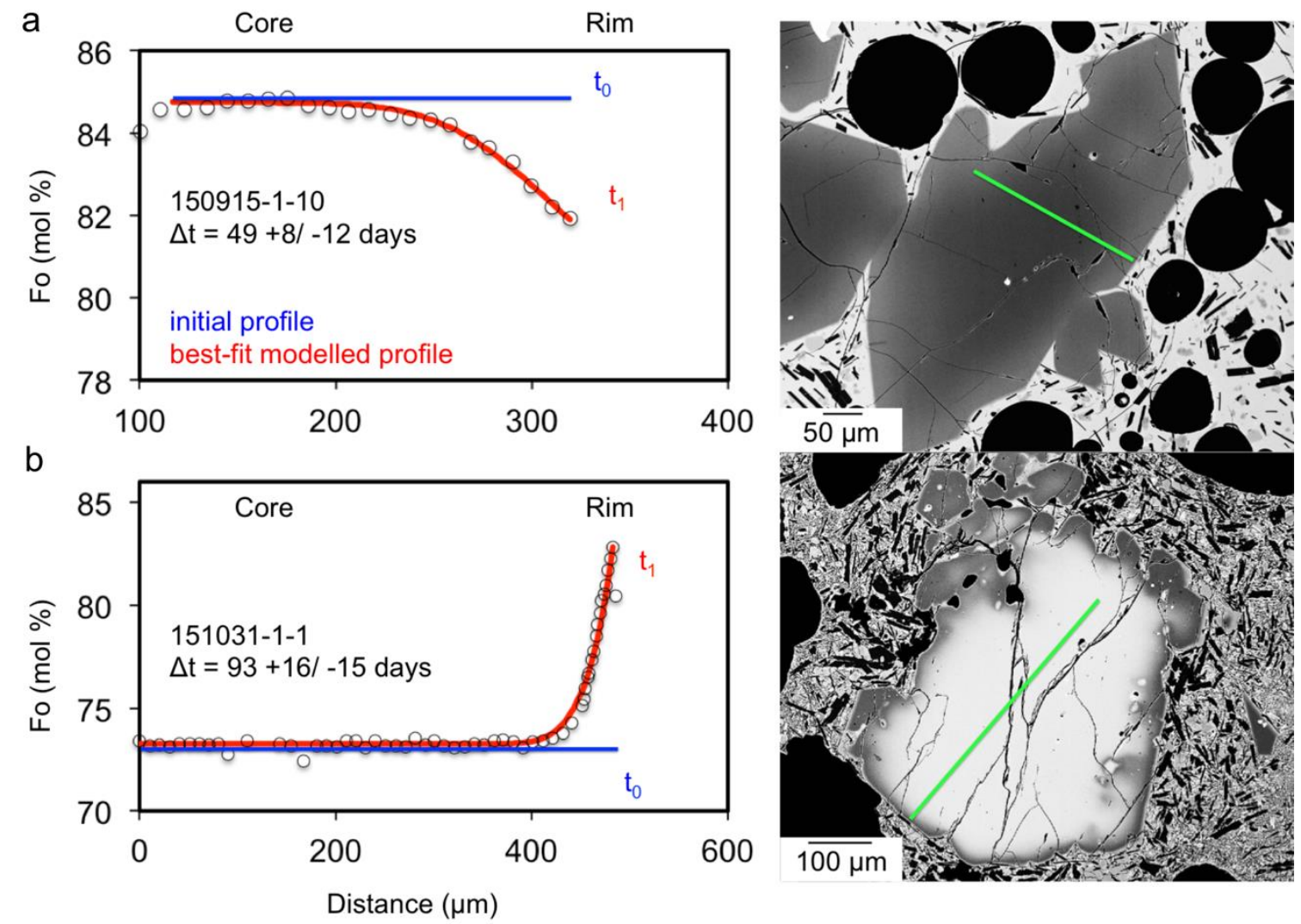

Fig. 5 Modelled diffusion profiles of representative normal (a) and reverse zoned (b) olivine crystals erupted on September 15 (Phase II) and October 31 (Phase III) which equilibrate to intermediate compositions of $\mathrm{Fo}_{81.8}$ and Fo82.8, respectively. Back-scattered electron images (BSE) are on the left. Blue lines show the initial compositional profiles at $\mathrm{t}_{0}$, which changed due to diffusive $\mathrm{Mg}$-Fe exchange to the measured profiles at $\mathrm{t}_{1}$ (unfilled circles). The time of diffusion $\Delta \mathrm{t}$ was modelled to constrain the reactivation dates of the olivine crystals

The use of a one-dimensional model may lead to the overestimation of calculated diffusion times, because the compositional gradients may have been affected by diffusion in more than one direction. The crystals were selected carefully with respect to symmetrical diffusion profiles and growth faces perpendicular to the profile direction. However, the random orientation of olivine crystals in natural samples does not allow to completely exclude any influence of two-dimensional 
diffusion. Therefore, the diffusion times modelled in this study are always only maximum timescales. The uncertainties used for the modelling were $\pm 10{ }^{\circ} \mathrm{C}$ in temperature and $\pm 0.2 \%$ in Fo-content. Temperature has the largest impact on uncertainties of $t$, whereas pressure and $\mathrm{fO}_{2}$ have only a minor influence. Uncertainty in Fo-content has a larger impact when the compositional difference between core and diffusion margin is small. All profiles were modelled with $1 \mathrm{kbar}$ pressure, which corresponds to the pressure at the bottom of the shallow plumbing system $(\sim 1.5$ $\mathrm{km} \mathrm{bsl}$ ), but models were also tested for 0.5 and $2 \mathrm{kbar}$ to consider that diffusive equilibration could have occurred in the shallow sills and dykes or deeper in the central reservoir as indicated by deep seismic signals recorded during April 16-25 2015 ( 7.5 - 2 km bsl, Lengliné et al. 2016). Using 0.5 and 2 kbar result in a difference in modelled times of -2 to $-8 \%$ and 4 to $9 \%$ compared to the diffusion times at $1 \mathrm{kbar}$. This shows clearly, that uncertainties in pressure have a negligible effect. DIPRA calculates uncertainties based on uncertainties in $\mathrm{T}$ and Fo-content, but also includes all modelled curves, that theoretically fit the measured profile and have the same discrepancy as the best fit curve (see below; Girona \& Costa, Eq. 10.). The uncertainties obtained from diffusion modelling with DIPRA are in the range of $12-46 \%$ for most crystals, but reach up to $64-93 \%$ for two crystals with very short diffusion times and a small compositional difference between core and diffusion margin.

Additionally, DIPRA provides a discrepancy term of the fitted curve. The discrepancy is a value for the difference between the best fit modelled curve and the measured concentrations including the analytical uncertainties and is therefore a term for the goodness of fit (Girona and Costa 2013). It is defined as the ratio of modelled points, that are off the measured concentration \pm uncertainty at this distance, to the total number of points (Girona and Costa 2013). The discrepancies of the profiles modelled in this study are $<15 \%$, except of the crystal 151031-1-1 (32\%), and are mostly due to scattering of Fo-content in several crystal cores.

\subsection{Results and discussion}

\subsubsection{Olivine zoning and compositions}

Four types of compositional zoning were found in olivine grains: (1) normal, (2) reverse, (3) rare complex zoning, and (4) unzoned crystals. Additionally, rare normal zoned olivine crystals with stepwise zoning were found (Fig. 4; 6 a). Normal zoned olivine crystals are the main species found in this study (45\% of all analysed crystals), followed by reverse and unzoned crystals ( 28 and 26 $\%$, respectively). Normal zoned olivine crystals are dominant in the samples from June 2014 (80 $\%)$, July 2015 (83\%), and September 15 (77\%), October 07 (56\%) and 16 (62\%) during the August-November eruption, whereas olivine crystals embedded in May lavas show no or only a 
weak reverse zoning. On August 28, both normal and reverse zoned olivine crystals occur with a similar percentage of $40 \%$. During the final phase on October 24 and 31, the amount of normal zoned crystals decreases to 19 / $8 \%$, whereas reverse (31 / $62 \%$ ) and unzoned crystals (44 / $31 \%$, respectively) become more abundant.

Olivine crystals with sizes from $<100 \mu \mathrm{m}$ to $1500 \mu \mathrm{m}$ were found in the analysed samples (Fig. 6). Normal zoned olivines have a dominant size range from 200 to $700 \mu \mathrm{m}$, but single crystals reach $750-1000 \mu \mathrm{m}, 1200 \mu \mathrm{m}$, and $1500 \mu \mathrm{m}$ (Fig. 6 a). Reverse zoned crystals show a serial size distribution from $<100 \mu \mathrm{m}$ to $1200 \mu \mathrm{m}$ with two more prominent groups at $<200 \mu \mathrm{m}$ and $800-$ $1100 \mu \mathrm{m}$. Unzoned olivine crystals are restricted to small sizes $<400 \mu \mathrm{m}$ except of two crystals with $600 \mu \mathrm{m}$ and $750 \mu \mathrm{m}$. However, the distribution of crystal sizes within the samples is random except of small olivine crystals $(<200 \mu \mathrm{m})$ with weak or no zoning, which occur exclusively in analysed products of May 2015, Phase I and late Phase III (October 31) of August-November eruption.

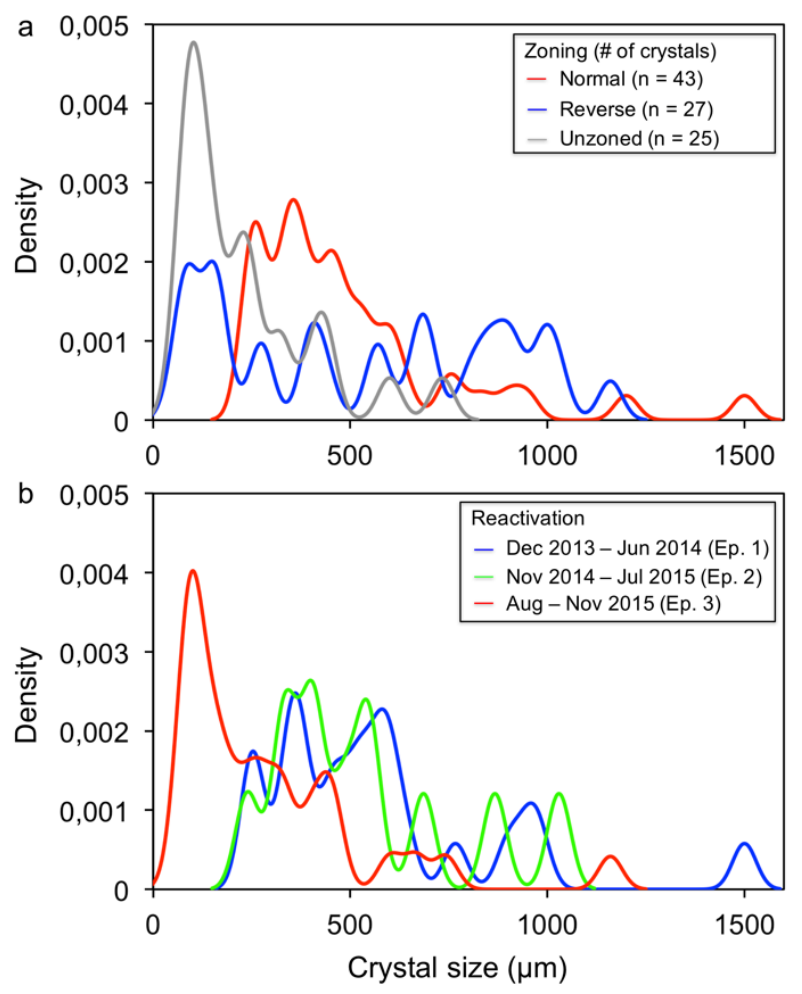

Fig. 6 Kernel density estimations (KDE) of olivine crystal sizes related to (a) zoning type and (b) crystal reactivation times. Normal zoned olivine crystals span a wide size range from 200 to $1500 \mu \mathrm{m}$ and are the dominant type that was reactivated during Episodes 1 and 2. Reverse zoned olivine crystals are found in all size ranges $(<100$ to $1200 \mu \mathrm{m})$ and occur in all episodes. Similar to the small unzoned olivine crystals (mostly $<100 \mu \mathrm{m}$, but up to $700 \mu \mathrm{m}$ ) small reverse zoned crystals become more abundant in the samples from AugustNovember 2015 eruption (Phases II and III) 
Timescales of magmatic processes during the eruptive cycle 2014-2015 at Piton de la Fournaise, La Réunion, obtained from $\mathrm{Mg}-\mathrm{Fe}$ diffusion modelling in olivine

We found that REU 140624-12 from June 2014 contains dominantly high-Fo olivine cores (Fo83.784.9) but low-Fo at the diffusive margins $\left(\mathrm{Fo}_{80.8-82.2}\right)$ except of one large resorbed olivine (REU 140621-12-1), which has a core with Fo ${ }_{82.1}$ and a margin with Fo ${ }_{83.1}$. No olivine crystals sufficient for line profiles analysis were found in the aphyric material from the February 2015 eruption (REU 150204-2). REU 150518-1 from the May eruption contains only unzoned olivine crystals of two different core compositions ( $\mathrm{Fo}_{77.6-77.9}$ and $\mathrm{Fo}_{79.3-79.7)}$. Variable core compositions (Fo79.1-84.4) were found in olivine crystals from REU 150731-7 from the July eruption, whereas compositions at the diffusion margins are uniform and more evolved than the most cores (Fo80.1-80.8).

For the main August-November 2015 eruption, core compositions range from Fo ${ }_{79.6-85.1}$. Focontents at diffusion margins (Fig. 4 d-i) increase with ongoing eruption from Fo 79.6-81.1 $_{\text {(REU }}$ 150828-8) to Fo80.5-81.9 (REU 150915-1), Fo81.5-83.4 (REU 151007-3), Fo82.1-82.6 (REU 151016-1), Fo82-84.1 (REU 151026-1a), and Fo82.5-84.5 (REU 151031-1).

\subsubsection{Magma compositions}

Fo-contents of olivine crystal cores which are unaffected by diffusion and the equilibrated margins should directly reflect the different compositions of the magmas from which the cores initially crystallized and to which they partially equilibrated later by diffusion, respectively. The core compositions reflect the magma in which the crystal resided until the moment when reactivation occurred and diffusion began. The composition of the margin then reflects the equilibrium composition of the hybrid, which formed from mixing with the magma by which the olivine was reactivated. Fig. 7 a shows Fo-contents of olivine crystals (cores and margins) with respect to the time when diffusion started at the margins.

The compositions of the outermost diffusive margins indicate rather variable melt compositions that are always intermediate (Fo80.1-84.5) between the mafic recharge (with Fo85.1) and erupted magmas with evolved Fo77-79 during June 2014 to August/early September 2015 (Phase I). Such compositions dominate the intermediate magmas present at depth. During the final stages of activity (Phases II and III) the erupted products are in equilibrium with more forsteritic olivine (Fo80.5-84.5). The last stage of eruption (Phase III, October 16 to 31 2015) produced the most forsteritic olivine cores $\left(\mathrm{Fo}_{85.1}\right)$ that are in equilibrium with their host melt. The mafic endmember in equilibrium with up to $\sim \mathrm{Fo}_{86}$ that was erupted at the end of Phase III document decreasing degrees of interaction with the resident magma batches. This implies that this mafic magma composition represents the principal magma type that feeds into the crustal magma system of Piton de la Fournaise from mantle depths. The documented compositional range of magmas present in the plumbing system is consistent with the model of a complex transcrustal magma plumbing system with a vertical 
Timescales of magmatic processes during the eruptive cycle 2014-2015 at Piton de la Fournaise, La Réunion, obtained from $\mathrm{Mg}-\mathrm{Fe}$ diffusion modelling in olivine

arrangement of magma batches of different compositions where the degree of differentiation increases with decreasing depth (Bureau et al. 1998a; Coppola et al. 2017; Gurioli et al. 2018).

\subsubsection{Diffusion times and olivine reactivation episodes}

Calculated diffusion times vary from $4+1 /-1$ to $680+300 /-150$ days for most olivine crystals of the studied eruptions during the June 2014 to November 2015 activity (Fig. 7). Only a large resorbed crystal REU 140621-12-1 gave longer diffusion times of at least 1330 days corresponding to the time prior to the long quiescence phase between 2010 and 2014. With the known eruption date and the modelled diffusion times in olivine crystals, each olivine crystal can be placed along the time line of the 2014-2015 eruptive cycle with respect to the onset of the diffusion process for this particular crystal (Fig. 7 a). This allows us to relate diffusion times for a particular crystal to events of eruption and/or seismicity that occurred prior to the eruption of that crystal. The record of these reactivation events is documented in olivine crystals that have residence times from 165 $+47 /-42$ to $337+85 /-77$ days and $430+69 /-95$ to $680+300 /-153$ days before their eruption during July and August-November 2015. When the whole data set is viewed in context (Fig. 7 a), our results show that such earlier events tend to cluster in distinct "episodes of reactivation" and mixing: one from December 2013 to June 2014 (Episode 1) and a second from November 2014 to May 2015 (Episode 2). Thus, the initiation of the 2014-2015 eruption sequence may have been preceded by recharge and possibly mixing already about several months prior to the eruptions in June 2014 and February 2015. A third, late episode of reactivation (Episode 3) occurred only 9 days prior to and during Phase I of the August-November 2015 eruption (August 17 to September 13). An even more recent diffusion event is recorded in crystals erupted at the end of Phase II to Phase III with only $15+14 /-10$ to $24+7 /-6$ days (October 01 to 09). The eruption in May 2015 is unusual, this eruption is not connected to strong olivine reactivation. May 2015 eruptions emitted the most evolved lavas of the studied period (Coppola et al. 2017). The olivine crystals found in the sample from May 2015 eruption are mostly unzoned and also compositionally quite evolved and in equilibrium with the host bulk rock ( $\mathrm{Fo}_{77.6-79.7)}$. Only two olivine crystals erupted in July 2015 with core compositions of $\mathrm{Fo}_{79.1}$ and $\mathrm{Fo}_{84.4}$ have diffusion times that can be related to the May eruption (reactivation on May $14+21 /-19$ days and May $31+9 /-13$ days). This observation is surprising given the strong ground deformation and the unusual combination of strong deep and shallow seismicity signals that were registered just before this eruption (Lengliné et al. 2016; Boudoire et al. 2017; Fig. 7 b). 


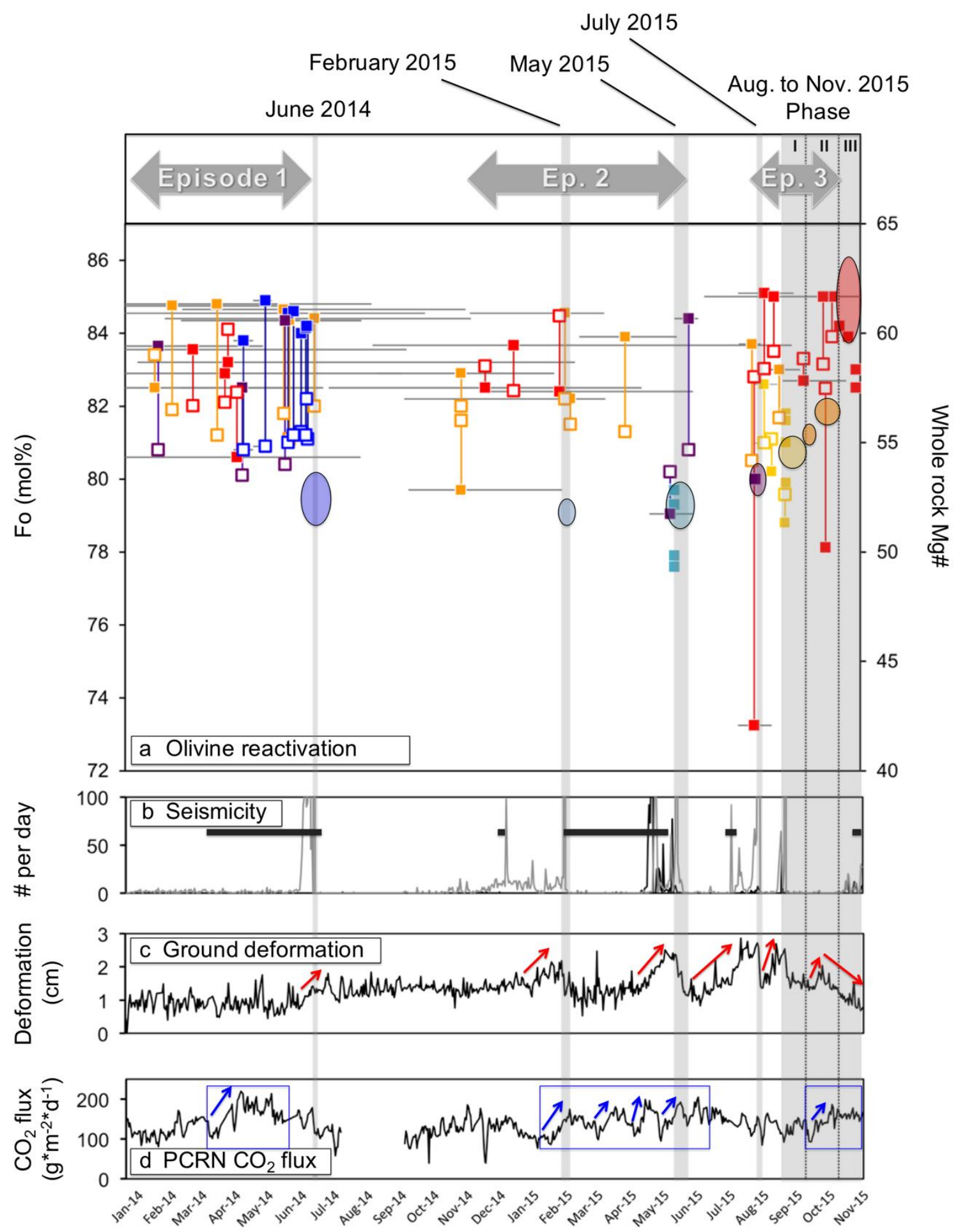

\begin{tabular}{|c|c|c|}
\hline $\begin{array}{l}\text { OI core / margin erupted in } \\
-\square \text { June } 2014 \\
\square \text { May } 2015 \\
-\square \text { July } 2015 \\
\square \text { Phase I Aug-Nov } 2015 \\
\square \text { Phase II } \\
\square \square \text { Phase III }\end{array}$ & $\begin{array}{l}\text { calc. OI in equilibrium with } \\
\text { melt erupted at that time } \\
\text { (for reference): } \\
\text { based on whole rock } \\
\text { Eruptions }\end{array}$ & $\begin{array}{ll}\text { Seismicity } \\
-\quad \text { shallow (asl) } \\
-\quad \text { deep (0-9 km bsl) } \\
=\quad \text { deep eccentric } \\
\\
\text { (Boudoire et al. 2017) }\end{array}$ \\
\hline
\end{tabular}

Fig. 7 Reactivation times and Fo-content of olivine cores (filled squares) and their corresponding diffusion margins (non-filled squares) erupted in 2014/2015 compared to (b) seismicity, (c) ground deformation (distal 
Timescales of magmatic processes during the eruptive cycle 2014-2015 at Piton de la Fournaise, La Réunion, obtained from $\mathrm{Mg}$-Fe diffusion modelling in olivine

baseline between GNSS-stations GITG-PRAG; Boudoire et al. 2017), and (d) $\mathrm{CO}_{2}$ soil flux on the distal western volcanic flank (PCRN; Boudoire et al. 2017). Grey bars mark the eruptions in June 2014, February, May, July, and August-November 2015. The diffusive equilibration of olivine crystals is related to distinct Episodes 1 - 3 (grey double-headed arrows) of mafic recharge and magma mixing. Most olivine crystals were reactivated in intermediate hybrid magmas, which erupted in October 2015. Olivine crystals started to equilibrate as early as December 2013 to June 2014 (Episode 1) and November to May 2015 (Episode 2). Both episodes correlate with deep $\mathrm{CO}_{2}$ degassing and occur prior to the deep seismic swarm in April 2015 (7.5 - $2.5 \mathrm{~km} \mathrm{bsl}$; Lengliné et al. 2016) and may therefore indicate the formation of hybrids at deeper crustal levels until their ascent into the shallow reservoir prior to May eruption. Although May eruption occurred after a deep seismic swarm and during a phase of intense inflation, olivine crystals from the products of May, July or August -November eruption do not record a reactivation event that can be related to April-May 2015. Olivine crystals with short diffusion times were reactivated and erupted from June 2014 to August-November 2015 (Phase I), whereas the products of July 2015 and Phases II / III contain “older” olivine crystals. After the magma batches in the shallow dykes erupted during June 2014 to May 2015, the central system emptied during Phases II and III of August-November eruption

Episode 1 correlates to a deep eccentric seismic swarm and an increase in soil $\mathrm{CO}_{2}$ recorded in March-April 2014 which indicate magmatic ascent from deep mantle levels below the volcano's western flank (Boudoire et al. 2017). However, the geophysical record shows no ground deformation and seismicity in the shallow system except of the two weeks prior to June 2014 eruption. For Episode 2 and 3 we document a clear coincidence of (1) ground deformation that is (2) directly correlated to increased seismicity, and (3) recharge and mixing of magma batches at the same time as recorded in the diffusion times of olivine crystals that were erupted later. Apparently, the magmatic system was successively charged up with increasing intensity and frequency during June 2014 to May 2015. During this time, only small volumes of magmas leaked from the shallow plumbing system. We did not find olivine crystals that would have been affected by a massive recharge event related to the May 2015 eruption, which was preceded by a deep seismic swarm in April (Peltier et al. 2016). The eruption of this evolved magma containing unzoned crystals might have been triggered by change in the volcano stress field due to deeper magma pressurization, without physical interaction (mixing) between residing magma and ascending magma batches. The increasing recharge frequency resulted in increasingly more mafic magmas erupted and, finally, the recharging magmas themselves were erupted later during the most productive, final eruption in October 2015 (Coppola et al. 2017). 
Timescales of magmatic processes during the eruptive cycle 2014-2015 at Piton de la Fournaise, La Réunion, obtained from $\mathrm{Mg}-\mathrm{Fe}$ diffusion modelling in olivine

\subsubsection{Process and timing of renewed activity during the 2014/2015 eruptive cycle}

The beginning of the 2014/2015 eruptive cycle in June 2014 was preceded by a long period of 41 months of quiescence and slow recharge of mafic magma into the central plumbing system between December 2013 and June 2014. The recharge initiated mixing and hybridization between intruding magnesian magmas ( Fo86) and more evolved resident melts and created a range of intermediate hybrid magmas (in equilibrium with Fo80-84.5, Fig. 4; 8; 9). However, neither these hybrids nor the mafic recharge magmas are present in the eruptive products during the subsequent activity until Phase II of August-November eruption. On the other hand, the lack of erupted melts in equilibrium with $>\mathrm{Fo}_{84.5}$ (except for the very end of the eruptive cycle) suggests that such mafic magmas were either completely consumed during the hybridization processes or did not ascent into the shallow system.

All olivine crystals with long diffusion times, that were reactivated during Episode 1 and 2, equilibrated to Fo>80. These compositions are too forsteritic to be in equilibrium with the evolved magmas erupted in the same period of time ( $\mathrm{Fo}_{\sim 77-79}$, olivine-melt equilibrium calculated from bulk rock composition; Fig. 7 a). The observation that the magmas that actually did erupt during most of the 2014/2015 activity are generally more evolved than magmas represented by their older crystal cargo indicates that only the evolved magmas were activated and erupted during the recharge, mixing and hybridization process. Therefore, the small eruptions in June 2014, February, and May 2015 were likely fed only from the shallow sill and dyke system, which contained differentiated magma batches (Coppola et al. 2017). The differences of the erupted products in composition and crystal content indicate that the olivine-poor June 2014 and May 2015 and aphyric February lavas origin from independent small magma batches. The presence of evolved olivine crystals (Fo<80) only in the evolved magmas of May 2015 that were picked up immediately prior to their eruption suggests that at least parts of the shallow sills and dykes remained largely unaffected by mixing processes, at least compositionally. Deeper hybridization and mixing processes are more truly recorded only in the olivine crystals with long diffusion times and various core compositions. The relative high abundance of forsteritic olivine crystals in the products of June 2014 might have been caused by reactivation from older residual cumulates and mush emplaced by magma intrusion in 2010-2011 before the quiescence phase (Gurioli et al. 2018; Fig. 8). The entrainment with mafic magmas entering the shallow system is unlikely due to the absence of shallow seismicity and inflation that would indicate a mafic recharge.

The reactivation of olivine crystals by intermediate hybrids in Episodes 1 and 2 occurred after a seismic swarm at mantle depths in March-April 2014 (Boudoire et al. 2017) and prior to the onset of deep crustal seismicity in April 2015 (7.5 km bsl, Lengliné et al. 2016) and correlates with periodical increase of distal $\mathrm{CO}_{2}$ soil emissions (Boudoire et al. 2017; Fig. 7 c, e). Therefore, we suggest that the hybrids were initially formed and stored in the central system $(>7.5 \mathrm{~km})$ during 
Timescales of magmatic processes during the eruptive cycle 2014-2015 at Piton de la Fournaise, La Réunion, obtained from $\mathrm{Mg}-\mathrm{Fe}$ diffusion modelling in olivine

Episode 1 and 2. The eruption of evolved magma batches in May 2015 was likely triggered by these rising hybrids pressurizing the shallow crustal system during April-May 2015 (as evidenced by the deep seismic signals, that rose from 7.5 to $2.5 \mathrm{~km}$ bsl; Lengliné et al. 2016). This is consistent with the diffusive margin of the olivine we found to be reactivated in May (Fo80.2-80.8), which is close to equilibrium with the early Phase II magmas ( Fo81, Fig. 7 a).

After the eruption of olivine crystals with short diffusion times in June 2014 and May 2015, the products of July 2015 eruption bear some of the "oldest" olivine crystals found in this study (up to $547+96$ / -67 days). The abrupt occurrence of "old" olivine crystals and the accelerating inflation rate after the deep seismic swarm in April mark the transition between the eruptions in June 2014 May 2015 that were exclusively shallow fed and the more deeply fed August-November 2015 eruption. The eruption of olivine crystals with long diffusion times only peaks at the transition of Phases II and III ( $237+32 /-152$ to $680+300 /-153$ days $)$ and then decreases conversely to the increasingly more mafic composition of erupted magmas.

Residence times show that at least two distinct recharge pulses occurred during the final eruption and are reversely correlated to lava output rate. The eruption of olivines with short diffusion times in Phase I and III is connected to high output rates. All analysed olivine crystals from August 28 (Phase I) are either unzoned or show reverse zoning and a short diffusion time of $20+12 /-9$ days. This correlates with deep seismic signals recorded during August 13 to 25 that indicate a new recharge into the shallow system (Coppola et al. 2017). Whereas the sampled products from September 15 to October 16 bear dominantly "old" olivine crystals, the samples from October 24 and 31 carry olivine crystals with short diffusion times again that were reactivated during the late Phase II (October $01+7$ / -6 days to $09+14$ / -10 days). The onset of new seismicity on October 15 after the mostly aseismic Phase II and the strong increase in eruption intensity on October 16 mark the intrusion of mafic magma into the shallow system that triggered the three intense eruptive pulses in Phase III. The correlation of deep, vertically extended seismicity and the increasing amount of reverse zoned olivine crystals in the final products may mark a transcrustal "break-through" of mafic magmas (Saunders et al. 2012; Magee et al. 2018). The absence of olivine crystals starting diffusion after October 13 and the occurrence of small newly grown, unzoned olivine indicate that the magnesian magmas which erupted during the final pulses on October 24 and 31 flushed the almost emptied shallow system with only few residuals of previously erupted magmas (Fig. 6 a, b; 7 a, Phase III). 


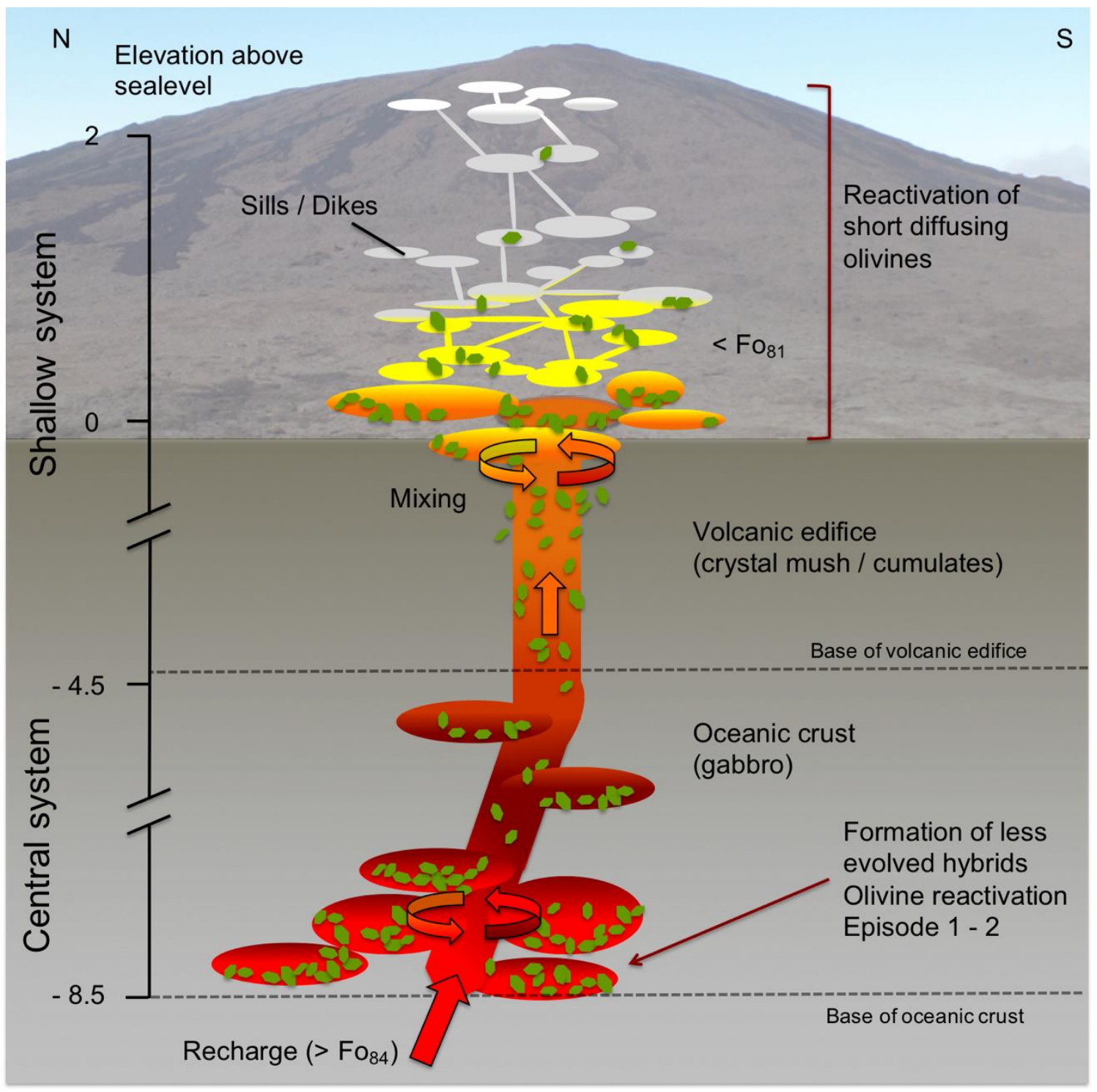

Fig. 8 Schematic drawing of the plumbing system beneath Piton de la Fournaise. The volcano is underlain by a sill and dyke system with batches of evolved magma down to sealevel. The plumbing system is periodical refilled by less evolved magmas that arise from depth and mix with shallower stored residuals. During 2014 - April 2015, this led to the formation of hybrid magmas and two reactivation episodes of olivine crystals from cumulates or crystal mush in the central plumbing system $(\sim 7.5 \mathrm{~km}$ bsl). These hybrids erupted after their ascent in mid-April 2015 during the large August-November 2015 eruption

In contrast to the decadal cycles identified by Vlastélic et al. (2018) in the signature of source magmas, our results show that the timescales of replenishment and magma transfer into the crustal plumbing system (as evidenced by deep eccentric seismicity in March-April 2014) up to the shallow system (mid-April 2015) can be significantly shorter (<2 yrs). Similar residence and mixing times and the documented links between compositional variations in olivine and their episodic reactivation from older crystal mushes in the magma reservoirs have also been observed for the major 2007 caldera-forming eruption at Piton de la Fournaise (Albert et al. 2019). However, the 
Timescales of magmatic processes during the eruptive cycle 2014-2015 at Piton de la Fournaise, La Réunion, obtained from $\mathrm{Mg}-\mathrm{Fe}$ diffusion modelling in olivine

distinct difference to this preceding 2007 eruption is that deep fissures allowed the escape and eruption of large magma volumes on the lower flanks of Piton de la Fournaise as olivine-rich lava flows that contained 50\% of olivine. Many of them crystallized at shallow depths just before ascent. Such massive lateral eruptions apparently can bypass resident, older shallow magma reservoirs and their crystal mushes through eruptions at the lower flank of the volcano. By contrast, the lowerintensity recharge before and during the eruptions of the 2014-2015 cycle studied here did mix and hybridize with older magmas stored in the central plumbing system.

\subsection{Conclusions}

The compositions, sequence and processes of magmas and their evolution in the magma plumbing system that fed the recent eruptions (2014/2015) at Piton de la Fournaise volcano have been reconstructed through time from compositions and diffusion modelling of zoned olivine crystals.

After 41 months of quiescence, a new eruptive cycle at PdF in June 2014 led up to the large August to November 2015 eruption. The broad compositional range of cores of olivine crystals analysed in this study $\left(\mathrm{Fo}_{73.2-85.1}\right)$ shows that magma recharge reactivated crystals from various older shallow reservoirs of different composition and probably variable crustal depths. This recharge triggered diffusive exchange and related zoning of the olivine crystals. The delay times between reactivation and eventual eruption in hybrid magmas was estimated from diffusion profiles: Olivine crystals of various core compositions were reactivated in at least two main episodes: (1) December 2013 to June 2014 and (2) November 2014 to May 2015. A third late reactivation episode is linked to the August-November 2015 eruption (Phases I and III).

Although the erupted products became increasingly evolved from June 2014 to May 2015, the olivine crystals that were erupted during July 2015 and August-November homogenized to more forsteritic compositions at the same time. The distinctly short diffusion times and evolved equilibrium composition of olivine crystals erupted during June 2014 and May 2015 indicate that the initially small eruptions at the beginning of an eruptive cycle primarily affect shallow stored evolved residual magmas and were possibly triggered by stress change related to deep magma ascent. The deep seismic crisis in April 2015 marks the transcrustal ascent of more mafic hybrid magmas that were stored over longer times in the central system (up to two years) and became reactivated only during larger and more intense eruptions (as during August-November 2015, Phases II and III). However, products from the eruption in July 2015 already contain olivine crystals with a large range of compositions and long diffusion times similar to the following voluminous August-November eruption and unlike the earlier smaller eruptions. Therefore, the July eruption represents the transition from early small eruptions of only shallow evolved magmas to the large August-November eruption, when more mafic magmas from the deeper central plumbing system 
were erupted. Phase I of August-November eruption started with evolved products that contained exclusively olivine crystals with short diffusion times that were reactivated immediately prior to the eruption. The eruption continued with olivine crystals that document long diffusion timescales in Phase II and the eruption of the "oldest" olivines at the beginning of Phase III that homogenized since December 2013. With the on-going final eruption, increasingly more mafic hybrids contained increasingly "younger" olivine crystals that had started to homogenize from July to October 2015. Finally, the three eruptive pulses of Phase III (October 16, 24, and 31) were completely dominated by the mafic recharge magma. These last eruptive pulses represent a "break-through" regime where new recharge magma has (almost) completely flushed the shallow plumbing system and erupts with little interaction with resident older magma batches and their contained crystals.

Our modelling of diffusion times in zoned olivine crystals allows to reconstruct magmatic activity within a plumbing system by linking timescales and chemical compositions of stored magmas to monitored geophysical and geochemical signals. The compositions of cores and diffusive margins of olivine crystals identify both magmas that are involved into and hybrid magmas resulting from mixing processes, which can be related via diffusion time modelling to the arrival of mafic recharge $\left(\mathrm{CO}_{2}\right.$ surface flux) and depth information (seismicity). Linking these techniques improves the understanding of periodically refilled plumbing systems in highly active basaltic systems like Piton de la Fournaise.

\section{Acknowledgements}

This research was funded by RFBR grant \# 16-55-12040 to B.G. and partially supported by DFG grant No Wo 362/51-1 to G.W.. A.D. was funded by ANR project "STRAP” ANR-14-CE03-0004STRAP. The fieldwork was supported by the Geo-Gender-Chancenfonds of the Georg-AugustUniversity Göttingen. We thank A. Kronz for the support at the electron microprobe and $\mathrm{K}$. Techmer for the assistance at the scanning electron microscope. The team of the OVPF collected the samples analysed in this study. Many thanks to R. Abart, and an anonymous reviewer, as well as editor C. Ballhaus for the reviews and constructive comments, which helped to improve the manuscript. 
Timescales of magmatic processes during the eruptive cycle 2014-2015 at Piton de la Fournaise, La Réunion, obtained from $\mathrm{Mg}-\mathrm{Fe}$ diffusion modelling in olivine

\section{References}

Albarède F, Luais B, Fitton G, Semet M, Kaminski E, Upton BGJ, Bachèlery P, Cheminée JL (1997) The geochemical regimes of Piton de la Fournaise volcano (Réunion) during the last 530000 years. J Petrol 38(2): 171-201. https://doi.org/10.1093/petroj/38.2.171

Albert H, Costa F, DiMuro A, Herrin J, Métrich N, Deloule E (2019) Magma interactions, crystal mush formation, timescales, and unrest during caldera collapse and lateral eruption at ocean island basaltic volcanoes (Piton de la Fournaise, La Réunion). Earth Planet Sci Lett 515: 187-199. https://doi.org/10.1016/j.epsl.2019.02.035

Boivin P, Bachèlery P (2009) Petrology of 1977 to 1998 eruptions of Piton de la Fournaise, La Réunion Island. J Volcanol Geotherm Res 184(1): 109-125. https://doi.org/10.1016/j.jvolgeores.2009.01.012

Boudoire G, Di Muro A, Liuzzo M, Ferrazzini V, Peltier A, Gurrieri S, Michon L, Giudice G, Kowalski P, Boissier P (2017) New perspectives on volcano monitoring in a tropical environment: Continuous measurements of soil $\mathrm{CO} 2$ flux at Piton de la Fournaise (La Réunion Island, France). Geophys Res Lett 44(16): 8244-8253. https://doi.org/10.1002/2017GL074237

Boudoire G, Brugier Y-A, Di Muro A, Wörner G, Arienzo I, Metrich M, Zanon V, Braukmüller N, Kronz A, Le Moigne Y, Michon L (2019) Eruptive activity on the western flank of Piton de la Fournaise (La Réunion Island, Indian Ocean): insights on magma transfer, storage and evolution at an oceanic volcanic island. J Petrol, egz045, https://doi.org/10.1093/petrology/egz045

Bradshaw RW, Kent AJR (2017) The analytical limits of modeling short diffusion times. Chem Geol 406: 667-677. https://doi.org/10.1016/j.chemgeo.2017.07.018

Bureau H, Métrich N, Pineau F, Semet MP (1998a) Magma-conduit interaction at Piton de la Fournaise volcano (Réunion Island): a melt and fluid inclusion study. J Volcanol Geotherm Res 84(1): 39-60. https://doi.org/10.1016/S0377-0273(98)00029-8

Bureau H, Pineau F, Métrich N, Semet MP, Javoy M (1998b) A melt and fluid inclusion study of the gas phase at Piton de la Fournaise volcano (Réunion Island). Chem Geol 147(1):115130. https://doi.org/10.1016/S0009-2541(97)00176-9 
Timescales of magmatic processes during the eruptive cycle 2014-2015 at Piton de la Fournaise, La Réunion, obtained from $\mathrm{Mg}$-Fe diffusion modelling in olivine

Bureau H, Métrich N, Semet MP, Staudacher T (1999) Fluid-magma decoupling in a hot-spot volcano. Geophys Res Lett 26(23):3501-3504. https://doi.org/10.1029/1999GL005422

Carslaw HS, Jaeger JC (1959) Conduction of heat in solids. 2nd edn. Clarendon Press, Oxford, p 510

Cashman KV, Giordano G (2014) Calderas and magma reservoirs. J Volcanol Geotherm Res 288:28-45. https://doi.org/10.1016/j.jvolgeores.2014.09.007

Chakraborty S (2010) Diffusion coefficients in olivine, wadsleyite and ringwoodite. Rev Mineral Geochem 72(1):603-639. https://doi.org/10.2138/rmg.2010.72.13

Cooper KM, Kent AJR (2014) Rapid remobilization of magmatic crystals kept in cold storage. Nature 506(7489):480-483. https://doi.org/10.1038/nature12991

Cooper KM, Sims KWW, Eiler JM, Banerjee N (2016) Timescales of storage and recycling of crystal mush at Krafla Volcano, Iceland. Contrib Mineral Petrol 171(6):54. https://doi.org/10.1007/s00410-016-1267-3

Coppola D, Di Muro A, Peltier A, Villeneuve N, Ferrazzini V, Favalli M, Bachèlery P, Gurioli L, Harris AJL, Moune S, Vlastélic I, Galle B, Arellano S, Aiuppa A (2017) Shallow system rejuvenation and magma discharge trends at Piton de la Fournaise volcano (La Réunion Island). Earth Planet Sci Lett 463:13-24. https://doi.org/10.1016/j.epsl.2017.01.024

Costa F, Chakraborty S (2004) Decadal time gaps between mafic intrusion and silicic eruption obtained from chemical zoning patterns in olivine. Earth Planet Sci Lett 227(3):517-530. https://doi.org/10.1016/j.eps1.2004.08.011

Costa F, Dungan M (2005) Short time scales of magmatic assimilation from diffusion modeling of multiple elements in olivine. Geology 33(10):837-840. https://doi.org/10.1130/g21675.1

Costa F, Chakraborty S, Dohmen R (2003) Diffusion coupling between trace and major elements and a model for calculation of magma residence times using plagioclase. Geochim Cosmochim Acta 67(12):2189-2200. https://doi.org/10.1016/S0016-7037(02)01345-5

Costa F, Coogan LA, Chakraborty S (2010) The time scales of magma mixing and mingling involving primitive melts and melt-mush interaction at mid-ocean ridges. Contrib Mineral Petrol 159(3):371-387. https://doi.org/10.1007/s00410-009-0432-3 
Timescales of magmatic processes during the eruptive cycle 2014-2015 at Piton de la Fournaise, La Réunion, obtained from $\mathrm{Mg}-\mathrm{Fe}$ diffusion modelling in olivine

Di Muro A, Métrich N, Vergani D, Rosi M, Armienti P, Fougeroux T, Deloule E, Arienzo I, Civetta L (2014) The shallow plumbing system of Piton de la Fournaise volcano (la Réunion island, Indian ocean) revealed by the major 2007 caldera-forming eruption. J Petrol 55(7):12871315. https://doi.org/10.1093/petrology/egu025

Di Muro A, Staudacher T, Ferrazzini V, Métrich N, Besson P, Garofalo C, Villemant B (2014) Shallow magma storage at Piton de la Fournaise volcano after 2007 summit caldera collapse tracked in Pele's hairs. In: Carey R, Cayol V, Poland M, Weis D (eds) Hawaiian volcanoes: from source to surface. Geophysical Monograph Series, pp 189-212. https://doi.org/10.1002/9781118872079.ch1

Di Muro A, Métrich N, Allard P, Aiuppa A, Burton M, Galle B, Staudacher T (2016) Magma degassing at Piton de la Fournaise volcano. In: Bachelery P, Lenat J-F, Di Muro A, Michon L (eds) Active volcanoes of the southwest Indian Ocean: Piton de la Fournaise and Karthala. Springer-Verlag, Berlin Heidelberg, pp 203-222. https://doi.org/10.1007/978-3642-31395-0_12

Girona T, Costa F (2013) DIPRA: A user-friendly program to model multi-element diffusion in olivine with applications to timescales of magmatic processes. Geochem Geophys Geosyst 14(2):422-431. https://doi.org/10.1029/2012GC004427

Gordeychik B, Churikova T, Kronz A, Sundermeyer C, Simakin A, Wörner G (2018) Growth of, and diffusion in, olivine in ultra-fast ascending basalt magmas from Shiveluch volcano. Sci Rep 8(11775):1-15. https://doi.org/10.1038/s41598-018-30133-1

Gurioli L, Di Muro A, Vlastélic I, Moune S, Thivet S, Valer M, Villeneuve N, Boudoire G, Peltier A, Bachèlery P, Ferrazzini V, Métrich N, Benbakkar M, Cluzel N, Constantin C, Devidal JL, Fonquernie C, Hénot JM (2018) Integrating field, textural, and geochemical monitoring to track eruption triggers and dynamics: a case study from Piton de la Fournaise. Solid Earth 9(2):431-455. https://doi.org/10.5194/se-9-431-2018

Hartley ME, Morgan DJ, Maclennan J, Edmonds M, Thordarson T (2016) Tracking timescales of short-term precursors to large basaltic fissure eruptions through Fe-Mg diffusion in olivine. Earth Planet Sci Lett 439:58-70. https://doi.org/10.1016/j.eps1.2016.01.018

Helz RT, Thornber CR (1987) Geothermometry of Kilauea Iki lava lake, Hawaii. Bull Volcanol 49(5):651-668. https://doi.org/10.1007/bf01080357 
Timescales of magmatic processes during the eruptive cycle 2014-2015 at Piton de la Fournaise, La Réunion, obtained from $\mathrm{Mg}$-Fe diffusion modelling in olivine

Kahl M, Chakraborty S, Costa F, Pompilio M (2011) Dynamic plumbing system beneath volcanoes revealed by kinetic modeling, and the connection to monitoring data: An example from Mt. Etna. Earth Planet Sci Lett 308(1):11-22. https://doi.org/10.1016/j.epsl.2011.05.008

Kahl M, Chakraborty S, Costa F, Pompilio M, Liuzzo M, Viccaro M (2013) Compositionally zoned crystals and real-time degassing data reveal changes in magma transfer dynamics during the 2006 summit eruptive episodes of Mt. Etna. Bull Volcanol 75(2):692. https://doi.org/10.1007/s00445-013-0692-7

Kahl M, Chakraborty S, Pompilio M, Costa F (2015) Constraints on the nature and evolution of the magma plumbing system of Mt. Etna volcano (1991-2008) from a combined thermodynamic and kinetic modelling of the compositional record of minerals. J Petrol 56(10):2025-2068. https://doi.org/10.1093/petrology/egv063

Lénat JF, Bachèlery P (1990) Structure et fonctionnement de la zone centrale du Piton de la Fournaise. In: Lénat JF (ed) Le Volcanisme de la Réunion. Centre de Recherches $\begin{array}{llll}\text { Volcanologiques, } & \text { Clermont-Ferrand, } & \text { 257-296. }\end{array}$ https://www.researchgate.net/publication/260289059

Lengliné O, Duputel Z, Ferrazzini V (2016) Uncovering the hidden signature of a magmatic recharge at Piton de la Fournaise volcano using small earthquakes. Geophys Res Lett 43(9):4255-4262. https://doi.org/10.1002/2016GL068383

Liuzzo M, Di Muro A, Giudice G, Michon L, Ferrazzini V, Gurrieri S (2015) New evidence of CO2 soil degassing anomalies on Piton de la Fournaise volcano and the link with volcano tectonic structures. Geochem, Geophys, Geosyst 16(12):4388-4404. https://doi.org/10.1002/2015GC006032

Magee C, Stevenson CTE, Ebmeier SK, Keir D, Hammond JOS, Gottsmann JH, Whaler KA, Schofield N, Jackson CAL, Petronis MS, O’Driscoll B, Morgan J, Cruden A, Vollgger SA, Dering G, Micklethwaite S, Jackson MD (2018) Magma plumbing systems: a geophysical perspective. J Petrol 59(6):1217-1251. https://doi.org/10.1093/petrology/egy064

Marsh BD (2006) Dynamics of magmatic systems. Elements 2, 287-292. https://doi.org/10.2113/gselements.2.5.287 
Timescales of magmatic processes during the eruptive cycle 2014-2015 at Piton de la Fournaise, La Réunion, obtained from $\mathrm{Mg}-\mathrm{Fe}$ diffusion modelling in olivine

Morgan DJ, Blake S, Rogers NW, DeVivo B, Rolandi G, Macdonald R, Hawkesworth CJ (2004) Time scales of crystal residence and magma chamber volume from modelling of diffusion profiles in phenocrysts: Vesuvius 1944. Earth Planet Sci Lett 222(3):933-946. https://doi.org/10.1016/j.epsl.2004.03.030

Nercessian A, Hirn A, Lépine J-C, Sapin M (1996) Internal structure of Piton de la Fournaise volcano from seismic wave propagation and earthquake distribution. J Volcanol Geotherm Res 70(3):123-143. https://doi.org/10.1016/0377-0273(95)00042-9

Oeser M, Dohmen R, Horn I, Schuth S, Weyer S (2015) Processes and time scales of magmatic evolution as revealed by $\mathrm{Fe}-\mathrm{Mg}$ chemical and isotopic zoning in natural olivines. Geochim Cosmochim Acta 154:130-150. https://doi.org/10.1016/j.gca.2015.01.025

Oeser M, Ruprecht P, Weyer S (2018) Combined Fe-Mg chemical and isotopic zoning in olivine constraining magma mixing-to-eruption timescales for the continental arc volcano Irazú (Costa Rica) and $\mathrm{Cr}$ diffusion in olivine. Am Mineral 103(4):582-599. https://doi.org/10.2138/am-2018-6258

Peltier A, Bachèlery P, Staudacher T (2009) Magma transport and storage at Piton de La Fournaise (La Réunion) between 1972 and 2007: A review of geophysical and geochemical data. J Volcanol Geotherm Res 184(1):93-108. https://doi.org/10.1016/j.jvolgeores.2008.12.008

Peltier A, Beauducel F, Villeneuve N, Ferrazzini V, Di Muro A, Aiuppa A, Derrien A, Jourde K, Taisne B (2016) Deep fluid transfer evidenced by surface deformation during the 20142015 unrest at Piton de la Fournaise volcano. J Volcanol Geotherm Res 321:140-148. https://doi.org/10.1016/j.jvolgeores.2016.04.031

Pichavant M, Brugier Y, Di Muro A (2016) Petrological and experimental constraints on the evolution of Piton de la Fournaise magmas. In: Bachelery P, Lenat J-F, Di Muro A, Michon L (eds) Active volcanoes of the southwest Indian Ocean: Piton de la Fournaise and Karthala. Springer-Verlag, Berlin Heidelberg, pp 171-184. https://doi.org/10.1007/978-3$\underline{642-31395-0 \_10}$

Prior DJ, Boyle AP, Brenker F, Cheadle MC, Day A, Lopez G, Peruzzi L, Potts G, Reddy S, Spiess R, Timms NE, Trimby P, Wheeler J, Zetterstrom L (1999) The application of electron backscatter diffraction and orientation contrast imaging in the SEM to textural problems in rocks. Am Mineral 84(11-12):1741-1759. https://doi.org/10.2138/am-1999-11-1204 
Timescales of magmatic processes during the eruptive cycle 2014-2015 at Piton de la Fournaise, La Réunion, obtained from $\mathrm{Mg}$-Fe diffusion modelling in olivine

Prôno E, Battaglia J, Monteiller V, Got J-L, Ferrazzini V (2009) P-wave velocity structure of Piton de la Fournaise volcano deduced from seismic data recorded between 1996 and 1999. J Volcanol Geotherm Res 184(1):49-62. https://doi.org/10.1016/j.jvolgeores.2008.12.009

Putirka KD (2008) Thermometers and barometers for volcanic systems. Rev Mineral Geochem 69(1):61-120. https://doi.org/10.2138/rmg.2008.69.3

Rae ASP, Edmonds M, Maclennan J, Morgan D, Houghton B, Hartley ME, Sides I (2016) Time scales of magma transport and mixing at Kīlauea Volcano, Hawai'i. Geology 44(6):463466. https://doi.org/10.1130/G37800.1

Roult G, Peltier A, Taisne B, Staudacher T, Ferrazzini V, Di Muro A, the OVPF team (2012) A new comprehensive classification of the Piton de la Fournaise activity spanning the 19852010 period. Search and analysis of short-term precursors from a broad-band seismological station. J. Volcanol. Geotherm. Res 241-242, 78-104. https://doi.org/10.1016/j.jvolgeores.2012.06.012

Ruth DCS, Costa F, Bouvet de Maisonneuve C, Franco L, Cortés JA, Calder ES (2018) Crystal and melt inclusion timescales reveal the evolution of magma migration before eruption. Nat Commun 9(2657):1-9. https://doi.org/10.1038/s41467-018-05086-8

Salaün A, Villemant B, Semet MP, Staudacher T (2010) Cannibalism of olivine-rich cumulate xenoliths during the 1998 eruption of Piton de la Fournaise (La Réunion hotspot): Implications for the generation of magma diversity. J Volcanol Geotherm Res 198(1):187204. https://doi.org/10.1016/j.jvolgeores.2010.08.022

Saunders K, Blundy J, Dohmen R, Cashman K (2012) Linking petrology and seismology at an active volcano. Science 336(6084):1023-1027. https://doi.org/10.1126/science.1220066

Staudacher T, Peltier A (2016) Ground deformation at Piton de la Fournaise, a review from 20 years of GNSS monitoring. In: Bachelery P, Lenat J-F, Di Muro A, Michon L (eds) Active volcanoes of the southwest Indian Ocean: Piton de la Fournaise and Karthala. SpringerVerlag, Berlin Heidelberg, pp 251-269. https://doi.org/10.1007/978-3-642-31395-0_15

Ubide T, Kamber BS (2018) Volcanic crystals as time capsules of eruption history. Nat Commun 9(326):1-12. https://doi.org/10.1038/s41467-017-02274-w 
Timescales of magmatic processes during the eruptive cycle 2014-2015 at Piton de la Fournaise, La Réunion, obtained from $\mathrm{Mg}-\mathrm{Fe}$ diffusion modelling in olivine

Viccaro M, Giuffrida M, Nicotra E, Cristofolini R (2016) Timescales of magma storage and migration recorded by olivine crystals in basalts of the March-April 2010 eruption at Eyjafjallajökull volcano, Iceland. Am Mineral 101(1):222-230. https://doi.org/10.2138/am-2016-5365

Vlastélic I, Di Muro A, Bachèlery P, Gurioli L, Auclair D, Gannoun A (2018) Control of source fertility on the eruptive activity of Piton de la Fournaise volcano, La Réunion. Sci Rep 8(14478):1-7. https://doi.org/10.1038/s41598-018-32809-0

Wand MP, Jones MC (1995) Kernel Smoothing. Chapman \& Hall/CRC, pp. 3-7.

Zellmer GF, Blake S, Vance D, Hawkesworth C, Turner S (1999) Plagioclase residence times at two island arc volcanoes (Kameni Islands, Santorini, and Soufriere, St. Vincent) determined by $\mathrm{Sr}$ diffusion systematics. Contrib Mineral Petrol 136(4):345-357. https://doi.org/10.1007/s004100050543

Zellmer GF, Sparks RSJ, Hawkesworth CJ, Wiedenbeck M (2003) Magma emplacement and remobilization timescales beneath Montserrat: insights from $\mathrm{Sr}$ and $\mathrm{Ba}$ zonation in $\begin{array}{lllll}\text { plagioclase } & \text { phenocrysts. } & \text { J } & \text { Petrol }\end{array}$ https://doi.org/10.1093/petrology/44.8.1413 


\title{
4 Timescales from magma mixing to eruption in alkaline volcanism in the Eifel volcanic fields, western Germany
}

\author{
Caren Sundermeyer ${ }^{1}$, Gerhard Wörner ${ }^{1}$, Jochen Gätjen ${ }^{1}$, and Lena Weimann ${ }^{1}$ \\ ${ }^{1}$ Geowissenschaftliches Zentrum, Georg-August Universität, Göttingen, Germany \\ * Correspondence and requests for materials should be addressed to C.S. (email: csunder@gwdg.de)
}

\subsection{Abstract}

Diffusion profiles in olivine crystals from the final mafic eruption products of the compositionally zoned tephra deposit were measured to identify recharge and eruption-triggering events prior to the eruption of the Laacher See volcano (12.9 kyr). These products represent the hybrid of mixing between phonolite and intruding basanite at the bottom of the reservoir, which is likely related to the eruption-triggering event. Additionally, olivine crystals from ten basanitic scoria cones and maar deposits (East Eifel) and two nephelinites (West Eifel) were analyzed to constrain histories of olivine in Quaternary basanite magmas. Olivine crystals from the Laacher See hybrids vary in core composition (Fo83-89) and show reversely zoned rims with relatively high Fo87.8-89 compared to olivine in East Eifel basanites erupted in nearby, older scoria cones. Towards the crystal margin, olivine in the hybrids develop a normally zoned overgrowth (Fo $86.5-87.5)$. Olivine from East Eifel basanites show similar zonation and core compositions (Fo80-88) but less forsteritic rims (Fo83-88) indicating that these basanites are less primitive than those recharging the Laacher See reservoir $\left(>\mathrm{Fo}_{89}\right)$. Olivine in the West Eifel nephelinites show rims similar to those from Laacher See (Fo ${ }_{87.5-}$ 90), but have normal zoning and high-Fo cores $\left(\mathrm{Fo}_{88-92}\right)$. This indicates that olivine in the Laacher See hybrids originate from cumulates entrained by a near-primary basanite before hybridization with the phonolite. Diffusion modeling indicate timescales between entrainment and eruption of Laacher See of only months. These timescales are remarkably shorter than those calculated for olivine from basanitic cones (up to 500 days).

\section{Keywords}

Olivine, zoning, timescales, diffusion, mixing 


\section{Declaration}

Funding: This research was funded by department funds of Abteilung Geochemie, GZG, Universität Göttingen.

Conflicts of interest/Competing interests: The authors declare no competing interests.

\subsection{Introduction}

The mitigation of potentially violent eruptions of evolved magmatic systems necessitate a better understanding of the pre-eruptive processes, how fast magmas ascend, and how fast resident magmatic systems can reactivate and erupt. Many recent studies focus on linking the chemical evolution of magmatic systems to the related timescales (e.g. Albert et al. 2015, 2016, 2019; Kahl et al. 2011, 2013; Viccaro et al. 2016; Rasmussen et al. 2018; Ubide and Kamber 2018). It was shown that the interaction of ascending mafic magmas with more evolved melts and crystal mush are a common process in many volcanic systems (e.g. Bachmann and Bergantz 2004; Marsh 2006; Hildreth and Wilson 2007). Mafic recharges and subsequent magma mixing are major factors in destabilizing magmatic systems and potentially triggering eruptions (e.g. Sparks et al. 1977; Murphy et al. 2000; Eichelberger et al. 2006; Wark et al. 2007; Ruprecht and Plank 2013; Cashman and Giordano 2014). These processes are preserved in chemically zoned crystals, either phenocrysts from the recharging magmas or antecrysts disaggregated from older crystal mush. Crystal zoning provides information about chemical compositions of the interacting magmas and the timescales between this interaction and eruption. After the entrainment by a foreign magma, the crystals start to homogenize with the new composition to reach equilibrium. This diffusion process will endure until (1) the crystal is completely homogenized or (2) the process is interrupted by cooling (e.g. eruption). If diffusion remains incomplete, the compositional gradient between crystal core and rim (in equilibrium with the new melt) can be modeled to constrain the timescales of diffusion, to track the relative periods of time between distinct magmatic events (e.g. magma mixing and eruption; e.g. Costa and Dungan 2005; Cooper and Kent 2014) and reconstruct the temperature history of crystal residence (Rubin et al. 2017; Rout and Wörner 2018). Diffusion of major and trace elements in olivine occurs in the range of hours to years and is therefore useful to identify processes that are directly connected to eruptions (e.g. Costa and Chakraborty 2004; Costa and Dungan 2005; Kahl et al. 2011, 2013; Lynn et al. 2018; Bradshaw et al. 2018; Gordeychik et al. 2018; Albert et al. 2015, 2016, 2019; Mutch et al. 2019; Sundermeyer et al. 2020).

Magma ascent is often connected with the disaggregation of older, but cognate crystal mushes and/or mixing with more evolved magmas stored at shallower levels (e.g. Cooper et al. 2016). Recent studies show that mixing and eruption in basaltic magma systems can occur within days to 
months (e.g. Viccaro et al. 2016; Brenna et al. 2018; Lynn et al. 2018; Albert et al. 2019; Sundermeyer et al. 2020). Even large and compositionally evolved, silicic systems can also yield timescales of only a few years between recharge events and eruption, which is an exceedingly short time for reactivation of these long-lived systems (Cooper and Kent 2014; Cooper et al. 2016; Druitt et al. 2012, 2016).

In this study, diffusion times of olivine crystals from the Laacher See in the East Eifel volcanic field (western Germany) are calculated to track the timing of pre-eruptive processes and recharge times in a phonolitic magma chamber prior to eruption. The olivine crystals analyzed here are antecrysts released from basanitic crystal mush before mafic recharge and mixing with a phonolite magma. Major $(\mathrm{Mg}-\mathrm{Fe})$ and trace elements $(\mathrm{Mn}, \mathrm{Ca}, \mathrm{Ni})$ were chosen to model residence times in the hybrid phonolite + basanite mingled/mixed magmas that formed at the bottom of the magma chamber within the upper crust (Wörner and Wright 1984). Furthermore, in order to constrain ascent rates of such basanite magmas from deep to shallow reservoirs, olivine crystals from basanitic scoria cones of the East Eifel and, for comparison, nephelinitic maar deposits of the West Eifel, were also analyzed to determine their magmatic history before eruption and, by analogy, with respect to mixing with the phonolite magma reservoir at Laacher See volcano.

\subsection{Geological setting}

\subsubsection{Eifel volcanic field}

The Quaternary Eifel alkaline intra-plate volcanic fields are located in the Rhenish Massif, western Germany. The Eifel belongs to the Central European Volcanic Zone, a belt of Cenozoic volcanic centers, that extends in SW-NE direction from the Massif Central and the Rhine Graben towards the Rhenish Massif (Michon and Merle 2001; Nowell et al. 2006). In the Eifel, a first phase of volcanism occurred at 44-40 / 38-34 Ma in the Hocheifel (Fekiacova et al. 2003; Jung et al. 2006), where alkaline magmas as basanites, nephelinites, and alkali basalts were erupted (Jung et al. 2006). A second phase of younger volcanic activity took place during the Quaternary and can be related to a thermal anomaly of $150-200{ }^{\circ} \mathrm{C}$ higher than ambient temperatures in the asthenospheric mantle (Ritter et al. 2001; Nowell et al. 2006). The regions of Quaternary volcanism subdivide into the older West Eifel and the younger East Eifel volcanic field (WEVF and EEVF; Fig. 1a). The WEVF consists of 240 eruptive centers, mostly scoria cones and maars (Duda and Schmincke 1985; Mertes \& Schmincke 1985). In the WEVF, eruptive activity lasted from $0.7 \mathrm{Ma}$ to $0.01 \mathrm{Ma}$ (Mertes and Schmincke 1985). Volcanism in the EEVF started at 0.46 Ma, the most recent eruption occurred at Ulmener Maar at $11 \mathrm{kyr}$ BP (Schmincke 2007). West Eifel volcanic products are dominated by high-K magmas such as leucitite, nephelinite and basanite (Mertes and Schmincke 1985). The East Eifel is divided into two subfields: a north-western part close to the oldest volcanic center Rieden 
( 430-460 kyr; Schmincke 2007) that produced phonolitic, leucititic and nephelinitic magmas and a younger, south-eastern field (starting at 215-190 kyr at Wehr volcano, Wörner et al. 1988; Schmincke 2007). The SE field is dominated by basanitic and tephritic scoria cones and maars (Duda and Schmincke 1978; Bednarz and Schmincke 1990; Schmincke 2007). More evolved phonolitic products were erupted at three main locations: Rieden, Wehr, and Laacher See (Schmincke 2007; Wörner et al. 1988).

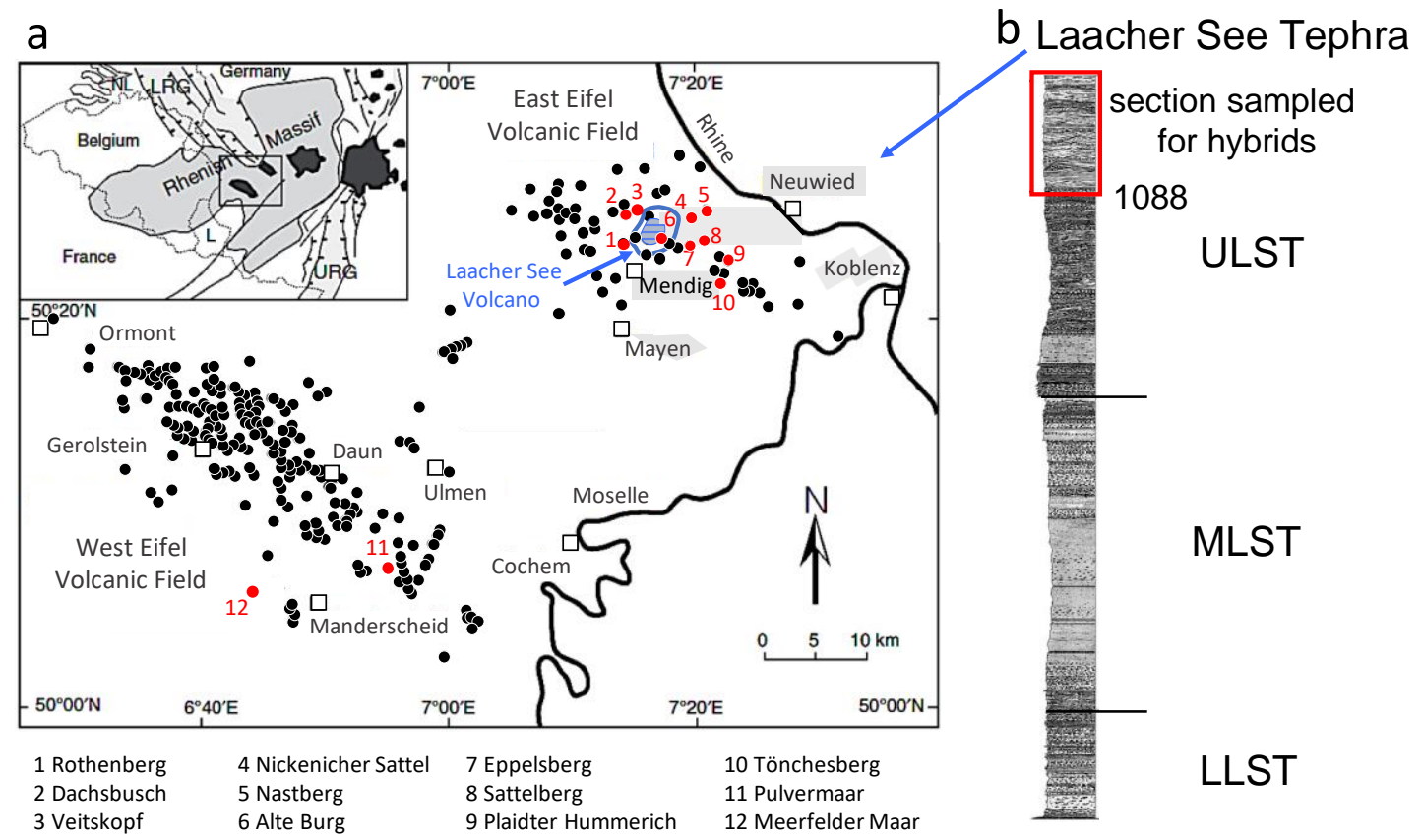

Fig. 1 (a) Map of the Eifel Volcanic Field (redrawn and modified after Mertes 1983). Black dots show eruptive centers, red dots mark sample locations. (b) Stratigraphy of the Laacher See Tephra (modified after Ginibre et al. 2004). The samples origin from the finally erupted mafic hybrids at the top of the ULST (>1088) marked by the red box. Inset show location of the volcanic fields in relation to the uplifted Rhenish Shield and the Upper and Lower Rhine Graben (URG, LRG).

\subsubsection{Laacher See volcano - chemical evolution and eruption}

Laacher See volcano is located in the center of the East Eifel volcanic field to the west of the Neuwied Basin (van den Bogaard and Schmincke 1984; Schmincke et al. 1999; Schmincke 2007). The magmatic reservoir of Laacher See consists of a magma chamber with its top located at $~ 3-6$ $\mathrm{km}$ depth as indicated by pressure estimates based on experimental phase equilibria (Berndt et al. 2001; Harms et al. 2004; Wörner 1982; Wörner and Schmincke 1984b) and xenolith evidence (Wörner et al. 1982; van den Bogaard and Schmincke 1984). The magma chamber is interpreted to be embedded in cumulates (Tait et al. 1989) and a carapace of cogenetic syenitic rocks that contain 
interstitial phonolitic melt (Rout and Wörner 2018). This magmatic system is emplaced into sedimentary country rocks of the Lower Devonian and reaches down to phyllites and metamorphic schists (Wörner et al. 1982; van den Bogaard and Schmincke 1984).

The eruption of Laacher See occurred $12.880 \pm 0.040 \mathrm{kyr}$ BP (tephra in varved lake sequences, e.g. Brauer et al. 1999a; Lane et al. 2015; Bronk Ramsey et al. 2015), an age that overlaps with a ${ }^{14} \mathrm{C}$ age of $12.934 \pm 0.165 \mathrm{kyr}$ BP (Baales et al. 2002). The eruption was one of the last recorded in the EVF except of the younger eruption of Ulmener Maar at $11 \mathrm{kyr}$ BP (Schmincke 2007). Within days to weeks, the volcano released about $6.3 \mathrm{~km}^{3}$ (DRE) of volcanic products (van den Bogaard and Schmincke 1985). It was the largest eruption in Europe during the late Quaternary and dispersed over $20 \mathrm{~km}^{3}$ of pumice and ash over $>230000 \mathrm{~km}^{2}$ of central Europe (van den Bogaard and Schmincke 1985; Baales et al. 2002; Engels et al. 2015). The Laacher See tephra (LST) was deposited to the east-northeast, south and, at the very end of the eruption, south to west of the volcano (van den Bogaard and Schmincke 1985; van den Bogaard 1995). Evolution and structure of the magmatic reservoir are well constrained by numerous studies on the erupted volcanic products (Wörner and Schmincke 1984a, b; Wörner and Wright 1984; Wörner et al. 1985; Tait et al. 1989; Bourdon et al. 1994; van den Bogaard 1995; Harms and Schmincke 2000; Berndt et al. 2001; Ginibre et al. 2004; Schmitt 2006; Schmitt et al. 2010; Rout and Wörner 2018). The compositionally and texturally stratified LST deposits as described by Wörner and Schmincke (1984a) are subdivided into three main units: Lower, Middle, and Upper Laacher See tephra (LLST, MLST, and ULST, based on Schmincke 1977; Fig. 1b). The LLST and MLST are characterized by highly evolved and crystal-poor $(<10 \%)$ phonolite. Towards the top of the deposit, crystal content increases to up to $>50 \%$ in the uppermost layers. Simultaneously, magmatic compositions become less evolved towards a more mafic phonolite at the uppermost ULST. These observations indicate that the LST represents the content of an inversely erupted, chemically zoned magma chamber. Mass balance arguments based on major and trace element modeling of magmatic differentiation suggest that the $\approx 6 \mathrm{~km}^{3}$ of zoned phonolite magma formed from about ten times the volume of parent basanite by crystal fractionation (Wörner and Schmincke 1984a, b). The formation times of the Laacher See phonolite are still discussed. Bourdon et al. (1994), based on U-Th disequilibria, document a two-step formation over a period of $\sim 100 \mathrm{kyr}$ by differentiation from an originally primitive basanite to mafic phonolite and additional 10-20 kyr towards a more evolved phonolite after emplacement in the shallow crust. The chemical zonation within the phonolite magma reservoir formed likely as result of convective fractionation within the differentiating magma body, as evidenced from studies on the composition of cumulate nodules (Tait et al. 1989) and zoned sanidine (Ginibre et al. 2004). The timescales necessary to produce the compositional layering are within a range of $\sim 3 \mathrm{kyr}$ (Tait et al. 1989) which is largely consistent with the 10-20 kyr of total 
residence time for phonolite magmas in the Laacher See magma system (Bourdon et al. 1994; Schmitt 2006; Schmitt et al. 2010).

The eruption of crystal-rich mafic phonolite towards top of the ULST represents the lower parts of the magma chamber. The last material in the eruption sequence are compositionally heterogeneous mafic clasts with a disequilibrium mineralogy of olivine, Mg-rich clinopyroxene megacrysts, phlogopite sanidine, and the entire range of phenocrysts also observed in the crystal-rich phonolite. These hybrids are interpreted to have formed by mixing and mingling between phonolite magma, cumulate minerals and an intruding basanite (Wörner and Schmincke 1984a, b; Wörner and Wright 1984, Wörner et al. 1985). The event of basanitic recharge was suggested to have been immediately prior to the eruption, as indicated from the incomplete mixing and the occurrence of hybrid magmas only in the lowermost part of the reservoir and thin post-mixing overgrowths on resorbed basanitic clinopyroxene crystals (Wörner and Wright 1984). These authors interpret the mixing therefore as a result rather than the trigger of eruption.

\subsection{Samples and analytical methods}

\subsubsection{Sample description}

This study focuses on olivine in samples from the most mafic hybrid products (phonolite + basanite) from the uppermost part of the Laacher See tephra deposit (Fig. 1a, b) in order to constrain the time scale of mixing/mingling to eruption of the phonolite magma reservoir. The analyzed material covers 47 olivine crystals from nine samples from the mafic hybrids of the ULST (Upper Laacher See hybrids, ULSH). To further study the ascent times for such mafic magmas from their sources at deep (upper mantle / lower crustal) levels towards the shallow crust and to the surface, 21 samples from ten basanitic scoria cones and maar deposits in the East Eifel (Alte Burg = AB, Dachsbusch $=$ HDA, Eppelsberg $=$ EPB, Nastberg $=$ NAS, Nickenicher Sattel $=$ NISA, Plaidter Hummerich PLH, Rothenberg = E41, Sattelberg = SAT, Tönchesberg =TÖN, and Veitskopf =VEI), and five samples from two locations in the West Eifel (Meerfelder Maar at Deudesfeld $=$ DEU, Pulvermaar $=$ PUL) were also analyzed (Fig. 1a).

\subsubsection{Laacher See hybrids}

Upper Laacher See hybrid clasts represent sample 1089 to the most mafic 1101-3 with MgOcontents of 1.0 to 6.9 wt. \% (whole rock sample numbers and data from Wörner and Schmincke 1984a; Wörner and Wright, 1984). The samples were obtained from the last, uppermost section of the ULST (Fig. 1b) and cover (1) relatively homogeneous pumiceous hybrids which are similar to ULST phonolites with respect to their mineral content dominated by sanidine and plagioclase, with 
minor amounts of amphibole, clinopyroxene, phlogopite, magnetite and sphene. However, these samples also contain forsterite-rich olivine with Cr-spinel inclusions (LSH-1, -2, -3). More mafic hybrids (2) are less vesicular, often compositionally heterogeneous on a cm scale with crystal-rich schlieren in dark dense mafic clasts that contain olivine and clinopyroxene megacrysts (LS-A, LSB, ULSH-1, -2; Wörner and Wright, 1984; Wörner and Schmincke 1984a). Olivine either occur as euhedral crystals up to $8 \mathrm{~mm}$ in size, with some having resorption with a late skeletal overgrowth (Fig. 2a). Groundmass olivine ( $<50 \mu \mathrm{m})$ are observed in all Laacher See hybrid lava samples and show either resorption similar to the macrocrysts or a reaction corona of clinopyroxene.

\subsubsection{Mafic magmas from scoria cones and maar deposits in the East and West Eifel}

Basanite and nephelinite samples include lava and dikes (E41, EPB-D, and SAT-3) as well as agglutinates from Eppelsberg, Plaidter Hummerich, and Sattelberg scoria cones that cover their eruptive sequence and compositional variations from the base to the last erupted products. The samples have a low-vesicular to dense ( $<10$ Vol.\% vesicles, except of PLH-3 with 20 Vol.\%), porphyric texture with brownish zoned clinopyroxene ( $<15 \mathrm{Vol} . \%$ ), olivine (up to $5 \mathrm{Vol} . \%$ ) and rare phlogopite as main phenocrysts. Olivine phenocrysts are euhedral to subhedral, but have commonly resorbed outer grain boundaries (Fig. 2b). Rare olivine-rich mantle-derived xenoliths, partially with a clinopyroxene reaction corona, occur in samples from Rothenberg, Nickenicher Sattel, Sattelberg, and Tönchesberg. From the West Eifel, we also collected a mafic crystal cumulate (PUL-2) and mantle-derived peridotite nodules as well as juvenile melilite-nephelinite clasts from, respectively, the Pulvermaar and Meerfelder Maar tephra deposit (see Mertes and Schmincke 1985; Duda and Schmincke 1985 for bulk lava compositions). 


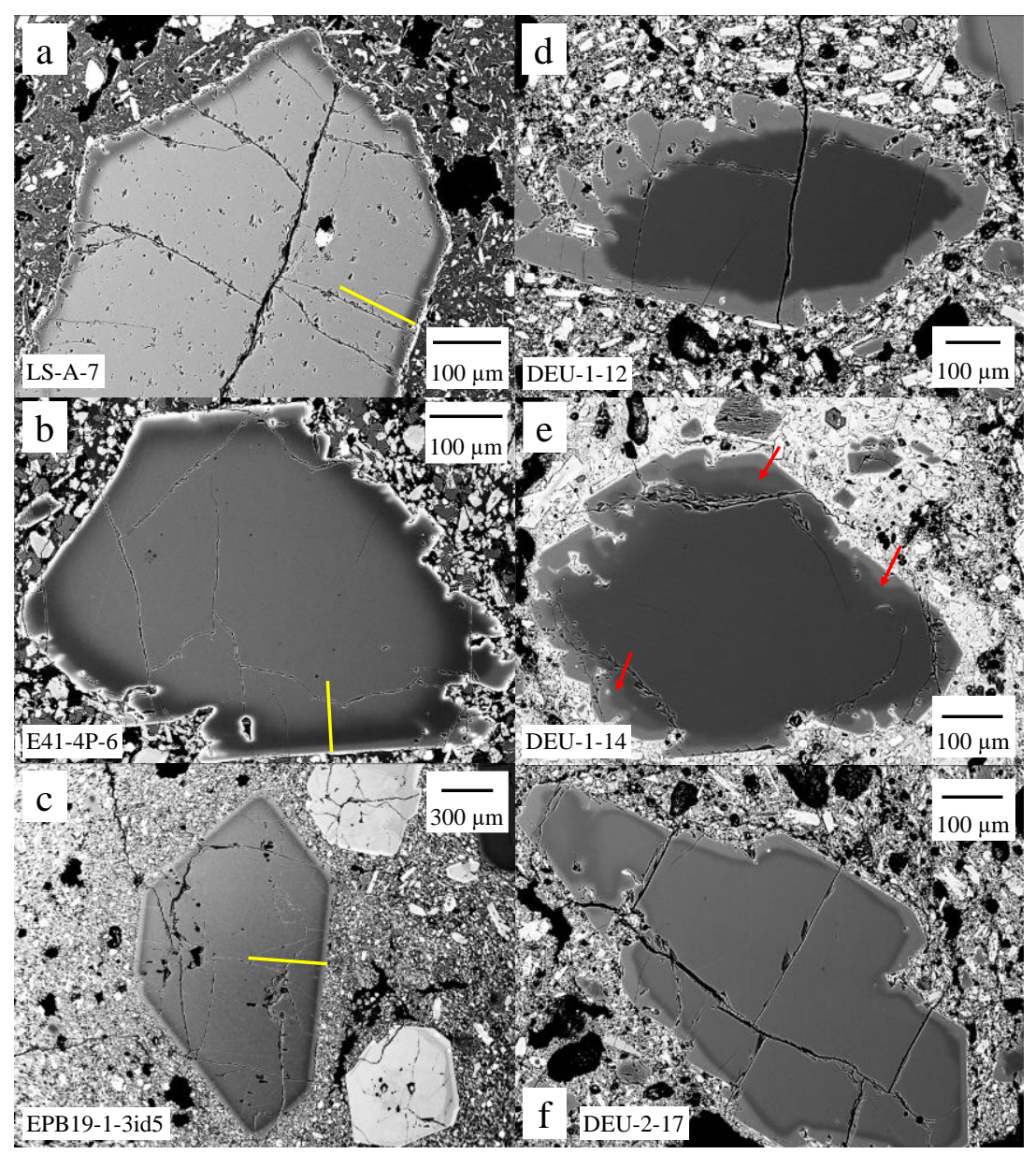

Fig. 2 Back-scattered electron (BSE) images of representative olivine crystals from the samples from Laacher See (a), Rothenberg (b), Eppelsberg (c), and Meerfelder Maar (d-f). Olivine from Rothenberg and Eppelsberg show the complex reverse zoning (reverse-normal) that is typical for all olivine crystals from the East Eifel samples. Yellow lines mark measured line profiles (see Fig. 4a, b). Olivine from Meerfelder Maar samples reveal the normal zoned high-Fo cores that dominate the samples from the West Eifel. Red arrows mark the rarely observed normal-normal zoning with two steps. DEU-2-17 shows a rare reverse-normal zoning as usually found in olivine crystals from the East Eifel samples.

\subsubsection{Mineral analyses}

Electron microprobe analyses were performed using the JEOL JXA 8900RL instrument at the Geoscience Center, Georg-August-University, Göttingen. Major ( $\mathrm{Si}, \mathrm{Mg}, \mathrm{Fe}$ ) and trace elements ( $\mathrm{P}, \mathrm{Al}, \mathrm{Cr}, \mathrm{Mn}, \mathrm{Ca}, \mathrm{Ni}, \mathrm{Co}$, and $\mathrm{Zn}$ ) were measured at conditions similar to those described in Gordeychik et al. (2018): Counting times were set to $15 / 5 \mathrm{~s}$ for peak/background of the major elements, 60/30 s for Mn, 120/60 s for Ca, Cr, and Zn, 180/90 s for Co, 260/130 s for $\mathrm{Ni}$ and $\mathrm{Al}$, and $300 / 150 \mathrm{~s}$ for P. Accelerating voltage was set to $20 \mathrm{keV}$ with a beam current of $300 \mathrm{nA}$ and a beam focused to $1 \mu \mathrm{m}$. The extended counting times and high beam current result in $2 \sigma$ uncertainties of $<1 \%$ for the major elements, $<2 \%$ for $\mathrm{Ca}, \mathrm{Mn}$, and $\mathrm{Ni}$, and $<4 \%$ for $\mathrm{Al}$. 
Uncertainties for are 9-12\% for Co and 6-10\% for P, but can reach up to $20 \%$ in olivine crystals with $\mathrm{P}<0.01$ wt.\%. $\mathrm{Zn}$ and $\mathrm{Cr}$ have uncertainties of $10-40 \%$ and $10-70 \%$ due to their low concentration close to the detection limits (0.006 wt.\% and 0.004 wt.\%, respectively). Reference materials for calibration are San Carlos olivine $(\mathrm{Si}, \mathrm{Mg})$, hematite $(\mathrm{Fe})$, rhodonite $(\mathrm{Mn})$, wollastonite (Ca), $\mathrm{NiO}(\mathrm{Ni})$, anorthite ( $\mathrm{Al}), \mathrm{ScPO}_{4}(\mathrm{P}), \mathrm{Cr}_{2} \mathrm{O}_{3}(\mathrm{Cr})$, Co metal (Co), and gahnite ( $\left.\mathrm{Zn}\right)$. All standards were measured before and after every measurement session, San Carlos olivine and hematite were additionally analyzed after every line profile measured.

Quantitative line profiles were measured from rim to core (2-5 $\mu \mathrm{m}$ step size) to document chemical zonation in olivine at high spatial and analytical resolution. Additionally, single point analyses (cores and rims) were performed on 30 olivine crystals from the ULST, 147 olivine crystals from the East Eifel basanite samples and 82 olivine crystals from West Eifel nephelinite samples. Two to three measurement points were set on every olivine grain to obtain representative core and rim compositions. Our analyses focus on olivine macrocrysts but include also olivine crystals in the matrix as well as olivine-rich xenoliths. All analytical data is given in Online Resource 1 and 2.

Element distribution maps for $\mathrm{Ni}, \mathrm{Ca}, \mathrm{P}, \mathrm{Al}$, and $\mathrm{Cr}$ were measured for two olivine grains $(240 * 240$ $\mu \mathrm{m}$ and $240 * 416 \mu \mathrm{m}$ ) of a complexly zoned crystal from Eppelsberg basanite (EPB19-1-3id8). Measurement conditions during mapping were $20 \mathrm{keV}$ at high $600 \mathrm{nA}$ to detect trace elements more precisely.

\subsubsection{Constraints on temperature, pressure, and crystal orientation}

Temperature is the major factor that controls elemental diffusion and must be therefore carefully constrained for diffusion modeling. Temperatures were calculated based on the Al-in-olivine/spinel - thermometer (Coogan et al. 2014) based on 20 olivine-spinel-pairs in samples from Laacher See Tephra, six in samples from Eppelsberg (EPB), and three in samples from Rothenberg (E41) using same measurement conditions for olivine as described above. A special analytical set-up was applied to measure spinel inclusions ( $20 \mathrm{keV}, 20 \mathrm{nA}$, a focused beam). Counting times were set to 30/15 s for Ti and $\mathrm{Cr}$, and 15/5 s for $\mathrm{Si}, \mathrm{Al}, \mathrm{V}, \mathrm{Mg}, \mathrm{Fe}, \mathrm{Mn}, \mathrm{Ni}, \mathrm{Zn}$. The analyses encompass Crspinel inclusions from all compositional zones of olivine crystals. The spinels have \#Cr of 0.05 0.50 , which match the calibration range of the thermometer $(0<\# \mathrm{Cr}<0.69$; Coogan et al. 2014). The complete dataset is given in Online Resource 3.

\subsubsection{Temperature constraints for Laacher See hybrids}

Olivine-spinel pairs from Laacher See hybrids give $1047-1145{ }^{\circ} \mathrm{C}$ (average: $1106 \pm 43^{\circ} \mathrm{C}$ ) for Fo8687 cores and $1162-1218{ }^{\circ} \mathrm{C}$ (average: $1172 \pm 32{ }^{\circ} \mathrm{C}$ ) for Fo89 rims. These temperatures for Fo $86-87$ 
olivine-spinel pairs are only slightly above the temperature of $1060{ }^{\circ} \mathrm{C}$ for hybrids estimated by Wörner and Wright (1984) for the equilibrium of olivine inclusions ( $\left.\mathrm{Fo}_{85}\right)$ in clinopyroxene in the same rock types from the same stratigraphic ULST section (their sample 1099-12). Olivine-spinel temperatures calculated here reflect crystallization temperatures at the time when the spinel was enclosed into the growing olivine crystals. The thermometer is not sensitive to re-equilibration during cooling of the lavas or after mixing with lower temperature phonolite due to the very slow diffusion of $\mathrm{Al}$ in olivine (Coogan et al. 2014). These temperatures therefore represent the maximum temperatures of the basanite magmas during olivine crystallization. After ascent, cooling and hybridization with relatively "colder" mafic phonolite magma $\left(880^{\circ} \mathrm{C}\right.$, Wörner and Schmincke 1984; Berndt et al. 2001), the temperature at which the olivine cores started to equilibrate to the new equilibrium composition must have been significantly lower, i.e. between 1170 and $880{ }^{\circ} \mathrm{C}$. Since the hybrid samples show a large range of compositions along a mixing trend (Wörner and Wright 1984), the relative proportions of basanite to phonolite, and thus the temperatures after hybridization, were highly variable, which must be considered in the modeling. Because the cooling rate and temperature distribution is unknown, an effective temperature was estimated for every sample. We defined $\mathrm{T}_{\text {effective }}=0.95 * \mathrm{~T}_{\text {calculated }}$ (Chakraborty and Ganguly 1991; Costa et al. 2008). This relationship is defined for element diffusion with activation energies $E_{a}=200 \mathrm{~kJ} \mathrm{~mol}^{-1}$ (Chakraborty and Ganguly 1991; Costa et al. 2008). This is in the range of the activation energies for diffusion in olivine used in the software DIPRA (Diffusion Process Analysis) by Girona and Costa (2013): $\mathrm{E}_{\mathrm{Fo}}=201 \mathrm{~kJ} \mathrm{~mol}^{-1}, \mathrm{E}_{\mathrm{Mn}}=201 \mathrm{~kJ} \mathrm{~mol}^{-1}, \mathrm{E}_{\mathrm{Ni}}=220 \mathrm{~kJ} \mathrm{~mol}^{-1}$, and $\mathrm{E}_{\mathrm{Ca}}=193-207 \mathrm{~kJ} \mathrm{~mol}^{-}$ ${ }^{1}$ depending on the crystallographic orientation. The estimation of an effective temperature close to the maximum temperature is based on the exponential dependency of the diffusion coefficient on $\mathrm{T}$. Therefore, the major part of diffusion occurred at the beginning of the diffusion process, when temperatures are still high (Costa et al. 2008). This estimation results in an effective temperature $\mathrm{T}_{\text {effective }} \sim 1114 \pm 32^{\circ} \mathrm{C}$ for $\mathrm{Fo}_{89}$.

Taking the calculated temperatures for the basanite $\left(1172{ }^{\circ} \mathrm{C}\right)$ and the maximum temperature of $\sim 880^{\circ} \mathrm{C}$ for the mafic phonolite, the temperatures for the mafic phonolite can be estimated using the 40 / $60 \%$ ratio of phonolite/basanite mixing proportions by Wörner and Wright (1984) as 1055 ${ }^{\circ} \mathrm{C}$. Using mixing proportions calculated by Tomlinson et al. (2020) with minimum $30 \%$ basanite results in a minimum temperature $\mathrm{T}=940-968{ }^{\circ} \mathrm{C}$. However, the proportions of basanite $/$ phonolite cannot be assumed to be the same for all hybrid samples. Considering the uncertainty of the Coogan et al. (2014) thermometer and the $30 \%$ basanite component being a minimum value, we estimate a minimum temperature of $\mathrm{T}=1000{ }^{\circ} \mathrm{C}$ for the temperature of the hybrid lavas. Calculating timescales of olivine equilibration with this low temperature results in maximum diffusion times that are $\sim$ seven times longer than those calculated for the $\mathrm{T}_{\text {effective }}$ of $1114{ }^{\circ} \mathrm{C}$. 


\subsubsection{Temperature constraints for mafic lavas erupted at the scoria cones}

Temperatures were constrained from spinel inclusions in olivine for the mafic samples from the Rothenberg dyke and the Eppelsberg basanite. In the basanite samples, spinel inclusions with an adequate size for analysis and compositions within the calibration range of the thermometer are rare. Within the sample from Rothenberg, some of the inclusions were compositionally close to Tibearing magnetite and only crystallization temperatures for Fo ${ }_{84-86}$ could be constrained (1152-1170 ${ }^{\circ} \mathrm{C}$, average: $1159 \pm 23^{\circ} \mathrm{C}$ ). For the sample from Eppelsberg basanite, crystallization temperatures of $1157-1202{ }^{\circ} \mathrm{C}$ (average: $1183 \pm 26{ }^{\circ} \mathrm{C}$ ) are constrained only for less forsteritic olivine compositions $\left(\mathrm{Fo}_{83-84}\right)$.

\subsubsection{Pressure and crystal orientation}

For Laacher See hybrid clasts we took a minimum pressure of $2 \mathrm{kbar}$ for diffusion modeling based on the depth of the magma chamber constrained by previous workers (Wörner \& Schmincke 1984a; Berndt et al. 2001; Harms et al. 2004). The error caused by uncertain pressure values is negligible with respect to the uncertainty of temperatures.

Elemental diffusion in olivine is strongly anisotropic and can be described as $6 D_{a}=6 D_{b}=D_{c}$ (Dohmen et al. 2003; Costa and Chakraborty 2004) with $\mathrm{D}_{\mathrm{a}, \mathrm{b}, \mathrm{c}}$ as diffusion coefficients along the crystallographic axes. Diffusion modeling therefore requires the knowledge of crystal orientation with respect to the direction of the measured profile. For oblique cuts, the orientation of the olivine crystals was determined via EBSD (electron backscatter diffraction; Prior et al. 1999) at the FEI Quanta 200 F scanning electron microscope at the Geoscience Center, Georg-August-University, Göttingen. The thin sections were not coated to avoid signal weakening. 10-15 measurement points were set along the analyzed line profiles to exclude heterogeneities in crystal orientation using a DigiView V camera (EDAX-Ametek) and TSL OIM software for data collection (measurement conditions: $15 \mathrm{keV}, 150 \mu \mathrm{A}$, and $4 \mu \mathrm{m}$ spot size).

\subsubsection{Our approach to diffusion modeling}

Olivine crystals from the final products of the Laacher See eruption were used to constrain residence times of olivine crystals in the late mafic, hybrid clasts. As a complement, olivine from basanite lavas (bombs, lapilli and dikes) from several nearby (but significantly older) basanite scoria cones were also analyzed to constrain ascent times from mantle or lower crustal depths. Since we concentrate on the outer diffusion boundaries between core and crystal margins, these diffusion times should represent the timespan between when olivine crystals were entrained into a new magma and their rapid cooling after eruption to the surface. We term this point of entrainment as 
reactivation time of older olivine crystals (Sundermeyer et al. 2020). Olivine crystals can be reactivated from prior storage in a crystal mush or cogenetic cumulates, or from a resident, more evolved magma by a newly ascending more mafic magma. On the other hand, olivine crystals may be carried up in mafic magmas from depth into shallower reservoirs where they mix with evolved, olivine-free magma. The compositional relations between olivine (Fo-content) and hybrid magmas $(\mathrm{Mg} \#)$ will depend on which of these processes was operating. In any case, the magma mixing event initiates diffusive re-equilibration of olivine cores to the new equilibrium composition determined by the composition of the new hybrid host magma. Given a sufficiently long time, which mostly depends on temperature and size of the crystals, the core may completely homogenize with the new surrounding magma. However, if this process remains incomplete (e.g. due to fast eruption or cooling during the eruption), the compositional gradient between rim and core can be used to determine the timescales of equilibration and the original core compositions can constrain parent magma compositions. In our samples, the olivine crystals often show an additional very thin (few microns) zoned overgrowth at the outermost grain boundary, which is the product of a late, short crystallization from the hybrid host and/or diffusion event that reflects a final phase in the history of the crystals. In this study, the term grain boundary is used for this outermost zone to clearly distinguish it from the diffusion boundary between the core and rim.

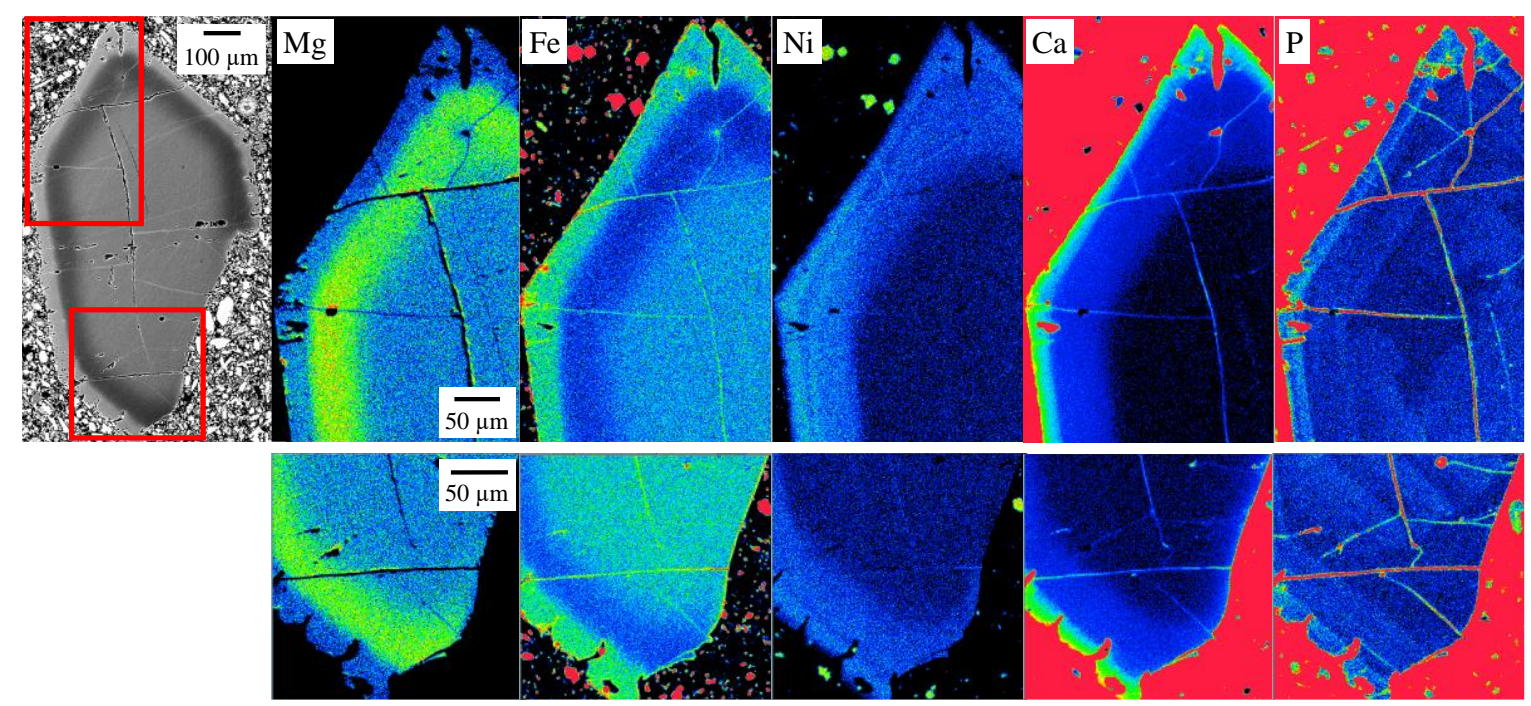

Fig. 3 Backscattered electron image (BSE) showing mass contrasts (dark $=\mathrm{Mg}$-rich; bright $=\mathrm{Fe}$-rich) and elemental distribution mappings of $\mathrm{Mg}, \mathrm{Fe}, \mathrm{Ni}, \mathrm{Ca}$, and $\mathrm{P}$ in olivine (EPB19-1-3-id5). Red squares mark the mapped areas. Element concentrations increase from blue over green to reddish colors. Reverse-normal zonation is clearly visible by the high-Mg rim and low-Mg grain boundary. $\mathrm{P}$ is highly concentrated in the rim, but shows also zoning in the olivine core, which is already re-equilibrated in other elements. 
Zones of growth and diffusion, both forming compositional gradients, and growth during diffusion must be identified for diffusion modeling (Shea et al. 2015b). Neglecting the amount of growth will result in an overestimation of the modeled timescales (Costa et al. 2008). However, there are several ways to distinguish diffusion from growth zoning. Compositional maps that focus on sharp crystal apexes show different zoning patterns for growth and diffusion: while growth zoning will produce compositional zones strictly parallel to the crystal faces, thus mimicking the crystal apexes, diffusion will produce smooth rounded zonation haloes across the apexes. Fig. 3 shows an example of such diffusive smoothing around crystal apexes and thus suggests that zoning in these olivine crystals from Laacher See hybrids result from diffusion. The comparison of fast ( $\mathrm{Mg}-\mathrm{Fe})$ and more slowly diffusing elements $(\mathrm{Ni}, \mathrm{Al}, \mathrm{P})$ is an additional tool to distinguish whether compositional gradients are induced by diffusion or growth. Line profiles for $\mathrm{Ni}, \mathrm{Al}$, and $\mathrm{P}$ show significantly steeper and narrower gradients compared to the Fo-content between both core / rim and rim /grain boundary (Fig. 4). Therefore, this is solid evidence that the $\mathrm{Mg}$-Fe gradients are the result of a diffusion-dominated process. Further, the relationship between Fo-content and $\mathrm{NiO}$ also allows to distinguish growth and diffusion due to the different diffusion of $\mathrm{Mg}-\mathrm{Fe}$ and $\mathrm{Ni}$ (Gordeychik et al. $2018,2020)$. For normal zoned olivine, growth results in a convex trend from core to rim in a NiOFo diagram (Fig. 5). Diffusion is characterized by generally shallower trends (concave in normal zoned crystals and convex in reverse zoned crystals) due to the faster interdiffusion of $\mathrm{Mg}-\mathrm{Fe}$ compared to the diffusion of Ni. The core-to-rim gradients in olivine from East Eifel mafic lavas and Laacher See hybrids show a shallow trend from core to rim and rim to grain boundary, which indicate that these gradients are dominated by diffusion. 
a

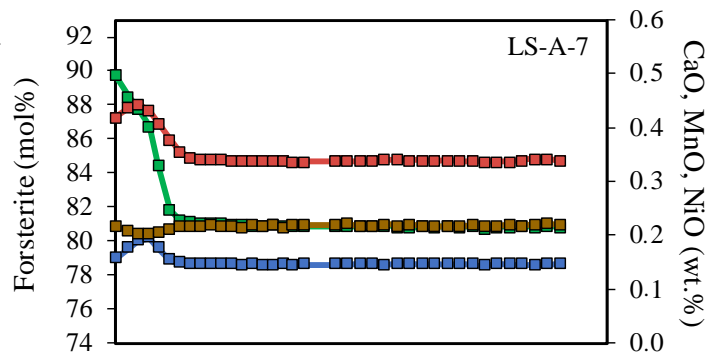

b
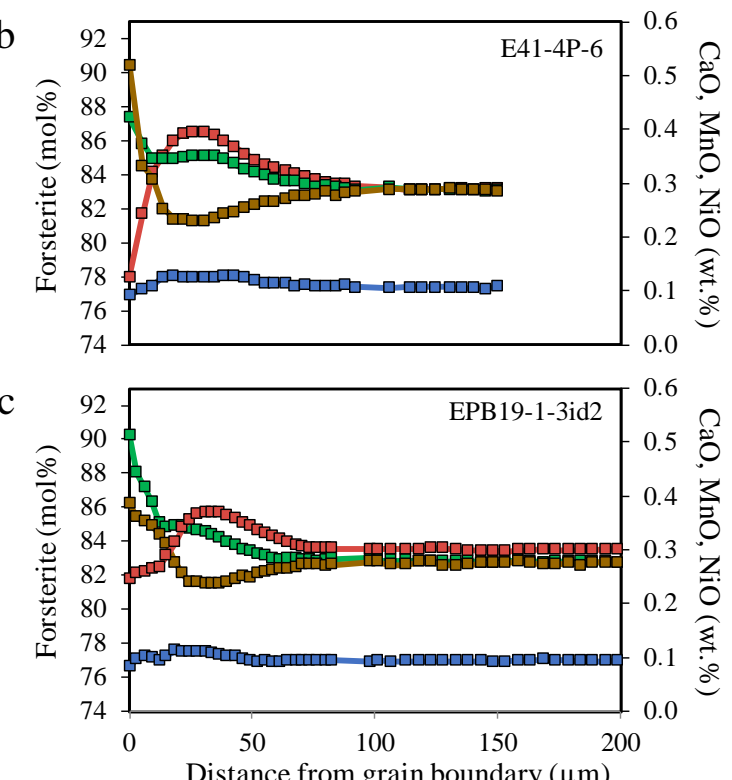
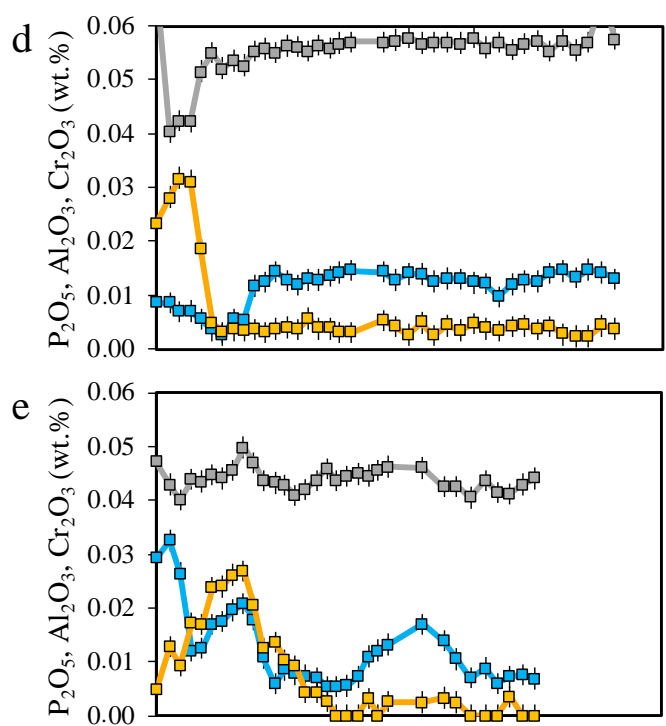

$\mathrm{f}$

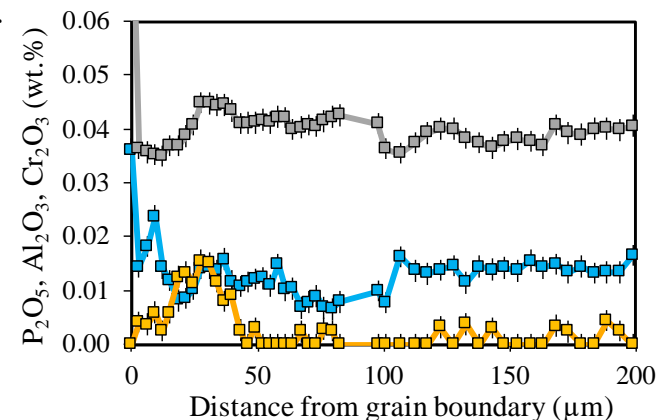

$$
\begin{array}{ll}
-\mathrm{Fo} & -\mathrm{P}_{2} \mathrm{O}_{5} \\
-\mathrm{CaO} & -\mathrm{Al}_{2} \mathrm{O}_{3} \\
-\mathrm{MnO} & -\mathrm{Cr}_{2} \mathrm{O}_{3} \\
-\mathrm{NiO} &
\end{array}
$$

Fig. 4 Major and trace element concentrations in selected olivine crystals from (a, d) Laacher See, (b, e) Rothenberg, and (c, f) Eppelsberg. For $\mathrm{Fo}, \mathrm{MnO}, \mathrm{CaO}$, and $\mathrm{NiO} 2 \sigma$-uncertainties are within the symbols. Olivine from basanitic samples show at least two additional growth zones in trace elements at distances of $\sim 40$ and $\sim 100 \mu \mathrm{m}$ from the grain boundary. These zoning is absent in major element concentrations due to re-equilibration. This zonation is absent in olivine from ULST samples.

The distinct compositional zones may have formed at different times and temperatures. These processes can be modeled using e.g. the non-isothermal diffusion model NIDIS (Non-Isothermal Diffusion Incremental Step model) from Petrone et al. (2016), which was recently modified by Rout et al. (2020). This model allows the stepwise modeling of diffusion in complex zoned crystals at different temperatures. The core started diffusive equilibration to the rim composition at a time $t_{1}$ and a temperature $T_{1}$ and equilibrated for a timespan $\Delta t_{1}$. After that time, the grain boundary is formed and the rim started equilibration to the grain boundary composition (at a time $t_{2}$ and a temperature $\mathrm{T}_{2}$ ). During the time span $\Delta \mathrm{t}_{2}$ the rim equilibrates, but simultaneously the core equilibration continues diffusive exchange at the different temperature $T_{2}$. The sum of the times $\Delta t_{1}$ 
and $\Delta \mathrm{t}_{2}$ represent the time the whole crystal equilibrated (Petrone et al. 2016). However, our modeling shows that the time $\Delta \mathrm{t}_{1}$ of core diffusion can only be very short (days) and also suffers from uncertainties introduced by the stepwise non-isothermal modeling approach. Therefore, we decided to model the entire profile (core / rim and rim / grain boundary) with only one intermediate temperature $\mathrm{T}_{\text {effective, }}$ that accounts for cooling during the diffusion process. Additionally, we calculated the maximum diffusion times of olivine crystals from Laacher See assuming that diffusion took place at the minimum temperature of $\mathrm{T}=1000{ }^{\circ} \mathrm{C}$. We used a step model between the core with an initial composition $\mathrm{C}_{1}$ and the rim with a composition $\mathrm{C}_{2}$. The rim evolves to the composition $\mathrm{C}_{3}$ of the grain boundary. It is difficult to constrain whether the outermost overgrowth already existed at the beginning of diffusive rim equilibration or if the diffusion took place in direct contact between rim and melt before the overgrowth has formed. Therefore. it cannot be excluded in the case of the resorbed grain boundaries, that an overgrowth existed and that it developed a sshaped diffusion profile that was later (partly) removed by dissolution. Therefore, we tested both, a model based on diffusion between rim and overgrowth as well as between rim and melt. We found that due to the narrow gradients $(<15 \mu \mathrm{m})$, the difference in calculated timescales is negligible and within the overall uncertainties of the model (see discussion below). The gradient between the narrow overgrowth rim and the grain boundary was not modeled for olivine from Eppelsberg and Rothenberg basanite, because the gradients of Fo and slowly diffusing trace elements are similar and thus indicate a growth-dominated formation.

The time obtained from the modeling represents the period between reactivation (= mafic recharge) and cooling (= eruption). Note, however, that the timescales presented here only constrain maximum times because (1) the Laacher See eruption lasted several days with the hybrid ULST material being erupted towards the very end and the duration of the eruption would be part of the calculated diffusion times. Also, (2) for basanite lava and dike samples from scoria cones it cannot be excluded that diffusion continued after the eruption due to non-instantaneous cooling. Both would result in an overestimation of timescales between reactivation and the onset of eruption.

Diffusion profiles were modeled using the software DIPRA (Diffusion Process Analysis) by Girona and Costa (2013). The calculation of timescales is based on a finite 1-dimensional, numerical modeling approach that considers the change of Fo content in the olivine with time due to diffusion and thus the compositional dependence of changing diffusion coefficients (Girona and Costa 2013). In all analyzed olivine crystals, the diffusion of $\mathrm{Mg}-\mathrm{Fe}, \mathrm{Mn}, \mathrm{Ca}$, and $\mathrm{Ni}$ was modeled separately. A detailed overview of all modeling parameters is given in Online Resource 4. The software uses the root-mean-square-method ( $r m s$ ) to find the best-fit model curve (Girona and Costa 2013). For this, the initial concentrations $\mathrm{C}_{1}, \mathrm{C}_{2}$, and $\mathrm{C}_{3}$ must be defined. Within a number of steps $d t$ and $d x$ in time and space, which must be provided, DIPRA searches the best-fit between the measured profile and the model curves for every time and space step. 


$$
r m s=\sqrt{\frac{1}{N} \sum N\left(C_{i}^{x, j}-C_{i}^{x}\right)^{2}}
$$

with $\mathrm{N}$ as the number of data points, $C_{j}^{x}$ being the measured concentration $\mathrm{C}$ of an element $\mathrm{i}$ at a distance $\mathrm{x}$, and $C_{i}^{x, j}$ being the modeled concentration $\mathrm{C}$ of an element $\mathrm{i}$ at a distance $\mathrm{x}$ after $\mathrm{j}$ time steps (Girona and Costa 2013). The software automatically adjusts the diffusion coefficient $D_{c}$ to account for crystal orientation, when the angles between crystallographic axes and measured profile are added. This follows the equation by Carslaw and Jaeger (1959),

$$
\mathrm{D}_{\text {profile }}=\mathrm{D}_{\mathrm{a}}(\cos \alpha)^{2}+\mathrm{D}_{\mathrm{b}}(\cos \beta)^{2}+\mathrm{D}_{\mathrm{c}}(\cos \gamma)^{2}
$$

where $D_{a, b, c}$ are diffusion coefficients along the measured profile, a-, b-, and c-axis, and $\alpha, \beta$, and $\gamma$ are angles between a profile and the crystallographic axes.

DIPRA provides two types of uncertainties. One is a simple error of diffusion times based on the uncertainty of composition, temperature and the range of different model curves, which match the measured data within compositional uncertainty but are not the best-fit. The second is called discrepancy and represents the goodness of fit. It is calculated based on the number of data points of the best-fit modeled curve, which do not match the corresponding data point at the same distance $x$ (Girona and Costa 2013). We used the $2 \sigma$-uncertainties obtained from the analytical measurements ( $\mathrm{Fo}=0.2 \mathrm{~mol} \%, \mathrm{Mn}=0.004$ wt. $\%, \mathrm{Ca}=0.003$ wt. $\%$, and $\mathrm{Ni}=0.003$ wt. $\%$ ), and the standard deviations from the calculation of $\mathrm{T}_{\text {effective }}$ that include the uncertainty given for the thermometer $\left( \pm 20^{\circ} \mathrm{C}\right.$, Coogan et al. 2014). The uncertainties for $\mathrm{T}$ are $\pm 32{ }^{\circ} \mathrm{C}$ for Laacher See hybrid samples, $\pm 23{ }^{\circ} \mathrm{C}$ for Rothenberg, and $\pm 26{ }^{\circ} \mathrm{C}$ for Eppelsberg. Temperature is the dominant parameter controlling diffusion and therefore uncertainties of diffusion times. The uncertainties for $\mathrm{T}$ used here result in time uncertainties that are mostly in the range of $26-78 \%$ for diffusion modeling of $\mathrm{Mg}-\mathrm{Fe}, 32-119 \%$ for $\mathrm{Mn}, 29-104 \%$ for $\mathrm{Ca}$, and 30-130 \% for $\mathrm{Ni}$, but can reach up to $300 \%$ for crystals with very short diffusion times (days) and a low compositional contrast between $\mathrm{C}_{1}, \mathrm{C}_{2}$, and $\mathrm{C}_{3}$. 


\subsection{Results and discussion}

\subsubsection{Chemical composition of olivine crystals from Laacher See hybrids}

1. Typical olivine crystals from Laacher See hybrids are between 100 and $500 \mu \mathrm{m}$ in size and are clearly in disequilibrium with the "phonolitic" minerals (e.g sanidine, plagioclase, amphibole, titanite) in the mingled rocks. As such, these olivine crystals are xenocrysts to the phonolite but could be phenocrysts with respect to the basanite. Compositionally, these "macrocrysts" can be divided into three zones: (1) core compositions that are variable between different crystals (Fo83.189.1, $\mathrm{NiO}=0.07-0.24$ wt.\%, Fig. 6) but uniform within a particular crystal. (2) All crystals show a high-Fo rim $\left(\mathrm{Fo}_{87.8-89}, \mathrm{NiO}=0.15-0.2 \mathrm{wt} . \%\right)$, which is rather uniform for all crystals, and (3) a thin $(<10 \mu \mathrm{m})$ overgrowth at the outer grain boundary back to $\mathrm{Fo}_{84.7-86.8}$ and $\mathrm{NiO}=0.12-0.15 \mathrm{wt}$.\% (Fig. 3, Fig. 4a-c). This results in complex (reverse-normal) zoning forming peculiar "inverse loops" in Ni-Fo diagrams (Fig. 5). It is apparent that these olivine crystals must have had a prolonged history during which they encountered different melt compositions from which they grew and, respectively, with which they exchanged by diffusion.

2. Olivine megacrysts (up to $8 \mathrm{~mm}$ ) differ profoundly from these strongly zoned olivine crystals described above: megacrysts are compositionally homogeneous throughout their cores and are only zoned at the outermost $<50 \mu \mathrm{m}$ of the crystals. However, the composition and inverse looped pattern of the outermost zoning are similar to the macrocrysts. Minor and trace elements in general show zoning patterns similar to Fo at the rims and are unzoned in the olivine cores. The trend of zoning pattern for NiO differs from those of Fo in several crystals (Fig. 7). Whereas Fo is reversely zoned, $\mathrm{NiO}$ shows normal zonation and a rim is absent $\left(\mathrm{NiO}_{\text {core }}=0.19-0.23 \mathrm{wt} . \%\right)$. This NiO-concentration is intermediate, but higher compared to other olivine cores with the same Fo content.

3. Matrix olivine $\left(\mathrm{Fo}_{87.4-89.2}, \mathrm{NiO}=0.17-0.2 \mathrm{wt} . \%\right)$ are small (less than $\left.30 \mu \mathrm{m}\right)$ and distinctly more Mg-rich than the outer grain boundaries of the olivine crystals described above, but similar to the rim composition $\left(\mathrm{Fo}_{86.3-89.1}, \mathrm{NiO}=0.14-0.2 \mathrm{wt} . \%\right)$.

4. Xenoliths: Olivine from xenoliths in the Laacher See hybrid samples were not analyzed in this study. Three types of ol-bearing xenoliths are distinguished: cpx-rich and ol-bearing wehrlites, mantle-derived peridotites, and ol-rich, dense cumulate clasts with olivine compositions of Fo84-86 (Wörner and Schmincke 1984a; Wörner and Wright 1984). 


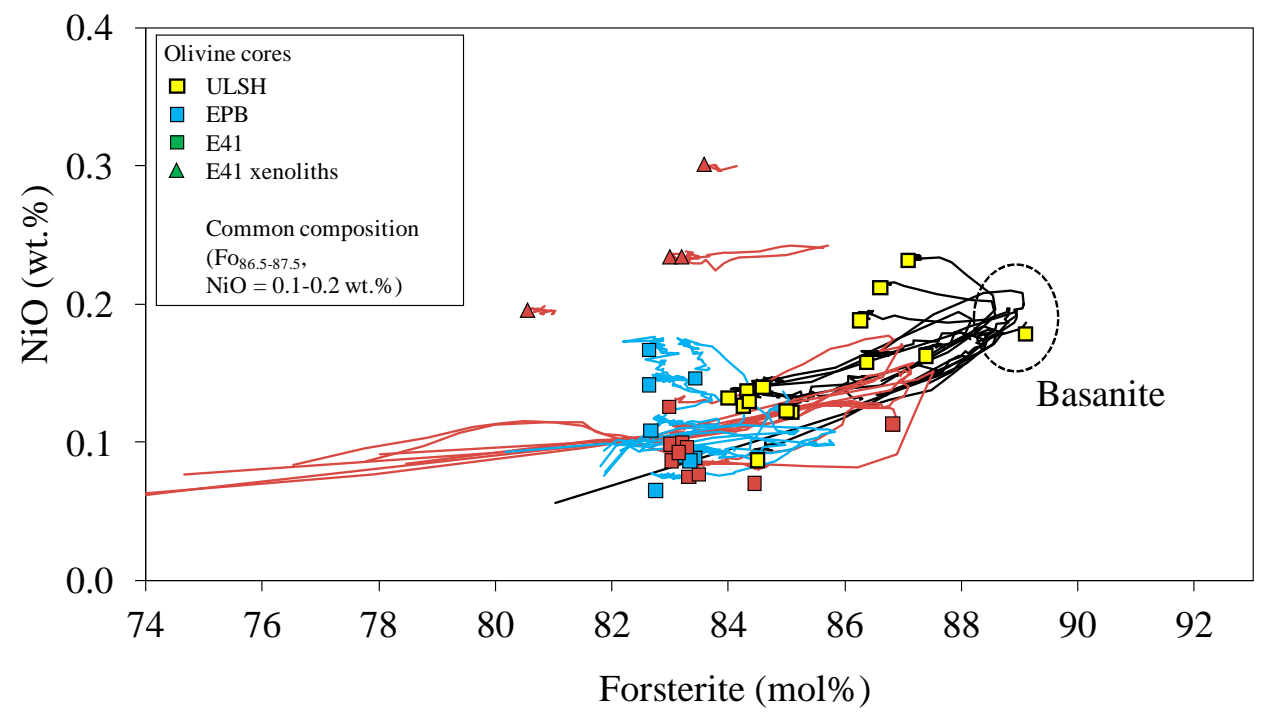

Fig. 5 Measured NiO and Fo concentrations along line profiles in zoned olivine crystals from Laacher See phonolite, and Rothenberg and Eppelsberg basanite. Olivine crystals show exclusively reverse-normal zoning. Olivine cores can be divided into distinct groups based on $\mathrm{NiO} / \mathrm{Fo}$ distribution along the profile. This allows to distinguish growth- and diffusion-formed zonation due to the faster diffusion of $\mathrm{Mg}$-Fe compared to $\mathrm{NiO}$.

Origin of the different olivine types: All olivine crystals in Laacher See hybrid lavas are clearly related to the basanite magma that intruded and intermingled with the resident phonolite before eruption. Olivine macrocrysts are considered to represent the phenocrysts of the basanite magma. Their cores and rim zonation reflect the ascent and compositional history of the basanite before intruding and mingling into the Laacher See phonolite magma. Olivine megacrysts occur together with large $(>1.5 \mathrm{~cm})$ compositionally homogeneous clinopyroxenes and equally homogeneous megacrystic phlogopites $(>1 \mathrm{~cm})$ and therefore are likely derived from the same sources. Probably, these megacrysts represent crystal cargo that was picked up by the basanite during ascent from older basanitic intrusive bodies.

Since the rims of the macrocrysts and microcrystic olivine in the matrix are of the same composition, the crystallization of matrix olivine probably occurred contemporary with the highFo rim formation of the macrocrysts. Both also show resorbed crystal shapes. Therefore, we argue that the matrix olivine must have been formed before the basanite-phonolite mingling event.

In essence, this means that the basanite magma intruding into the Laacher See phonolite reservoir prior its eruption must itself have had a history of mixing and zoned growth before mingling with the crystal-rich mafic phonolite. As we will demonstrate below, this prior history of the Laacher See basanite is distinct from the history of basanite lavas that erupted in near-by scoria cones. 

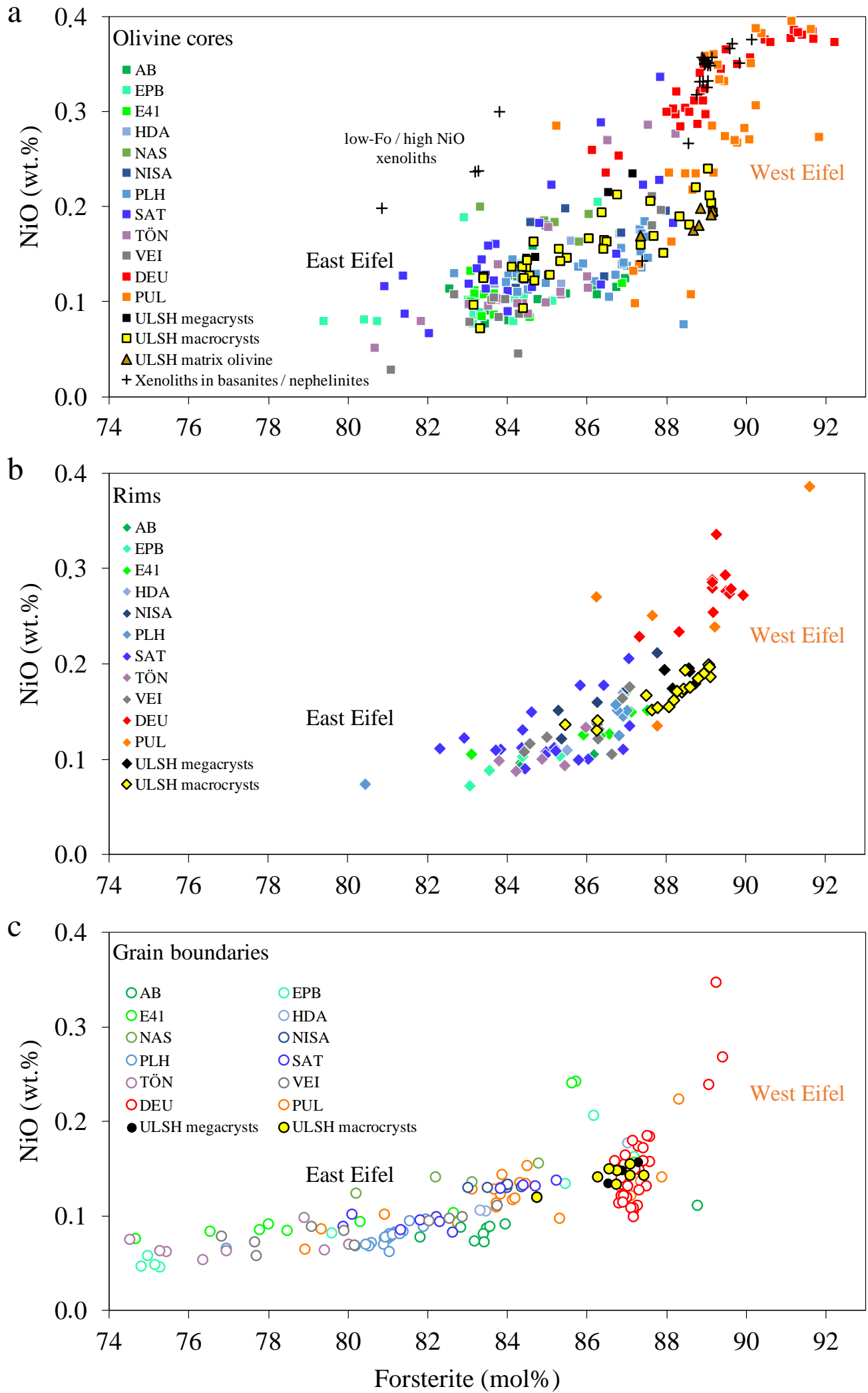

Fig. 6 NiO-Fo diagrams for (a) cores, (b) rims, and (c) grain boundaries of all olivine crystals analyzed in this study. Bright grey and reddish fields mark the measured core compositions from West and East Eifel 
samples in all diagrams. The yellow field marks the common composition with Fo86.5-87.5 that is present in all samples. Core compositions of olivine crystals clearly differ between high-Fo compositions for the West Eifel nephelinite and more evolved compositions found in the East Eifel basanite samples.

\subsubsection{Chemical composition of olivine phenocrysts in East Eifel basanites}

The olivine phenocrysts analyzed in samples from the basanitic East Eifel scoria cones that formed close to the Laacher See eruptive center also share a complex-reverse zoning pattern similar, but not identical to those of the olivine crystals from the Laacher See hybrids. A common feature is the homogeneous core at variable Fo and a relatively Fo-richer rim (Figs. 4, 5, 7). However, the maximum rim compositions of phenocrysts in basanites are always below $\mathrm{Fo}_{88}$ and thus never reach the maximum Fo in rims observed in Laacher see hybrid samples ( Fo $\left._{89}\right)$. One olivine crystal from an EPB sample shows a distinct zoning pattern for $\mathrm{NiO}$ and Fo similar to the megacrysts from Laacher See hybrid samples.

Line profiles of trace elements $(\mathrm{P}, \mathrm{Al})$ in olivine crystals from $\mathrm{E} 41$ and $\mathrm{EPB}$ samples also reveal a more complex history with distinct growth zones (Fig. 3; Fig. 4e, f). P has a low diffusivity (Watson et al. 2015) and can therefore preserve compositional growth zonation, while $\mathrm{Mg}$-, Fe-, $\mathrm{Mn}$-, and $\mathrm{Ni}$ will be equilibrated by diffusion (Milman-Baris et al. 2008; Bouvet de Maissonneuve et al. 2016). Several correlated peaks in P- and Al-contents show at least two distinct growth zones in olivine from the Rothenberg basanite (E41) at $\sim 40 \mu \mathrm{m}$ and $\sim 100 \mu \mathrm{m}$ distance inwards from the grain boundary (Fig. 4e, f).

Olivine core compositions are rather variable and range from Fo80.7-88.4 (Fig. 6a) with compositional

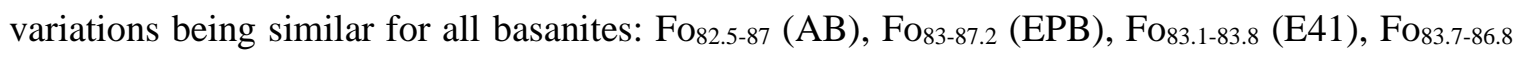
(HDA), Fo83.3-86.4 (NAS), Fo84.2-88 (NISA), Fo82.7-88.4 (PLH), Fo80.9-88.2 (SAT), Fo80.7-88.2 (TÖN), and Fo81.1-87.9 (VEI). NiO-contents in olivine cores are also variable in all basanite samples between $\sim 0.05$ and 0.21 wt. $\%$.

Overall, the rim compositions of olivine crystals from the basanite samples show a range similar to the cores $\left(\mathrm{Fo}_{80.4-87.8}, \mathrm{NiO}=0.07-0.21\right.$ wt.\%). However, the compositional variability between different rims (up to $7 \mathrm{~mol} \% \mathrm{Fo}$ ) is large, but for each crystal always higher in Fo than the core. This results in typical "humped" concentration profiles (e.g. Figs. 5, 7) were the maximum Fo content is generally different. The high average Fo contents of the rims clearly indicate that the maximum is formed by olivine crystals interacting with basanite magma that is generally more mafic than the host melt from which the olivine cores have grown (but not as mafic as for the olivine rims found in Laacher See hybrid lavas, see above). 

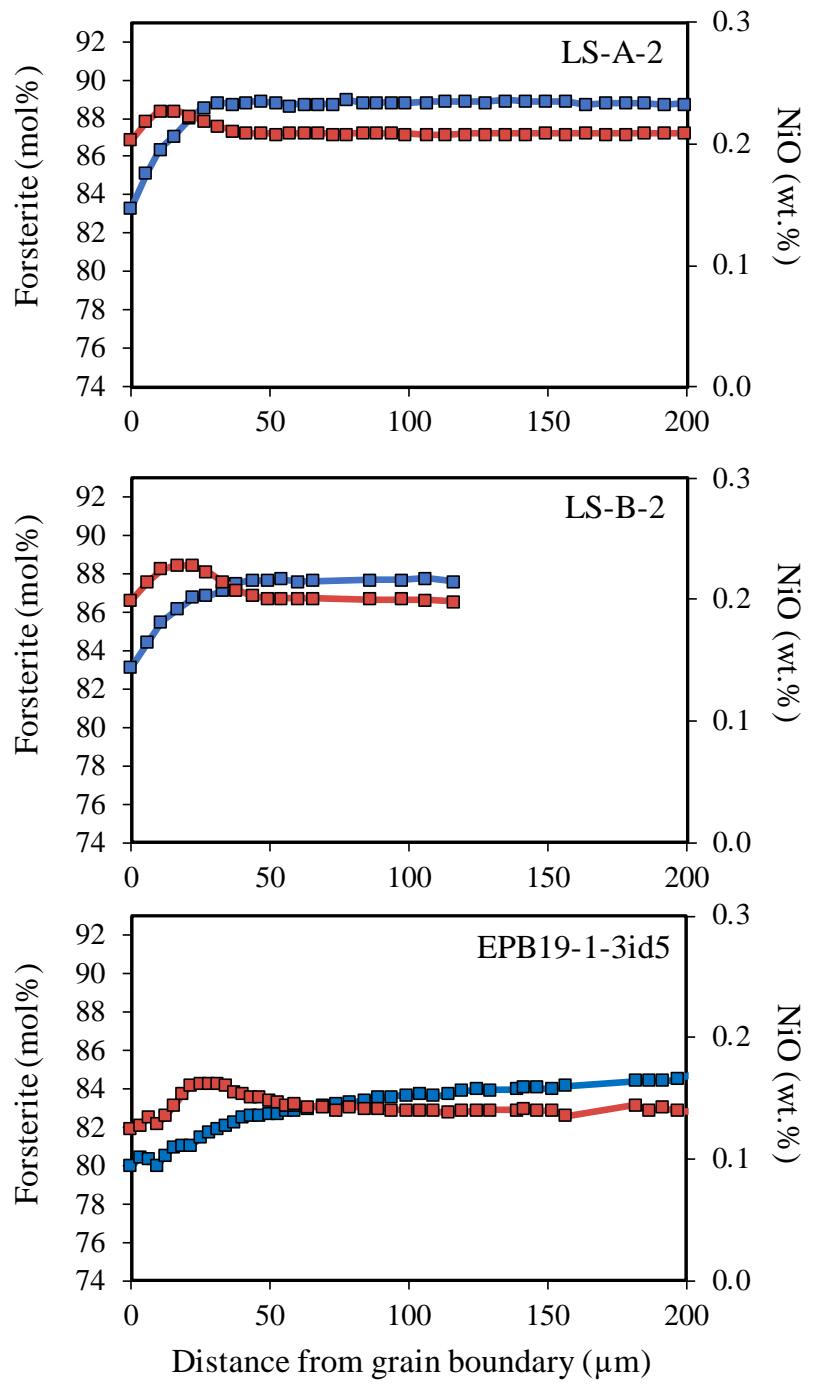

Fig. 7 Olivine in ULSH and EPB samples show rarely distinct zoning patterns in NiO compared to other elements as $\mathrm{Mg}-\mathrm{Fe}, \mathrm{Mn}$, and $\mathrm{Ca}$. Commonly, element distribution of $\mathrm{Ni}$ along the measured profiles is similar to Fo. Lynn et al. (2017) interpret this phenomenon as result of diffusion-triggered zoning due to heating or magma mixing, which changed only the faster diffusing $\mathrm{Mg}$-Fe.

The large compositional range of rim compositions may be taken as evidence that the mafic basanite melts from which the rims have grown are rather different in compositions. This may be unexpected because the rims should represent equilibrium with a new, most mafic basanitic melt and should therefore expected to be similar in all samples. However, the rims do not show a flat compositional plateau, rather the concentration profiles always form a sharp maximum (Fig. 4a-c), which may not represent the original equilibrium composition. A possible explanation is resorption of the crystal surface that has cut to variable depth into the compositional gradient extending from a uniform high-Fo rim. In that case the original rim composition would have been variably "eroded" by resorption and overprinted later by diffusive equilibration towards a new, less mafic equilibrium 
composition. If so, only the maximum Fo-rich rim composition $\left(\sim \mathrm{Fo}_{86-88}\right)$ in a sample can be assumed to be close to the original equilibrium composition of the new melt.

Fo-contents at the grain boundaries are generally low but cover a wide range (Fo68.6-87.2). This may be partly caused by analytical limitations due to the steep gradients and the narrow zoned grain boundary overgrowth $(<10 \mu \mathrm{m})$ which could not safely be measured to the very boundary of all crystals (Fig. 6c).

Matrix olivine $(<50 \mu \mathrm{m})$ were analyzed only in basanite samples from $\mathrm{EPB}\left(\mathrm{Fo}_{73.8-79.6}, \mathrm{NiO}=0.04-\right.$ 0.08 wt.\%). They are even more evolved than the grain boundary of the phenocrysts ( $\mathrm{Fo}_{79.4-87.2}, \mathrm{NiO}$ $=0.07-0.21 \mathrm{wt} . \%)$, which again may be due to the limited spatial resolution of the analysis at the crystal boundary

\subsubsection{Chemical composition of olivine crystals from West Eifel nephelinites}

Olivine phenocrysts from the West Eifel samples are dominantly normal zoned with a high-Fo core and a low-Fo rim (Fig. 2d). Olivine crystals with three compositional zones are also rarely found and show either a normal-normal zoning with a two-step decrease of Fo-content towards the rim or a reverse-normal zoning as observed for olivine from the East Eifel samples (Fig. 2 e, f).

Olivine cores are more primitive with Fo86.1-92.2 (DEU) and Fo85.2-91.8 (PUL) and $\mathrm{NiO}=0.1-0.39$ wt.\%. Olivine rims are less forsteritic with Fo87.3-89.9 (DEU) and Fo86.3-91.6 (PUL).

Matrix olivine were analyzed in DEU (Fo (66.5-88.4, $\mathrm{NiO}=0.05-0.22$ wt.\%) and PUL $\left(\mathrm{Fo}_{74.9}, \mathrm{NiO}=\right.$ 0.05 wt.\%). The compositions of matrix olivine from DEU correlate with the grain boundaries of the phenocrysts and are also close to the common composition (Fo86.5-87.5, NiO =0.1-0.2 wt.\%), to which the grain boundaries of all analyzed olivine compositions tend to converge (Fig. 6c). It is notable that this common composition is the same as for the crystal boundaries of olivine crystals in Laacher see hybrids.

\subsubsection{Ol-rich xenoliths}

Small peridotite xenoliths (less than $2 \mathrm{~cm}$ ) occur rarely in basanite samples of the East Eifel but are abundant in more primitive West Eifel centres. Analyses were performed on 14 xenolithic olivine from four East Eifel basanite lavas and one West Eifel nephelinite. In the East Eifel, two types were identified based on their olivine composition: (1) one type is low in Fo and $\mathrm{NiO}\left(\mathrm{Fo}_{79.3-80.9}, \mathrm{NiO}=\right.$ 0.11-0.19 wt.\%; samples NISA and E41), and (2) a high-Fo and high-NiO type (Fo88.6-90.1, $\mathrm{NiO}=$ 0.27-0.38 wt.\%; NISA, SAT and TÖN). However, one analysis from SAT matches none of the compositions $\left(\mathrm{Fo}_{87.4}, \mathrm{NiO}=0.14 \mathrm{wt} . \%\right)$. Olivine from a small xenolith found in the E41 basanite 
dike have low $\mathrm{Fo}_{83-84.1}$, but a high $\mathrm{NiO}=0.23-0.3$ wt. $\%$. This xenolith shows a cpx-reaction rim with the basanite host. Its interior shows equilibrated grain textures and therefore probably represent older dunitic cumulates from basanite magmas unrelated to the Laacher See eruption. The distinct high-Fo / high-NiO type can be clearly identified as olivine from mantle xenoliths. Such low-Fo / high-NiO olivine compositions fall distinctly above the general Fo-Ni trends (Fig. 5, 6) and their rims show increasing Fo at constant Ni. Following the interpretation of Gordeychik et al. (2020), such olivine core compositions are strongly affected by extended diffusion with an evolved host magma, reflecting the faster $\mathrm{Mg}-\mathrm{Fe}$ interdiffusivity compared to $\mathrm{Ni}$. These cores have later again been overprinted by diffusive exchange with more mafic magma, thus creating the horizontal trend between core and rims in Fo-NiO space (Fig. 5).

The xenolithic olivine of the sample DEU (14 analyses) from the West Eifel show exclusively the high-Fo / high-NiO composition (Fo88.7-89.1, $\mathrm{NiO}=0.3-0.4$ wt.\%), but these compositions are still more evolved than some of the phenocrysts analyzed in West Eifel nephelinite.

\subsubsection{Calculated diffusion times}

Diffusion times were calculated from modeling compositional gradients measured for $\mathrm{Mg}-\mathrm{Fe}, \mathrm{Mn}$, $\mathrm{Ca}$, and $\mathrm{Ni}$ across olivine crystals from the Laacher See hybrids and from lavas erupted from two basanitic scoria cones (E41 and EPB) (Fig. 8).

For olivine from the Laacher See hybrids, the timescales obtained from olivine core-rim-grain boundary zoning range from $1 \pm 1$ to $49+35 /-20$ days based on $\mathrm{Mg}$-Fe diffusion at $\mathrm{T}_{\text {effective }}=1114$ ${ }^{\circ} \mathrm{C}$ (Fig. 9; Tab. 1). Diffusion times for Mn, Ca, and Ni vary between 1-34 (+25/-12), 1-30 (+18 / -13), and 1-36 (+41 / -28) days, respectively, and show a good agreement for trace elements and Fo-content. To also estimate the maximum possible timescales, diffusion was modeled at the reasonable minimum temperature of $1000{ }^{\circ} \mathrm{C}$, which gives diffusion times between 10 and 410 days. 

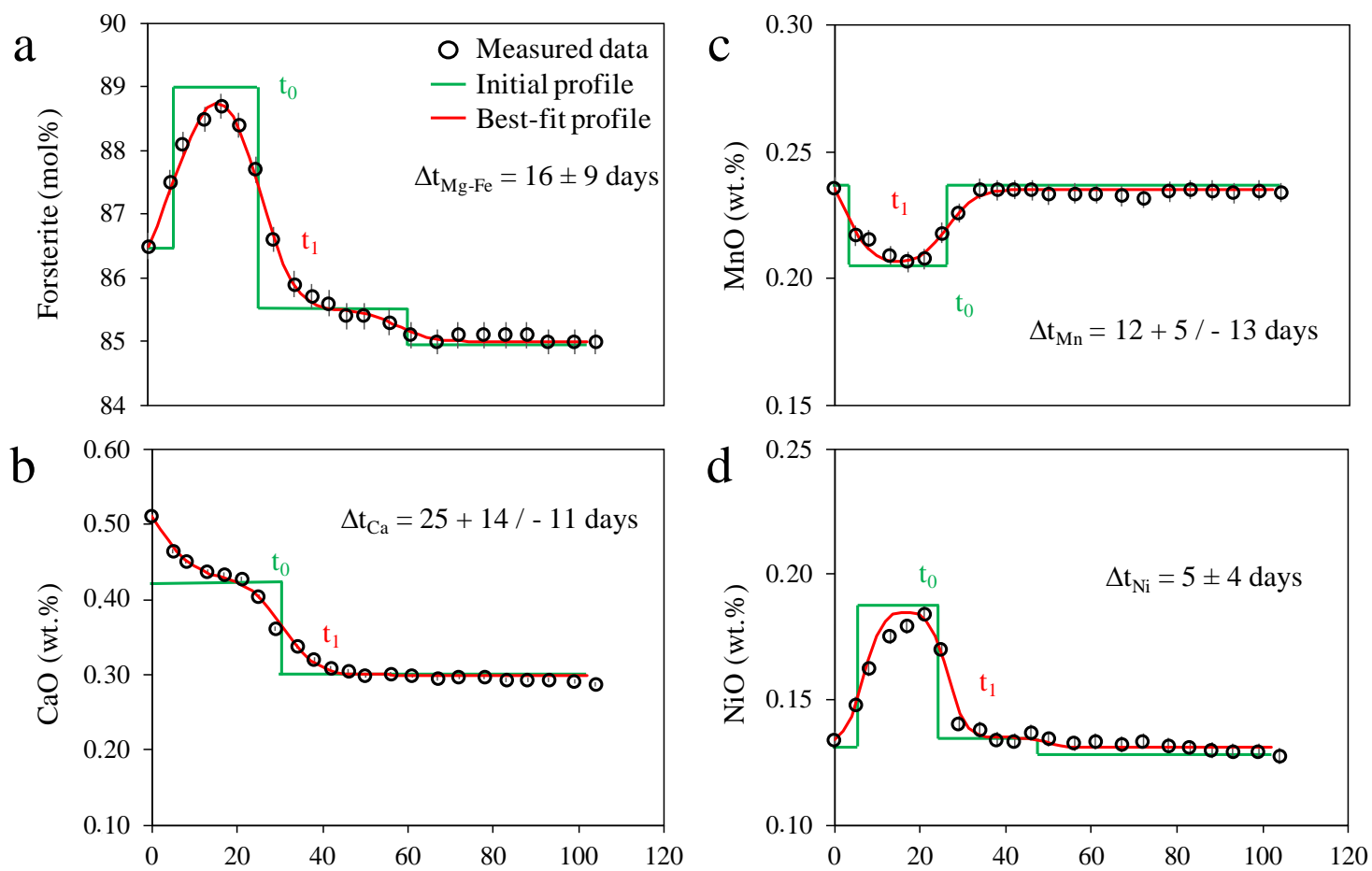

Fig. 8 Diffusion modeling of (a) Mg-Fe, (b) $\mathrm{Ca}$, (c) Mn, and (d) Ni in a representative olivine crystal (LSH1-1). Green lines show the estimated initial zoning at the time $t_{0}$, when the olivine is reactivated and starts diffusive equilibration for a timespan $\Delta \mathrm{t}$ until diffusion is interrupted at the time $\mathrm{t}_{1}$ (red line) by cooling (e.g. eruption). The time obtained by modeling a curve best-fitting the measured profile represents the residence time in the basanitic magma and subsequently the hybrid magma of the ULST until Laacher See eruption.

Diffusion times calculated for olivine from the basanite samples E41 and EPB are generally longer (up to 490 days). Olivine from E41 gave a range of timescales between 47 (+18/-14) and 406 (+238 / -126) days for Mg-Fe diffusion. Mn, Ca, and Ni gave comparable results, except for crystal E41-4-3, with $t_{\mathrm{Fo}}=406$ days and $\mathrm{t}_{\mathrm{Ni}}=154(+64 /-82)$ days. However, given the uncertainties these diffusion times still overlap. 


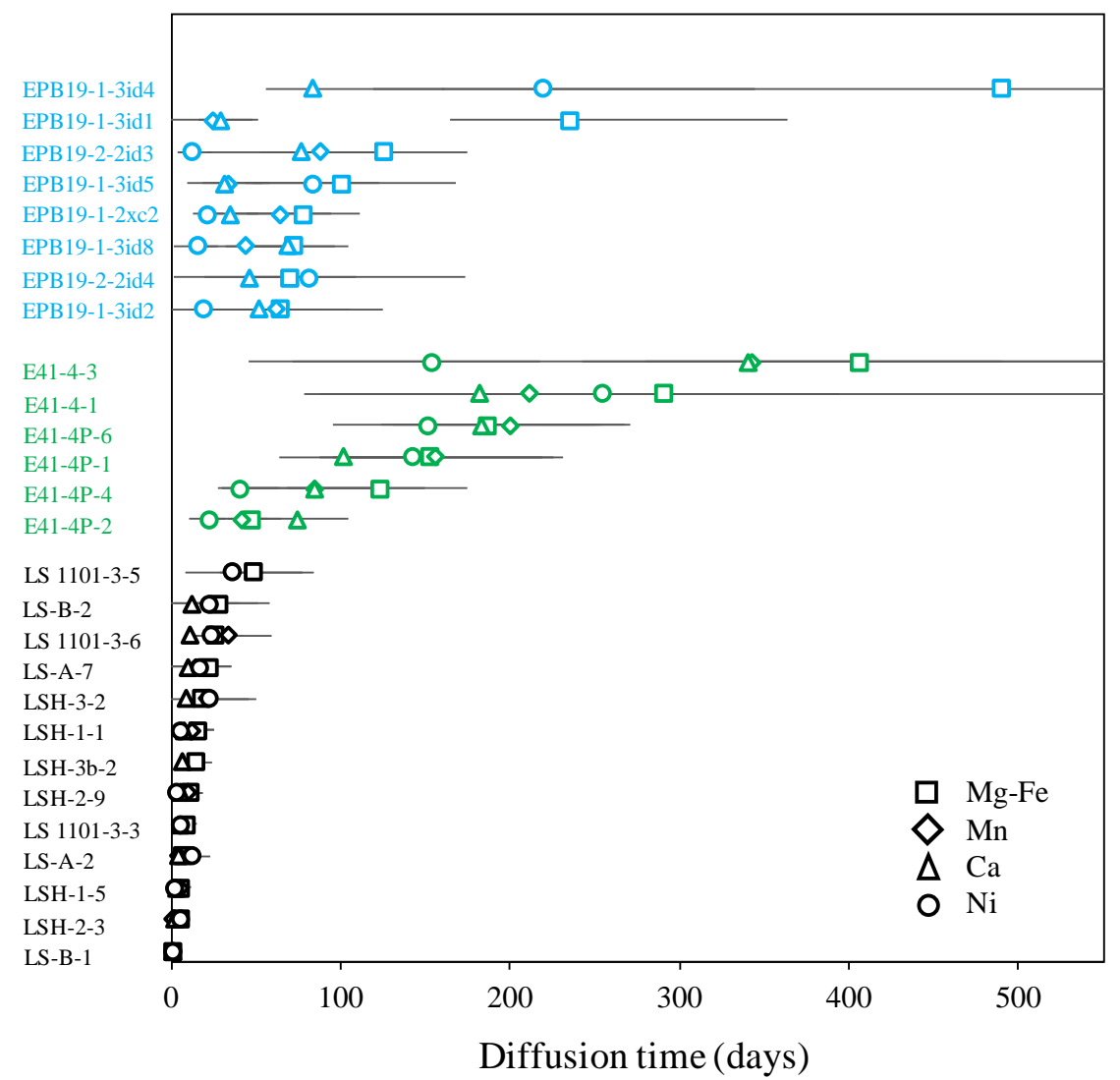

Fig. 9 Diffusion times of $\mathrm{Mg}-\mathrm{Fe}, \mathrm{Mn}, \mathrm{Ca}$, and $\mathrm{Ni}$ in olivine from Laacher See, Rothenberg, and Eppelsberg. Diffusion times of analyzed olivine crystals from Laacher See are exceedingly short ( $<50$ days) indicating the phonolitic magma chamber was reactivated only months prior to eruption. Olivine from the basanitic samples show diffusion times, which vary from tens of days up to 500 days. Large uncertainties are mainly caused by temperature uncertainties. Modeling of major and trace elements within one crystal gave comparable diffusion times within the uncertainties except of one crystal from Eppelsberg, where diffusion of Fo differs by a factor of 10 from trace elements.

Olivine from EPB gave Mg-Fe diffusion times of $64(+42 /-42)$ to $490(+327 /$-330) days (maximum times along a-axis). These samples have both the largest uncertainties and the largest scatter retrieved from Mg-Fe and trace element modeling (Tab. 1). By contrast, diffusion times for trace elements range between 25 and 88 days for $\mathrm{Mn}, 29$ to 77 days for $\mathrm{Ca}$, and 12 to 83 days for $\mathrm{Ni}$ (excepting EPB19-1-3id4). These diffusion times for trace elements are in agreement with each other (within uncertainties; Fig. 9; Tab. 1). Thus, even for the same crystal crystals, the diffusion times for Fo are up to 10 times longer than those estimated for trace elements. Such systematically shorter diffusion times indicate a problem with the simple model set up: For several crystals, additional compositional steps are observed in the trace element profiles, which indicate a multistep growth between core and rim rather than a single event. These steps are absent in Fo-profiles, because they were likely already erased by diffusion. Therefore, modeling the Fo-content with a 
single step between core and rim, but two or more steps for the trace elements results in the observed deviation and an overestimation of $\mathrm{Mg}$-Fe diffusion times. However, it is not possible to identify and model the initial multi-step profiles for Fo. Therefore, the shorter diffusion times for trace elements are likely to be more realistic than those obtained from $\mathrm{Mg}$-Fe modeling.

Tab. 1 Diffusion times of olivine crystals from Laacher See mafic phonolite-basanite hybrid clasts (LSsamples) and Rothenberg (E41) and Eppelsberg (EPB) basanite. Diffusion times from EPB are maximum times calculated for diffusion along a-axis.

\begin{tabular}{|c|c|c|c|c|c|c|c|c|c|c|c|c|}
\hline \multirow[t]{2}{*}{ Crystal No. } & \multicolumn{3}{|c|}{$\mathrm{Mg}-\mathrm{Fe}$} & \multicolumn{3}{|c|}{$\mathrm{Mn}$} & \multicolumn{3}{|c|}{$\mathrm{Ca}$} & \multicolumn{3}{|c|}{$\mathrm{Ni}$} \\
\hline & Time & - & + & Time & - & + & Time & - & + & Time & - & + \\
\hline LS-A-2 & 7 & 4 & 4 & 4 & 3 & 4 & 9 & 4 & 5 & 12 & 6 & 11 \\
\hline LS-A-7 & 22 & 8 & 14 & 14 & 14 & 22 & 30 & 13 & 18 & 17 & 9 & 10 \\
\hline LS-B-1 & 1 & 1 & 1 & 1 & 1 & 3 & 1 & 1 & 1 & 1 & 1 & 1 \\
\hline LS-B-2 & 28 & 13 & 23 & 22 & 20 & 36 & 17 & 7 & 10 & 22 & 11 & 18 \\
\hline LSH-1-1 & 16 & 9 & 9 & 12 & 5 & 13 & 25 & 11 & 14 & 5 & 4 & 4 \\
\hline LSH-1-5 & 6 & 4 & 5 & 6 & 4 & 6 & - & - & - & 2 & 2 & 4 \\
\hline LSH-2-3 & 5 & 3 & 4 & 1 & 1 & 3 & 9 & 8 & 6 & 6 & 3 & 4 \\
\hline LSH-2-9 & 11 & 6 & 7 & 10 & 5 & 8 & 13 & 6 & 12 & 3 & 2 & 3 \\
\hline LSH-3-2 & 18 & 6 & 10 & 21 & 10 & 25 & 20 & 8 & 16 & 23 & 14 & 27 \\
\hline LSH-3b-2 & 14 & 9 & 10 & - & - & - & - & - & - & - & - & - \\
\hline $1101-3-3$ & 9 & 3 & 6 & 5 & 2 & 4 & 9 & 3 & 7 & 5 & 3 & 3 \\
\hline $1101-3-5$ & 49 & 20 & 35 & - & - & - & - & - & - & 36 & 28 & 41 \\
\hline $1101-3-6$ & 26 & 14 & 16 & 34 & 12 & 25 & - & - & - & 24 & 10 & 14 \\
\hline E41-4-1 & 291 & 213 & 103 & 211 & 61 & 159 & 182 & 80 & 77 & 254 & 167 & 346 \\
\hline E41-4-3 & 406 & 126 & 238 & 343 & 297 & 252 & 340 & 97 & 151 & 154 & 82 & 64 \\
\hline E41-4P-1 & 153 & 66 & 78 & 156 & 61 & 63 & 102 & 38 & 59 & 142 & 43 & 84 \\
\hline E41-4P-2 & 47 & 14 & 18 & 42 & 14 & 15 & 74 & 32 & 31 & 22 & 11 & 10 \\
\hline E41-4P-4 & 123 & 55 & 52 & 85 & 55 & 65 & 85 & 48 & 34 & 41 & 14 & 23 \\
\hline E41-4P-6 & 187 & 57 & 67 & 200 & 54 & 71 & 183 & 59 & 67 & 151 & 56 & 116 \\
\hline ЕРВ19-1-2xс2 & 78 & 33 & 33 & 64 & 27 & 30 & 35 & 18 & 16 & 21 & 8 & 10 \\
\hline ЕРB19-1-3id1 & 235 & 71 & 129 & 25 & 9 & 23 & 29 & 30 & 22 & - & - & - \\
\hline ЕРB19-1-3id2 & 64 & 42 & 42 & 62 & 38 & 63 & 52 & 16 & 37 & 19 & 19 & 37 \\
\hline ЕРB19-1-3id4 & 490 & 330 & 327 & - & - & - & 84 & 28 & 77 & 219 & 100 & 125 \\
\hline ЕРВ19-1-3id5 & 101 & 53 & 67 & 34 & 25 & 24 & 31 & 13 & 23 & 83 & 40 & 40 \\
\hline ЕРВ19-1-3id8 & 72 & 26 & 33 & 44 & 26 & 26 & 69 & 37 & 28 & 16 & 14 & 12 \\
\hline ЕРB19-2-2id3 & 125 & 52 & 50 & 88 & 67 & 40 & 77 & 24 & 42 & 12 & 8 & 12 \\
\hline EPB19-2-2id4 & 70 & 28 & 39 & - & - & - & 46 & 26 & 26 & 81 & 79 & 92 \\
\hline
\end{tabular}

\subsection{Implications for magmatic evolution and eruption}

Olivine compositions and zoning patterns show that basanite from the East and nephelinite magmas from the West Eifel volcanic field are distinct in their origin and histories. They are again different from the basanite magma that intruded into the Laacher See magma system and most likely triggered its eruption $12.9 \mathrm{kyr}$ ago. The observation that olivine from the East Eifel basanite samples are less forsteritic (corresponding to more evolved magmas) than those from the West Eifel, correlates with the generally more evolved volcanic products in the East Eifel compared to the West 
Eifel (Schmincke 2007) and the scarcity of mantle. Our analyses of olivine crystals reveal two distinct trends for East and West Eifel volcanic products with respect to their Fo- and NiOrelationship (Fig. 6a). Olivine core compositions from the West Eifel nephelinite samples fall on a steep crystallization trend of mantle-derived melts starting from an equilibrium composition with $>\mathrm{Fo}_{90}$ and high $\mathrm{NiO}(>0.3 \mathrm{wt} . \%)$. The near primary nature of these nephelinite magmas is also indicated by the abundance of mantle-derived peridotite xenoliths (Meerfelder Maar; WittEickschen et al. 2003) and high-pressure cumulates from the base of the crust (Pulvermaar; Lloyd 1987; Duda and Schmincke 1985).

The reverse zoning pattern commonly found in olivine from East Eifel basanite samples indicate a common history for most olivine crystals and their host magmas, which is different from that of the nephelinites. The compositional range of their cores results from mixing of variably evolved basanitic melts with equilibrium olivine of $<\mathrm{Fo}_{88}$ and low $\mathrm{NiO}(<0.2 \mathrm{wt} . \%)$. The typical reverseloop zonation starting from these cores towards a relatively uniform, more forsteritic rim (Fo 86.5 87.5) indicate that these magmas and their olivine crystals were entrained/mixed after previous storage by new ascending, more mafic basanite magmas. Note that this history appears to be repeated in all basanite-derived olivine crystals. The uniform rim composition $(\sim \mathrm{Fo}$ 86.5-87.5, $\mathrm{NiO}=$ 0.1-0.2 wt.\%) corresponds (1) to the maximum Fo-content found in olivine cores from East Eifel basanite and (2) marks the common rim composition, to which all cores equilibrated. This composition also is equivalent (3) to the common composition of olivine grain boundaries from Laacher See hybrids. Moreover (4), this common composition is also the minimum Fo- and NiOcontent found in olivine rims / grain boundaries in West Eifel nephelinite samples, whose magnesian cores represent primary magma compositions (Fig. 6a-c). Thus, this composition is common to all samples that we studied and is intermediate between more evolved basanite (cores) and primary mantle-derived melts.

\subsubsection{History and composition of the Laacher See recharge magma}

It was previously assumed that the basanite recharging into the Laacher See magma chamber is equivalent to magmas previously erupted in older basanitic scoria cones surrounding the Laacher See volcano (Wörner and Wright 1984). However, the cores of olivine macrocrysts in Laacher See hybrids show a large compositional range that extends from $\mathrm{Fo}_{83}$ to $>\mathrm{Fo}_{88}$ (Fig. 6a) and their rim compositions even reach up to $\mathrm{Fo}_{89.1}$ and $\mathrm{NiO}=0.24 \mathrm{wt}$. $\%$. Such olivine composition is neither observed in East Eifel basanite nor West Eifel nephelinite and extends the trend of olivine cores from basanites towards a more magnesian composition (Fig. 6a). These magnesian olivine macrocrysts in the Laacher See hybrids then indicate that the recharging basanite had a different history and composition from basanites that erupted in scoria cones (Fig. 5, 6b, 10b I). The large 
range in core compositions, however, also at least partly overlaps with cores observed in basanites und therefore indicate that some olivine crystals in the recharging basanite initially had similar histories compared to those in the basanites erupted in scoria cones. However, before the basanite recharge entered the Laacher See magma chamber, it was in equilibrium with $\geq$ Fo $_{89}$, it contained magnesian microcrysts now found in the hybrid matrix and also carried (rare) mantle-derived peridotites. There are two important conclusions from these observations: (1) Just prior to recharge and mixing with the phonolite, this new magma had entrained olivine crystals with a range of compositions that were stored either in a crystal mush or contained in basanite magma in the crust at the time when the Laacher See volcano erupted, and (2) this new basanite magma was significantly more mafic than any of the basanites erupted from the nearby scoria cones. The outer grain boundaries of olivine crystals from the hybrids are uniform in composition (Fo86.5-87.5, Fig. 6c) and thus reflect the composition in equilibrium with the hybrid matrix that formed after basanitephonolite mixing.

\subsubsection{Origin and mixing history of basanite magmas in the East Eifel}

Distinct growth zones in olivine crystals from the basanite samples shown by $\mathrm{P}$ - and Al-content are evidence for several heating events (Milman-Barris et al. 2008) that may reflect frequent recharges as documented also from products of several eruptive centers in the WEVF (Shaw et al. 2002; Shaw 2004). The basanite magmas from the scoria cones are either products of mixing between mafic magmas with variable, slightly more evolved magmas or they entrained cumulate crystals of variable composition from a residual crystal mush. In both cases, a compositional range of low-Fo olivine cores is observed. Since no magnesian olivine cores $>\mathrm{Fo}_{88}$ are found in basanite lavas, the mafic endmember of mixing cannot have been a primary magma which would be expected to carry olivine $>\mathrm{FO}_{90}$ as is recorded in West Eifel nephelinites. Except for the recharge magma that formed the Laacher See hybrids, there is no evidence for (near-) primary basanite magmas erupted to the surface in the East Eifel. However, both the basanites and the Laacher See hybrids may share a similar magnesian endmember (Fo89). The common composition Fo86.5-87.5 can be produced by mixing of more evolved basanite magma (represented by the variable olivine cores with Fo80-86) and a recharge in equilibrium with $\mathrm{Fo}_{89}$.

If the recharging basanite from the Laacher See is compositionally different ( $\left.\mathrm{Fo}_{89}\right)$, this brings up the question why this composition is absent in olivine crystals from the "regular" basanite samples from scoria cones. Whatever the reason is for this difference, it must be related to a particular character of the basanite magma that mixed with and triggered the eruption of the Laacher See phonolite. 
The different diffusion times calculated for olivine from Laacher See and the basanite samples indicate that time may be a significant factor in explaining the differences. Although only olivine from two basanitic samples (EPB and E41) were modeled and their diffusion times and these may not be representative for the East Eifel basanite eruptions in general, we note that the timescales for mixing and diffusion are up to 10 times longer than those obtained from the basanite involved in the formation of the Laacher See hybrids. Possibly, the olivine crystals from the basanite samples equilibrated during longer diffusion times at high temperatures $\left(\sim 1100^{\circ} \mathrm{C}\right)$ to "erode" initially Forich compositions towards the common composition found in the basanites. To test this hypothesis further studies on olivine diffusion times from many more basanitic cones would be needed. Alternatively, we suggest that differences in the magmatic plumbing and ascent time are crucial factors.

This implies that (1) scoria cones are fed from basanite magmas with an extended history (weeks to > one year) of residence and basanite-basanite mixing and (2) the Laacher See eruption involved mixing and mingling with a more mafic basanite magmas that must have risen directly from mantle magma reservoirs in much shorter time (months). If true, this would have profound implications for assessing precursor activity of potential future eruptions in the region.

\subsubsection{What happened prior to the eruption of the Laacher See volcano?}

The pre-eruptive processes, eruption triggering events and the timescales of reactivation of the Laacher See magmatic system have long been subject to study, but details remain unclear. U-Th isotope dating of minerals that crystallized from the Laacher See phonolite magma has clearly shown that evolved phonolitic magmas resided for more than 20.000 years below the Laacher See volcano before it eventually erupted (Bourdon et al. 1994; Schmitt 2006; Schmitt et al. 2010). This naturally begs the question why phonolite magmas did not erupt earlier and what was the final triggering event. It is known from other volcanic settings that mafic recharge events and subsequent magma mixing may cause precursor geophysical activity (e.g. Kahl et al. 2011, 2013; Sundermeyer et al. 2020) and eventually trigger eruptions (Sparks 1977; Murphy et al. 2000; Eichelberger et al. 2006; Wright et al. 2011; Ruprecht and Plank 2013; Cashman and Giordano 2014; Wolff et al. 2015; Wiebe 2016). Therefore - with respect to the Eifel Volcanic fields, it is important to understand ascent and mixing time scales for mafic magmas. To this end, diffusion times of olivine were already calculated for several primitive eruptive centers in the West Eifel such as Baarley, Gemündener Maar, and Meerfelder Maar (Shaw and Klügel 2002; Shaw 2004). Zoned olivine in xenoliths document fast ascent times from the mantle and probably several recharge events only years prior to the eruption (Shaw 2004) with only months to hours between the last mixing and eruption (Shaw and Klügel 2002; Denis et al. 2013; Shaw et al. 2018). 


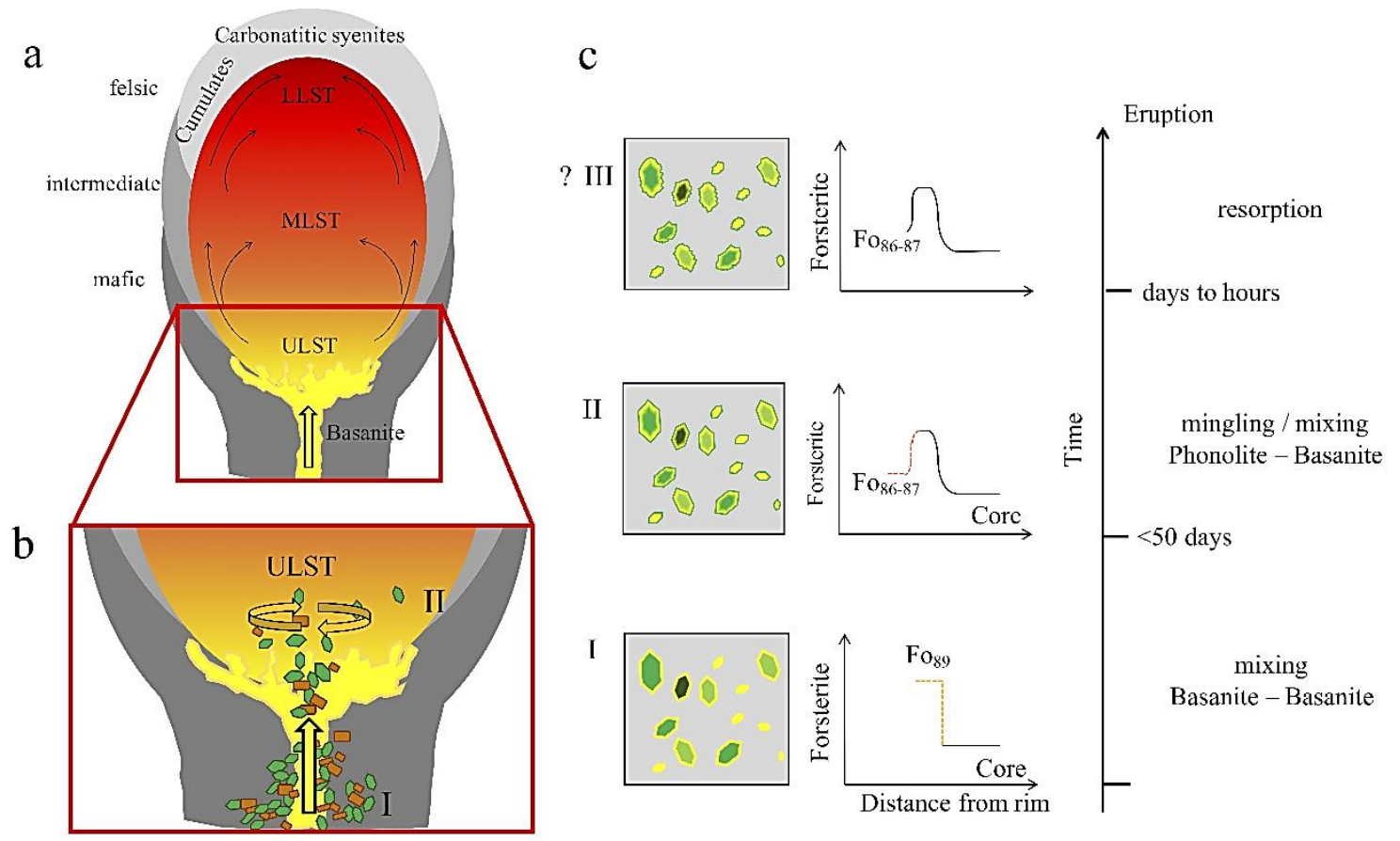

Fig. 10 (a) Schematic drawing of the chemically zoned Laacher See magma chamber (after Wörner and Schmincke 1984b; Tait et al. 1989; Ginibre et al. 2004; Schmitt et al. 2010). (b) shows a zoom of the lower part of the magma chamber and the processes of recharge, crystal reactivation, and mixing, which are detailed shown in (c). (I) An ascending basanite in equilibrium with Fo 89 partially disaggregates a crystal mush below the phonolitic Laacher See magma chamber. Olivine cores were reactivated from the mush and start to equilibrate to Fo89. At the same time, small olivine crystals from in the groundmass. (II) The basanitic recharge enters the lower part of the magma chamber and mixes with the crystal-rich phonolite producing the mafic phonolite-basanite hybrids. Due to cooling and changing melt composition, the olivine antecrysts form an outermost overgrowth and equilibrate to Fo86.5-87.5 within up to 50 days. (III) The grain boundaries of olivine crystals are partially resorbed by a late dissolution event.

Diffusion times of olivine crystals analyzed in this study indicate similar timescales (within months) for the basanite magma that intruded into the Laacher See phonolite magma system just before the cataclysmic eruption $12.9 \mathrm{kyr}$ ago. Earlier recharge events that did not result in eruptions of phonolite magmas were constrained by Rout and Wörner (2020) to have occurred frequently every 1500 to 3000 years during the 20.000 years history of phonolite magma residence. Using diffusion modeling of zoned sanidine phenocrysts from carbonatitic syenites representing the top of the magma chamber (Fig. 10a), Rout and Wörner (2018) proposed a final heating and destabilization event within years prior to the eruption. This event is not preserved in the olivine crystals likely due to re-equilibration. However, Rout and Wörner (2018) also modeled diffusive re-equilibration of exsolution lamellae in sanidines, that formed during a period of relatively cold storage in the 
syenitic, crystal-rich carapace surrounding the magma reservoir that indicate heating above the solvus of $725^{\circ} \mathrm{C}$ within $15-50$ days prior to the eruption. These timescales are consistent with short olivine diffusion times calculated in this study at $\mathrm{T}=1114{ }^{\circ} \mathrm{C}$. The temperatures estimated for the syenites surrounding the phonolite are $\sim 325-400{ }^{\circ} \mathrm{C}$ lower than those calculated here for from olivine-spinel pairs in the basanite intruding into the base of the magma system. A strong temperature gradient must have existed between the LLST syenites, the evolved phonolite at the top to the mafic phonolite, phonolitic crystal mush and the intruding basanite at the bottom. Such a temperature gradient was already estimated by Wörner and Wright (1984) between the LLST to ULST phonolite $\left(800-860^{\circ} \mathrm{C}\right)$ and the mafic hybrids $\left(1060^{\circ} \mathrm{C}\right)$. This also supports the hypothesis that magma mixing / heating was restricted to the bottom of the reservoir as also indicated by the occurrence of hybrid components only in the uppermost ULST (i.e. the lowermost part of the magma chamber; Wörner and Wright 1984; Tait et al. 1989; Berndt et al. 2001; Ginibre et al. 2004). As outlined above, the olivine macrocrysts in the hybrid magmas had a history distinct from those found in basanitic scoria cones and were entrained into the basanite magma only shortly before mixing and eruption (stage I in Fig. 10). However, it is unconstrained whether these olivine crystals were stored before entrainment in a crystal mush at the bottom of the Laacher See magma chamber, i.e. resulted from the previous intrusions of basanite documented by Rout and Wörner (2020) or whether these olivine crystals were derived from a deeper reservoir below (and not directly connected to) the Laacher See magma reservoir. We can, however, speculate that the previous basanite intrusions were not able to enter the Laacher See magma chamber directly due to the nearly-rigid crystal mush functioning as a temporary barrier (Pallister et al. 1992) until a particularly strong recharge event brought new, near-primary magma from deep (mantle) levels. This caused destabilization of the Laacher See magma reservoir and eruption after 20.000 years of residence in the shallow crust. At this point in time, things were happening rather fast: The recharging basanite mixed with the phonolite, the olivine crystallized the outermost grain boundaries during cooling (normal zoning of olivine) and the rim-grain-boundary started to equilibrate by diffusion towards a less forsteritic composition of the hybrid matrix (Fo86.5-87.5) at a lower temperature $\sim 1100{ }^{\circ} \mathrm{C}$ (see II in Fig. 10b). Diffusion times show that this process of intrusion and mixing occurred months prior to eruption and therefore is very likely the final eruption trigger. These diffusion times are maximum estimates for a temperature of $1100^{\circ} \mathrm{C}$ and the period between mixing and the onset of eruption might have been even shorter.

The narrow range of timescales indicate that the recharge was a single event rather than an extended phase of continuous intrusions. Previous studies (Folch and Martí 1998; Snyder 2000; Wark et al. 2007) showed that mafic recharge events can trigger silicic eruptions within months even without wholesale magma mixing, simply due to overpressurization caused by volatile exsolution from the cooling and crystallizing recharge magma. A similar scenario is assumed to have triggered the 1991 
Pinatubo eruption (Pallister et al. 1992; Kress 1997; Folch and Martí 1998) and may be also reasonable for Laacher See.

Our results show that the phonolitic magma chamber can be activated and brought to eruption within months after an extended storage time of up to $20 \mathrm{kyr}$ of differentiated phonolite magma in the upper crust. Given the uncertainties in such diffusion modeling, this timescale is in accordance with estimates by Rout and Wörner (in press) based on diffusion modeling of Ba in sanidines from the same rocks that also gave diffusion times of months after phonolite-basanite mixing.

\subsection{Conclusions}

Magmatic processes prior to the phonolitic Laacher See eruption (12.9 kyr) have been reconstructed with respect to their timescales and the composition of involved magmas using compositions and diffusion modeling in olivine crystals from the hybrid phonolite-basanite tephra clasts that were produced at the very end of the eruptive sequence. These hybrids were interpreted to have formed after intrusion of basanite magma into the lowermost part of a chemically zoned phonolite magma chamber.

The composition and zonation of olivine crystals constrain the pre-eruptive history of the evolved Laacher See magma reservoir after 20 kyr of storage:

1. Laacher See hybrids that formed from basanite-phonolite mixing and mingling contain olivine crystals that show complex reverse zonation with variable cores ( Fo $\left._{83-89}\right)$. and more magnesian rims with Fo87.8-89.

2. Compositional mapping and measured profiles show that the smooth compositional gradients between core and rims formed by diffusion and partial equilibration after entrainment by a more mafic basanite magma.

3. The basanite that intruded into the resident Laacher See phonolite reservoir was more mafic than basanites erupted in nearby scoria cones. This unusually mafic basanite contained olivine crystals that were entrained from older intrusions during ascend just before entering the Laacher See magma system.

4. Mixing of mafic basanite and the crystal-rich phonolite magma at the base of the Laacher See magma chamber resulted in hybrids that are in equilibrium with Fo86.5-87.5 as shown by the outermost olivine grain boundary compositions.

5. Basanite lavas erupted from the older scoria cones surrounding Laacher See volcano represent slightly more evolved compositions as represented by their less forsteritic olivine cores $\left(\mathrm{Fo}_{80}\right.$ 88) compared to the basanite recharging the Laacher See reservoir $\left(\mathrm{Fo}_{89}\right)$. These cores 
equilibrated after mixing, but again with less mafic basanite hybrid magmas (in equilibrium with Fo86.5-87.5).

6. We document short diffusion times within the range of only months for the compositional zonation in olivine crystals from the Laacher See hybrids. The olivine crystals started diffusive equilibration with the mafic basanite (Fo89) before entering the Laacher See magma chamber. Subsequently the crystals further exchanged by diffusion to the new hybrid host (Fo86.5-87.5) after phonolite-basanite mixing. The calculated diffusion timescales encompass both, the time after entrainment of olivine by the mafic basanite and the mixing event just before eruption of Laacher See and are in close agreement with Ba-diffusion modeling on sanidine crystals from the same suite of hybrid rocks from Laacher See volcano by Rout and Wörner (parallel submission to CMP).

Our results for diffusion modeling of olivine in hybrid lava clasts from the Laacher See volcano give time scales that show that the Laacher See magma chamber erupted after $20 \mathrm{kyr}$ of crustal residence within a few to a maximum of 14 months after the intrusion of a new mafic basanite magma. This recharge event likely triggered the eruption by overpressurization due to intrusion, by cooling and crystallization of, and volatile exsolution from the recharge magma.

\section{Acknowledgements}

We thank K. Techmer for help with EBSD measurements and A. Kronz for guiding our electron microprobe analyses. B. Gordeychik is appreciated for his support in diffusion modeling. 


\section{References}

Albert H, Costa F, Martí J (2015) Timing of magmatic processes and unrest associated with mafic historical monogenetic eruptions in Tenerife Island: J Petrol 56(10):1945-1966. https://doi.org/10.1093/petrology/egv058

Albert H, Costa F, Martí J (2016) Years to weeks of seismic unrest and magmatic intrusions precede monogenetic eruptions. Geology 44(3):211-214. https://doi.org/10.1130/G37239.1

Albert H, Costa F, Di Muro A, Herrin J, Métrich N, Deloule E (2019) Magma interactions, crystal mush formation, timescales, and unrest during caldera collapse and lateral eruption at ocean island basaltic volcanoes (Piton de la Fournaise, La Réunion). Earth Planet Sci Lett 515: 187-199. https://doi.org/10.1016/j.eps1.2019.02.035

Baales M, Jöris O, Street M, Bittmann F (2002) Impact of the late glacial eruption of Laacher See volcano, Central Rhineland, Germany. Quat Res 58(3):272-288. https://doi.org/10.1006/qres.2002.2379

Bachmann O, Bergantz GW (2004) On the origin of crystal-poor rhyolites: extracted from batholithic crystal mushes. J Petrol 45(8):1565-1582. https://doi.org/10.1093/petrology/egh019

Bednarz U, Schmincke H-U (1990) Evolution of the Quaternary melilite-nephelinite Herchenberg volcano (East Eifel). Bull Volcanol 52:426-444.

Berndt J, Holtz F, Koepke J (2001) Experimental constraints on storage conditions in the chemically zoned phonolitic magma chamber of the Laacher See volcano. Contrib Mineral Petrol 140:469-486.

Bourdon B, Zindler A, Wörner G (1994) Evolution of the Laacher See magma chamber: Evidence from SIMS and TIMS measurements of U-Th disequilibria in minerals and glasses. Earth Planet Sci Lett 126:75-90.

Bouvet de Maissonneuve C, Costa F, Huber C, Vonlanthen P, Bachmann O, Dungan MA (2016) How do olivines record magmatic events? Insights from major and trace element zoning. Contrib Mineral Petrol 171(56). https://doi.org/10.1007/s00410-016-1264-6 
Bradshaw RW, Kent AJR, Tepley III FJ (2018) Chemical fingerprints and residence times of olivine in the 1959 Kilauea Iki eruption, Hawaii: Insights into picrite formation. Am Mineral 103(11):1812-1826. https://doi.org/10.2138/am-2018-6331

Brauer A, Endres C, Negendank JFW (1999) Lateglacial calendar year chronology based on annually laminated sediments from Lake Meerfelder Maar, Germany. Quatern Int 61(1):1725. https://doi.org/10.1016/S1040-6182(99)00014-2

Brenna M, Cronin SJ, Smith IEM, Tollan PME, Scott LM, Prior DJ, Baambery K, Ukstins IA (2018) Olivine xenocryst diffusion reveals rapid monogenetic basaltic magma ascent following complex storage at Pupuke Maar, Auckland Volcanic Field, New Zealand. Earth Planet Sci Lett 499:13-22. https://doi.org/10.1016/j.eps1.2018.07.015

Bronk Ramsey C, Albert PA, Blockley SPE, Hardiman M, Housley RA, Lane CS, Lee S, Matthews IP, Smith VC, Lowe JJ (2015) Improved age estimates for key Late Quaternary European tephra horizons in the RESET lattice. Quat Sci Rev 118:18-32. https://doi.org/10.1016/j.quascirev.2014.11.007

Carslaw HS, Jaeger JC (1959) Conduction of heat in solids. 2nd edn. Clarendon Press, Oxford, p 510.

Cashman KV, Giordano G (2014) Calderas and magma reservoirs. J Volcanol Geotherm Res 288:28-45. https://doi.org/10.1016/j.jvolgeores.2014.09.007

Chakraborty, S, Ganguly J (1991) Compositional zoning and cation diffusion in garnets. In: Ganguly J (ed) Diffusion, atomic ordering and mass transport. Advances in Physical Geochemistry, Vol. 8. Springer-Verlag, New York, p 120-175. https://doi.org/10.1007/978-1-4613-9019-0 4

Coogan LA, Saunders AD, Wilson RN (2014) Aluminium-in-olivine thermometry of primitive basalts: Evidence of an anomalously hot mantle source for large igneous provinces. Chem Geol 368:1-10. http://dx.doi.org/10.1016/j.chemgeo.2014.01.004

Cooper KM, Kent AJR (2014) Rapid remobilization of magmatic crystals kept in cold storage. Nature 506:480-483. https://doi.org/10.1038/nature12991

Cooper KM, Sims KWW, Eiler JM, Banerjee N (2016) Timescales of storage and recycling of crystal mush at Krafla Volcano, Iceland. Contrib Mineral Petrol 171(6):54. https://doi.org/10.1007/s00410-016-1267-3 
Costa F, Chakraborty S (2004) Decadal time gaps between mafic intrusion and silicic eruption obtained from chemical zoning patterns in olivine. Earth Planet Sci Lett 227(3-4):517-530. https://doi.org/10.1016/j.epsl.2004.08.011

Costa F, Dungan M (2005) Short time scales of magmatic assimilation from diffusion modeling of multiple elements in olivine. Geology 33(10):837-840. https://doi.org/10.1130/g21675.1

Costa F, Dohmen R, Chakraborty S (2008) Time scales of magmatic processes from modeling the zoning patterns of crystals. Rev Mineral Geochem 69(1):545-594. https://doi.org/10.2138/rmg.2008.69.14

Denis CMM, Demouchy S, Shaw CSJ (2013) Evidence of dehydration in peridotites from the Eifel volcanic field and estimates on the rate of ascent. J Volcanol Geotherm Res 258:85-99. http://dx.doi.org/10.1016/j.jvolgeores.2013.04.010

Dohmen R, Becker H-W, Chakraborty (2003) Point defect equilibration and diffusion in olivine at low temperatures $\left(\mathrm{T}<1000^{\circ} \mathrm{C}\right)$. Eur J Mineral 15(42).

Duda A, Schmincke H-U (1985) Polybaric differentiation of alkali basaltic magmas: evidence from green-core clinopyroxenes (Eifel, FRG). Contrib Mineral Petrol 91:340-353.

Druitt TH, Costa F, Deloule E, Dungan M, Scaillet B (2012) Decadal to monthly timescales of magma transfer and reservoir growth at a caldera volcano. Nature 482, 77-80. https://doi.org/10.1038/nature10706

Druitt TH, Mercier M, Florentin L, Deloule E, Cluzel N, Flaherty T, Médard E, Cadoux A (2016) Magma storage and extraction associated with plinian and interplinian activity at Santorini caldera (Greece). J Pet 57(3):461-494. https://doi.org/10.1093/petrology/egw015

Eichelberger JC, Izbekov PE, Browne BL (2006) Bulk chemical trends at arc volcanoes are not liquid lines of descent. Lithos 87(1-2):135-154. https://doi.org/10.1016/j.lithos.2005.05.006

Engels S, van Geel B, Buddelmeijer N, Brauer A (2015) High-resolution palynological evidence for vegetation response to the Laacher See eruption from the varved record of Meerfelder Maar (Germany) and other central European records. Rev Palaeobot Palyno 221:160-170. https://doi.org/10.1016/j.revpalbo.2015.06.010 
Fekiacova Z, Mertz DF, Renne P (2003) Geodynamic setting of the Hocheifel volcanism, western Germany. Geophysical Research Abstracts 5:10355.

Folch A, Martí J (1998) The generation of overpressure in felsic magma chambers by replenishment. Earth Planet Sci Lett 163:301-314.

Ginibre C, Wörner G, Kronz A (2004) Structure and dynamics of the Laacher See magma chamber (Eifel, Germany) from major and trace element zoning in sanidine: a cathodoluminescence and electron microprobe study. J Petrol 45(11):2197-2223. https://doi.org/10.1093/petrology/egh053

Girona T, Costa F (2013) DIPRA: A user-friendly program to model multi-element diffusion in olivine with applications to timescales of magmatic processes. Geochem Geophys Geosyst 14(2):422-431. https://doi.org/10.1029/2012GC004427

Gordeychik B, Churikova T, Kronz A, Sundermeyer C, Simakin A, Wörner G (2018) Growth of, and diffusion in, olivine in ultra-fast ascending basalt magmas from Shiveluch volcano. Sci Rep 8(11775):1-15. https://doi.org/10.1038/s41598-018-30133-1

Gordeychik B, Churikova T, Simakin A, Shea T, Wörner G (2020) Fo and Ni relations in olivine differentiate between crystallization and diffusion trends. (in revision, J Petrol, November $19,2019)$

Harms E, Schmincke H-U (2000) Volatile composition of the phonolitic Laacher See magma (12,900 yr BP): implications for syn-eruptive degassing of $\mathrm{S}, \mathrm{F}, \mathrm{Cl}$ and $\mathrm{H}_{2} \mathrm{O}$. Contrib Mineral Petrol 138:84-98.

Harms E, Gardner JE, Schmincke H-U (2004) Phase equilibria of the Lower Laacher See Tephra (East Eifel, germany): constraints on pre-eruptive storage conditions of a phonolitic magma reservoir. J Volcanol Geotherm Res 134(1-2):135-148.

Hildreth W, Wilson CJN (2007) Compositional zoning of the Bishop Tuff. J Petrol 48(5):951-999. https://doi.org/10.1093/petrology/egm007

Jung C, Jung S, Hoffer E, Berndt J (2006) Petrogenesis of Tertiary mafic alkaline magmas in the Hocheifel, Germany. J Petrol 47(8):1637-1671. https://doi.org/10.1093/petrology/eg1023 
Kahl M, Chakraborty S, Costa F, Pompilio M (2011) Dynamic plumbing system beneath volcanoes revealed by kinetic modeling, and the connection to monitoring data: An example from Mt. Etna. Earth Planet Sci Lett 308(1-2):11-22. https://doi.org/10.1016/j.epsl.2011.05.008

Kahl M, Chakraborty S, Costa F, Pompilio M, Liuzzo M, Viccaro M (2013) Compositionally zoned crystals and real-time degassing data reveal changes in magma transfer dynamics during the 2006 summit eruptive episodes of Mt. Etna. Bull Volcanol 75(2):692. https://doi.org/10.1007/s00445-013-0692-7

Kress V (1997) Magma mixing as a source for Pinatubo sulphur. Nature 389:591-593.

Lane CS, Brauer A, Martín-Puertas C, Blockley SPE, Smith VC, Tomlinson EL (2015) The late Quaternary tephrostratigraphy of annually laminated sediments from Meerfelder Maar, Germany. Quat Sci Rev 122:192-206. https://doi.org/10.1016/j.quascirev.2015.05.025

Lloyd FE (1987) Characterization of mantle metasomatic fluids in spinel lherzolites and alkali clinopyroxenites from the West Eifel and South West Uganda. In: Menzies M, Hawkesworth CJ (eds), Mantle Metasomatism. Academic Press, London, pp 911-1023.

Lynn KJ, Shea T, Garcia MO (2017) Nickel variability in Hawaiian olivine: Evaluating the relative contributions from mantle and crustal processes. Am Mineral 102:507-518. http://dx.doi.org/10.2138/am-2017-5763

Lynn KJ, Shea T, Garcia MO, Costa F, Norman MC (2018) Li diffusion in olivine records magmatic priming of explosive basaltic eruptions. Earth Planet Sci Lett 500:127-135. https://doi.org/10.1016/j.eps1.2018.08.002

Marsh BD (2006) Dynamics of magmatic systems. Elements 2, 287-292. https://doi.org/10.2113/gselements.2.5.287

Mertes H (1983) Aufbau und Genese des Westeifeler Vulkanfeldes. Bochumer Geol und Geotechn Arb 9:1-415.

Mertes H, Schmincke H-U (1985) Mafic potassic lavas of the Quaternary West Eifel volcanic field. Contrib Mineral Petrol 89:330-345.

Michon L, Merle O (2001) The evolution of the massif Central rift: spatio-temporal distribution of the volcanism. Bulletin de la Société Géologique de France 172:201-211. 
Milman-Barris MS, Beckett JR, Baker MB, Hofmann AE, Morgan Z, Crowley MR, Vielzeuf D, Stolper E (2008) Zoning of phosphorous in igneous olivine. Contrib Mineral Petrol 155(6):739-765. https://doi.org/10.1007/s00410-007-0268-7

Murphy MD, Sparks RSJ, Barclay J, Carroll MR, Brewer TS (2000) Remobilization of andesite magma by intrusion of mafic magma at the Soufriere Hills Volcano, Montserrat, West Indies. J Petrol 41(1):21-42.

Mutch EJF, Maclennan J, Shorttle O, Edmonds M, Rudge JF (2019) Rapid transcrustal magma movement under Iceland. Nat Geosci 12:569-574. https://doi.org/10.1038/s41561-019$\underline{0376-9}$

Nakamura M (1995) Residence times and crystallization history of nickeliferous olivine phenocrysts from the northern Yatsugatake volcanoes, Central Japan: Application of a growth and diffusion model in the system Mg-Fe-Ni. J Volcanol Geotherm Res 66(1-4):81100.

Nowell DAG, Jones MC, Pyle DM (2006) Episodic Quaternary volcanism in France and Germany. J Quat Sci 21(6):645-675. https://doi.org/10.1002/jqs.1005

Pallister JS, Hoblitt RP, Reyes AG (1992) A basalt trigger for the 1991 eruptions of Pinatubo volcano? Nature 356:426-428.

Petrone CM, Bugatti G, Braschi E, Tommasini S (2016) Pre-eruptive magmatic processes re-timed using a non-isothermal approach to magma chamber dynamics. Nat Commun 7:12946. https://doi.org/10.1038/ncomms12946

Prior DJ, Boyle AP, Brenker F, Cheadle MC, Day A, Lopez G, Peruzzi L, Potts G, Reddy S, Spiess R, Timms NE, Trimby P, Wheeler J, Zetterstrom L (1999) The application of electron backscatter diffraction and orientation contrast imaging in the SEM to textural problems in rocks. Am Mineral 84(11-12):1741-1759. https://doi.org/10.2138/am-1999-11-1204

Rasmussen DJ, Plank TA, Roman DC, Power JA, Bodnar RJ, Hauri EH (2018) When does the eruption run-up begin? Multidisciplinary insight from the 1999 eruption at Shishaldin volcano. Earth Planet Sci Lett 486:1-14. https://doi.org/10.1016/j.eps1.2018.01.001

Ritter JRR, Jordan M, Christensen UR, Achauer U (2001) A mantle plume below the Eifel volcanic fields, Germany. Earth Planet Sci Lett 186:7-14. 
Rout SR, Wörner G (2018) Zoning and exsolution in alkali feldspars from Laacher See volcano (Western Germany): constraints on temperature history prior to eruption. Contrib Mineral Petrol 173(95). https://doi.org/10.1007/s00410-018-1522-X

Rout SS, Schmidt BC, Wörner G (2020) Constraints on non-isothermal diffusion modeling: An experimental analysis and error assessment using halogen diffusion in melts. Am Mineral 105(2):227-238. https://doi.org/10.2138/am-2020-7193

Rout, SS, Wörner G (2020) Constraints on the pre-eruptive magmatic history of Laacher See volcano (Germany) (submitted March 2020 to Contrib Mineral Petrol)

Rubin AE, Cooper KM, Till CB et al. (2017) Rapid cooling and cold storage in a silicic magma reservoir recorded in individual crystals. Science 356:1154-1156.

Ruprecht P, Plank T (2013) Feeding andesitic eruptions with a high-speed connection from the mantle. Nature 500,68-72. https://doi.org/10.1038/nature12342

Schmincke H-U (1977). Eifel Vulkanismus östlich des Gebietes Rieden-Mayen. Fortschr Mineral 55(2):1-32.

Schmincke H-U, Park C, Harms E (1999) Evolution and environmental impacts of the eruption of Laacher See volcano (Germany) 12,900 a BP. Quat Int 61:61-72.

Schmincke H-U (2007) The Quaternary Volcanic Fields of the East and West Eifel (Germany). In: Ritter JRR, Christensen UR (eds) Mantle Plumes. Springer, Berlin, Heidelberg.

Schmitt AK (2006) Laacher See revisited: High-spatial-resolution zircon dating indicates rapid formation of a zoned magma chamber. Geology 34(7):597-600. https://doi.org/10.1130/G22533.1

Schmitt AK, Wetzel F, Cooper KM, Zou H, Wörner G (2010) Magmatic longevity of Laacher See volcano (Eifel, Germany) indicated by U-Th dating of intrusive carbonatites. J Petrol 51(5):1053-1085. https://doi.org/10.1093/petrology/egq011

Shaw CSJ, Klügel A (2002) The pressure and temperature conditions and timing of glass formation in mantle-derived xenoliths from Baarley, West Eifel, Germany: the case for amphibole breakdown, lava infiltration and mineral - melt reaction. Miner Petrol 74:163-187. https://doi.org/10.1007/s007100200003 
Shaw CSJ (2004) The temporal evolution of three magmatic systems in the West Eifel volcanic field, Germany. J Volcano Geotherm Res 131(3-4):213-240. https://doi.org/10.1016/S0377-0273(03)00363-9

Shaw CSJ, Lebert BS, Woodland AB (2018) Thermodynamic modelling of mantle-melt interaction evidenced by veined wehrlite xenoliths from the Rockeskyllerkopf volcanic complex, West $\begin{array}{lllll}\text { Eifel volcanic field, Germany. J } & \text { Petrol }\end{array}$ https://doi.org/10.1093/petrology/egy018

Shea T, Lynn KJ, Garcia MO (2015b) Cracking the olivine zoning code: Distinguishing between crystal growth and diffusion. Geology 43(10):935-938. https://doi.org/10.1130/G37082.1

Snyder D (2000) Thermal effects of the intrusion of basaltic magma into a more silicic magma chamber and implications for eruption triggering. Earth Planet Sci Lett 175:257-273. https://doi.org/10.1016/S0012-821X(99)00301-5

Sparks SRJ, Sigurdsson H, Wilson L (1977) Magma mixing: a mechanism for triggering acid explosive eruptions. Nature 267:315-318.

Sundermeyer C, Di Muro A, Gordeychik B, Wörner G (2020) Timescales of magmatic processes during the eruptive cycle 2014-2015 at Pion de la Fournaise, La Réunion, obtained from Mg-Fe diffusion modelling in olivine. Contrib Mineral Petrol 175(1). https://doi.org/10.1007/s00410-019-1642-y

Tait SR, Wörner G, van den Bogaard P, Schmincke H-U (1989) Cumulate nodules as evidence for convective fractionation in a phonolite magma chamber. J Volcanol Geotherm Res 37:2137.

Ubide T, Kamber BS (2018) Volcanic crystals as time capsules of eruption history. Nat Commun 9(326):1-12. https://doi.org/10.1038/s41467-017-02274-w

van den Bogaard P, Schmincke H-U (1984) The eruptive center of the late Quaternary Laacher See tephra. Geologische Rundschau 73(3):933-980.

van den Bogaard P, Schmincke H-U (1985) Laacher See Tephra: A widespread isochronous late Quaternary tephra layer in central and northern Europe. GSA Bulletin 96(12):1554-1571. https://doi.org/10.1130/0016-7606(1985)96<1554:LSTAWI>2.0.CO;2 
van den Bogaard P (1995) ${ }^{40} \mathrm{Ar} /{ }^{39} \mathrm{Ar}$ ages of sanidine phenocrysts from Laacher See Tephra $(12,900$ yr BP): Chronostratigraphic and petrological significance. Earth Planet Sci Lett 133:163174.

Viccaro M, Giuffrida M, Nicotra E, Cristofolini R (2016) Timescales of magma storage and migration recorded by olivine crystals in basalts of the March-April 2010 eruption at Eyjafjallajökull volcano, Iceland. Am Mineral 101(1):222-230. https://doi.org/10.2138/am-2016-5365

Wark DA, Hildreth W, Spear FS, Cherniak DJ, Watson EB (2007) Pre-eruptive recharge of the Bishop magma system. Geology 35(3):235-238. https://doi.org/10.1130/G23316A.1

Watson EB, Cherniak DJ, Holycross ME (2015) Diffusion of phosphorous in olivine and molten basalt. Am Mineral 100(10):2053-2065. http://dx.doi.org/10.2138/am-2015-5416

Wiebe RA (2016) Mafic replenishments into floored silicic magma chambers. Am Mineral 101(2):297-310. http://dx.doi.org/10.2138/am-2016-5429

Witt-Eickschen G, Klemd R, Seck HA (2003) Density contrast of fluid inclusions associated with melt (glass) from two distinct suites of mantle peridotites from the West Eifel, Germany: Implications for melt origin. Eur J Mineral 15(1):95-102. https://doi.org/10.1127/0935$\underline{1221 / 2003 / 0015-0095}$

Wolff JA, Ellis BS, Ramos FC, Starkel WA, Boroughs S, Olin PH, Bachmann O (2015) Remelting of cumulates as a process for producing chemical zoning in silicic tuffs: A comparison of cool, wet and hot, dry rhyolitic magma systems. Lithos 236-237:275-286. https://doi.org/10.1016/j.lithos.2015.09.002

Wörner G (1982) Geochemisch-mineralogische Entwicklung der Laacher See Magmakammer. Ph.D. thesis, Ruhr Universität Bochum.

Wörner G, Schmincke H-U (1984a) Mineralogical and chemical zonation of the Laacher See tephra sequence (East Eifel, W. Germany). J Petrol 25(4):805-835.

Wörner G, Schmincke H-U (1984b) Petrogenesis of the zoned Laacher See tephra. J Petrol 25(4):836-85.

Wörner G, Wright TL (1984) Evidence for magma mixing within the Laacher See magma chamber (East Eifel, Germany). J Volcanol Geotherm Res 22:301-327. 
Wörner G, Staudigel H, Zindler A (1985) Isotopic constraints on open system evolution of the Laacher See magma chamber (Eifel, West Germany). Earth Planet Sci Lett 75:37-49.

Wörner G, Viereck L, Plaumann S, Pucher R, van den Bogaard P, Schmincke H-U (1988) The Quaternary Wehr volcano: A multiphase evolved eruption center in the east Eifel volcanic field (FRG). N Jb Miner Abh 159(1):73-99.

Wright HMN, Folkes CB, Cas RAF, Cashman KV (2011) Heterogeneous pumice populations in the 2.08-Ma Cerro Galán ignimbrite: implications for magma recharge and ascent preceding a large-volume silicic eruption. Bull Volcanol 73:1513-1533. https://doi.org/10.1007/s00445-011-0525-5 


\section{Conclusions}

\subsection{Final conclusions}

This dissertation investigates the timing of pre-eruptive magmatic processes using the compositional and temporal information that is preserved in zoned olivine crystals. The zonation of olivine crystals cannot be only used to obtain timescales related to diffusive equilibration with the surrounding melt but is also a valuable tool to identify the compositions of interacting magmas that can be ideally linked to monitoring data of active volcanoes.

The results of this study show that the eruptions at each of the studied volcanoes were preceded by mafic recharges and magma mixing, during which olivine crystals were entrained either from a crystal mush by the ascending magmas or through magma mixing in newly formed hybrids. Olivine crystals show partially complex histories that include distinct growth intervals with eventual events of dissolution as documented by the zoning of slow diffusing elements as $\mathrm{P}, \mathrm{Al}$, or Cr. Diffusion times show that the timing of the last events prior to eruptions is on a scale of days to months. This clearly supports the theory that recharge events are potentially able to trigger eruptive activity. These short timescales were retrieved from each of the volcanic settings studied here, including both the frequently active hot-spot and arc volcanoes Piton de la Fournaise and Shiveluch, respectively, but also the long-lived phonolitic system of Laacher See volcano.

\subsubsection{Shiveluch}

Clasts from a maar deposit from Shiveluch contain four types of zoned olivine crystals identified in the study of Gordeychik et al. (2018). These are distinguished by their core compositions and the degree to which cores have been affected by diffusion during equilibration with a more evolved melt. Originally, the cores had a uniform high-Fo composition of Fo92, which is either preserved (group 1) or modified by diffusive exchange with a more evolved melt in equilibrium with Fo86.4 (group 2-4). After this entrainment of the Fo-rich cores into more evolved melt, growth of high-Fo rims $\left(\mathrm{FO}_{90}\right)$ resumed from a more magnesian melt after partial dissolution due to temperature increase. Finally, olivine crystallized an outermost overgrowth with $\mathrm{Fo}_{80}$ that shows oscillatory trace element zoning. Diffusion modeling was applied to the gradients between core and Fo-rich rim, and for the outermost gradients towards the crystal surface. The first diffusion step gave 
timescales between 100-2000 days, whereas the outermost parts diffused only 1-10 days. This last event is related to magmatic ascent after a mixing event producing the hybrid in equilibrium with Fo90. The short timescales indicate rather fast ascent rates and suggest that the mixing acted as a trigger for subsequent eruption.

\subsubsection{Piton de la Fournaise}

Piton de la Fournaise on La Réunion belongs to the most active volcanos on earth. The eruptive cycle in 2014-2015 provided the chance to track magmatic activity in a complex transcrustal plumbing system. In the study of Sundermeyer et al. (2020), diffusion times and compositional information from zoned olivine crystals are linked to the monitoring record of geophysical activity and rates of degassing at the surface.

The small eruptions in June 2014 and May 2015 produced low volumes of evolved basalts. The reactivation of Fo-poor olivine in evolved melts only days to few months prior to their eruption and correlating to shallow seismic activity and ground deformation indicates that these small eruptions were only fed from magma batches stored at shallow levels. The eruption of increasingly more mafic magmas during July 2015 and the following large August-November eruption imply that progressively more deeply stored magmas were activated. Although the intensity and erupted volumes during the July eruption are comparable to the small eruptions before, their products - by contrast - already contain olivine with long diffusion times such as those of the subsequent, much larger August-November eruptions. The July eruptions therefore mark a "transition" between shallow and deeply fed eruptions. Interestingly, the comparison of our results and monitoring data implies that the more mafic magmas had already arrived in the transcrustal plumbing system as early as before 2014. The diffusion in olivine antecrysts contained in these magmas started after a swarm of mantle seismicity at the end of 2013, which shows that the mafic magmas were likely stored in the deeper crust until their ascent into the shallow system in April 2015. The most mafic melts of the entire eruptive sequence occurred at the end of October 2015 and likely ascended directly from the mantle after the eruptible magma from the shallow plumbing system was nearly emptied.

The August-November 2015 eruption was rather not triggered by a single recharge event, but more likely by periodical recharges from the mantle underplating causing an increase of the volume of magma and thus pressurizing and destabilizing the plumbing system progressively since the beginning of 2014. The compositional zoning of olivine crystals erupted during the AugustNovember events and the timescales calculated for their residence in the more mafic melts allowed detecting at least three recharge events prior to the June 2014, February, and August-November 2015 eruptions. 


\subsubsection{Laacher See}

It is unusual to apply olivine diffusion modeling to a phonolitic system such as Laacher See due to the absence of olivine crystals in more differentiated magmas. The Laacher See magma reservoir is insofar quite special, because the last erupted products are hybrids from a phonolite-basanite mixing and contain xenocrystic olivine from the basanite along with minerals typical for more evolved alkaline magmas such as sanidine, plagioclase, hauyne, amphibole, and sphene. Despite of their resorbed surfaces, olivine crystals show complex reverse-normal zonation that document their involvement into two distinct processes. Chemical composition of distinct sections of the zoning pattern allows to reconstruct magmatic compositions. The compositions of olivine cores show that they originate from a range of basanites in equilibrium with Fo83-89. The rather uniform rim compositions with Fo87.8-89 represent a more mafic basanite ( $\geq \mathrm{Fo}_{89}$ ), which entrained the olivine crystals from deeper cumulates or mush before ascent towards and mixing with the phonolite at

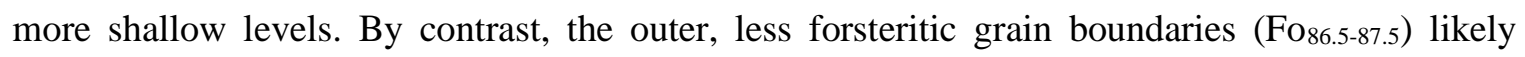
formed after the basanite intruded into the Lacher See magma chamber and mixed with the phonolite.

We modeled Mg-Fe diffusion between the distinct zones at an intermediate temperature, assuming that the time the olivine spent in the basanite was rather short. Diffusion times of $<50$ days to $<410$ days, depending on the chosen temperature of $1100^{\circ} \mathrm{C}$ or $1000^{\circ} \mathrm{C}$, show that the resident phonolite magma within the Laacher See magma chamber was activated and erupted within the range of only months after a basanitic recharge. The composition of this basanite ( $\left.\mathrm{Fo}_{89}\right)$ is close to a primary, mantle-derived composition.

Interestingly, the recharging basanite at Laacher See was found to be more mafic than the basanites that erupted at the studied East Eifel scoria cones (represented by olivine rims with Fo $_{86.5-87.5}$ ) and also more mafic than every basanite from which the compositional variable olivine cores crystallized (Fo80-88). Only some studied nephelinites from the West Eifel (Pulvermaar and Meerfelder Maar) crystallized olivine with similar core compositions of $>\mathrm{FO}_{90}$. The reasons for the absence of olivine more magnesian than $\mathrm{Fo}_{89}$ in the basanites from scoria cones and the resulting question, whether a more mafic basanite in equilibrium with Fo $_{89}$ was possibly involved in the formation of these more evolved basanites prior to their eruption to the surface, cannot be answered with our data. However, the observed differences between scoria cone basanites and the basanite triggering the Laaacher See eruption must be due to differences in the plumbing systems or to different rates and mechanisms of ascent as implied by the different olivine diffusion times. Aparently, the ascent of the mafic basanite that lead to a critical recharge and eruption of the 
Laacher See magma chamber was unique in its near-primary composition compared to the basanites erupted at East Eifel scoria cones.

\section{References}

Gordeychik B, Churikova T, Kronz A, Sundermeyer C, Simakin A, Wörner G (2018) Growth of, and diffusion in, olivine in ultra-fast ascending basalt magmas from Shiveluch volcano. Sci Rep 8(11775):1-15. https://doi.org/10.1038/s41598-018-30133-1

Sundermeyer C, Di Muro A, Gordeychik B, Wörner G (2020) Timescales of magmatic processes during the eruptive cycle 2014-2015 at Pion de la Fournaise, La Réunion, obtained from $\mathrm{Mg}-\mathrm{Fe}$ diffusion modelling in olivine. Contrib Mineral Petrol 175(1). https://doi.org/10.1007/s00410-019-1642-y 


\section{Appendix I - Curriculum vitae}


Appendix I - Curriculum vitae 


\section{Appendix II - Publication bibliography}

\section{Paper}

Gordeychik B, Churikova T, Kronz A, Sundermeyer C, Simakin A, Wörner G (2018) Growth of, and diffusion in, olivine in ultra-fast ascending basalt magmas from Shiveluch volcano. Sci Rep 8(11775):1-15. https://doi.org/10.1038/s41598-018-30133-1

Sundermeyer C, Di Muro A, Gordeychik B, Wörner G (2020) Timescales of magmatic processes during the eruptive cycle 2014-2015 at Pion de la Fournaise, La Réunion, obtained from Mg-Fe diffusion modelling in olivine. Contrib Mineral Petrol 175(1). https://doi.org/10.1007/s00410-019$1642-\mathrm{y}$

Sundermeyer C, Wörner G, Gätjen J, Weimann L (2020) Timescales from magma mixing to eruption in alkaline volcanism in the Eifel volcanic fields, western Germany. (submitted in March 2020 to Contrib Mineral Petrol)

\section{Conference abstracts}

Sundermeyer C, Di Muro A, Techmer K, Gordeychik B, Wörner G (2017) Heritage and residence of olivines based on modelling elemental diffusion profiles from the 2015 eruption at Piton de la Fournaise, La Réunion. GeoBremen, Bremen, September 25-27. Poster

Gordeychik B, Churikova T, Kronz A, Sundermeyer C, Simakin A, Wörner G (2018) Zonation in olivines in ultra-fast ascending magmas from Shiveluch volcano. AGU Fall Meeting, Washington, D.C. December 10-14. Oral presentation

Gordeychik B, Churikova T, Kronz A, Sundermeyer C, Simakin A, Wörner G (2018) Fast ascend of basaltic magmas from 7600 BP eruption of Shiveluch. JKASP, Petropavlovsk-Kamchatsky, Russia, August 20-26. Oral presentation

Sundermeyer C, Di Muro A, Techmer K, Gordeychik B, Wörner G (2018) Heritage and residence of olivines based on Fe-Mg diffusion from the August-November 2015 eruption at Piton de la Fournaise, La Réunion. EGU, Vienna, April 8-13. Poster

Gordeychik B, Churikova T, Kronz A, Sundermeyer C, Simakin A, Wörner G (2019) Diffusion in olivine of basalt magmas from Shiveluch volcano. Department of Earth Sciences Conference, Durham University, United Kingdom, June 11. Poster 
Sundermeyer C, Di Muro A, Gordeychik B, Wörner G (2019) Timescales of magmatic processes during the eruptive cycle 2014-2015 at Piton de la Fournaise, La Réunion, Obtained by Mg-Fe diffusion modelling in olivine. GeoMünster, Münster, September 23-25. Oral presentation

Sundermeyer C, Rout SS, Wörner G (2020) Timescales from mixing to eruption in alkaline volcanism in the Eifel volcanic fields obtained from sanidine and olivine diffusion modelling. EGU, Vienna, May 3-8. Poster 


\section{Appendix III - Index of Electronic Supplementary Material}

The appendix contains all electronic supplementaries, that are submitted / published with the distinct papers.

\section{Gordeychik et al. (2018):}

SM.docx: Index and detailed description of the electronic supplementary material. 41598_2018_30133_MOESM2_ESM. Tables SM1.1.xlsx: Measurement conditions. 41598_2018_30133_MOESM3_ESM. Tables SM1.2.xlsx Comparison of measured and recommended chemical composition of the Olivine San Carlos standard. 41598_2018_30133_MOESM5_ESM. Tables SM3.xlsx: Estimation of P, T, and fO $\mathrm{O}_{2}$. 41598_2018_30133_MOESM6_ESM.Table SM4.xlsx: Outer core diffusion times. 41598_2018_30133_MOESM7_ESM. Table SM5.xlsx: Advanced core diffusion times. 41598_2018_30133_MOESM8_ESM. Table SM6.xlsx: Diffusion times in the transition zone.

\section{Sundermeyer et al. (2020):}

410_2019_1642_MOESM1_ESM.xlsx: All electron microprobe data of analyzed olivines from Piton de la Fournaise.

410_2019_1642_MOESM2_ESM.xlsx: Chemical composition of glass matrix and melt inclusions measured for thermometry. The file also includes the calculated temperatures.

410_2019_1642_MOESM3_ESM.xlsx: Modelling parameters, initial conditions, and timescales retrieved from diffusion modelling of $\mathrm{Mg}$-Fe in olivine.

\section{Sundermeyer et al. (in prep.):}

Online_Resource_1.xlsx: Raw data of olivine point analyses.

Online_Resource_2.xlsx: Raw data of measured line profiles.

Online_Resource_3.xlsx: Analytical data for spinel inclusions and host olivine for thermometry and calculated temperatures.

Online_Resource_4.xlsx: Parameters for diffusion modelling and calculated diffusion times for olivines from Laacher See, Rothenberg and Eppelsberg. 